PNNL-17707

WTP-RPT-177, Rev. 0

U.S. DEPARTMENT OF

(i.) ENERGY

Prepared for the U.S. Department of Energy under Contract DE-AC05-76RL01830

\title{
An Approach to Understanding Cohesive Slurry Settling, Mobilization, and Hydrogen Gas Retention in Pulsed Jet Mixed Vessels
}

PA Gauglitz

BE Wells

May 2009
JA Fort

PA Meyer 


\title{
DISCLAIMER
}

This report was prepared as an account of work sponsored by an agency of the United States Government. Neither the United States Government nor any agency thereof, nor Battelle Memorial Institute, nor any of their employees, makes any warranty, express or implied, or assumes any legal liability or responsibility for the accuracy, completeness, or usefulness of any information, apparatus, product, or process disclosed, or represents that its use would not infringe privately owned rights. Reference herein to any specific commercial product, process, or service by trade name, trademark, manufacturer, or otherwise does not necessarily constitute or imply its endorsement, recommendation, or favoring by the United States Government or any agency thereof, or Battelle Memorial Institute. The views and opinions of authors expressed herein do not necessarily state or reflect those of the United States Government or any agency thereof.

\author{
PACIFIC NORTHWEST NATIONAL LABORATORY \\ operated by \\ BATTELLE \\ for the \\ UNITED STATES DEPARTMENT OF ENERGY \\ under Contract DE-AC05-76RL01830
}

Printed in the United States of America
Available to DOE and DOE contractors from the
Office of Scientific and Technical Information,
P.O. Box 62, Oak Ridge, TN 37831-0062;
ph: (865) 576-8401
fax: (865) 5765728
email: reports@adonis.osti.gov

\footnotetext{
Available to the public from the National Technical Information Service, U.S. Department of Commerce, 5285 Port Royal Rd., Springfield, VA 22161 ph: (800) 553-6847 fax: (703) 605-6900

email: orders@nits.fedworld.gov online ordering: http://www.ntis.gov/ordering.htm
} 


\section{An Approach to Understanding Cohesive Slurry Settling, Mobilization, and Hydrogen Gas Retention in Pulsed Jet Mixed Vessels}

PA Gauglitz

BE Wells

JA Fort

PA Meyer

May 2009

Test specification: 24590-PTF-TSP-RT-06-007, Rev 0

Test Plan: TP-RPP-WTP-480

Test exceptions: 24590-WTP-TEF-RT-07-00013

R\&T focus area: Pretreatment

Test Scoping Statement(s): SCN-044 


\section{Completeness of Testing}

This report summarizes the results of analyses of data obtained from the referenced reports. The analyses and the report, which used data from, but did not involve, laboratory testing, followed the quality assurance requirements outlined in the River Protection Project - Waste Treatment Plant Support Program (RPP-WTP) Quality Assurance Plan (RPP-WTP-QA-001, QAP) and implemented through the River Protection Project - Waste Treatment Plant Support Program (RPP-WTP) Quality Assurance Manual (RPP-WTP-QA-003, QAM).

The descriptions provided in this report are an accurate account of both the conduct of the work and the data analyses performed. A summary of the analysis results is reported. Also reported are any unusual or anomalous occurrences that are different from expected results. The analysis results and this report have been reviewed and verified.

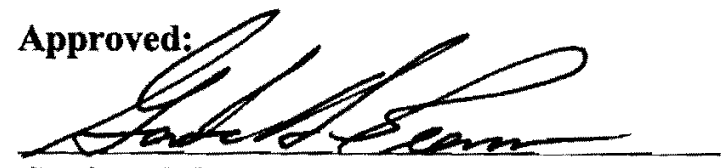

Gordon H. Beeman, Manager RPP-WTP Support Program

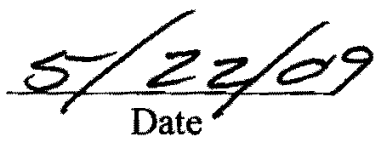




\section{Acknowledgements}

The authors would like to thank Wayne Cosby for his valuable editorial support and Lenna Mahoney, Judith Bamberger, Judy Cuta, and Bill Kuhn for their careful technical reviews and discussions. We would also like thank Adam Poloski, Richard Daniel, and Joel Tingey for their technical insights and expertise associated with the rheology and settling behavior of wastes and simulants. 



\section{Contents}

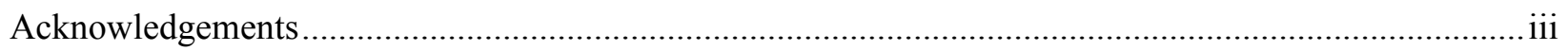

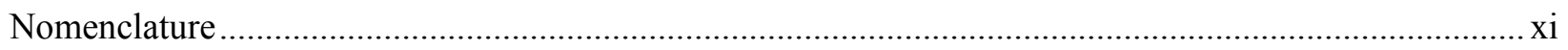

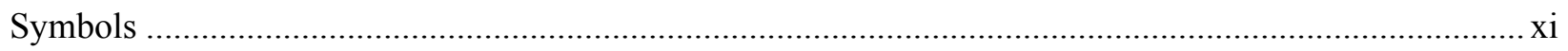

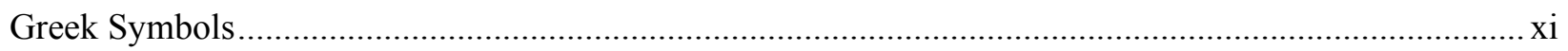

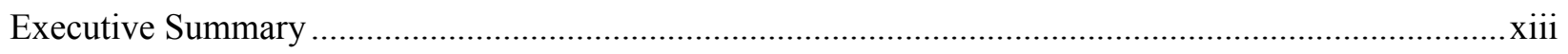

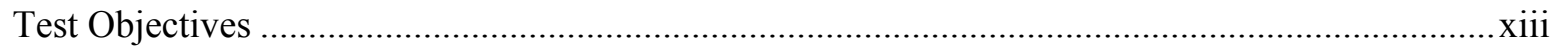

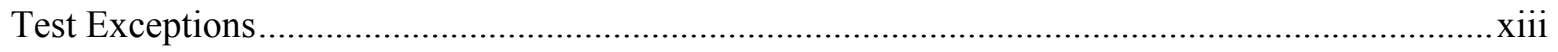

Results and Performance Against Success Criteria ..................................................................... xiv

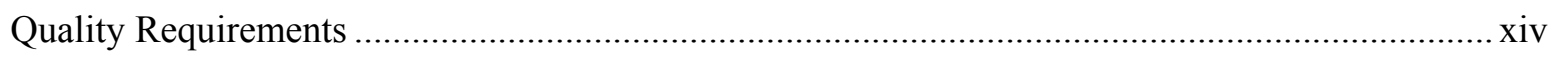

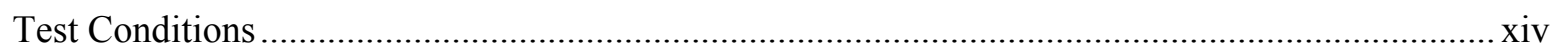

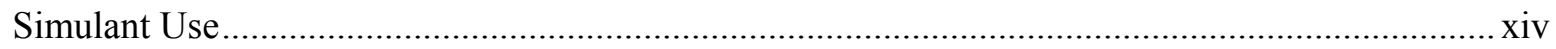

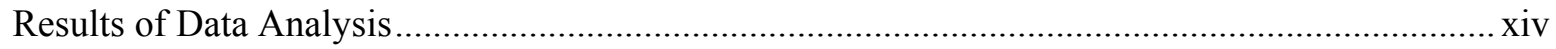

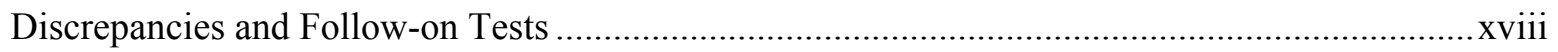

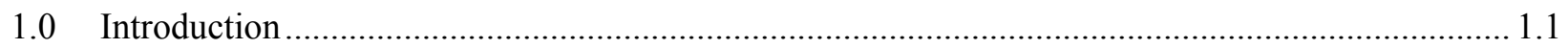

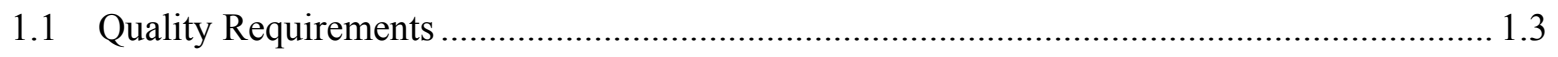

1.2 Hydrogen Gas Retention and Release in Process Vessels ................................................... 1.3

1.3 Approach to Managing Retention and Release of Hydrogen Gas ....................................... 1.5

1.4 Approach to Managing the Strength and Thickness of Settled Layers................................. 1.6

1.5 Approach to Understanding Hydrogen Retention in PJM Mixed Vessels ............................. 1.6

1.6 Bubble-Scale Mechanisms of Retention and Release ......................................................... 1.8

1.6.1 Mechanisms of Bubble Retention at the Bubble Scale ............................................... 1.8

1.6.2 Mechanisms of Bubble Release at the Bubble Scale ................................................. 1.11

2.0 Summary of Settling Behavior and Settled Waste Strength..................................................... 2.1

2.1 Previous Laboratory-Scale Studies of Settled Layer Strength and Settling Dynamics ........... 2.4

2.1.1 Effect of Solids Content on Shear Strength and Bingham Yield Stress...................... 2.6

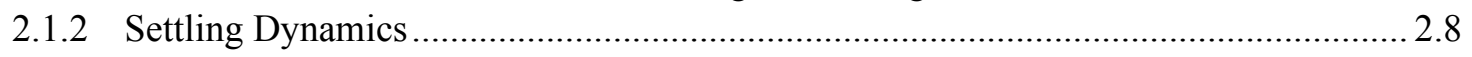

2.1.3 Full-Scale Settling and Settled Layer Shear Strength ......................................... 2.12

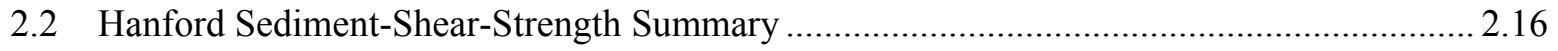

2.2.1 Shear-Strength Measurement Techniques ......................................................... 2.16

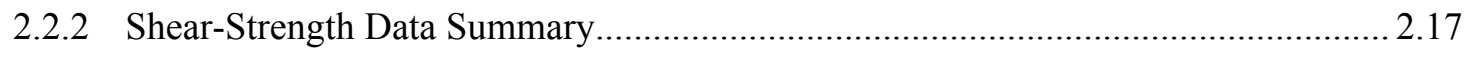

3.0 In Situ Settling of Select Hanford Sediment ................................................................................ 3.1 
3.1 AZ-101 Full-Scale Settling Behavior and Settled Waste Strength ...................................... 3.1

3.1.1 AZ-101 Thermocouple Response to Mixer Pump Operation ....................................... 3.1

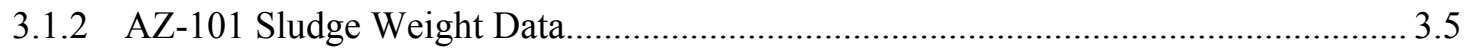

3.1.3 AZ-101 Gamma Scan Results........................................................................... 3.7

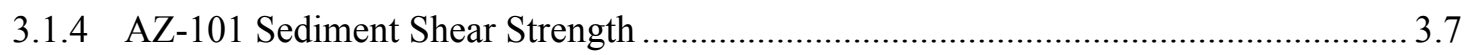

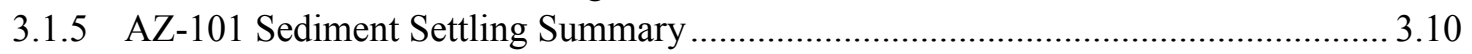

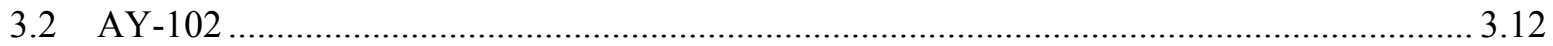

3.2.1 AY-102 Sediment Level Data........................................................................... 3.13

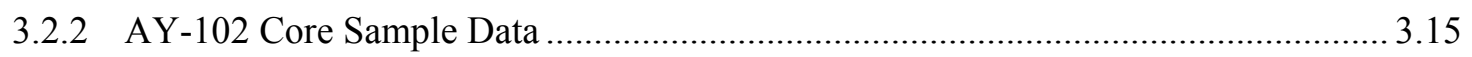

3.2.3 AY-102 Sediment Settling Summary ….............................................................. 3.19

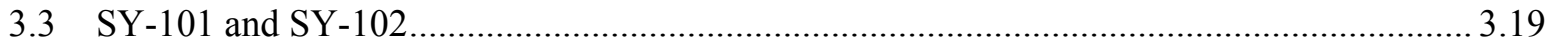

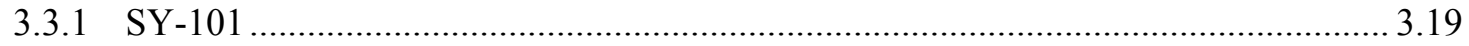

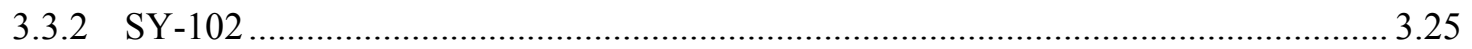

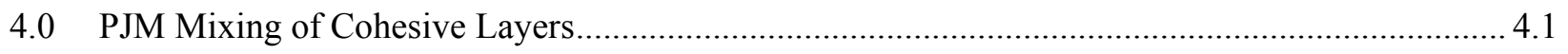

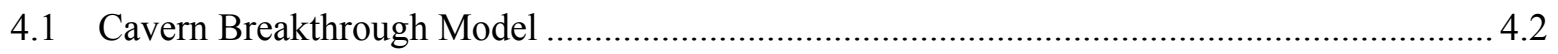

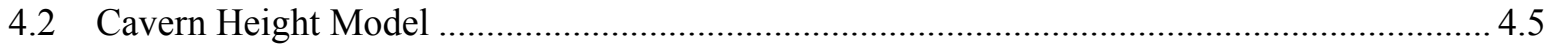

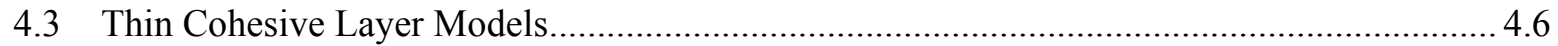

4.4 Cohesive Layer Mobilization Summary and Comparison of Predicted PJM Performance with Estimated Settled Layers ..................................................................................... 4.10

5.0 Steady-State and Stagnant Zone Holdup for M3 Vessels ........................................................ 5.1

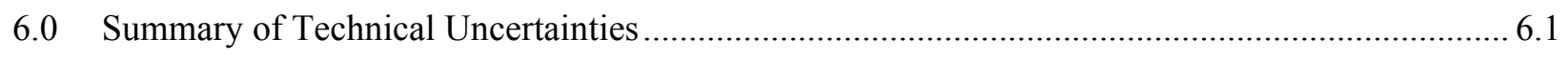

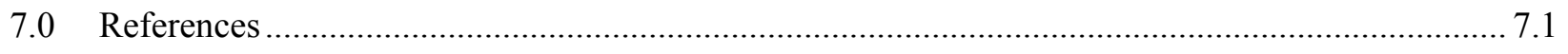

Appendix A: Data Table for Shear Strength ............................................................................... A.1

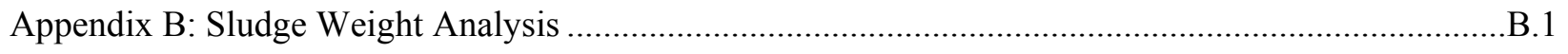

Appendix C: Steady-State Gas Holdup and Comparison to the Maximum Allowed Release of

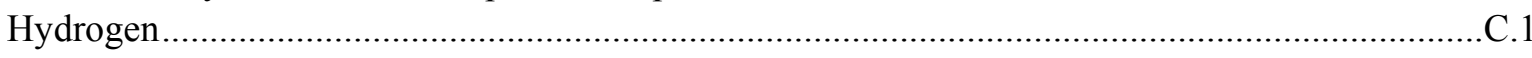




\section{Figures}

1.1. Important Parameters and Behavior for Quantifying Gas Retention and Release in Settling Cohesive Waste

1.2. Gas Retention and Release Behavior in Settling Waste During Normal Operations, During an Outage in PJM Mixing and During the Re-Start of PJM Mixing

1.3. Conceptual Gas Holdup During Normal Operations, an Outage in PJM Mixing, and the ReStart of PJM Mixing

1.4. Conceptual Comparison of Gas Holdup to the Maximum Allowed Holdup During Normal Operations, an Outage in PJM Mixing, and the Re-Start of Reduced PJM Mixing.

1.5. Bubbles Retained by Capillary Forces and by Waste Strength and Armored Bubbles .................. 1.9

2.1. Shear Strength as a Function of Solids Content for Actual Waste Samples and Clay Simulants ... 2.7

2.2. Shear Strength as a Function of Undissolved Solids Content for Actual Waste Samples and Kaolin Clay.....

2.3. Assumed Relationship between Shear Strength and Undissolved Solids Content for the Slurry Identified by MacLean (1999) as Diluted $\mathrm{Al}(\mathrm{OH})_{3}-\mathrm{Fe}(\mathrm{OH})_{3}$ and Comparison with Other Data .. 2.10

2.4. Estimated Shear Strength as a Function of Time for Simulants and Full-Scale AZ-101 Behavior

2.5. Shear Strength as a Function of Solids Content for Cases 1-3 and Kaolin Clay ........................ 2.13

2.6. Shear Strength Increase for Settling Layers ........................................................................ 2.14

2.7. Shear Strength (or Yield Stress) During Normal PJM Operation Increases with Depth and Increases with Lower Cloud Heights..

2.8. Data Summary of Shear-Vane Shear Strength, Sediment from 21 Hanford Tanks, 136 Measurements

2.9. Data Summary of Waste-Extrusion Shear Strength, Sediment from 17 Hanford Tanks, 319 Measurements.

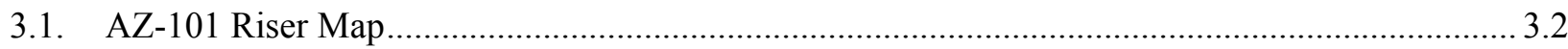

3.2. AZ-101 Settled Solids Thermocouples Uncovered During Oscillatory Operation of Mixer Pumps 1 and 2

3.3. Gamma-Monitoring System Data 0 to 45 Hours after Pump Shutdown (Reproduced from Carlson et al. 2001; Y-Axis is Height Above Tank Bottom [inches]) ......................................... 3.8

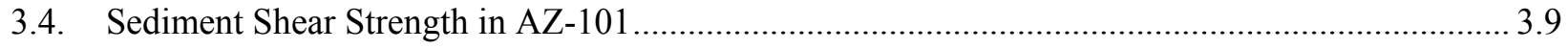

3.5. AZ-101 Sediment Level as a Function of Time after Mobilization ............................................ 3.11

3.6. AZ-101 Sediment Level as a Function of Time after Mobilization ............................................ 3.12

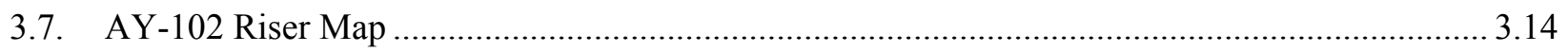

3.8. AY-102 Sediment Level History from Start of C-106 Retrieval Campaign ............................... 3.15

3.9. AY-102 Sediment Shear Strength for Waste Cores 270 Through 273 ...................................... 3.16

3.10. Time Until Sample with Elevation of Sediment..................................................................... 3.17

3.11. AY-102 Sediment Shear Strength for Waste Cores 270 Through 273 as a Function of Time...... 3.17 
3.12. AY-102 Sediment Shear Strength as a Function of Percent Water for Sediment Core Segments from Waste Cores 270 and 273.

3.13. AY-102 Sediment Percent Water and Sediment Density for Sediment Core Segments from Waste Cores 270 and 273.

3.14. SY-101 Riser Map

3.15. Temperature Profile History in Riser 17B, April 2000 (Information Only)

3.16. Temperature Profile History in Riser 17B, April 2000-August 2000 (Information Only)

3.17. Temperature Profile History in Riser 17C, April 2000 (Information Only)

3.18. Temperature Profile History in Riser 17C, April 2000-August 2000 (Information Only)

3.19. SY-101 Sediment History as a Function of Time after Mobilization and Dilution 3.25

3.20. SY-102 Riser Map 3.26

3.21. SY-102 Shear Strength 235 Days Post SY-101 Transfer 3.28

3.22. SY-102 Sediment Level as a Function of Time Since Most Recent SY-101 Transfer (see Table 3.3)

4.1. Representative Configurations for Settled Layers of Cohesive Waste: A) Full Tank, B) Thick Layer, and C) Thin Layer....

4.2. Cavern Breakthrough due to Central Upwelling in the Center of a Ring of PJMs.

4.3. A Single Jet in a Vessel with a Non-Newtonian Slurry as Depicted by Bamberger et al. (2005)... 4.3

4.4. Cavern Breakthrough Correlation Predications for Cavern Height and Breakthrough, Which Assumes the Limiting Steady-Jet Behavior and a Uniform Slurry Density, as a Function of Shear Strength for HLP-22 Parameters and a Slurry Density of $1200 \mathrm{~kg} / \mathrm{m}^{3}$.....

4.5. PJMs Mobilizing Cohesive Layers around each PJM

4.6. Effective Cleaning Radius Correlations for Impinging Jets .....

4.7. Effective Cleaning Radius Correlations for Impinging Jets on Thin Cohesive Layers (based on a slurry density of $1200 \mathrm{~kg} / \mathrm{m}^{3}$ )

4.8. Comparison of the Estimated Shear Strength of Settling Layers with the PJM Performance Predicted by the Cavern Breakthrough Correlation, which Assumes the Limiting Steady-Jet Behavior, a Uniform Slurry Density, and HLP-22 Parameters with a Slurry Density of $1200 \mathrm{~kg} / \mathrm{m}^{3}$.......

4.9. Comparison of the Estimated Shear Strength (or Yield Stress) of Stratified Layers During Normal PJM Operation with the PJM Performance Predicted by the Cavern Breakthrough Correlation, Which Assumes the Limiting Steady-Jet Behavior, a Uniform Slurry Density, and HLP-22 Parameters with a Slurry Density of $1200 \mathrm{~kg} / \mathrm{m}^{3}$

5.1. Retained Gas Fraction (total gas, not just hydrogen) as a Function of the Total GasGeneration Rate 


\section{Tables}

S.1. Key Technical Gaps and Testing and Analysis Needs ............................................................. xix

1.1. Information Needed for Understanding Hydrogen Retention in PJM Mixed Vessels ................... 1.7

2.1. Estimated Shear Strength of Settled Layers .......................................................................... 2.2

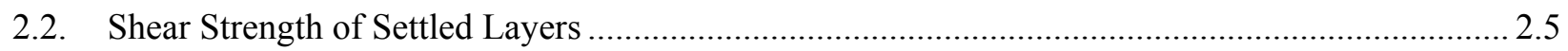

2.3. Hanford Shear Strength Data; Tank and Measurement Technique .......................................... 2.17

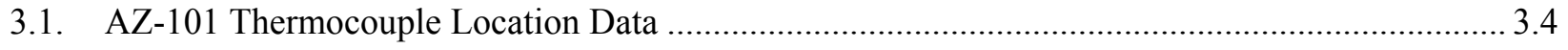

3.2. AZ-101 Sludge Weight Sediment Level ................................................................................ 3.6

3.3. Estimated Time for Thermocouples to Reach Supernatant Liquid Temperatures....................... 3.24

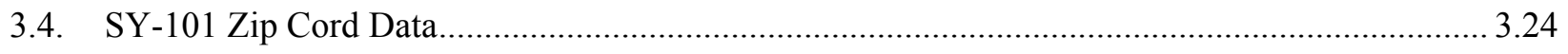

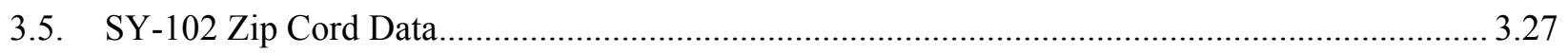

4.1. Test Parameters and Results Used to Estimate the Coefficient C ............................................... 4.4

4.2. Test Parameters used to Determine the Cavern Height Model Coefficient.................................. 4.6

5.1. Summary of Steady State Gas Holdup for Selected Vessels with Settling Slurries and a Comparison to the Maximum Allowed Release ............................................................................ 5.5

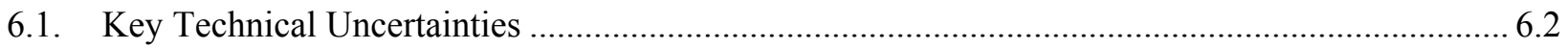





\section{Nomenclature}

\begin{tabular}{|c|c|c|c|}
\hline AFA & antifoam agent & PUREX & plutonium-uranium extraction \\
\hline DOE & U.S. Department of Energy & QA & quality assurance \\
\hline DST & double-shell tank & QAM & Quality Assurance Manual \\
\hline ECR & effective cleaning radius & QAP & Quality Assurance Plan \\
\hline EFRT & external flowsheet review team & QARD & Quality Assurance Requirements and \\
\hline HGR & hydrogen gas release & & Descriptions \\
\hline HLW & high-level waste & REDOX & reduction-oxidation \\
\hline LFL & lower flammability limit & RPP & River Protection Project \\
\hline NCAW & neutralized current acid waste & SSP & suspended solids profiler \\
\hline NQA & nuclear quality assurance & TWINS & Tank Waste Information System \\
\hline PJM & pulse jet mixer & UDS & undissolved solids \\
\hline PMMA & polymethylmethacrylate & URSILLA & ultrasonic interface level analyzer \\
\hline PNNL & Pacific Northwest National Laboratory & WTP & $\begin{array}{l}\text { waste treatment and immobilization } \\
\text { plant }\end{array}$ \\
\hline
\end{tabular}

\section{Symbols}

$\begin{array}{ll}\text { A } & \text { cross sectional area of the vessel } \\ c_{J} & \text { jet coefficient for circular free jet } \\ c_{u} & \text { jet coefficient for impinging jet } \\ d & \text { sphere diameter } \\ d_{0} & \text { jet nozzle diameter } \\ D_{P} & \text { mean pore diameter through which a bubble } \\ & \text { must pass to escape retention } \\ \mathrm{ft} & \text { foot } \\ \mathrm{g} & \text { acceleration due to gravity } \\ \mathrm{G}_{\mathrm{v}} & \text { total gas-generation rate in a vessel } \\ \mathrm{g}_{\mathrm{v}} & \text { volume of gas generated per unit volume of } \\ & \text { slurry per unit time } \\ \mathrm{g} & \text { gram } \\ \mathrm{H} & \text { effective slurry depth } \\ \mathrm{H}_{\mathrm{C}} & \text { height of cavern in settled slurry }\end{array}$

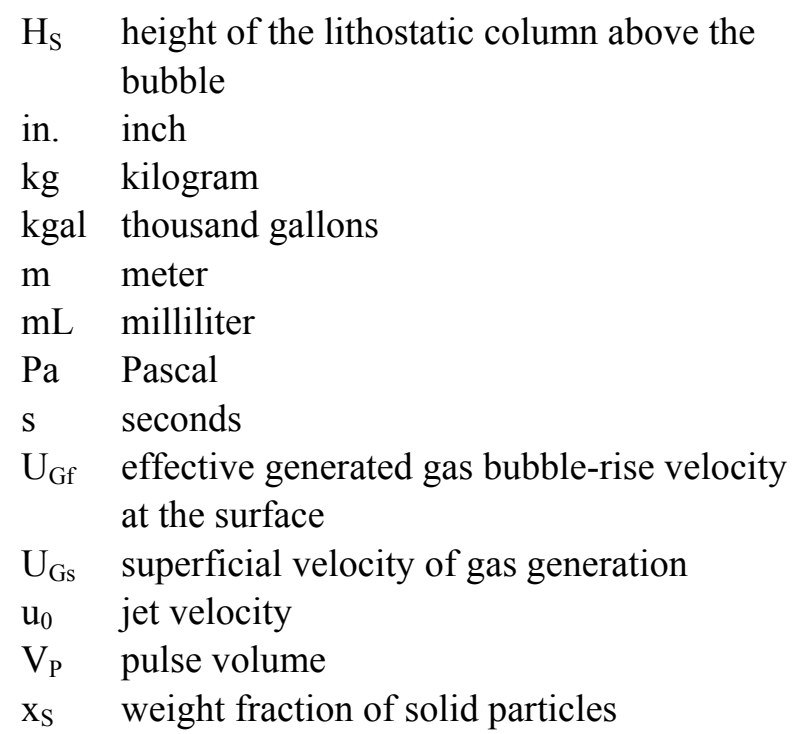

\section{Greek Symbols}

$\begin{array}{llll}\alpha_{\text {Gss }} & \text { steady-state gas holdup } & \sigma & \text { surface tension } \\ \Delta \rho & \text { difference between bulk sediment and liquid } & \tau_{\mathrm{s}} & \text { shear strength } \\ & \text { density } & \tau_{\mathrm{y}} & \text { yield stress } \\ \rho_{\mathrm{S}} & \text { density of solid particles } & \varphi_{\mathrm{S}} & \text { volume fraction of solid particles } \\ \rho_{\mathrm{L}} & \text { density of liquid } & & \end{array}$





\section{Executive Summary}

The Hanford Waste Treatment and Immobilization Plant (WTP) is being designed and built to pretreat and vitrify a large portion of the waste in Hanford's 177 underground waste storage tanks. Numerous process vessels will hold waste at various stages in the WTP. Some of these vessels have mixing-system requirements to maintain conditions where the accumulation of hydrogen gas stays below acceptable limits, and the mixing within the vessels is sufficient to release hydrogen gas under normal conditions and during off-normal events.

Some of the WTP process streams are slurries of solid particles suspended in Newtonian fluids that behave as non-Newtonian slurries, such as Bingham yield-stress fluids. When these slurries are contained in the process vessels, the particles can settle and become progressively more concentrated toward the bottom of the vessels, depending on the effectiveness of the mixing system. One limiting behavior is a settled layer beneath a particle-free liquid layer. The settled layer, or any region with sufficiently high solids concentration, will exhibit non-Newtonian rheology where it is possible for the settled slurry to behave as a soft solid with a yield stress. In this report, these slurries are described as settling cohesive slurries. The slurry rheology will also depend on the particle characteristics and their interactions in addition to the solids concentration. If a liquid region of the vessel exists with sufficiently few particles, this region will be Newtonian. As has been observed historically within the Hanford waste tanks, the non-Newtonian region with sufficient settled solids will retain hydrogen gas bubbles unless the mixing system can mobilize the settled solids and release the hydrogen gas. An External Flowsheet Review Team (EFRT) identified potential inadequate mixing of these vessels as a technical issue, and this issue is referred to as M3 - Inadequate Design of Mixing Systems - Pulse Jet Mixers (PJMs).

The purpose of this report is to define an approach to understanding cohesive slurry settling, mobilization, and hydrogen gas retention in pulsed jet mixed vessels. An overall approach to the hydrogen gas issue is presented, which illustrates the relationship between waste properties and PJM performance. This approach underscores the importance of quantifying how waste becomes inhomogeneous when mixing stops, the rate that solids settle, and the physical and rheological properties of the stratified waste. Previous work for the Hanford tank farms and the WTP project is being evaluated to determine where sufficient information exists and where needed information is uncertain or absent. A model of PJM performance for mobilizing settling layers is presented, and the performance limits are compared with the estimated strength of settling and stratified layers. The use of the settling and PJM performance models is demonstrated to evaluate how well PJMs mobilize slurries during and after off-normal events with settled or stratified layers and how the settling behavior of a slurry affects the capability of mixing systems to remobilize waste.

\section{Test Objectives}

This section is not applicable. No testing was performed for this investigation.

\section{Test Exceptions}

This section is not applicable. No testing was performed for this investigation. 


\section{Results and Performance Against Success Criteria}

This section is not applicable. No testing was performed for this investigation.

\section{Quality Requirements}

Pacific Northwest National Laboratory's (PNNL's) Quality Assurance Program is based on requirements defined in U.S. Department of Energy (DOE) Order 414.1C, Quality Assurance, and 10 CFR 830, Energy/Nuclear Safety Management, Subpart A-Quality Assurance Requirements (a.k.a., the Quality Rule). PNNL has chosen to implement the requirements of DOE Order 414.1C and 10 CFR 830, Subpart A by integrating them into the laboratory's management systems and daily operating processes. The procedures necessary to implement the requirements are documented through PNNL's StandardsBased Management System.

PNNL implements the River Protection Project—Waste Treatment Plant Support Program (RPP-WTP) quality requirements by performing work in accordance with the RPP-WTP Quality Assurance Plan (RPP-WTP-QA-001, QAP). Work will be performed to the quality requirements of Nuclear Quality Assurance (NQA)-1-1989, Part I, Basic and Supplementary Requirements, NQA-2a-1990, Part 2.7, and DOE/RW-0333P, Rev 13, Quality Assurance Requirements and Descriptions (QARD). These quality requirements are implemented through the RPP-WTP Quality Assurance Manual (RPP-WTP-QA-003, QAM).

This report is based on data from testing performed under prior programs as referenced. PNNL assumes that the data from these references have been fully reviewed and documented in accordance with the analysts' QA programs. PNNL only analyzed data from the referenced documentation, with the single exception of some shear-strength estimates reported in Figure 3.4 (see Section 3) that were made previously but not previously published. At PNNL, the performed calculations as well as the documentation and reporting of results and conclusions were performed in accordance with RPP-WTP QAM. Internal verification and validation activities were addressed by conducting an independent technical review of the final data report in accordance with PNNL procedure QA-RPP-WTP-604. This review verifies that the reported results are traceable and that inferences and conclusions are soundly based. This review procedure is part of PNNL's RPP-WTP QAM.

\section{Test Conditions}

This section is not applicable. No testing was performed for this investigation.

\section{Simulant Use}

This section is not applicable. No testing was performed for this investigation.

\section{Results of Data Analysis}

A review of existing studies on settling dynamics and waste shear strength is presented, and a new evaluation of small- and large-scale laboratory settling tests and operational examples from Hanford tank operations is provided. This evaluation shows that a wide range of settling dynamics and layer strength can be expected. As a reasonable upper bound, an average settled layer shear strength of up to $200 \mathrm{~Pa}$ can 
be expected within a day, though there is uncertainty in this estimate. An estimated typical strength of 30 $\mathrm{Pa}$ can be expected within a day. The existing studies do not provide estimates for settling dynamics and the settled-layer strength at shorter times, and there is no information showing the expected increase in strength as a function of depth within a settling layer. As described below, for sufficiently strong layers, a PJM mixing system will be unable to mobilize the layer. Accordingly, quantitative information on settling behavior will be needed to establish the frequency of PJM operation to avoid the formation of layers that are too strong to be readily re-mobilized.

Though vessel mixing to avoid the formation of strong layers is planned, existing data on the strength of settled layers are analyzed to obtain an estimate on the highest strength that might occur in a vessel if long-term settling and compaction are allowed to occur. This analysis considers the entire data set rather than selecting maximum values as was done in previous work. The analysis presented here argues that the $95^{\text {th }}$ percentile strength is an appropriate choice, and this shear strength is 7,000 $\mathrm{Pa}$.

Previous work on PJM mixing of non-Newtonian fluids is used to develop a model for predicting the waste properties of settled non-Newtonian layers that can just be mobilized by PJMs, which is the performance limit of the PJM system for releasing hydrogen gas and eliminating stagnant regions. The predicted performance limit is compared to the estimated strengths of settling and stratified layers. The model included the effects of the settled-layer strength and thickness, jet velocity and diameter, vessel size, and the number of PJMs. The model assumes the limit of steady jets, which occurs for sufficiently large pulse volumes. The effects of reduced pulse volume are not included but would reduce the estimated performance. The model is based on having a uniform density slurry, which does not occur with settling slurries, and the impact of this assumption has not yet been determined. The results show that mobilizing settled layers becomes more difficult with increasing layer thickness and shear strength. For a layer that is half the full-vessel depth in HLP-22, $8 \mathrm{~m} / \mathrm{s}$ jets (4-in. diameter) will be just capable of mobilizing layers that are up to $13 \mathrm{~Pa}$, and $12 \mathrm{~m} / \mathrm{s}$ jets will just mobilize layers up to $30 \mathrm{~Pa}$, which is the typical strength that can be expected within a day of settling. This report uses $200 \mathrm{~Pa}$ as a reasonable upper bound for a settled layer after a day of settling, and the PJM performance prediction for HLP-22 conditions with $12 \mathrm{~m} / \mathrm{s}$ jets shows that a thin 200-Pa layer would be mobilized. In contrast, the model predictions show that if HLP-22 was half full with a 200-Pa layer, the PJM systems would be incapable of mobilizing the layer (see Section 4.1). Unfortunately, there are no data to evaluate the accuracy of the PJM performance predictions for settling non-Newtonian (cohesive) layers.

A review is given for gas-bubble retention and release mechanisms, and the existing information is sufficient to determine that all the pertinent mechanisms have been fully considered and that waste mobilization will release retained gas. Existing correlations for gas holdup in PJM-mixed vessels are reviewed, and one correlation is applied to estimate full-scale behavior of a number of WTP vessels at plant conditions. The results show that the steady-state hydrogen holdup can be as high as $18 \%$ of the lower flammability limit (LFL) in the vessel headspace should all of the gas be released instantaneously.

Finally, a number of technical uncertainties are identified based on an analysis of existing literature and data. Some of these uncertainties are associated with a lack of quantitative results for PJM mobilization of settling cohesive slurries, and other uncertainties are associated with a lack of information for waste properties needed for quantifying PJM performance and gas retention. Table S.1 groups these uncertainties in two categories; the first category is Technical Uncertainties for PJM Behavior with Settling Slurries, and the second category is Technical Uncertainties for Waste Characterization. 
The first two uncertainties are the most significant and are both associated with the scarcity of testing data for PJM performance on settled or stratified cohesive layers, and it is unclear if the existing correlations developed for vessels without layers can be used for settling waste. While the previous studies on PJM mixing of uniform non-Newtonian materials quantified many aspects of the PJM performance, data to quantify the roles of important operational parameters (jet velocity, pulse size, and duty cycle) and geometry (number of PJM tubes, nozzle size, bottom shape) are absent. In the category of waste characterization, the most significant uncertainty is that the existing models and data on settling dynamics and the strength of settled layers have not included experimental testing to confirm the scaling behavior or to determine the increasing strength with depth into a settled layer. It is expected that a sound understanding of settling dynamics will be needed to design, or to determine the operating limits of, a mixing system capable of managing the strength and thickness of settled layers. 
Table S.1. Key Technical Uncertainties

\section{Technical Uncertainties for PJM Behavior with Settling Slurries}

PJM performance behavior for off-normal ${ }^{(a)}$ events with settled cohesive layers has technical uncertainty based on existing data and models. The uncertainty includes quantifying the role of settled-layer properties (rheology and density) and determining how existing PJM correlations for non-settling cohesive slurries need to be modified for settling slurries. ${ }^{(b)}$ The effect of PJM operational parameters and geometries also needs to be developed.

a) Off-normal events refer to situations where PJM operation ceases for a period of time.

b) Settling slurries are mixtures of particles in Newtonian fluids where the particles can settle and become progressively more concentrated toward the bottom of a vessel, resulting in non-Newtonian rheology.

PJM performance behavior for normal operations with settling cohesive slurries that form stratified layers has technical uncertainty, including a lack of data and models to quantify the role of slurry rheology and density and to determine how existing PJM correlations for noncohesive slurries need to be modified for settling cohesive slurries. The effect of PJM operational parameters and geometries also needs to be developed. If the performance of a PJM system is sufficient to mobilize a completely settled slurry following an off-normal event, where the layer is expected to be stronger than when this same slurry is stratified during normal operations, then this PJM system should be sufficient to mobilize this slurry under normal operations.

Determine if low shear at the design distance from the PJM is sufficient to release bubbles. A slow release in poorly mixed regions is an unresolved issue — cohesive layer mixing studies might resolve this.

Extend existing correlations for gas holdup to fully account for settling cohesive materials that can form layers with shear strengths higher than about $40 \mathrm{~Pa}$. Gas holdup in vessels without spargers has received less study than mixing systems with PJMs and spargers. Depending on the testing results for mixing performance with settling waste, additional gas retention and release studies may be needed to reduce the uncertainty in holdup predictions.

\section{Technical Uncertainties for Waste Characterization}

Scaling behavior, including the role of vessel size, of the settling dynamics and the buildup of strength in the settled layer with a particular emphasis on shorter settling times and strength increase with depth into a layer is not well quantified with existing data and analysis. The best current estimates are presented in this report, but these estimates have uncertainty. Accurate predictions of the settling behavior and strength formation are needed, so the mixing system is designed to prevent settled layers that will exceed remobilization capabilities. Tank-farm studies of full-scale settling have shown substantially faster settling than expected based on laboratory tests. This inconsistency needs to be understood.

The foaming behavior of untreated actual wastes should be characterized to determine if there is a potential gas-retention mechanism in these waste materials prior to waste transfer to the WTP. 


\section{Discrepancies and Follow-on Tests}

This section is not applicable. No testing was performed for this investigation. 


\subsection{Introduction}

The Waste Treatment and Immobilization Plant (WTP) at Hanford is being designed and built to pretreat and vitrify a large portion of the waste in Hanford's 177 underground waste storage tanks. Numerous process vessels will hold waste at various stages in the WTP. Some of these vessels have mixing system requirements to maintain conditions where the accumulation of hydrogen gas stays below acceptable limits and the mixing within the vessels is sufficient to release hydrogen gas under normal conditions and during off-normal events (WTP 2008).

Some of the WTP process streams are slurries of solid particles suspended in Newtonian fluids that behave as non-Newtonian slurries. When these slurries are contained in the process vessels, the particles can settle and become progressively more concentrated toward the bottom of the vessels, depending on the effectiveness of the mixing system. One limiting behavior is a settled layer beneath a particle-free liquid layer. The settled layer, or any region with sufficiently high solids concentration, will exhibit nonNewtonian rheology. In this report, these slurries are described as settling cohesive slurries. The slurry rheology will also depend on the particle characteristics and their interactions in addition to the solids concentration. If a liquid region of the vessel exists with sufficiently few particles, this region will be Newtonian. The non-Newtonian region with sufficient settled solids will retain hydrogen gas bubbles unless the mixing system can mobilize the settled solids and release the hydrogen gas An External Flowsheet Review Team (EFRT) identified potential inadequate mixing of these vessels as a technical issue, and this issue is referred to as M3 - Inadequate Design of Mixing Systems-Pulse Jet Mixers (PJMs).

The focus of this report is to define an approach to understanding cohesive slurry settling, mobilization, and hydrogen gas retention in pulsed jet mixed vessels.. An overall approach to the hydrogen gas issue is presented, which illustrates the relationship between waste properties and PJM performance. The approach underscores the importance of quantifying how waste becomes inhomogeneous when mixing stops, the rate that solids settle, and the physical and rheological properties of the stratified waste. Previous work for the Hanford tank farms and WTP project is evaluated to determine where sufficient information exists and where needed information is uncertain or absent. Previous studies have developed theories and conducted scaled tests to quantify how PJMs release bubbles (Stewart et al. 2007, 2006a, 2006b; Bontha et al. 2005; Russell et al. 2005). These previous studies only considered essentially nonsettling non-Newtonian slurries that were uniform throughout the vessels, so the capability to retain bubbles was also uniform throughout the vessel. These studies did not consider waste materials where the materials in the tank could segregate into a settled layer with non-Newtonian properties below a liquid layer with Newtonian properties. Numerous other studies have investigated PJM mixing performance, but with the exception of the earliest study by Bontha et al. (2000), these studies also focused on vessels filled with non-Newtonian slurries that did not settle (Bontha et al. 2000, 2003a, 2003b; Enderlin et al. 2003; Johnson et al. 2003; Bates et al. 2003; Bamberger et al. 2005; Meyer et al. 2005; Johnson et al. 2005; Poloski et al. 2005; Bontha et al. 2007; and Kurath et al. 2007). Accordingly, additional understanding is needed for PJM mobilization of settled cohesive layers, including the role of important parameters, such as the shear strength and height of the settled layers, to allow the quantitative prediction of the gas retention and release from these layers. 
For waste slurries that settle and form layers, these layers can compact with time and with the added weight from the settled layer itself. The strength of these settled layers has an interdependent relationship with the settling and compaction behavior of the layers. ${ }^{(a)}$ The bubble-scale mechanisms of gas retention depend, in turn, on the properties of the settled layer. Figure 1.1 depicts this interdependence and represents the approach to quantifying the hydrogen gas retention and release behavior. The combination of waste configuration and settled layer strength are significant factors in determining the PJM mixing mechanisms and quantitative mixing performance. The key issues of gas holdup, gas-release mechanisms, and gas-release volumes are dominated by the geometry and performance of the mixing system for a given waste configuration and strength.

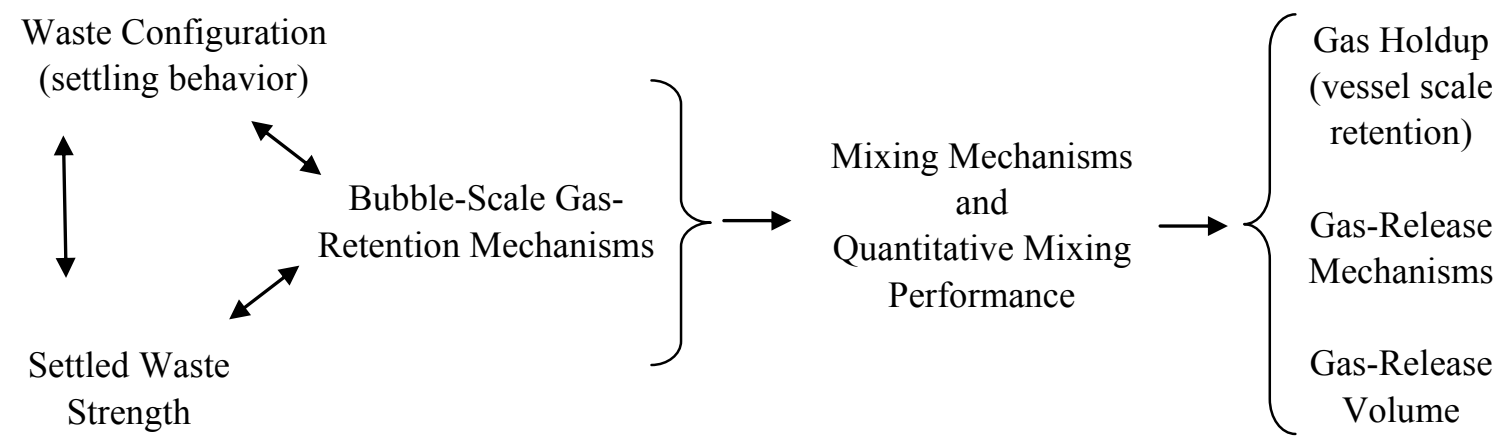

Figure 1.1. Important Parameters and Behavior for Quantifying Gas Retention and Release in Settling Cohesive Waste

As mentioned previously, the purpose of this report is to define an approach to understanding cohesive slurry settling, mobilization, and hydrogen gas retention in pulsed jet mixed vessels. The qualitative behavior of gas holdup with and without mixing is discussed in the remainder of Section 1 together with a discussion of information needed for understanding hydrogen retention in PJM mixed vessels. This is followed by a review of bubble-scale retention and release mechanisms. In Section 2, previous evaluations and data on waste settling and the strength of settled layers are reviewed. Section 3 provides a new evaluation of settling behavior and strength from full-scale waste operations conducted in Hanford double-shell tanks (DSTs). Section 4 describes the key behavior of PJM mobilization of cohesive layers and identifies technical uncertainties in understanding the PJM performance with settled layers. Section 5 predicts the steady-state holdup in WTP vessels at plant conditions using existing correlations (for nonsettling slurries). Finally, within each of the sections, technical uncertainties are identified that are pertinent to understanding hydrogen-gas retention in PJM mixed vessels. Section 7 lists these technical uncertainties.

(a) The property of waste qualitatively described as the strength can be quantified by a number of different parameters and measurements. Shear strength is one example, and in this report, shear strength refers to measurements made with the shear vane method or related measurements where the results are expressed as equivalent shear strength results. The Bingham yield stress is a second example. Here, the yield stress parameter in the Bingham model is determined from rheological measurements. Shear strength and yield strength are closely related, but are different parameters and determined from different measurements. For a discussion of these measurements, see Poloski et al. (2007). 


\subsection{Quality Requirements}

Pacific Northwest National Laboratory's (PNNL's) Quality Assurance Program is based on requirements defined in U.S. Department of Energy (DOE) Order 414.1C, Quality Assurance, and 10 CFR 830, Energy/Nuclear Safety Management, Subpart A-Quality Assurance Requirements (a.k.a. the Quality Rule). PNNL has chosen to implement the requirements of DOE Order 414.1C and 10 CFR 830, Subpart A by integrating them into the laboratory's management systems and daily operating processes. The procedures necessary to implement the requirements are documented through PNNL's StandardsBased Management System.

PNNL implements the River Protection Project-Waste Treatment Plant (RPP-WTP) quality requirements by performing work in accordance with the RPP-WTP Quality Assurance Plan (RPP-WTP-QA-001, QAP). Work will be performed to the quality requirements of Nuclear Quality Assurance (NQA)-1-1989 Part I, Basic and Supplementary Requirements, NQA-2a-1990, Part 2.7, and DOE/RW-0333P, Rev 13, Quality Assurance Requirements and Descriptions (QARD). These quality requirements are implemented through the RPP-WTP Quality Assurance Manual (RPP-WTP-QA-003, QAM).

This report is based on data from testing performed under prior programs as referenced. PNNL assumes that the data from these references have been fully reviewed and documented in accordance with the analysts' quality assurance (QA) programs. PNNL only analyzed data from the referenced documentation, with the single exception of some shear-strength estimates reported in Figure 3.4 (see Section 3) that were previously obtained but not previously published. At PNNL, the performed calculations as well as the documentation and reporting of results and conclusions were performed in accordance with the RPP-WTP QAM. Internal verification and validation activities were addressed by conducting an independent technical review of the final data report in accordance with PNNL procedure QA-RPP-WTP-604. This review verifies that the reported results are traceable and that inferences and conclusions are soundly based. This review procedure is part of PNNL's RPP-WTP QAM.

\subsection{Hydrogen Gas Retention and Release in Process Vessels}

Figure 1.2 depicts the hold-up of gas bubbles during normal PJM operations and during and following an off-normal event where PJM mixing stops. During normal operations, there is a steady-state holdup of gas bubbles, which is shown in the first schematic as bubbles rising in a well-mixed slurry. These gas bubbles are continuously being released during the PJM operations. Quantifying the steady-state holdup during normal operations is a primary technical need and is discussed further in Section 5. Determining the PJM mixing system and operational parameters that will eliminate stagnant zones throughout the vessel is also a technical need, and this is discussed in Section 4. The first schematic in Figure 1.2 shows a fully mobilized vessel with a small holdup of rising bubbles throughout the waste where the gas bubbles are continuously being released. With anything less than perfect mixing, the concentration of solids will increase towards the bottom of the vessels and this is also depicted in the first schematic in Figure 1.2. During a period when the PJMs stop, such as during an off-normal event, the particles in the waste settle in the suspending fluid. It is expected that the settled layer will be non-Newtonian and will have sufficient shear strength to retain all of the gas bubbles that are generated in the settled layer. Once the waste is sheared or mobilized, the bubbles will be released and are free to rise. The release of bubbles and some stagnant regions is depicted in the fourth schematic in Figure 1.2. If the PJM operations following an outage return to the same normal operations as before the outage, the settled layer should be 
fully mobilized, and the waste configuration should be the same as before the outage. The last schematic in Figure 1.2 shows this situation with gas bubbles being continuously released.

Figure 1.3 shows the qualitative behavior of the gas holdup (time averaged so the fluctuation with each PJM cycle is not shown) within the vessel for these different stages. During normal operations, there is a small steady-state holdup associated with the gas bubbles that are continuously being released. What is shown at the beginning of this time line is typically small but can be an important fraction of the allowed holdup. When the PJMs stop and the slurry begins settling into a layer, the gas holdup increases. When the PJMs restart, gas begins to be released and the gas-release volume and time-scale for release depend on the mixing-system performance and the configuration and strength of the settled layer. Eventually, a holdup of gas returns to the steady-state level before the outage.

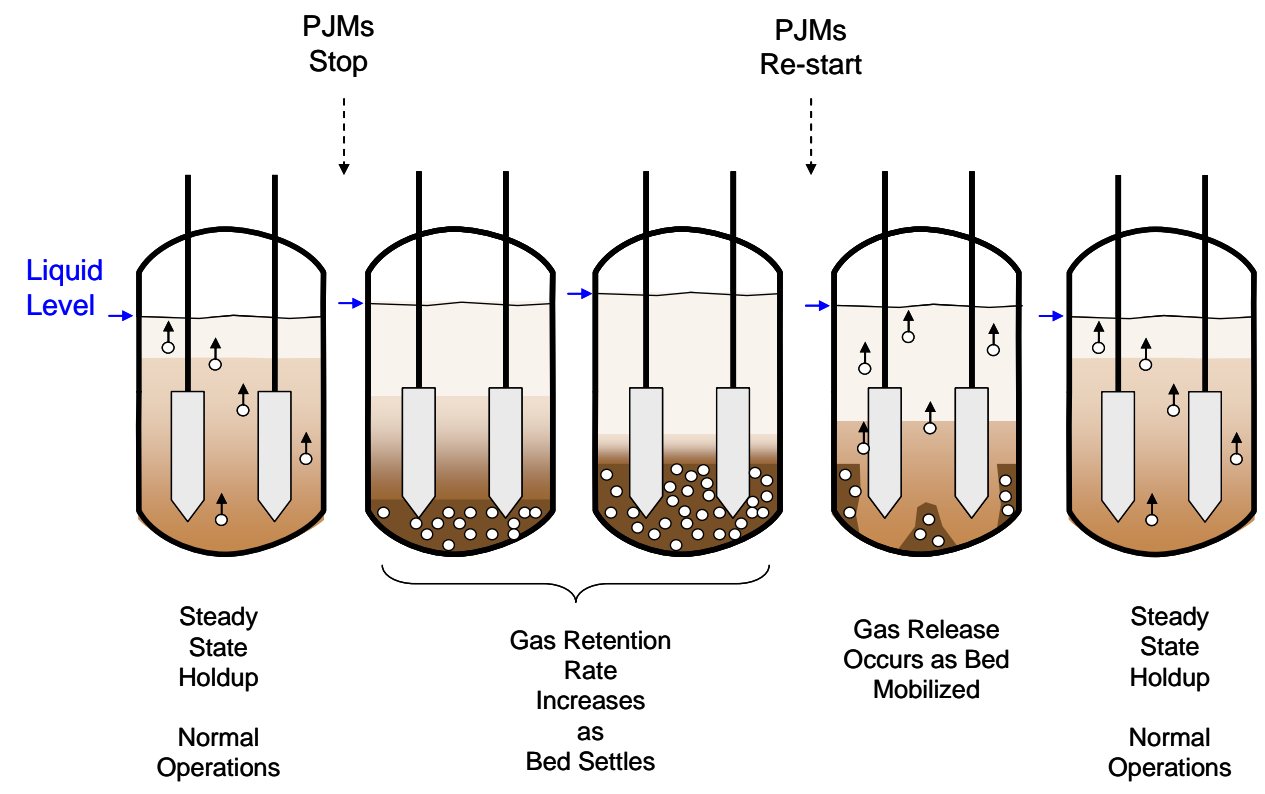

Figure 1.2. Gas Retention and Release Behavior in Settling Waste During Normal Operations, During an Outage in PJM Mixing and During the Re-Start of PJM Mixing 


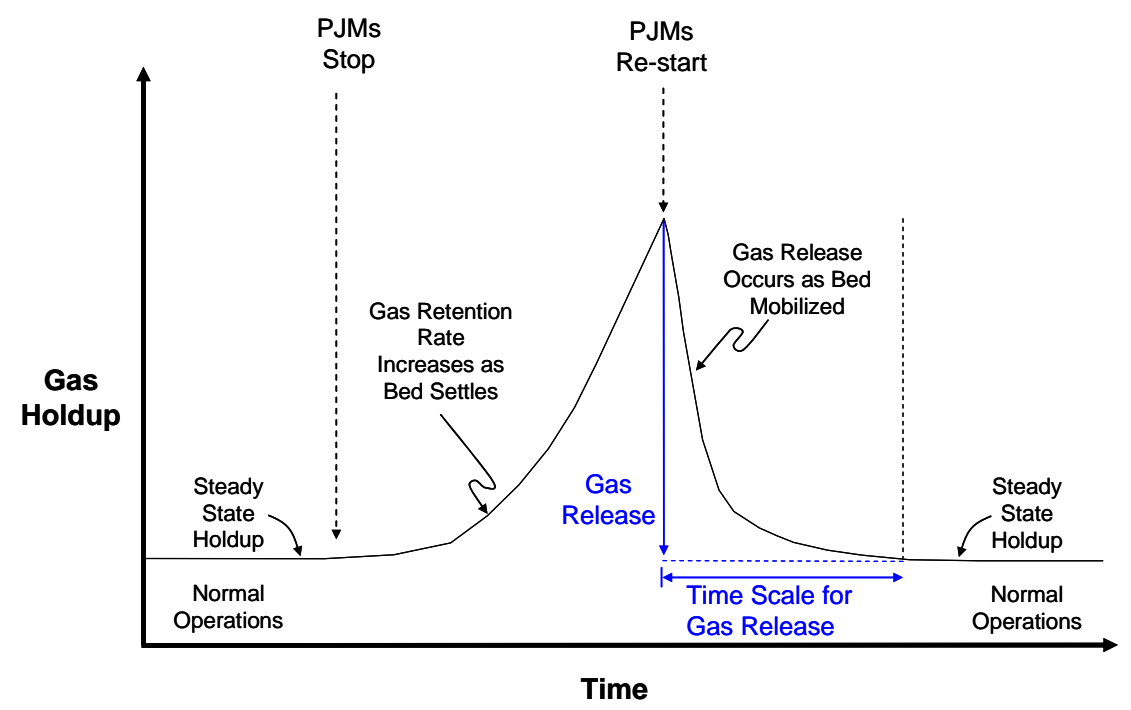

Figure 1.3. Conceptual Gas Holdup During Normal Operations, an Outage in PJM Mixing, and the ReStart of PJM Mixing

\subsection{Approach to Managing Retention and Release of Hydrogen Gas}

The current approach to managing the safety risk associated with hydrogen gas is to always maintain the inventory of hydrogen gas in each process vessel below specific acceptable levels (Eager 2008). During off-normal events, the holdup of hydrogen must be below the amount that could make the vessel headspace reach $100 \%$ of the lower flammability limit (LFL) if all of the retained hydrogen were instantaneously released. For normal operating conditions under the current safety basis, the maximum allowed holdup must be below the amount that would make the vessel headspace reach $25 \%$ of the LFL. Eager (2008) has reported calculations for the time to LFL, which is the amount of time, following a PJM outage, that it would take for the holdup to reach the level that could make the vessel headspace be $100 \%$ of the LFL. This calculation assumes all of the generated gas is retained in the waste.

Figure 1.4 depicts a conceptual example of how gas holdup is managed to maintain the holdup below the allowed levels. On the initial portion of the time line, the holdup has a steady-state value, which is determined by a range of parameters, including the gas-generation rate, the PJM mixing system geometry and operational parameters, and specific waste properties. The red line identified as the allowed gas holdup during normal operations depicts a holdup limit to keep the dome space below $25 \%$ of the LFL if that gas were released instantaneously. During this period of normal operation, the PJM mixing system must be sufficiently effective to maintain the holdup below the allowed maximum. Figure 1.4 also depicts the holdup at the end of the time line following an outage returning to the same level as before the outage with the PJMs also returning to normal operations. The middle portion of Figure 1.4 shows the situation during an off-normal event. When the PJMs stop mixing, the gas holdup rises. The PJMs must restart with sufficient mixing capability to release gas before the holdup reaches the value allowed during an outage.

The current calculation for the maximum retained gas assumes that the steady-state holdup during normal operation is negligible. Section 5 uses existing correlations for steady-state holdup to make preliminary (conservative) estimates of steady-state holdup. 


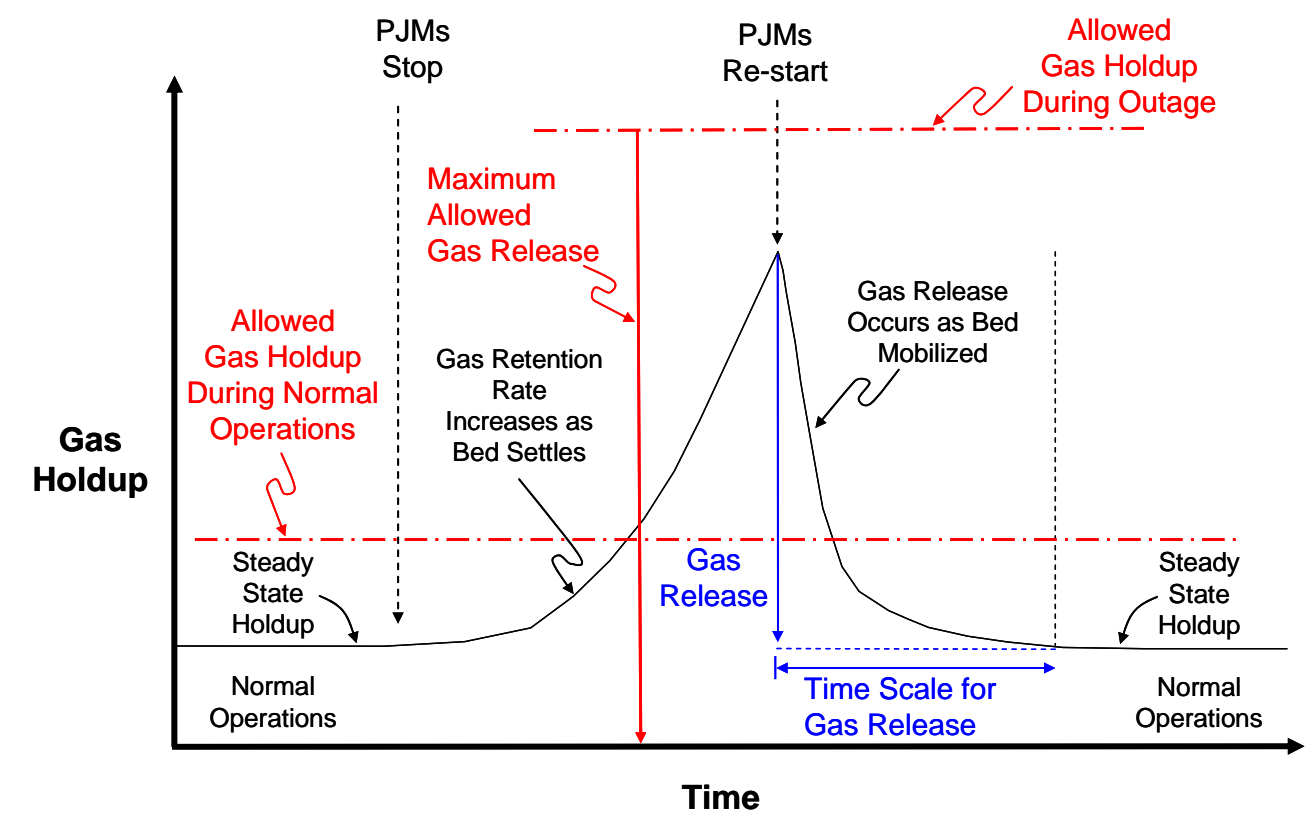

Figure 1.4. Conceptual Comparison of Gas Holdup to the Maximum Allowed Holdup During Normal Operations, an Outage in PJM Mixing, and the Re-Start of Reduced PJM Mixing

\subsection{Approach to Managing the Strength and Thickness of Settled Layers}

For waste materials that settle into cohesive layers, the depth of the layer and its strength increase with time. Previous studies of PJM mixing have shown that both increasing the layer depth and increasing the strength of the settled layer makes mobilization of these layers more difficult. For a specific PJM system, there is also a limit on layer depth and strength that represents the maximum capability of the mixing system. Accordingly, there is a time to remobilize limit, or frequency of PJM operation, which represents the maximum amount of time that the waste can be allowed to settle to avoid layers that are too deep and strong to mobilize completely with planned normal PJM operations.

\subsection{Approach to Understanding Hydrogen Retention in PJM Mixed Vessels}

Understanding hydrogen gas retention in PJM mixed vessels involves the physical phenomena of cohesive slurry settling and mobilization and how mobilization affects the retention and release of hydrogen gas bubbles. Table 1.1 shows the information needed to create a technical understanding of these key phenomena. The table organizes the information by topical areas, identifies the needed information, and briefly gives the current status of information. The first key question that needs to be addressed is whether the mechanisms of gas-bubble retention are sufficiently understood to conclude that all the pertinent mechanisms have been considered. For this information need, the existing work is considered sufficient. The second information need is to confirm that retained gas is released by waste mobilization. In this report, waste mobilization is defined as shearing the waste. The existing work is also considered sufficient to conclude that the mobilization will release gas, but a better understanding is needed to quantify the degree of slurry shearing that is sufficient to cause gas release due to mobilization. 
Table 1.1. Information Needed for Understanding Hydrogen Retention in PJM Mixed Vessels

\begin{tabular}{|c|c|c|c|}
\hline Topical Area & $\begin{array}{c}\text { Information Needed for } \\
\text { Topical Area }\end{array}$ & Chapter & Current Status \\
\hline $\begin{array}{l}\text { Bubble Retention } \\
\text { Mechanisms }\end{array}$ & $\begin{array}{l}\text { Sufficient understanding to } \\
\text { demonstrate that all pertinent } \\
\text { mechanisms have been fully } \\
\text { considered }\end{array}$ & 1.6 .1 & Existing work sufficient \\
\hline $\begin{array}{l}\text { Bubble Release } \\
\text { Mechanisms }\end{array}$ & $\begin{array}{l}\text { Sufficient understanding to } \\
\text { demonstrate that waste mobilization } \\
\text { releases retained hydrogen gas }\end{array}$ & 1.6 .2 & $\begin{array}{l}\text { Existing work sufficient to } \\
\text { demonstrate mobilization } \\
\text { releases gas. } \\
\text { Better understanding needed for } \\
\text { the degree of slurry shearing that } \\
\text { is sufficient to cause gas release } \\
\text { due to mobilization }\end{array}$ \\
\hline $\begin{array}{l}\text { Waste Properties: } \\
\text { Normal Operation }\end{array}$ & $\begin{array}{l}\text { Waste yield stress in a stratified } \\
\text { layer during PJM operation }\end{array}$ & 2 and 3 & $\begin{array}{l}\text { Existing rheology data analyzed } \\
\text { Further analysis needed to } \\
\text { estimate yield stress during PJM } \\
\text { operation, or select and use } \\
\text { bounding values }\end{array}$ \\
\hline $\begin{array}{l}\text { PJM Performance: } \\
\text { Normal Operation }\end{array}$ & $\begin{array}{l}\text { Performance capability of PJM } \\
\text { systems to mobilize waste with the } \\
\text { yield stress that occurs during } \\
\text { normal PJM operations }\end{array}$ & 4 & $\begin{array}{l}\text { New model proposed } \\
\text { Data to confirm model accuracy } \\
\text { needed, or develop bounding } \\
\text { analyses }\end{array}$ \\
\hline $\begin{array}{l}\text { Waste Properties: } \\
\text { Off Normal Event }\end{array}$ & $\begin{array}{l}\text { Waste-settling dynamics, including } \\
\text { settled-layer strength as a function of } \\
\text { depth and time, and the frequency of } \\
\text { waste mobilization needed to avoid } \\
\text { the formation of excessively strong } \\
\text { layers }\end{array}$ & 2 and 3 & $\begin{array}{l}\text { Existing settling and strength } \\
\text { data analyzed } \\
\text { Data needed on settled-layer } \\
\text { strength as a function of depth } \\
\text { and time, or select and use } \\
\text { bounding values }\end{array}$ \\
\hline $\begin{array}{l}\text { PJM Performance: } \\
\text { Off-Normal Event }\end{array}$ & $\begin{array}{l}\text { Performance capability of PJM } \\
\text { systems to mobilize waste of the } \\
\text { strength and thickness that occurs } \\
\text { during the off-normal event }\end{array}$ & 4 & $\begin{array}{l}\text { New model proposed } \\
\text { Data to confirm model accuracy } \\
\text { needed, or develop bounding } \\
\text { analyses }\end{array}$ \\
\hline $\begin{array}{l}\text { Gas Holdup During } \\
\text { Normal Operations }\end{array}$ & $\begin{array}{l}\text { Gas-holdup estimates in stratified } \\
\text { cohesive layers during PJM } \\
\text { operation }\end{array}$ & 5 & $\begin{array}{l}\text { Application of existing } \\
\text { correlations sufficient }\end{array}$ \\
\hline
\end{tabular}


For waste properties and PJM performance, the topical areas are separated into normal operations and offnormal events. For waste properties, information is needed on the yield stress and shear strength that can develop as a function of depth within the waste during normal operations and off-normal events. For offnormal events, information is needed on the frequency of waste mobilization to avoid the formation of difficult-to-mobilize layers with planned normal PJM operations. Existing data were analyzed, but additional analysis and some additional data are needed. An alternative to obtaining this information is to select and use bounding values. For PJM performance, the key information need is to determine the capability of the PJM systems to overcome the shear strength or yield stress and mobilize the waste. A new model is proposed in this report, but data to confirm the model accuracy and whether it is adequate are still needed. Again, an alternative to obtaining this information is to develop bounding analyses. Finally, information is needed to estimate gas holdup during normal operations, and existing correlations have been found to be sufficient.

\subsection{Bubble-Scale Mechanisms of Retention and Release}

The overall gas holdup in a process vessel is determined by both the retention and release mechanisms at the bubble scale and the macroscopic phenomena that determine the bubble rise velocity, such as mixing and vessel depth. This section summarizes the bubble-scale mechanisms of retention and release.

\subsubsection{Mechanisms of Bubble Retention at the Bubble Scale}

The generation, retention, and release of gas bubbles in high-level waste (HLW) storage tanks at Hanford have been the subject of detailed studies. In general, it was found that gas retention would occur in any tank that had a settled layer of wet solids provided there was sufficient gas generation and the layer had sufficient strength to hold bubbles. The retention of bubbles is not surprising and is known to occur in a variety of materials, ranging from yield stress fluids and pastes (Chhabra 1993) to ocean sediments (Wheeler 1990). Johnson et al. (1997, 2001) give overall summaries of the investigations for Hanford waste tanks. In one study evaluating gas retention in K-basin sludge, Gauglitz and Terrones (2002) evaluated existing literature on bubble retention and estimated that the maximum gas fraction that might be retained in settled materials would be $35 \%$.

The bubble-scale mechanisms of gas retention and bubble behavior in tank waste have been the subject of a number of studies (see, for example, Gauglitz et al. 1994, 1995, 1996, 2001; Stewart et al. 1996; Rassat et al. 1997, 1998, 1999; Bredt et al. 1995; Bredt and Tingey 1996; and Walker et al. 1994). The principal mechanisms of bubble retention can be grouped into three categories:

- bubbles retained by direct attachment to particles (often called armored bubbles)

- bubbles retained by the strength of the surrounding waste

- bubbles retained between particles by capillary forces.

In layers of liquid-saturated settled solid particles, called sediment, capillary forces and waste strength dominate bubble retention. In well-mixed vessels, bubbles directly attaching to particles can play an important role in the overall gas holdup within a vessel. The two dominant bubble-retention mechanisms in settled layers are discussed first below, followed by a summary of bubble retention via armored bubble formation. 
Figure 1.5 shows representative configurations of bubbles retained by these three bubble-scale mechanisms. Bubbles can be held in the interstitial spaces or pores between particles by capillary forces when the lithostatic load is sufficient to hold the particles in contact against the force of the bubbles' internal pressure trying to push them apart. The lithostatic load at any elevation is given by the weight of the particles above. The capillary-force retention mechanism requires either relatively large pores, which reduces the internal bubble pressure, or a deep waste column, which increases the lithostatic load, or both. These bubbles assume an irregular, dendritic shape conforming to the passages between the particles. When the internal pressure of a bubble overcomes the effect of the lithostatic load, it pushes the surrounding particles apart. The bubble is then restrained by the yield strength of the bulk waste as a particle-displacing bubble. The difference between these two types of bubbles is illustrated in Figure 1.5.

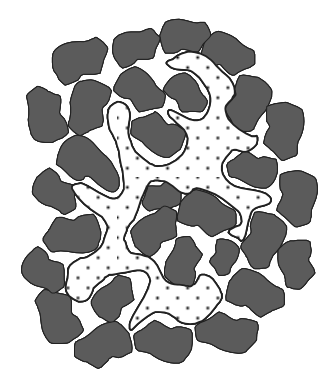

Bubble held within pores by capillary forces

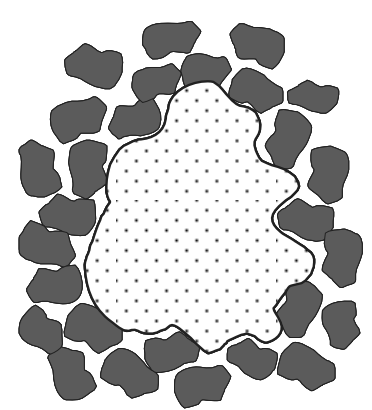

Bubble displacing particles and held by waste strength

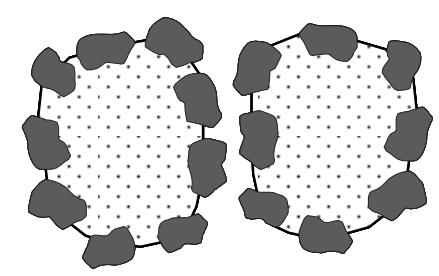

Armored Bubbles Resisting Coalescence

Figure 1.5. Bubbles Retained by Capillary Forces and by Waste Strength and Armored Bubbles

Whether a bubble is held by yield strength or capillary force is indicated by the Bond number criterion developed by Gauglitz et al. (1994, 1995, and 1996). This dimensionless number contains two parameters, a ratio of gravitational force to surface-tension force and a ratio of waste-strength force to surface-tension force. If the number exceeds unity, the bubbles are in a pore-filling configuration between particles and held by capillary forces. The Bond number is expressed as:

$$
\mathrm{N}_{\text {Bo }}=\frac{\Delta \rho g \mathrm{H}_{\mathrm{S}} \mathrm{D}_{\mathrm{p}}}{4 \sigma}+\frac{\tau_{\mathrm{y}} \mathrm{D}_{\mathrm{p}}}{4 \sigma} \mathrm{A}
$$

where $\mathrm{H}_{\mathrm{S}}=$ height of the lithostatic column above the bubble

$\mathrm{D}_{\mathrm{P}}=$ mean pore diameter through which a bubble must pass to escape retention. Assumed to be represented by the particle diameter.

$\Delta \rho=$ difference between bulk sediment and liquid density

$\sigma=$ surface tension

$\tau_{\mathrm{y}}=$ yield stress

$\mathrm{g}=$ acceleration due to gravity.

$\mathrm{A}$ is an area ratio related to how the yield stress resists bubble expansion; it was estimated to be 2.8 by Gauglitz et al. (1995) based on laboratory experiments. 
The term "armored bubbles" is often used in the field of mineral flotation to describe the capability of particles to stabilize bubbles against coalescence, and Figure 1.5 shows an example of two armored bubbles. In tank waste, this effect potentially leads to smaller, shielded bubbles that are not easily released into the vessel headspace. The attachment of waste particles to bubbles indicates that the waste particles are not completely wetted by the aqueous waste.

A number of studies have been done to evaluate the role of armored bubbles in causing foaming and gas retention in WTP vessels, and these studies have also investigated the role of antifoam agents (AFAs) in mitigating this problem (for example, see Guerrero et al. 2007; Burket et al. 2005; Josephs and Calloway 2001; and Stewart et al. 2007, 2006a). Wasan and co-workers have also investigated the fundamental mechanism for foaming and antifoam mechanisms in waste slurries (Wasan et al. 2004; Bindal et al. 2001, 2002). It was determined that small insoluble particles that attach to bubbles can inhibit the coalescence of bubbles by creating particle-stabilized foam lamellae that create stable foams. This is caused by the fact that the particle surfaces have intermediate or mixed wettability. These studies also determined the major mechanisms of antifoam action in foams stabilized by these solid particles.

In actual waste slurries, the insoluble sludge particles are a mixture of different chemical species. Each particle species, with some level of dissolved organic species adsorbed on their surfaces, will have different interactions at bubble/liquid interfaces and different interactions at the solid/liquid interface with antifoaming chemicals. Previous studies elucidated key mechanisms, and the study by Stewart et al. (2007) (see Section 7) specifically evaluated what simulant would comprise a bounding simulant.

In addition to the studies described above directly supporting the WTP, there have been a number of previous studies involving the mechanism of armored bubbles in relation to Hanford tank waste. Bryan et al. (1992a, 1992b, 1993) used simple frothing tests to highlight the importance of bubble/particle interactions on bubble retention. The reported results showed that particles that were not completely wetted by the aqueous solution (polymethylmethacrylate or PMMA) would attach to gas bubbles and cause the bubbles to be retained in a froth. Similar results were observed for bubbles in SY-101 chemical simulants with organics added. This work further showed that the wettability of the particles, which involved adding organics in the case of the chemical simulants, was the mechanism dominating the bubble/particle interactions.

Following the work of Bryan and his coworkers, Rossen, Gauglitz and their coworkers (Ali et al. 2000; Rossen and Das 1996; and Rossen and Kam 1996) investigated the mechanisms of stability of armored bubbles. They conducted a variety of frothing tests and also used interfacial rheology as a tool to probe bubble/particle interactions. In addition, they conducted theoretical studies on a number of issues related to how particles can stabilize bubbles through armoring. In the study by Rossen and Kam (1996), conditions were derived for stabilizing bubbles against gas dissolution into the surrounding liquid and the subsequent disappearance of these bubbles. Without this mechanism, isolated armored bubbles should not persist for extended periods of time. The results of Rossen and Kam (1996) showed that long-lived armored bubbles are plausible. However, other mechanisms, such as bubble coalescence, may still allow armored bubbles to be readily released.

The literature contains a number of studies on how particles affect the stability of froths and foams (relevant examples include Garrett 1979; Aronson 1986; Dippenaar 1982a, 1982b; Tang et al. 1989; Frye and Berg 1989a, 1989b; Hudales and Stein 1990; Koczo et al. 1994; Aveyard et al. 1994; Kulkarni et al. 
1977) and the similar situation of emulsions (Van Boekel and Walstra 1981; Hassander et al. 1989; Levine et al. 1989a, 1989b; Tambe and Sharma 1994, 1995). In these studies, particles both increased and decreased the stability of the bubbles, and the role of the particles depended on subtle differences in the bubble (droplet)/particle interactions.

While there have been extensive previous studies for resolving the performance of antifoaming agents in WTP vessels where antifoam agents will be used (see, for example, Josephs and Calloway 2001 and Stewart et al. 2007), there has been less attention given to some of the as-received wastes. There have only been measurements on actual waste samples from AN-102, AN-104, and AW-101 (Crowder 2001, 2003, 2004), and these samples were pretreated in various ways before foaming tests. An interesting example of stable froths in untreated waste are the observations reported by Rassat et al. (1997) where very stable froths were observed in an as-received waste sample from AN-103. Due to the complexity of bubble/particle interactions, coupled with the complex chemical behavior of actual tank waste, the role of armored bubbles and the formation of stable froths in actual waste are difficult to predict with any certainty. If a stable froth were to occur, the retained gas bubbles may not be readily released during normal PJM operation. Accordingly, there is a technical uncertainty in understanding foaming behavior and the role of armored bubbles in as-received wastes.

\section{Uncertainty 1.1 The foaming behavior of untreated actual wastes should be characterized to determine if there is a potential gas-retention mechanism in these waste materials prior to waste transfer to the WTP.}

\subsubsection{Mechanisms of Bubble Release at the Bubble Scale}

The mechanism of how gas bubbles will be released by waste mobilization depends on whether the bubbles are retained by capillary forces or by the waste strength. For bubbles retained by capillary forces, which is the expected retention mechanism for larger non-cohesive particles, it is expected that simply mobilizing the settled particles will be sufficient to initiate bubble release. Specifically, once a bed of settled non-cohesive particles is mobilized, individual particles can easily move away from their neighboring particles. When this happens, the pore throats that were retaining the bubbles by capillary forces can become much larger, and any retained bubbles can be readily released. The release of gas bubbles from non-cohesive beds of particles via fluidization or mobilization is not a common research topic, but the work of Ohshima et al. (1976) is one specific example explicitly showing that the holdup of trapped (stagnant) gas bubbles approaches zero as the minimum fluidization velocity is reached. In the review article by Cheremisinoff and Gupta (1983), this behavior reported by Ohshima et al. (1976) is noted and accepted.

For bubbles retained by the strength of the waste, which is the expected retention mechanism for cohesive materials, shearing the waste changes the waste from having solid properties to having fluid properties where buoyant objects will always have a net rise velocity, even though it might be small. Once the waste is a fluid, it will allow retained bubbles to begin rising and being released. The previous PJM studies on gas release showed conclusively that simulants that easily retain gas bubbles when stationary will release these bubbles when sheared (Stewart et al. 2007, 2006a, 2006b; Bontha et al. 2005; Russell et al. 2005). The fundamental mechanism that bubbles are free to rise when a Bingham yield stress fluid is sheared was demonstrated by Thomas (1979). In this study, slurries with a Bingham yield stress ranging from 10 to $25 \mathrm{~Pa}$ were sheared in the annular gap between two rotating cylinders. The shear rates 
ranged from 1 to $100 \mathrm{~s}^{-1}$, and large suspended glass and steel particles were shown to settle once shearing was initiated.

For bubbles that can be retained as armored bubbles, antifoaming agents are used to reduce or eliminate this mechanism of retention. Mobilization or mixing of the waste should have a negligible effect on releasing gas from armored bubbles, should they occur. 


\subsection{Summary of Settling Behavior and Settled Waste Strength}

A large body of information exists for the laboratory-scale gravity settling behavior of actual waste samples and for laboratory measurements of the shear strength (shear vane) or yield stress (Bingham model parameter from a rheogram) of waste samples taken from settled layers in Hanford waste tanks. Poloski et al. (2007) provide an extensive compilation and evaluation of these data, including estimates of the shear strength of a heel layer that would form as a result of the settling and compaction of settled layers. It is important to note that the rheological and settling behavior of the waste will change as it progresses through the WTP (Poloski et al. 2006a).

In addition to these laboratory measurements, there are four significant waste operations that were conducted in the Hanford tanks that provide useful data for estimating settling behavior and the strength of settled layers. These data are particularly useful because they are large-scale results obtained using actual waste. The four waste operations are the mixing study in AZ-101, the AY-102 behavior as it received sludge from $\mathrm{C}-106$, the periodic mixing and settling of waste in SY-101, and the SY-102 behavior as it received waste from SY-101. An evaluation of pertinent data from these operations is presented in Section 3.

In the sub-sections below, we further evaluate the laboratory-scale data, including additional data not reported in Poloski et al. (2007), and select those data that are specifically important for estimating the range of settled layer strengths that are expected for waste transferred to the WTP. We also present a cumulative probability distribution of these strength data to allow an estimate to be selected for an upper limit for the layer strength, such as the $95^{\text {th }}$ percentile strength. A detailed tabulation of the specific data used in this report is given in Appendix A.

Table 2.1 presents a summary of the overall evaluation of the various existing data on settled layer strength and also shows summary values from Poloski et al. (2007) for comparison. The categories for settling time were chosen to help explain the range of settling behavior, but they are similar to those used by Poloski et al. (2007). Due to the absence of models and data, there are no estimates for the time period of 0 to 10 hours, except for the low estimate that assumes a slurry with a 1-Pa Bingham yield stress. For the time period of 10 to 24 hours, estimates are given for all the bins, and the uncertainty in these estimates is described. As discussed in Section 2.1, after settling for 24 hours, a typical layer strength is estimated as $30 \mathrm{~Pa}$, and $200 \mathrm{~Pa}$ is given as a reasonable minimum upper bound. The bases for these estimates and their uncertainties are summarized in Table 2.1. For the compacted layer, our current estimates give values for the median and lower estimates for the shear strength that are similar to those presented in Poloski et al. (2007). Our current estimate for the higher shear strength that can be expected is 7,000 Pa, which is noticeably less than the maximum value reported by Poloski et al. (2007). Part of the reason for this difference is that we excluded the 25,000 $\mathrm{Pa}$ datum from our analysis because it is from a crust sample rather than from a settled layer. 
Table 2.1. Estimated Shear Strength of Settled Layers

\begin{tabular}{|c|c|c|c|c|c|}
\hline \multirow[t]{2}{*}{$\begin{array}{c}\begin{array}{c}\text { Settling Time } \\
\text { (hours) }\end{array} \\
\end{array}$} & \multicolumn{3}{|c|}{$\begin{array}{c}\text { Heel Shear Strength } \\
\text { (Pa) }\end{array}$} & \multirow{2}{*}{ Basis } & \multirow[b]{2}{*}{ Uncertainty } \\
\hline & $\begin{array}{l}\text { Low or } \\
\text { Minimum }\end{array}$ & $\begin{array}{l}\text { Median } \\
\text { Typical }\end{array}$ & $\begin{array}{c}\text { High or } \\
\text { Maximum }\end{array}$ & & \\
\hline $\begin{array}{l}\text { Settled } \\
0-10 \text { hours }\end{array}$ & 3 & $\begin{array}{l}\text { No } \\
\text { estimate }\end{array}$ & $\begin{array}{c}\text { No } \\
\text { estimate }\end{array}$ & $\begin{array}{l}\text { Low estimate assumes a 1-Pa Bingham } \\
\text { yield stress slurry that has a shear } \\
\text { strength } \sim 3 \text { times higher }\end{array}$ & $\begin{array}{l}\text { Based on a single estimate for the ratio of shear } \\
\text { strength and yield stress. The ratio of shear } \\
\text { strength to Bingham yield stress for diluted } \\
\text { B-203 and T-203 waste is } 5 \text { and } 8 \text {, respectively } \\
\text { (Tingey et al. 2003). A ratio approaching } 1,000 \\
\text { may be determined from core-sample analyses } \\
\text { of AZ-101 waste (see Urie et al. } 2002 \text { and } \\
\text { Appendix A, Table A.1). For recently settled } \\
\text { waste, the three-fold increase is used. }\end{array}$ \\
\hline $\begin{array}{l}\text { Settled } \\
10-24 \text { hours }\end{array}$ & 3 & 30 & 200 & $\begin{array}{l}\text { Minimum-as above. } \\
\text { Median—Pretreated AZ-101 waste } \\
\text { sample; see Section 2.1. } \\
\text { Maximum-AZ-101 in situ data; see } \\
\text { Section } 3.2 \text { and uncertainty discussion } \\
\text { at right. }\end{array}$ & $\begin{array}{l}\text { The high value of } 200 \mathrm{~Pa} \text { is given as a } \\
\text { reasonable and plausible minimum upper bound. } \\
\text { There is, however, uncertainty in this estimate as } \\
\text { discussed in Section 2.1.2. In particular, } \\
\text { Figure } 3.5 \text { and Figure } 3.6 \text { (see Section } 3 \text { ) for the } \\
\text { in situ settling of AZ-101 waste showed settled } \\
\text { material exceeding } 200 \mathrm{~Pa} \text { within } 24 \text { hours in } \\
\text { two locations. It is possible that this is a } \\
\text { localized behavior and not representative of the } \\
\text { waste in general. The method of estimating the } \\
\text { shear strength of the layer that is at least } 200 \mathrm{~Pa} \\
\text { is also an approximation (see Appendix B). } \\
\text { Also, additional recent laboratory measurements } \\
\text { on settled material from actual cladding waste } \\
\text { composites showed unusually fast settling and } \\
\text { high strengths with settling occurring over a } 3 \text {-hr } \\
\text { period and the strength of the settled material } \\
\text { ranging from } 100 \text { to } 700 \mathrm{~Pa} \text { and possibly higher } \\
\text { (see Section 2.1.2). }\end{array}$ \\
\hline
\end{tabular}


Table 2.1 (cont'd)

\begin{tabular}{|c|c|c|c|c|c|}
\hline \multirow[b]{2}{*}{$\begin{array}{l}\text { Settling Time } \\
\text { (hours) }\end{array}$} & \multicolumn{3}{|c|}{$\begin{array}{l}\text { Heel Shear Strength } \\
\text { (Pa) }\end{array}$} & \multirow[b]{2}{*}{ Basis } & \multirow[b]{2}{*}{ Uncertainty } \\
\hline & $\begin{array}{c}\text { Low or } \\
\text { Minimum }\end{array}$ & $\begin{array}{l}\text { Median } \\
\text { Typical }\end{array}$ & $\begin{array}{c}\text { High or } \\
\text { Maximum }\end{array}$ & & \\
\hline $\begin{array}{l}\text { Settled } \\
24-100 \text { hours }\end{array}$ & 30 & $>200$ & $>200$ & $\begin{array}{l}\text { Minimum-Estimate for in situ } \\
\text { AZ-101 waste; see Section 2.1.2. } \\
\text { Median and Maximum-AZ-101 in } \\
\text { situ data; see Section } 3.2 \text { and } \\
\text { uncertainty discussion for settled } 10 \text { to } \\
24 \text { hours in previous row. }\end{array}$ & See uncertainty discussion above. \\
\hline $\begin{array}{c}\text { Settled } \\
1,000-6,000 \\
\text { hours }\end{array}$ & 100 & $\begin{array}{l}\text { No } \\
\text { estimate }\end{array}$ & 6,200 & $\begin{array}{l}\text { Shear Vane Data: } \\
\text { Minimum-235 days in SY-102; see } \\
\text { Section 3.3.2 } \\
\text { Maximum-140 days in AY-102, see } \\
\text { Section 3.2, Figure } 3.11 \text { (see } \\
\text { Section 3). }\end{array}$ & Based on minimal data set. \\
\hline \multirow[t]{2}{*}{ Compacted } & $\begin{array}{c}5^{\text {th }} \\
\text { percentile }\end{array}$ & $\begin{array}{c}50^{\text {th }} \\
\text { percentile }\end{array}$ & $\begin{array}{c}95^{\text {th }} \\
\text { percentile }\end{array}$ & & \\
\hline & 50 & 725 & 7,000 & Shear Vane (Sect. 2.2.2) & $\begin{array}{l}\text { See Section 2.2; limited to available data. See } \\
\text { also Gap 2.2. }\end{array}$ \\
\hline \multicolumn{6}{|c|}{ Previous Estimates } \\
\hline & $\begin{array}{l}\text { Low or } \\
\text { Minimum }\end{array}$ & $\begin{array}{l}\text { Median } \\
\text { Typical }\end{array}$ & $\begin{array}{l}\text { High or } \\
\text { Maximum }\end{array}$ & & \\
\hline $\begin{array}{l}\text { General Heel } \\
\text { Properties }\end{array}$ & 40 & 700 & 25,000 & $\begin{array}{c}\text { Table S.1 } \\
\text { Poloski et al. (2007) }\end{array}$ & \\
\hline $\begin{array}{l}\text { Various Settling } \\
\text { Scenarios } \\
10-1000 \text { hours }\end{array}$ & - & - & 25,000 & $\begin{array}{c}\text { Table S.1 } \\
\text { Poloski et al. (2007) }\end{array}$ & \\
\hline
\end{tabular}




\subsection{Previous Laboratory-Scale Studies of Settled Layer Strength and Settling Dynamics}

Poloski et al. (2007) have provided an extensive compilation and evaluation of waste rheology and settling behavior. The summary properties for the shear strength of a settled heel are that it could have a maximum of $25,000 \mathrm{~Pa}$, a median value of $700 \mathrm{~Pa}$, and an estimated minimum of $40 \mathrm{~Pa}$. These values are shown in Table 2.1 as general heel properties. In an earlier study by Poloski et al. (2006a), a value of $<625 \mathrm{~Pa}$ was given as an estimate for the maximum shear strength for settled HLW pretreated sludge during a plant upset condition. The maximum value of 25,000 Pa given by Poloski is from a measurement on a crust sample from SY-101.

There have been a number of recent laboratory shear-strength measurements made on settled layers that formed in laboratory-scale settling experiments with Hanford tank waste samples. In one series of studies, waste composites representing eight different waste types were prepared and characterized before conducting leaching tests on the samples (see Fiskum et al. (2008) for a discussion of these waste groups and each of the reports in Table 2.2 for more details on the specific tanks in each waste group). For each composite sample, the sample naturally gravity settled over a period of a couple days, creating a settled layer and a supernatant layer, and the shear strength of the settled layer was measured. For this series of studies, data were reported for the bulk total undissolved solids (UDS) in the sample, the total UDS in the settled layer, and the final settled layer volume as a fraction of the total sample. Table 2.2 gives a summary of these measurements and references to the original reports. There are a number of general observations that can be gleaned from these measurements. For the four samples with less than $15 \mathrm{wt} \%$ UDS in the bulk samples (Groups 1, 6-8), the shear strength of the settled solids varied between 11 and 23 $\mathrm{Pa}$, and the settled sample volume ranged from $38.9 \%$ to $85.7 \%$ of the total sample. This is a relatively deep layer of settled waste with a shear strength in the range of $20 \mathrm{~Pa}$. The two strongest samples, which are plutonium-uranium extraction (PUREX) cladding waste sludge (Group 3) and reduction-oxidation (REDOX) cladding waste sludge (Group 4), had strengths between 100 and $700 \mathrm{~Pa}$. These samples were measured after sitting undisturbed for a 72-hour period, and it was estimated that the shear-strength values were low because both measurements were performed with the rotary vane of the instrument only half immersed into the sample. For the 700-Pa strength, Snow et al. (2009) estimated that the actual shear strength is likely on the order of 1,500 Pa. These samples had a total UDS in the bulk sample of about $30 \mathrm{wt} \%$ UDS, which is above what is expected for WTP vessels with settling slurries, but these higher strengths need to be considered.

There are a few additional measurements on the shear strength (or yield stress) of settled layers. Tingey et al. (2003) reported one of the measurements, which was for a tank T-204 sludge sample identified as the $1: 1$ dilution. This sample had $14.6 \mathrm{wt} \%$ total solids and formed a settled layer with an estimated 18 $\mathrm{wt} \%$ total solids (note that the total solids includes both dissolved and undissolved solids; Poloski et al. (2006b) estimated the $14.6 \mathrm{wt} \%$ total solids sample was $6.6 \mathrm{wt} \%$ UDS). A shear strength of $20 \mathrm{~Pa}$ was measured with a shear vane on the settled layer. The original T-204 core sample without any dilution was $31.5 \mathrm{wt} \%$ total solids and had a shear strength of $1520 \mathrm{~Pa}$ (Tingey et al., 2003). Poloski et al. (2003) reported the second measurement on a pretreated AZ-101 waste sample. The initial sample had $10.3 \mathrm{wt} \%$ UDS, and the settled layer had $22 \mathrm{wt} \%$ UDS. The shear strength of the $22 \mathrm{wt} \%$ USD sample varied with the aging of the sample, but the shear strength after a day of aging was constant at about $31 \mathrm{~Pa}$. The final example was a yield stress measurement on an untreated AZ-101 sample reported by Urie et al. (2004). 
This sample had about $7 \mathrm{wt} \%$ UDS in the received sample, and after settling and decanting the supernatant, the settled layer had about $45 \mathrm{wt} \%$ UDS. The average Bingham yield stress was 3.7 Pa for this sample.

Table 2.2. Shear Strength of Settled Layers

\begin{tabular}{|c|c|c|c|c|l||}
\hline $\begin{array}{c}\text { Waste } \\
\text { Group }\end{array}$ & $\begin{array}{c}\text { Bulk } \\
\text { Total UDS } \\
\mathbf{( w t )}\end{array}$ & $\begin{array}{c}\text { Settled Solids } \\
\text { Total UDS } \\
\mathbf{( w t \% )}\end{array}$ & $\begin{array}{c}\text { Settled Solids } \\
\text { Vol\% of Total } \\
\text { Sample } \\
\mathbf{( \% )}\end{array}$ & $\begin{array}{c}\text { Shear Strength } \\
\text { of Settled } \\
\text { Solids } \\
\mathbf{( P a )}\end{array}$ & \multicolumn{1}{||}{ Reference } \\
\hline 1 & 9.0 & 13.7 & 57.4 & 15 & Lumetta et al. (2009) \\
\hline 2 & 37.4 & 40.5 & 85.0 & 21 & Lumetta et al. (2009) \\
\hline 3 & 28.8 & 49.7 & 46.9 & 700 & Snow et al. (2009) \\
\hline 4 & 29.7 & 63.2 & 43.4 & $100-340$ & Snow et al. (2009) \\
\hline 5 & 18.5 & 21.6 & 87.2 & 72 & Fiskum et al. (2008) \\
\hline 6 & 14.7 & 24.8 & 54.8 & 20 & Fiskum et al. (2008) \\
\hline 7 & 10.0 & 11.4 & 85.7 & 23 & Edwards et al. (2009) \\
\hline 8 & 11.4 & 26.6 & 38.9 & $11-13$ & Fiskum et al. (2009) \\
\hline
\end{tabular}

The transient settling of waste slurries to form a cohesive sediment layer is a crucial step in determining the mixing system that will be needed to mobilize the settled layer. Poloski et al. (2007) also presented a settling model, based on hindered settling, and determined the model parameters for 58 sedimentation curves. These data were typically taken on small laboratory samples with a sample depth on the order of $10 \mathrm{~cm}$. Scaling these results to full-scale behavior has significant uncertainty, but predictions can be made with the model. Another approach to scaling up laboratory scale tests to full-scale systems has been developed where sediment compression occurs after hindered settling has progressed to where the settled layer reaches a gel point. This model is capable of handling the continued compaction from the lithostatic load of the sediment (Brooks et al. 1999, 1998; Rector and Bunker 1995a, 1995b). MacLean (1999) conducted a number of setting tests with different simulants and with a range of different size settling columns, the largest being 30 feet tall, to determine the effect of vessel size and geometry on the settling behavior. A model was also developed to predict full-scale behavior from smaller scale test results. These tests were conducted for about 300 days, and the 30 -foot column tests clearly showed an initial rapid settling behavior, followed by a much slower compaction.

While a number of gravity settling models have been developed and combined with experimental results, there continue to be significant unexplained differences between laboratory tests and full-scale behavior. One example is the settling behavior of AZ-101 actual waste. Peterson et al. (1989) and Gray et al. (1999) reported settling results for AZ-101 samples in laboratory vessels that were less than $10 \mathrm{~cm}$ tall. In these tests, the settling was essentially complete in about 2 days. Callaway (2000) used $100 \mathrm{~mL}$ graduated cylinders and measured settling behavior for AZ-101 waste and the results showed that the settling was essentially complete in about 1 day. The models presented by Poloski et al. (2007) and MacLean (1999) both include the sample height, and both show that the characteristic settling time increases in direct proportion to the height of the vessel. Accordingly, these models both predict that a settling experiment conducted in AZ-101, which has 300 inches of waste, i.e., about 50 times taller than the laboratory tests, would require about 50 times as long to settle. As shown in Section 3.1.5, an 
evaluation of full-scale settling in AZ-101 after the approximately 17.5-inch sediment layer was mobilized by mixer pumps shows that the solid-liquid interface settled from approximately 300 inches to 30 inches in about 2 days. In certain radial locations, a portion of waste settled to approximately 15 inches with shear strength $\geq 200 \mathrm{~Pa}$ in 1 to 2 days while throughout the tank, the material settled to approximately 20 inches with a shear strength $\geq 200 \mathrm{~Pa}$ over about a 25 -day period.

\subsubsection{Effect of Solids Content on Shear Strength and Bingham Yield Stress}

Tingey et al. (2003) and Rassat et al. (2003b) present summaries of shear strength and yield-stress data showing the effect of solids content for actual waste samples from B-203 and T-204. For comparison, Rassat et al. (2003b) also presented the results for clay slurry simulants, including a slurry of kaolin clay. The original data were reported with the $\mathrm{wt} \%$ of total solids, which includes dissolved salts, and Poloski et al. (2006b) calculated the wt $\%$ UDS for each sample (for the sample identified by Tingey et al. [2003] as the settled 1:1 dilution, the wt $\%$ UDS was not reported and has been calculated using the approach given by Poloski et al. [2006b]). Figure 2.1 shows these data with shear-strength measurements represented by closed symbols and Bingham yield-stress measurement using open symbols. Results are also shown for AZ-101 samples reported by Poloski et al. (2007, 2003) and Geeting et al. (2003). The shear-strength data for the strongest AZ-101 sample is the average of core 266 and 269 values of $4190 \mathrm{~Pa}$ and $1769 \mathrm{~Pa}$ given in Appendix A, Table A.1. The comparison between the shear strength and Bingham yield stress for AZ-101 shows the representative result that the shear strength will be larger, and the difference for AZ-101 is about a factor of 3 . The lines through each of the data sets are exponential correlations determined with a least squares fit to the data.

The data in Figure 2.1 show that even small changes in the solids content, such as through settling, stratification, and compaction, result in dramatic changes in the shear strength or Bingham yield stress. The data also show that at the same wt $\%$ UDS, the shear strength for different actual wastes can differ by 100 -fold or more. 


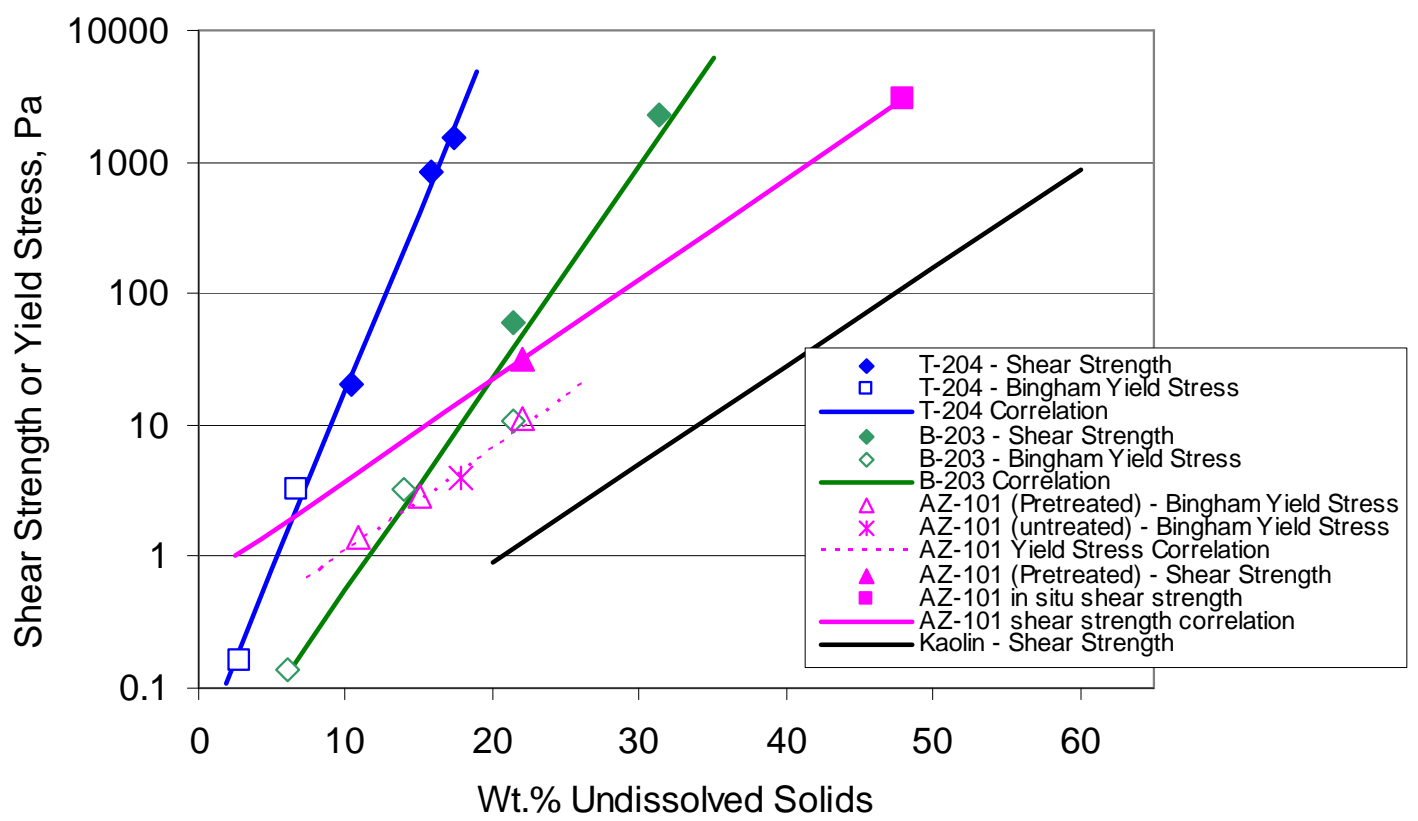

Figure 2.1. Shear Strength as a Function of Solids Content for Actual Waste Samples and Clay Simulants

For slurries that settle, the wt\% UDS will increase with settling, and, accordingly, the shear strength or Bingham yield stress will increase. Different settling scenarios can be considered to estimate how much the strength might increase. Settling during both off-normal events and during normal PJM operations needs to be considered. For off-normal events, a simplified settling scenario is that the slurry begins with a perfectly uniform distribution of solids and then settles in a layer with a uniform but higher concentration. For an initially uniform slurry with an UDS volume fraction of $\varphi_{\text {S initial, }}$, the solids volume fraction in a settled layer, $\varphi_{\mathrm{S} \text { Layer, }}$ assuming that the layer is uniform, is the following:

$$
\varphi_{\text {S Layer }}=\frac{\varphi_{\text {Sinitial }}}{\text { (layer height } / \text { initial layer height })}
$$

The correlations for shear strength and yield stress are given in terms of the $\mathrm{wt} \%$ UDS, so conversions between volume fraction and weight fraction (or percent) solids are needed. These conversions are given below.

$$
\begin{aligned}
& \varphi_{\mathrm{S}}=\frac{\mathrm{x}_{\mathrm{S}}\left(\rho_{\mathrm{L}} / \rho_{\mathrm{S}}\right)}{1+\mathrm{x}_{\mathrm{S}}\left[\left(\rho_{\mathrm{L}} / \rho_{\mathrm{S}}\right)-1\right]} \\
& \mathrm{x}_{\mathrm{S}}=\frac{\varphi_{\mathrm{S}}\left(\rho_{\mathrm{S}} / \rho_{\mathrm{L}}\right)}{1+\varphi_{\mathrm{S}}\left[\left(\rho_{\mathrm{S}} / \rho_{\mathrm{L}}\right)-1\right]}
\end{aligned}
$$

where the solid particle density is $\rho_{\mathrm{S}}$, and the liquid density is $\rho_{\mathrm{L}}$. With these three equations and estimates for solid and liquid densities, the initial wt $\%$ UDS of a uniform slurry can be used to determine the initial volume fraction, the volume fraction in a settled layer, and the wt $\%$ UDS in the settled layer. 
As mentioned previously, knowing the time required for settling waste to reach a specific strength is needed to determine how long the waste can settled before the PJMs must be used to mix and re-suspend the settled layer. A settling layer increases strength both through the increase in solids content over time and through an aging mechanism. Poloski et al. (2007) show an example of the aging mechanism for an AZ-101 sample where there was no settling. The shear strength increased from about 15 to 30 Pa over a 10-hr period of aging. As seen in Figure 2.1, relatively small changes in solids content result in much larger increases in shear strength. Accordingly, we will assume that the dominant physical mechanism for strength increase during settling is the increase in solids with time and that the aging mechanism can be neglected.

\subsubsection{Settling Dynamics}

Equations 2.1 to 2.3 together with a relationship between shear strength and wt\% UDS, such as shown in Figure 2.1, allows the solids content and strength of a settling layer to be determined as a function of time. Figure 2.2 reproduces gravity settling data for a $20-\mathrm{wt} \%$ kaolin slurry presented by Rassat et al.

(2003b). ${ }^{\text {(a) }}$ This test was conducted in a 50-mL graduated centrifuge tube. Figure 2.2 also shows the wt $\%$ UDS determined from Equations 2.1 to 2.3 with the kaolin $\left(\rho_{\mathrm{S}}=2.65 \mathrm{~g} / \mathrm{mL}\right)$ and water $\left(\rho_{\mathrm{L}}=0.998 \mathrm{~g} / \mathrm{mL}\right)$ densities reported in Rassat et al. (2003b). As seen in the figure, the wt $\%$ UDS begins at $20 \%$, which was the initial concentration of the uniform slurry and the increases during settling to about $38-\mathrm{wt} \%$ UDS over a 10- to 20-hr period. Rassat et al. (2003b) give the following correlation for the shear strength of kaolin clay slurries shown in Figure 2.1.

$$
\tau_{S}=0.0297 * \exp [0.1715 *(w t . \% \text { UDS })]
$$

Using this correlation, the shear strength of the settled layer can be estimated, and this is also shown in Figure 2.2. For this small laboratory-scale experiment, the shear strength reached about $20 \mathrm{~Pa}$ after about 20 hours of settling.

(a) The original data of Rassat et al. (2003b) were obtained and used in this work. 


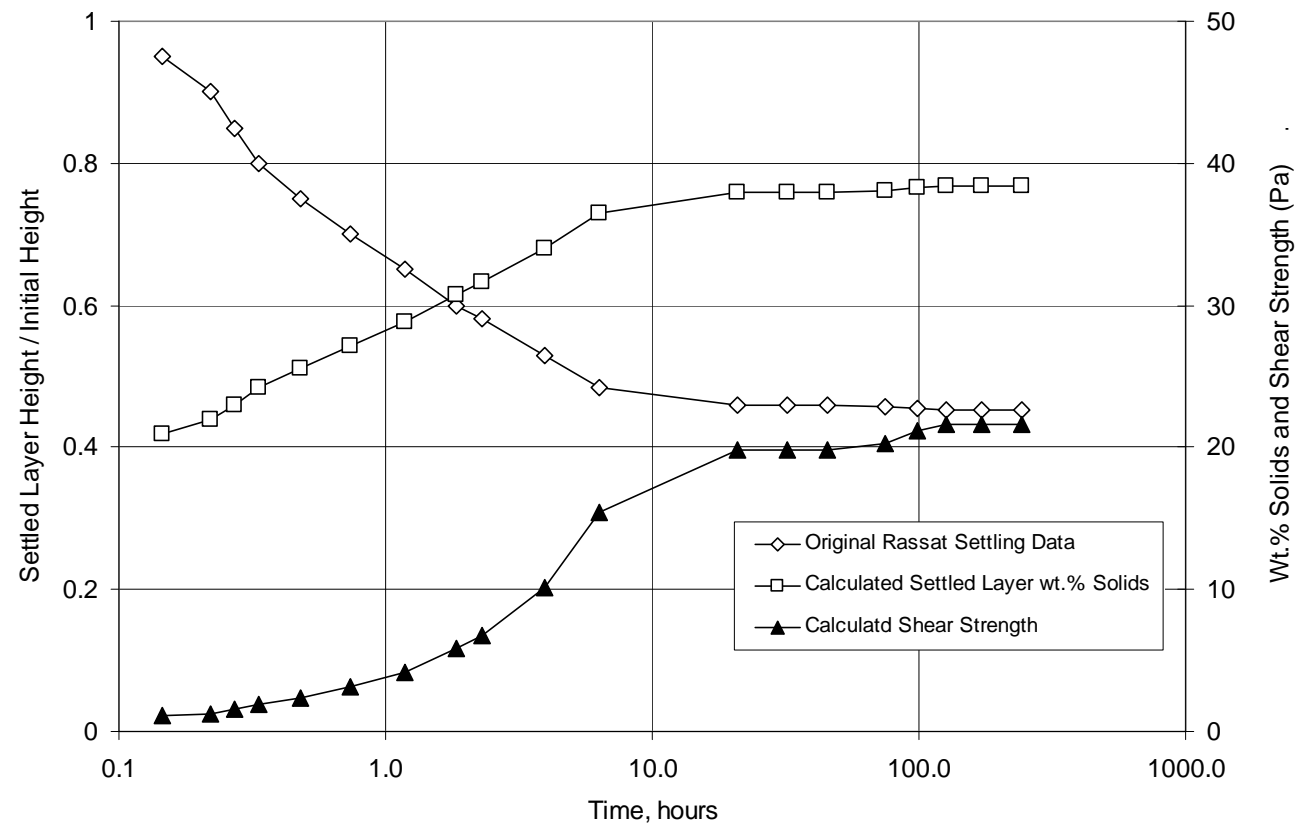

Figure 2.2. Shear Strength as a Function of Undissolved Solids Content for Actual Waste Samples and Kaolin Clay

This kind of analysis can be conducted for any material where settling data, solid and liquid densities, and a relationship between shear strength and $w t \%$ UDS are available. A particularly interesting group of settling experiments was conducted by MacLean (1999), and his results for the slurry described as the "diluted $\mathrm{Al}(\mathrm{OH})_{3}-\mathrm{Fe}(\mathrm{OH})_{3}$ " are analyzed here. In MacLean's study, the shear strength or yield stress was not measured, so to conduct a shear-strength analysis, a relationship consistent with the data presented in Figure 2.3 is assumed. Figure 2.4 shows the assumed relationship between wt $\%$ UDS and shear strength for the diluted $\mathrm{Al}(\mathrm{OH})_{3}-\mathrm{Fe}(\mathrm{OH})_{3}$ slurry. This relationship is given below

$$
\tau_{S}=0.22 * \exp [0.45 *(w t . \% U D S)]
$$

This assumed relationship for shear strength was selected to give a shear strength of $1 \mathrm{~Pa}$ at the initial wt $\%$ UDS of 3.4\%, reported by MacLean (1999, pg 5, errata) for this simulant. The slope of the "MacLean Estimate" curve in Figure 2.3 was selected by visual inspection to follow the general trend in the data for the T-204 samples.

For the MacLean diluted $\mathrm{Al}(\mathrm{OH})_{3}-\mathrm{Fe}(\mathrm{OH})_{3}$ slurry, data reported in MacLean (1999) were used to estimate the average density of the solid particles by using particle densities and the weight fraction for the two solid species- $\mathrm{Al}(\mathrm{OH})_{3}$ and $\mathrm{Fe}(\mathrm{OH})_{3}$. The average solids density is $\rho_{\mathrm{S}}=2.75 \mathrm{~g} / \mathrm{mL}$. The calculation uses the crystal densities of $\mathrm{Al}(\mathrm{OH})_{3}$ and $\mathrm{Fe}(\mathrm{OH})_{3}$ from Wells et al. (2007) and determines the average solid particle density based on the mass fraction of these two solid species reported by MacLean. The liquid density given in MacLean is $\rho_{\mathrm{L}}=1.175 \mathrm{~g} / \mathrm{mL}$.

With the relationship given by Equation 2.3 and the settling data reported by MacLean (1999), the strength of the settled layers as a function of time can be determined. Figure 2.4 shows the results for the 
settling experiments with the diluted $\mathrm{Al}(\mathrm{OH})_{3}-\mathrm{Fe}(\mathrm{OH})_{3}$ simulant together with the kaolin results shown in Figure 2.2. One of the key elements of the MacLean study was to quantify the effect of column size on the settling dynamics and the ultimate compaction of the settled layer. In Figure 2.4, the three smaller laboratory-scale results had somewhat similar settling dynamics, although theory predicts that settling time increases with vessel size. The large 30-ft column experiment clearly took longer to settle than the smaller laboratory experiments. A second important result shown in Figure 2.4 is the solids concentration towards the end of the settling period. As expected, the settled layer became more compacted and stronger in progressively larger vessels.

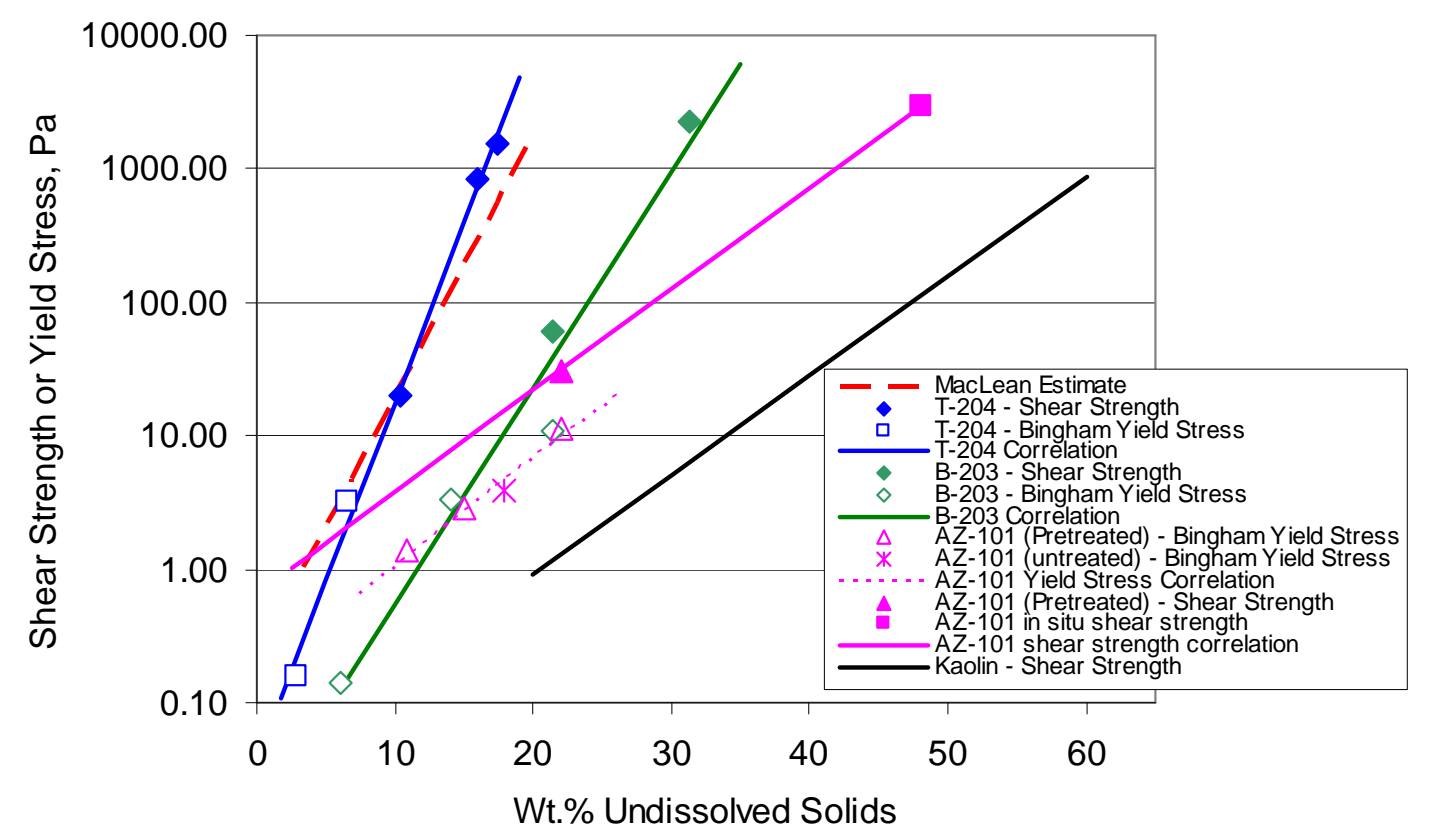

Figure 2.3. Assumed Relationship between Shear Strength and Undissolved Solids Content for the Slurry Identified by MacLean (1999) as Diluted $\mathrm{Al}(\mathrm{OH})_{3}-\mathrm{Fe}(\mathrm{OH})_{3}$ and Comparison with Other Data

Figure 2.4 also shows an estimate for the in situ shear strength as a function of time for a layer of settling AZ-101 waste. This result was obtained by applying the same method of combining settling data and densities with a relationship between shear strength and wt\% UDS. In Figure 3.5 (see Section 3) discussed later in this report, settling results are given for the full-scale settling of AZ-101 waste after the waste had been mobilized with mixer pumps. The data identified for the solid-liquid interface were used with Equations 2.1 to 2.3 and liquid and solid densities to estimate the wt $\%$ UDS in the settling layer. Callaway (2000) gives the liquid density of $\rho_{\mathrm{L}}=1.237 \mathrm{~g} / \mathrm{mL}$. The solid particle density for AZ-101 is not in existing formal reports but can be determined from the data of Urie et al. (2004). ${ }^{\text {(a) }}$ The reported physical-property measurements included the slurry and supernatant liquid densities and the mass fraction of undissolved solids for three samples each of material analyzed: as-received samples, samples with half

(a) In an October 2004 letter titled "Evaluation of Waste Data for Rheological Models Used in Waste Pipeline Transfer Assessment," BE Wells analyzed AZ-101 data and determined that the average particle density in the AZ-101 sediment is $2.43 \mathrm{~g} / \mathrm{mL}$. This earlier evaluation is repeated here. 
of the supernatant liquid decanted off, and samples with no supernatant liquid (i.e., settled solids). ${ }^{\text {(a) }}$ Because the samples only differ by the amount of liquid, it can be assumed that the composition of the undissolved solids does not differ between the samples. It is expected, therefore, that the average solidphase density is identical in all the analyzed samples. A least-squares minimization of the difference between the mass fraction of solids computed as a function of the slurry, liquid and solid densities to the reported mass fraction of solids for the AZ-101 samples results in a solid density of $2.43 \mathrm{~g} / \mathrm{mL}$.

The initial $\mathrm{wt} \%$ UDS was determined to be 3.28 -wt $\%$ UDS by assuming that the sediment layer in AZ-101 before the mixer-pump operations (17.5 inches with $48 \mathrm{wt} \%$ UDS; see Section 3.11) was mixed uniformly throughout the waste depth of 329 inches (Carlson et al. 2001) in AZ-101 during mixer-pump operation. The correlation in Figure 2.1 between shear strength and wt $\%$ UDS, which is given below, was used to determine the strength of the settled layer.

$$
\tau_{S}=0.651 * \exp [0.1756 *(w t . \% U D S)]
$$

For the AZ-101 shear strength curve in Figure 2.4, the two strength estimates at the longest settling times were estimated by different methods. For the data point at 80 days (1920 hours), the shear strength was estimated to be the average of the two pre-test shear-strength measurements shown in Figure 3.4. This estimate was used because the core sample taken after 80 days of settling appears similar, based on the qualitative evaluation in Figure 3.4, to the pre-test core samples. The data point at 28 days (672 hours) was estimated by evaluating the difference in compaction of the settled layer at 28 and 80 days. The settled-layer interface at both 28 and 80 days for four risers is given in Table 3.2 and presented in Figure 3.6. The difference between the sediment level was used to estimate the wt $\%$ UDS at 28 days from Equations 2.1 to 2.3 using the final value of $48-\mathrm{wt} \%$ UDS. The shear strength was then estimated from Equation 2.6 for each riser, and the average value of $1605 \mathrm{~Pa}$ is shown in Figure 2.4 for settling at 28 days.

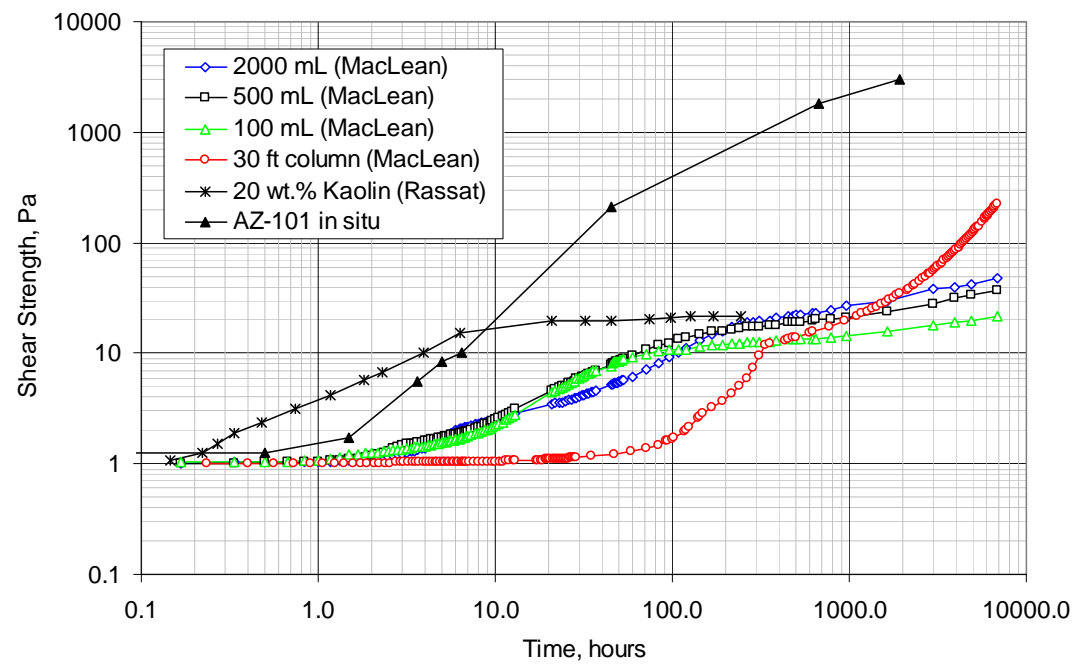

Figure 2.4. Estimated Shear Strength as a Function of Time for Simulants and Full-Scale AZ-101 Behavior

(a) The third sample of settled solids was not included in the current analysis given the sample's spurious liquid density value. 
Figure 2.4 provides a useful approach to summarizing settling dynamics and shear-strength increase for settling waste. For the simulants and AZ-101 in situ estimates, there is clearly a wide range in behavior for the different materials and the different vessel sizes. The kaolin and diluted $\mathrm{Al}(\mathrm{OH})_{3}-\mathrm{Fe}(\mathrm{OH})_{3}$ simulants, even for similar-size experiments, had between a 10- and 100-fold difference in the time needed to reach a particular strength. For the two large-scale experiments (AZ-101 in situ and the 30-ft column), the time needed to increase to a specific strength also varied by a factor of 10 to 100 . With the wide range in behavior, there is uncertainty in selecting representative values, but having reasonable typical and bounding values is useful. Comparing the simulant and AZ-101 in situ estimates in Figure 2.4, a reasonable typical shear strength for a settled layer after 24 hours is about $30 \mathrm{~Pa}$.

Estimating a reasonable upper bound has perhaps even more uncertainty than estimating a typical value. With the data shown in Figure 2.4 and Figure 3.6, at a time of 24 hours, a shear strength of $200 \mathrm{~Pa}$ can be estimated as a reasonable minimum upper bound, though this estimate is uncertain. On the one hand, the 30 -ft column settling test reported by MacLean shows a negligible strength increase after 24 hours, suggesting that $200 \mathrm{~Pa}$ is a very conservative upper bound. In contrast, the sediment level given in Figure 3.5 and Figure 3.6 for the settling in AZ-101 waste showed settling of material exceeding $200 \mathrm{~Pa}$ within 24 hours in two locations. It is possible that this is a localized behavior and not representative of the waste in general, and the method of estimating the shear strength of the layer that is at least $200 \mathrm{~Pa}$ is also an approximation (see Appendix B). Slower settling did occur in all the locations in AZ-101 (see Section 3.1) and the solid-liquid interface behavior was used to create the AZ-101 in situ curve in Figure 2.4.

Recent measurements on actual waste composite samples of PUREX cladding waste sludge and REDOX cladding waste sludge, discussed previously in Section 2.1, are notable examples for the upper range of high strengths and unusually fast settling (Snow et al. 2009). In these measurements, over $80 \%$ of the waste solids appeared to have settled by the first hour in a laboratory settling test, and the final settled volume was reached 1 to 2 hours later. The shear strength of settled solids (after a 72-hr settling time) ranged from 100 to $700 \mathrm{~Pa}$. It was estimated that the shear-strength values were low because both measurements were performed with the rotary vane of the instrument only half immersed into the sample. Measurements were made after a 72-hr settling time, and the shear strength after 1 to 2 hours of settling was not measured. If the settling was complete within a few hours, as shown in the settling experiments, the shear strengths after a few hours of settling may have been as high as the measured values of 100 to $700 \mathrm{~Pa}$. Overall, these results add additional uncertainty to the upper-bound estimate of $200 \mathrm{~Pa}$ at 24 hours.

\subsubsection{Full-Scale Settling and Settled Layer Shear Strength}

The strength of a settled layer of any material can be estimated using Equations 2.1 through 2.3 together with solid and liquid densities, and initial solids fraction, and a correlation between wt $\%$ UDS and shear strength. Instead of plotting the settled-layer height and shear strength as a function of time, as is done in Figure 2.2, the results can be shown directly as the layer strength as a function of settled-layer height. This approach to representing settling does not depict the time required to settle to a layer of a particular depth and strength, and this needs to be considered separately as shown by Figure 2.4. For addressing mixing needs during off-normal events, it is important to understand how the strength of a layer increases

as it settles (independent of the time required). ICD-19 (2008) gives $1 \mathrm{~Pa}$ as the maximum Bingham yield stress of waste slurries that can be transferred to the WTP. In this analysis, we will neglect the difference 
between shear strength and Bingham yield stress. If this shear strength is larger than the Bingham yield stress, which is expected, the settled layers are stronger than what is shown here. Figure 2.5 shows the four cases that will be used for estimating how the settled-layer shear strength increases as the layer settles. These cases all begin at a shear strength of $1 \mathrm{~Pa}$, which is the ICD-19 limit, and also represent the general actual waste behavior for T-204 and B-203 samples. Case 1 and case 2 are exponential equations, and case 3 is a power-law equation. The correlation for the kaolin clay, which is exponential, is also used in settling calculations below. For solid and liquid densities, Cases 1 to 3 use the average liquid and solid densities of Hanford waste from Wells et al. (2007): $\rho_{\mathrm{L}}=1.2 \mathrm{~g} / \mathrm{mL}$ is the average liquid density, and $\rho_{\mathrm{S}}=2.8 \mathrm{~g} / \mathrm{mL}$ is the average solid density. For slurries of kaolin in water, the densities given in Section 2.1 .1 and reported by Rassat et al. (2003b) are used $\left(\rho_{\mathrm{S}}=2.65 \mathrm{~g} / \mathrm{mL}\right.$ for kaolin, $\rho_{\mathrm{L}}=0.998 \mathrm{~g} / \mathrm{mL}$ for water).

Figure 2.6 shows the strength of layers as they settle for the three different cases and kaolin clay. The layers are assumed to begin at a scaled height of 0.7 , which is the typical fill height for vessel HLP-22 (these settling results will be compared to PJM performance in Section 4). For the layers that begin at $1 \mathrm{~Pa}$, they each begin with a different wt\% UDS as given by the correlations in Figure 2.5. One interesting feature in Figure 2.6 is that the settling curves for all four curves are strikingly similar, even though the curves relating shear strength and $w \mathrm{t} \%$ UDS for these materials in Figure 2.5 are quite different. This can be understood by considering a specific point on the settling curve. When the layer settles to a scaled height of 0.35 , or half the initial height, the volume fraction UDS will be twice the initial value, as given by Equation 2.1. When Equations 2.2 and 2.3 are used to determine the change in $\mathrm{wt} \%$ UDS, the increase in solid wt $\%$ is a bit less than twice. Figure 2.5 shows that doubling the concentration of kaolin from 20 to $40 \mathrm{wt} \%$ UDS increases the shear strength from about 1 to $30 \mathrm{~Pa}$. Figure 2.5 also shows that doubling the concentration of the Case 1 slurry from about 5 to $10 \mathrm{wt} \%$ UDS gives a very similar increase in shear strength.

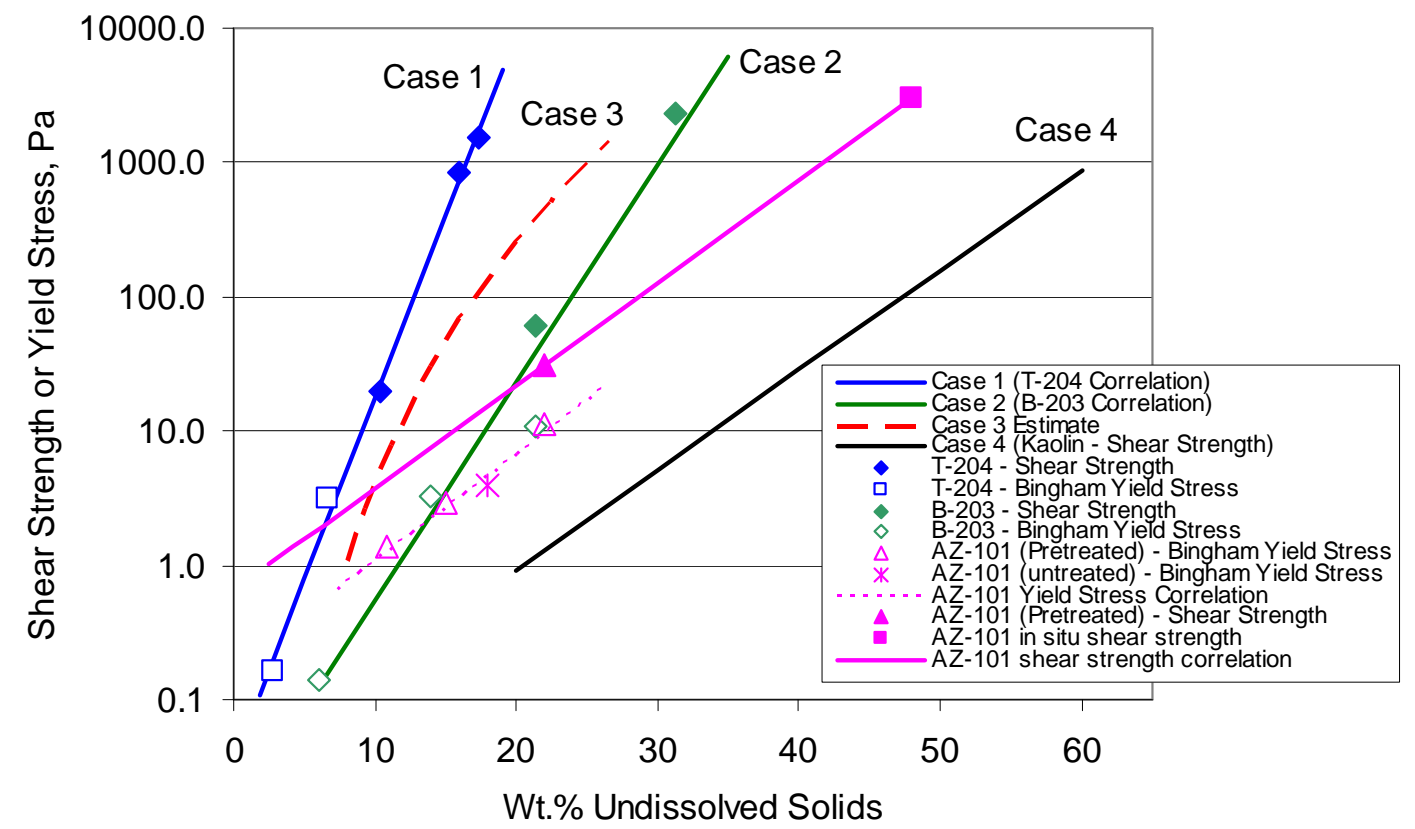

Figure 2.5. Shear Strength as a Function of Solids Content for Cases 1-3 and Kaolin Clay 
Figure 2.6 also shows an example of how dilution (i.e., reducing the initial solid concentration) changes the settling curve. The example given is for the Case 2 slurry that is diluted to begin at a shear strength of 0.1 Pa. For this example, the layer settles to a lower height. These curves of shear strength as a function of layer thickness will be compared to PJM performance for cohesive materials in Section 4.

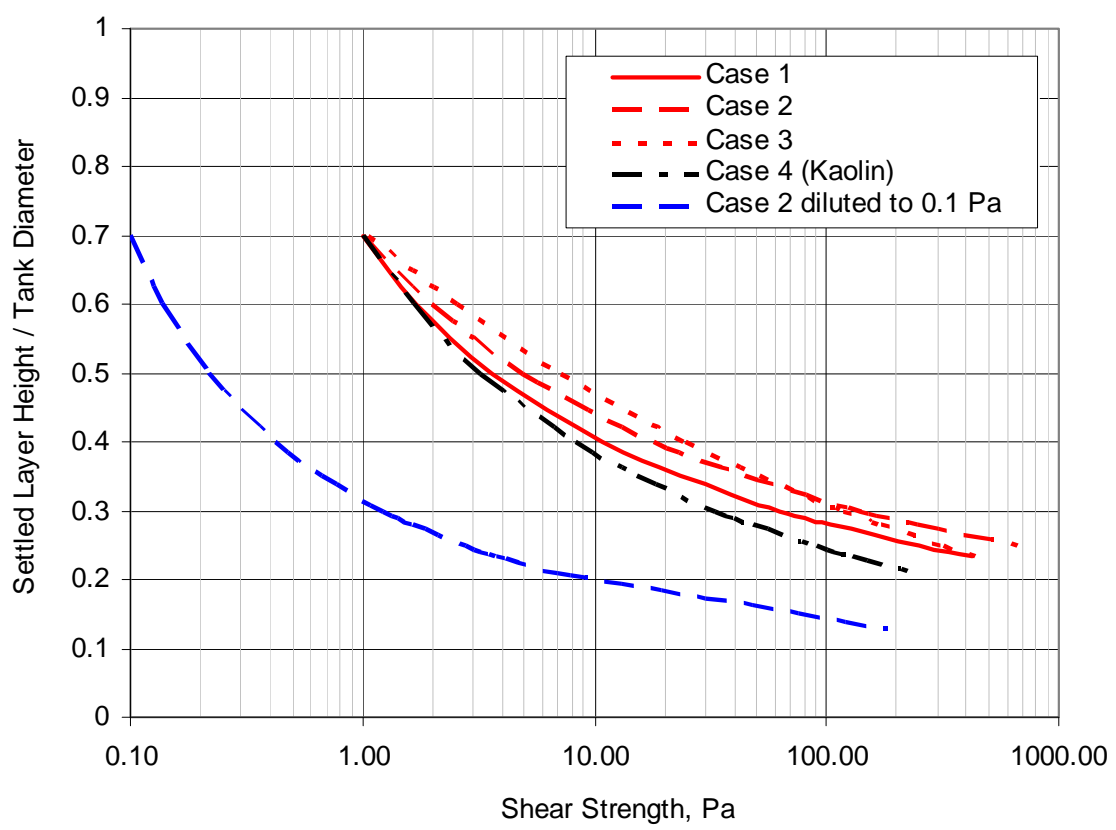

Figure 2.6. Shear Strength Increase for Settling Layers

A similar analysis showing how shear strength or yield stress increases with settling can be done for conditions where PJMs are running under normal operations. To do the analysis, a relationship is needed to give the volume fraction of UDS, $\varphi_{S}$, as a function of height for various mixing conditions, rather than using Equation 2.1. Recent studies of solids concentration as a function of height during PJM operation have been reported by Meyer et al. (2009). In Section 7.3.3 of this work, a discussion and data are given that describe that $\varphi_{S}$ in stratified (PJM mixed) solids layers decreases approximately linearly from the vessel bottom to the top of the solids cloud height where $\varphi_{\mathrm{S}}$ is zero. For cloud heights at or less than the fill level, the following relationship gives the concentration in volume fraction UDS of the slurry, $\varphi_{S}$, as a function of height:

$$
\varphi_{\mathrm{S}}=2 *\left[\frac{\text { fill level }}{\text { Cloud height }}\right] *\left[\varphi_{\text {Sinitial }}\right] *\left[1-\left(\frac{\text { height }}{\text { Cloud height }}\right)\right]
$$

where $\varphi_{S \text { initial }}$ is the initial volume fraction of solids assuming a uniform concentration. This relationship is used to calculate the volume fraction as a function of height for a range of cloud heights. To use this equation, the initial $\mathrm{wt} \%$ UDS is converted to the initial volume fraction, $\varphi_{\mathrm{S} \text { initial, }}$ using Equation 2.2 and liquid and solid densities given above. To determine the strength (or yield stress) at each height, the volume fraction given by Equation 2.7 is converted to wt $\%$ UDS with Equation 2.3, and then the shear strength (or yield stress) for the specific case is determined with the relationship between wt $\%$ UDS and shear strength (or yield stress) given in Figure 2.5. For a scenario of normal operations and a stratified 
layer, the Bingham yield stress is the appropriate parameter to consider rather than shear strength, but as mentioned previously in this section, we will neglect this difference.

Figure 2.7 shows the shear strength (or yield stress) for Case 2 and a $20.5 \mathrm{wt} \%$ kaolin slurry as a function of depth for stratified layers during normal PJM operations. This analysis does not specify what cloud height would be achieved for a particular material and PJM system, but simply shows how the strength increases with depth and with lower clouds. For the Case 2 results, one curve shows a uniform profile for perfect mixing and $1 \mathrm{~Pa}$ at all heights. For a scaled cloud height of 0.7 , the Case 2 slurry has a negligible strength at the top of the cloud and increases with depth, reaching a strength of about $40 \mathrm{~Pa}$ at the vessel bottom. For lower clouds, the solids concentration within the stratified layer increases, and the strength also increases. At some point, the strength exceeds the performance capability of the PJM system, and the cohesive behavior will result in incomplete mobilization. The results in Figure 2.7 will be compared to PJM performance for cohesive materials in Section 4. Figure 2.7 also shows results for a $20.5-\mathrm{wt} \%$ UDS kaolin slurry, which also has $1 \mathrm{~Pa}$ when perfectly mixed. The kaolin slurry is again similar to Case 2.

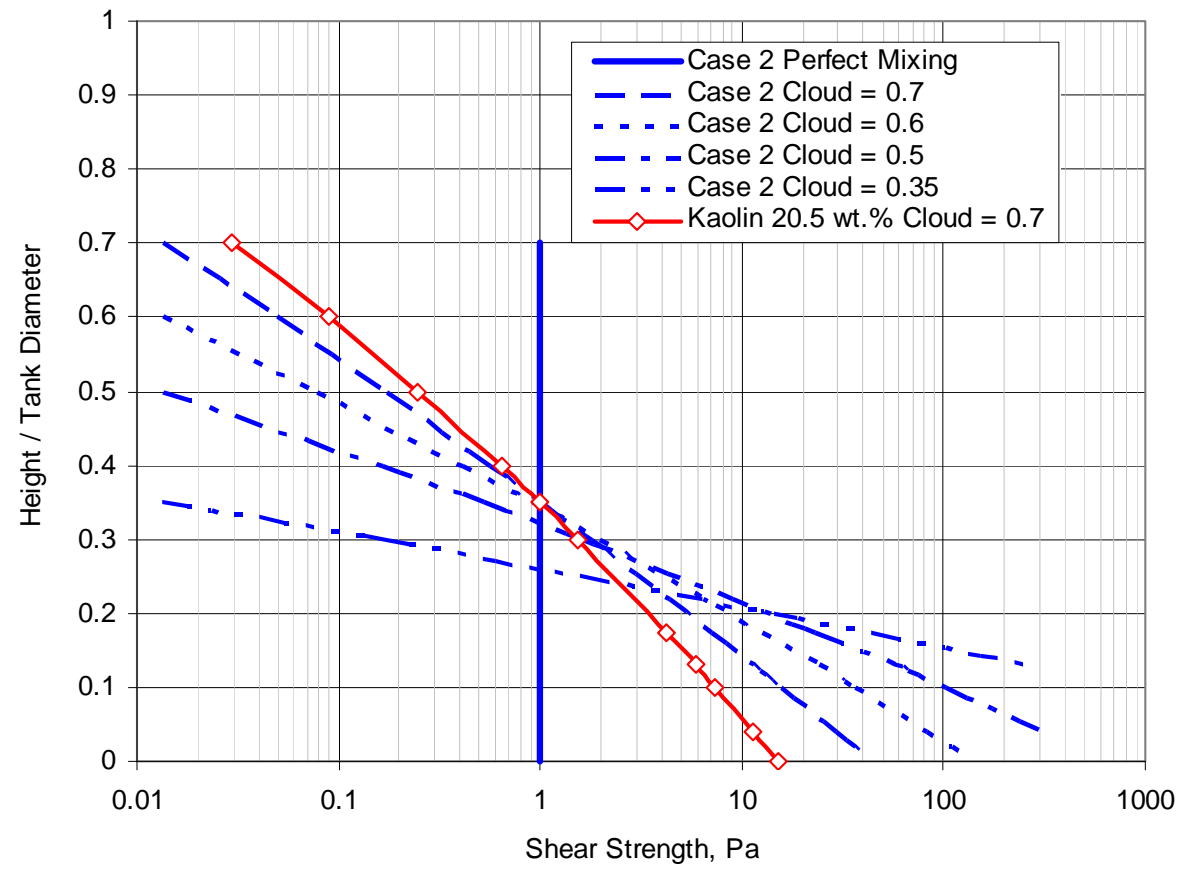

Figure 2.7. Shear Strength (or Yield Stress) During Normal PJM Operation Increases with Depth and Increases with Lower Cloud Heights

For PJM mixing, the settling behavior of the waste is critical. For off normal events, settled layers were estimated by assuming the layers were uniform. It is expected, however, that the solids fraction and thus the shear strength will increase with increasing depth into the layer due to compaction. Unfortunately, there are no data to evaluate the magnitude of this effect. There is also a significant difference between laboratory-scale tests and full-scale behavior. Accordingly, the following technical uncertainty exists. 
Uncertainty 2.1 Scaling behavior, including the role of vessel size, the settling dynamics, and the buildup of strength in the settled layer, is not well understood. This uncertainty is particularly important for shorter settling times and for quantifying how strength increases with depth into a layer. Accurate predictions of the settling behavior and strength formation are needed so that the mixing system is designed to prevent settled layers that will exceed remobilization capabilities. Tank-farm studies of full-scale settling have shown substantially faster settling than expected based on laboratory tests. This inconsistency needs to be understood.

\subsection{Hanford Sediment-Shear-Strength Summary}

Estimating the likely range for the strength of settling waste after different durations of settling is needed for selecting strength values for testing and for conducting calculations. Table 2.1 provides current estimates. Unfortunately, there are very few data to determine the statistical variation for Hanford tank waste for any settling duration less than years. Although still incomplete, there is a relatively larger data set for the shear strength of Hanford sediment samples that have settled for a very long time (described as compacted in Table 2.1). The statistical range of these shear-strength data can be used as an indicator for the statistical range for waste that has settled for shorter durations. The compacted sediment strength data also give an absolute upper bound for the sediment strength in the absence of any mobilization. The purpose of this section is to provide a cumulative probability distribution of the shear-strength data for waste sediment samples to allow the $5^{\text {th }}, 50^{\text {th }}$, and $95^{\text {th }}$ percentiles to be estimated. Section 2.2.1 gives a brief overview of shear-strength measurement techniques, and Section 2.2.2 gives the cumulative probability distributions.

\subsubsection{Shear-Strength Measurement Techniques}

Ex-tank (measurements performed on samples removed from the waste tank) and in situ shear-strength measurements have been conducted on Hanford sediments. The ex-tank measurement techniques include shear-vane and waste-extrusion techniques. Numerous references for the shear-vane technique exist in the literature. Shear-vane shear-strength data for the 22 tanks listed in Table 2.3 are considered.

Gauglitz and Aikin (1997) developed the methodology to determine waste-extrusion behavior whereby the shear strength of a waste sediment is determined based on visually comparing the behavior of horizontal waste-core extrusion for simulants with known shear strength to that of Hanford Waste. An "extrusion length" methodology based on the simulant extrusion data of Gauglitz and Aikin (1997) for estimating the yield stress in shear of Hanford Waste was developed in Rassat et al. (2003a). This methodology relies on measuring the initial extrusion length of the waste core at plastic failure. Although the waste-extrusion techniques rely on the behavior of ex-tank core extrusion, they may be as representative of in situ conditions as are available ex-tank. Waste-extrusion shear-strength data are considered for 17 tanks as listed in Table 2.3. 
Table 2.3. Hanford Shear Strength Data; Tank and Measurement Technique

\begin{tabular}{|c|c|c||}
\hline \multicolumn{3}{|c|}{ Shear-Strength Measurement Technique } \\
\hline Shear Vane & Waste Extrusion & Ball Rheometer \\
\hline AN-103 & A-101 & AN-103 \\
\hline AN-102 & AN-103 & AN-104 \\
\hline AN-107 & AN-104 & AN-105 \\
\hline AW-101 & AW-101 & AW-101 \\
\hline AW-103 & AY-102 & SY-101 \\
\hline AY-101 & B-203 & SY-103 \\
\hline AY-102 & B-204 & \\
\hline AZ-101 & S-102 & \\
\hline AZ-102 & SY-103 & \\
\hline B-111 & T-110 & \\
\hline B-201 & T-201 & \\
\hline B-202 & T-202 & \\
\hline B-203 & T-203 & \\
\hline C-104 & T-204 & \\
\hline C-107 & U-103 & \\
\hline SY-101 & U-107 & \\
\hline SY-102 & & \\
\hline SY-103 & & \\
\hline T-107 & & \\
\hline T-204 & & \\
\hline T-203 & & \\
\hline U-107 & & \\
\hline
\end{tabular}

In situ shear-strength measurements have been performed using the ball rheometer (Stewart et al. 1996). The rheology of the waste material can be estimated in situ directly from the drag force on a ball as it moves through the waste at various speeds. The six waste tanks in which the ball rheometer was deployed are listed in Table 2.3. The ball-rheometer data are not considered in this summary because the measurements were limited to regions of the sediments with a shear strength less than $900 \mathrm{~Pa}$ (the ball would be supported by sediment with a shear strength $\geq 900 \mathrm{~Pa}$; Meyer et al. 1997). The ball-rheometer was unable to be deployed to the tank bottom in each of the six listed waste tanks; in AN-103, the ball was supported at greater than half of the sediment depth (Hedengren et al. 2000; Stewart et al. 1995). Thus, to represent a sediment over its entire depth, the ball rheometer data can be biased low.

\subsubsection{Shear-Strength Data Summary}

The Hanford sediment shear-strength data are summarized by measurement technique. The presented data and references are tabulated in Appendix A. All data are from waste samples as close to in situ sediment conditions as possible.

In some instances, multiple measurements are available throughout the depth and/or at different radial locations in the tank. In others, single measurements are reported. The sample history can have a significant impact on results, and this may vary depending on the waste type. Data availability is also 
affected by the measurement technique. Further, some tanks contain significantly greater fractions of the Hanford undissolved solid inventory than others, and the data set itself represents only a part of the Hanford inventory. For this simple data summary, results are thus presented by measurement technique; not accounted for are measurement number, location, representativeness beyond initial sample conditions, and the relative fraction of Hanford inventory. Presenting the results by measurement technique also underscores that the data sets encompass different waste tanks.

Cumulative shear-strength distributions for shear-vane and waste-extrusion data are provided in Figure 2.8 and Figure 2.9, respectively. The probabilities are strictly based on measurement count; 136 shear-vane measurements and 325 waste-extrusion measurements are included. The $50^{\text {th }}$ percentiles (medians) of the shear-vane and waste-extrusion data are approximately 725 and $450 \mathrm{~Pa}$, respectively, and the $95^{\text {th }}$ percentiles are approximately 6,830 and $1,600 \mathrm{~Pa}$, respectively. The $95^{\text {th }}$ percentile is a conservative indicator of the upper limit of a data set with only $5 \%$ of the results exceeding this quantile and potential extreme values avoided. The median shear vane results compares very favorably with the median reported in Poloski et al. (2007). As indicated above, the shear vane data considered herein are from waste samples as close to in situ sediment conditions as possible and Poloski et al. considered all data including floating crust layer and diluted sample data.

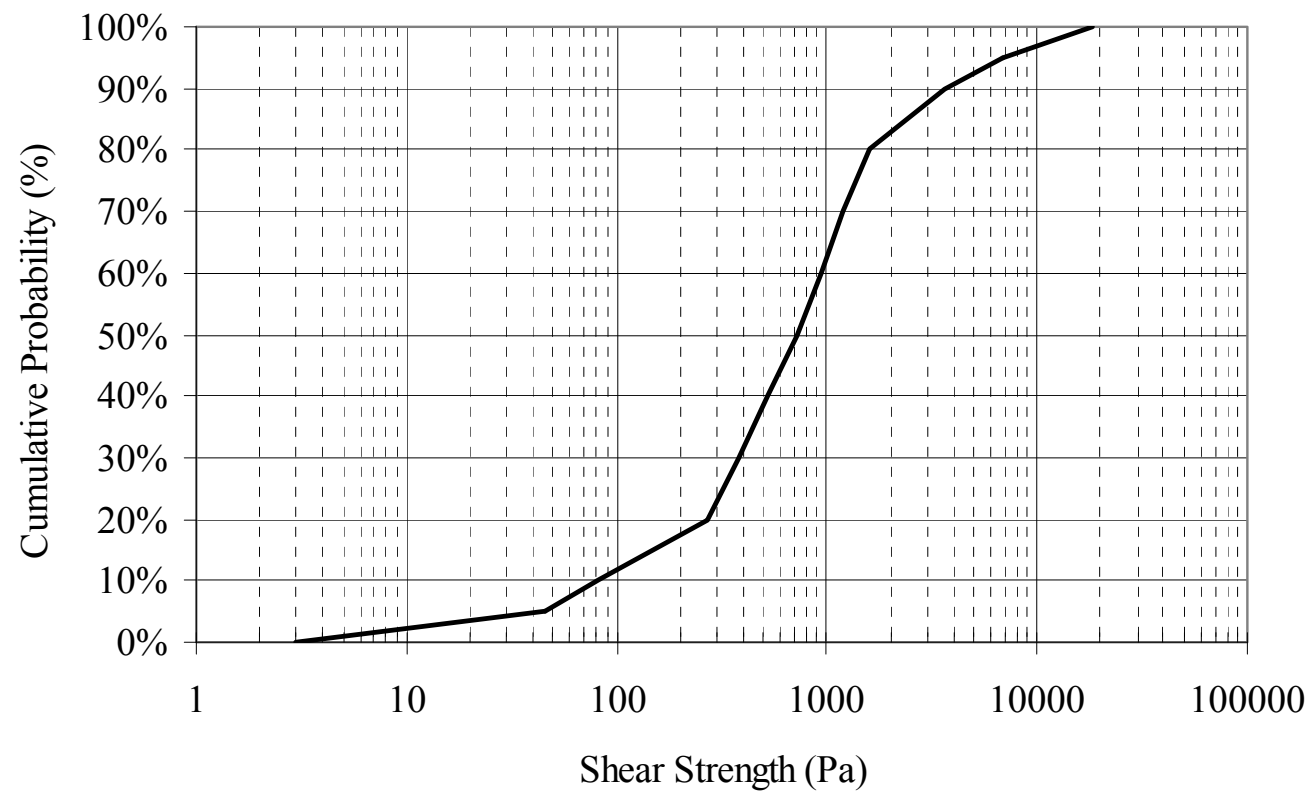

Figure 2.8. Data Summary of Shear-Vane Shear Strength, Sediment from 21 Hanford Tanks, 136 Measurements

The differences between Figure 2.8 and Figure 2.9 are not easily reconcilable. When the concurrent tank data are compared (AN-103, AW-101, AY-102, B-203, SY-103, T-203, T-204, and U-107; see Table 2.3), the median and $95^{\text {th }}$ percentiles are approximately 840 and 6,200 $\mathrm{Pa}$ for the shear vane data and 390 and 1,610 $\mathrm{Pa}$ for the waste-extrusion data. The concurrent data tanks include both sludge and saltcake wastes (waste designation from $\mathrm{Hu}$ 2007). As noted in $\mathrm{Hu}$ (2007), the shear vane and wasteextrusion shear strength results are significantly different in saltcake waste tanks and compare more favorably in the sludge waste tanks. It was postulated that the difference in the results for the saltcake 
wastes is due to solids precipitation ex-tank (see Section 3.3.1 regarding solids precipitation in SY-101 samples).

The waste-extrusion shear strength results for saltcake wastes in AW-101, AN-103, AN-104, and SY-103 are similar in magnitude (within a factor of two or better) and reproduce the same trends with shear strength and sample location as the in situ ball rheometer results (Gauglitz and Aiken 1997; Rassat et al. 2003a; waste designation from $\mathrm{Hu}$ 2007). The shear vane results for saltcake Tanks SY-103, AN-103, and AW-101 are in some instances up to an order of magnitude greater for concurrent elevations than the waste-extrusion and ball rheometer results (Gauglitz and Aiken 1997; Rassat et al. 2003a).

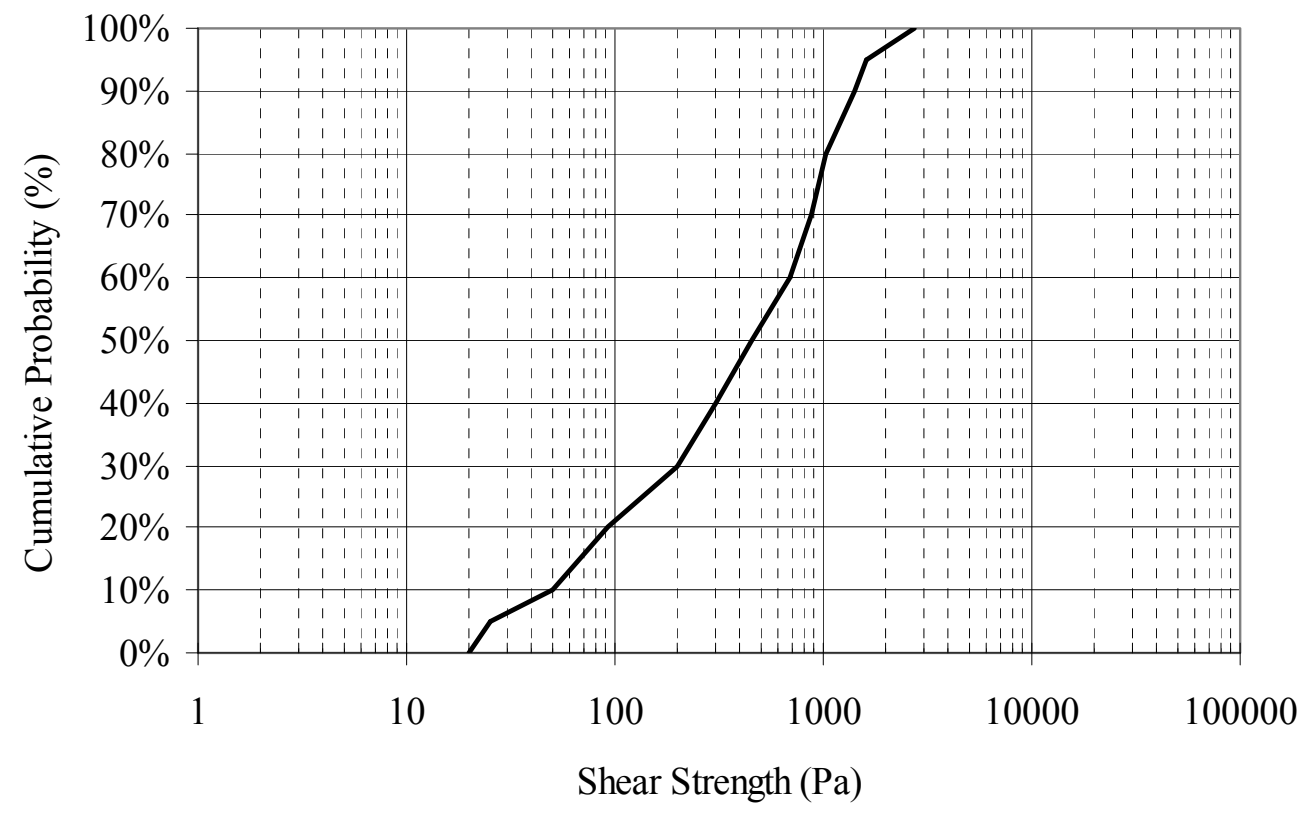

Figure 2.9. Data Summary of Waste-Extrusion Shear Strength, Sediment from 17 Hanford Tanks, 319 Measurements

Consideration of the Appendix A shear vane data from the concurrent sludge tanks (AY-102, B-203, T203, and T-204; waste designation from $\mathrm{Hu}$ [2007]) results in median and $95^{\text {th }}$ percentiles of approximately 630 and 5,100 $\mathrm{Pa}$ for the shear vane data and 1,020 and 1,780 $\mathrm{Pa}$ for the waste-extrusion data. The quantile differences in this limited data set serve to underscore the potential impacts of the number of measurements, their location, and their representativeness beyond initial sample conditions, as the shear measurements for B-203, T203, and T-204 are single measurements from composite samples that were analyzed a minimum of six years post-sampling event (see Tingey at al. 2003, Rassat et al. 2003a) and the waste-extrusion results are from individual core segment extrusions (extrusions are typically performed days to months after sampling). ${ }^{\text {(a) }}$ Relative to the rest of the Hanford waste tanks, the shear strength of AY-102 sediment samples has been extensively evaluated (see Section 3.2.2). A comparison of the AY-102 shear vane and waste-extrusion shear strength results is made in Onishi and Wells (2004). For concurrent core samples, the median shear vane results are typically $67 \%$ of the median waste-extrusion results.

(a) Sampling event and extrusion dates can be estimated from data available from TWINS: Tank Waste Information System database. http://twins.pnl.gov/twins3/twins.htm. 
It is anticipated that the shear-strength quantiles (e.g., $50^{\text {th }}$ and $95^{\text {th }}$ ) would be different if the effects noted above, such as the number of measurements and their locations, were used to weight the relative importance of individual measurements. Inclusion of the in situ ball rheometer data, which indicate maximum shear strengths of greater than $900 \mathrm{~Pa}$ in Hanford tanks that contain substantial inventories of saltcake solids, may also be expected to influence the quantile results. Because the shear-strength results do not account for the number of measurements, their location, their representativeness beyond initial sample conditions, and their relative fraction of Hanford inventory, the cumulative distributions are not weighting the data in the most meaningful way. An improved analysis of these data to determine a reasonable statistical combination could readily be done, but has not been pursued here.

While the analysis of the shear-strength data has limitations, the cumulative probability distributions give useful estimates for the strength of compacted sediment samples and for the range of the strengths. The $95^{\text {th }}$ percentile of the shear-vane results in Figure 2.8, approximated at 7,000 $\mathrm{Pa}$, is currently chosen as an estimated upper bound for sediment that has settled and compacted. This value is listed in Table 2.1 together with the $5^{\text {th }}$ and $50^{\text {th }}$ percentile shear-vane estimates of $50 \mathrm{~Pa}$ and $750 \mathrm{~Pa}$. An important qualitative observation is that that the $95^{\text {th }}$ percentile is about ten-fold larger than the $50^{\text {th }}$ percentile, and the $5^{\text {th }}$ percentile is also about ten-fold smaller than the $50^{\text {th }}$ percentile. In the absence of better estimates, these results suggest that a ten-fold difference can be expected between the $50^{\text {th }}$ percentile and the $95^{\text {th }}$ and $5^{\text {th }}$ percentiles. 


\subsection{In Situ Settling of Select Hanford Sediment}

All but one of the Hanford tanks containing UDS has settled sediment layers. In some of the UDScontaining tanks, the solid-liquid interface can be meters below the liquid surface; in others, the interstitial liquid level can be meters below the surface of the solids. This section considers the settling behavior of sediment in the former tanks (submerged sediment) with regard to 1) the solid-liquid interface level and rheology, specifically shear strength, from instances of sediment mobilization via mixer pumps with minimal water dilution (AZ-101), $\left.{ }^{(a)} 2\right)$ sediment mobilization and dilution with supernatant liquid via sluicing with subsequent transfer (C-106 retrieval into AY-102), and 3) mixer pump sediment mobilization, water dilution, transfer, and supernatant liquid dilution (SY-101 mitigation and transfer into SY-102). A discussion of AZ-101 is provided in Section 3.1, AY-102 in Section 3.2, and SY-101 and SY-102 in Section 3.3.

\subsection{AZ-101 Full-Scale Settling Behavior and Settled Waste Strength}

Two 300-horsepower mixer pumps were used to mobilize the sediment layer in AZ-101 from 4/27/00 to 5/31/00 (Carlson et al. 2001). Among the instrumentation available to quantify the operation, the capability of the mixer pumps to mobilize the sediment was tracked with thermocouples located throughout the waste and in the tank floor, a gamma-monitoring system (detects radionuclides), and deployment of the sludge weight (sludge weights are employed for solids level measurements, see $\mathrm{Hu}$ [2007]). Deployment of the sludge weight and core sampling can be used to provide sediment shearstrength information.

The riser map for AZ-101 is provided in Figure 3.1. (b) The mixer pumps are located in risers 001 and 003 , the gamma monitoring location was riser 055 , the sludge weight deployment was in risers $070,074,075$, and 076, and core samples were taken from risers 059 and 064 . The thermocouples at or near these locations may be identified as per Figure 3.2 and Table 3.1 discussed below.

The thermocouple response is discussed in Section 3.1.1, the sludge weight measurements in Section 3.1.2, gamma monitoring in Section 3.1.3, and shear-strength measurements from core samples in Section 3.1.4. A summary of the AZ-101 results is provided in Section 3.1.5.

\subsubsection{AZ-101 Thermocouple Response to Mixer Pump Operation}

The pre-mixer pump operation sediment depth in AZ-101 was approximately 17.5 inches (see discussion regarding sludge weight deployment below, Section 3.1.2). The undissolved solid content in the sediment can be estimated at $32 \%$ by volume, $48 \%$ by mass. The histories of available and pertinent thermocouples in AZ-101 indicate that, for the oscillatory operation of both mixer pumps (final operation completed at nominally 16:20 on 5/31/00), the majority of the sediment was mobilized (Carlson et al. 2001). Some tank thermocouples were not operational during the mixer pump operations (Carlson et al. 2001; Symons 1996); dome-space etc. thermocouples were not considered. All of the thermocouples in

(a) Minimal dilution of AZ-101 did occur during the operation of the mixer pump; approximately 60,000 gal (nominally $7 \%$ of the original supernatant liquid volume) of water was added due to failure of the rupture disk in mixer pump 2.

(b) Image from TWINS: Tank Waste Information System database. http://twins.pnl.gov/twins3/twins.htm. 
the sediment or tank floor that initially had higher temperature readings than those thermocouples in the liquid layer approached or reached the liquid-layer temperature because of mixer pump operation. The locations of the excavated thermocouples are provided in Figure 3.2, and their polar coordinates, elevations above the tank bottom, and radial separations from mixer pumps 1 and 2 are listed in Table 3.1. (a) Also listed in Table 3.1 are the liquid-layer thermocouples.

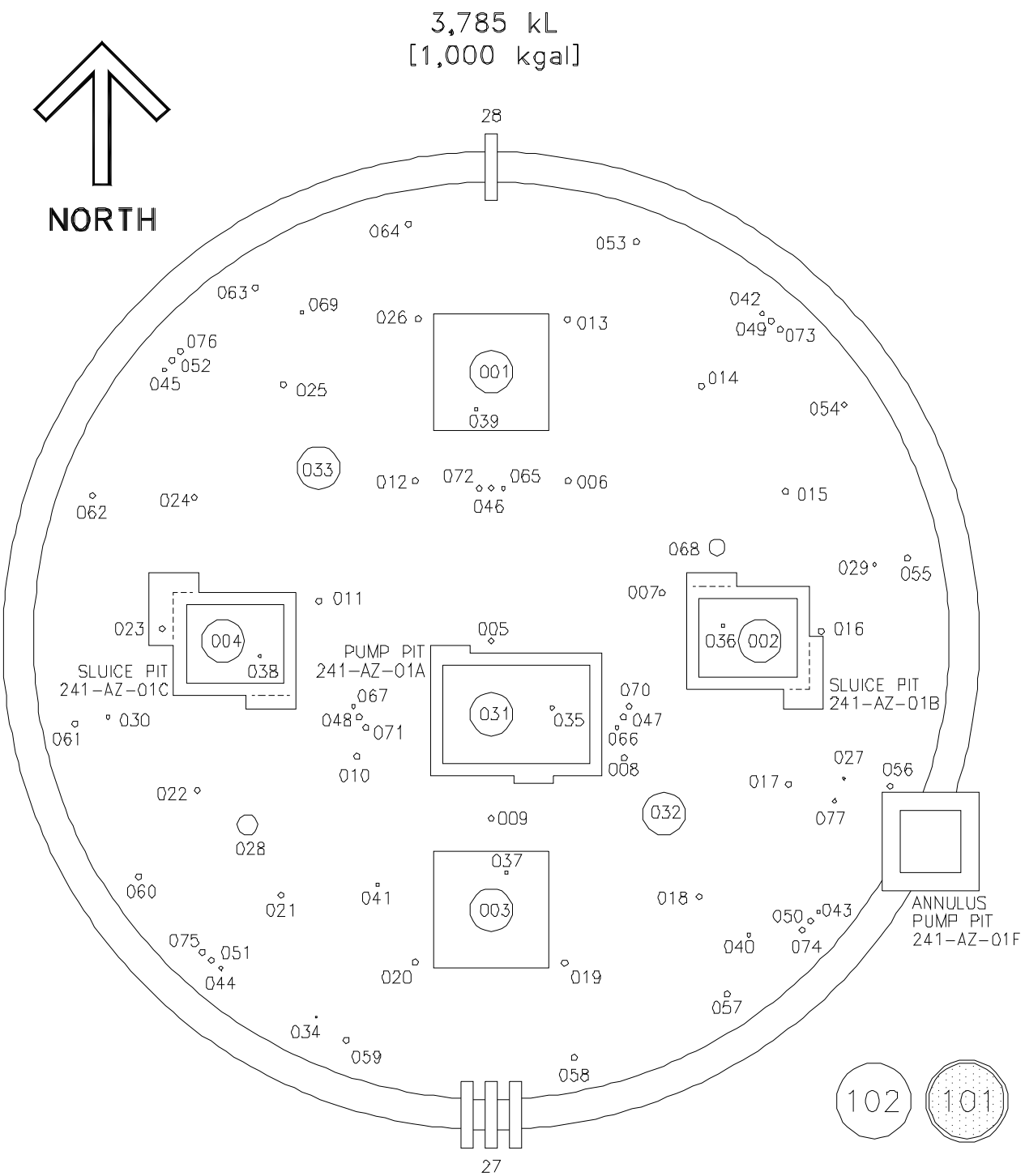

Figure 3.1. AZ-101 Riser Map

(a) Thermocouple locations are taken from Carlson et al. (2001) and Drawing H-14-010507, Rev. 0, sheet 1 of 2. 


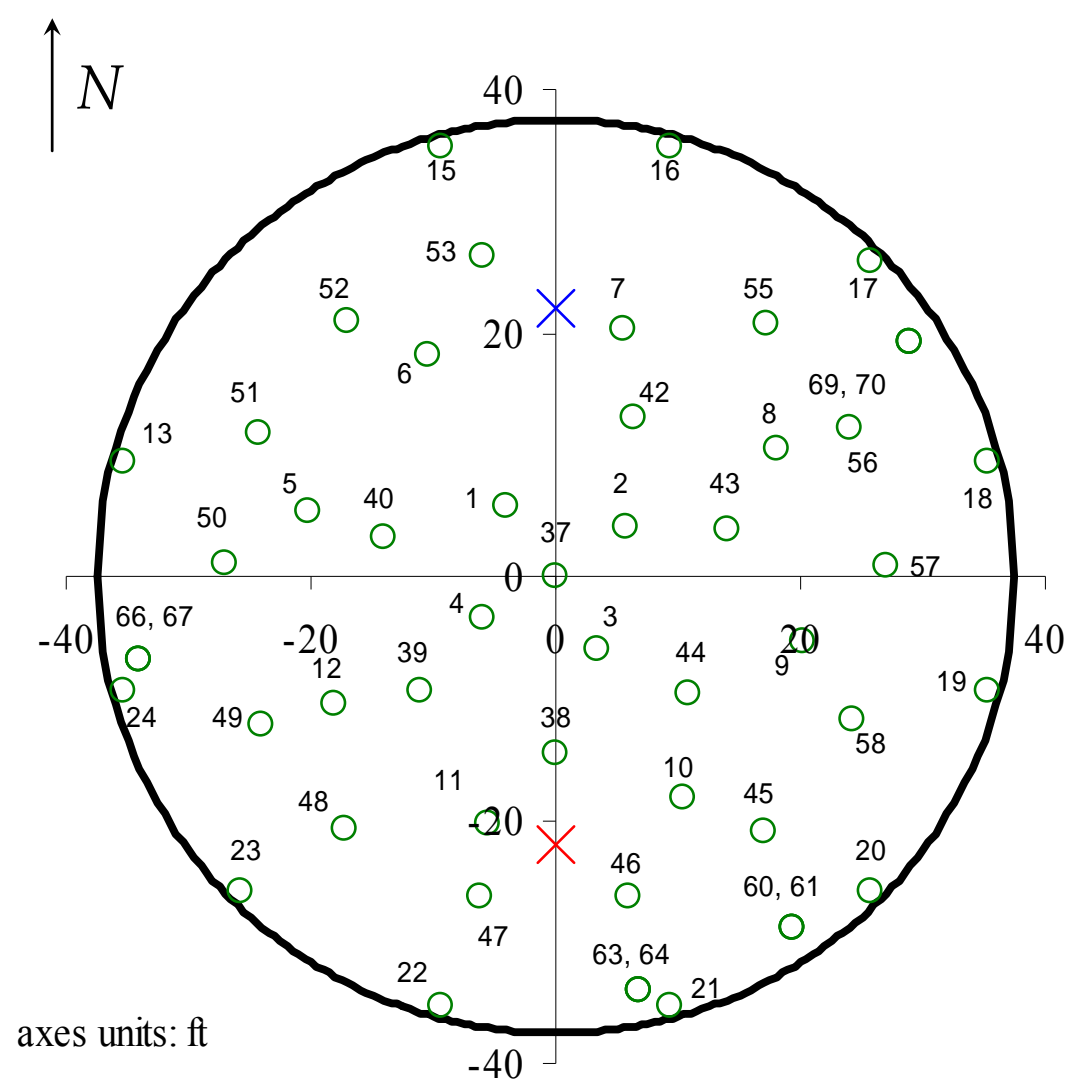

$\times$ Mixer Pump 1 $\times$ Mixer Pump 2

O Excavated Thermocouples

Figure 3.2. AZ-101 Settled Solids Thermocouples Uncovered During Oscillatory Operation of Mixer Pumps 1 and 2 
Table 3.1. AZ-101 Thermocouple Location Data

\begin{tabular}{|c|c|c|c|c|c|}
\hline $\begin{array}{c}\text { Thermocouple } \\
\text { Number }\end{array}$ & $\begin{array}{c}\text { Radius } \\
\text { (ft) }\end{array}$ & $\begin{array}{l}\text { Angle } \\
\text { (deg) }\end{array}$ & $\begin{array}{c}\text { Elevation } \\
\text { Above Tank } \\
\text { Bottom } \\
\text { (in) } \\
\end{array}$ & $\begin{array}{c}\text { Radial } \\
\text { Distance } \\
\text { from Mixer } \\
\text { Pump } 1 \\
\text { (ft) } \\
\end{array}$ & $\begin{array}{c}\text { Radial } \\
\text { Distance } \\
\text { from Mixer } \\
\text { Pump } 2 \\
\text { (ft) } \\
\end{array}$ \\
\hline 1 & 7 & 325 & $0^{(\mathrm{a})}$ & 28 & 16.8 \\
\hline 2 & 7 & 55 & 0 & 26.6 & 18.9 \\
\hline 3 & 7 & 150 & 0 & 16.3 & 28.3 \\
\hline 4 & 7 & 240 & 0 & 19.5 & 26.2 \\
\hline 5 & 21 & 285 & 0 & 34.1 & 26.2 \\
\hline 6 & 21 & 330 & 0 & 41.5 & 11.2 \\
\hline 7 & 21 & 15 & 0 & 42.6 & 5.7 \\
\hline 8 & 21 & 60 & 0 & 37.2 & 21.5 \\
\hline 9 & 21 & 105 & 0 & 26.2 & 34.1 \\
\hline 10 & 21 & 150 & 0 & 11.2 & 41.5 \\
\hline 11 & 21 & 195 & 0 & 5.7 & 42.6 \\
\hline 12 & 21 & 240 & 0 & 21.5 & 37.2 \\
\hline 13 & 36.5 & 285 & 0 & 47.2 & 37.4 \\
\hline 15 & 36.5 & 345 & 0 & 58 & 16.3 \\
\hline 16 & 36.5 & 15 & 0 & 58 & 16.3 \\
\hline 17 & 36.5 & 45 & 0 & 54.3 & 26.1 \\
\hline 18 & 36.5 & 75 & 0 & 47.2 & 37.4 \\
\hline 19 & 36.5 & 105 & 0 & 37.4 & 47.2 \\
\hline 20 & 36.5 & 135 & 0 & 26.1 & 54.3 \\
\hline 21 & 36.5 & 165 & 0 & 16.3 & 58 \\
\hline 22 & 36.5 & 195 & 0 & 16.3 & 58 \\
\hline 23 & 36.5 & 225 & 0 & 26.1 & 54.3 \\
\hline 24 & 36.5 & 255 & 0 & 37.4 & 47.2 \\
\hline 37 & 0 & 0 & 4 & 22 & 22 \\
\hline 38 & 14.5 & 180 & 4 & 7.5 & 36.5 \\
\hline 39 & 14.5 & 229.41 & 4 & 16.7 & 33.3 \\
\hline 40 & 14.5 & 282.86 & 4 & 28.9 & 23.5 \\
\hline 42 & 14.5 & 25.71 & 4 & 35.6 & 10.9 \\
\hline 43 & 14.5 & 74.35 & 4 & 29.4 & 22.8 \\
\hline 44 & 14.5 & 131.37 & 4 & 16.5 & 33.4 \\
\hline 45 & 27 & 140.84 & 4 & 17.1 & 46.2 \\
\hline 46 & 27 & 167.14 & 4 & 7.4 & 48.7 \\
\hline 47 & 27 & 193.34 & 4 & 7.6 & 48.7 \\
\hline 48 & 27 & 219.58 & 4 & 17.2 & 46.1 \\
\hline 49 & 27 & 243.12 & 4 & 26 & 41.8 \\
\hline 50 & 27 & 272.08 & 4 & 35.4 & 34.2 \\
\hline 51 & 27 & 295.72 & 4 & 41.6 & 26.4 \\
\hline 52 & 27 & 320.84 & 4 & 46.2 & 17.1 \\
\hline
\end{tabular}


Table 3.1 (cont'd)

\begin{tabular}{|c|c|c|c|c|c|}
\hline $\begin{array}{c}\text { Thermocouple } \\
\text { Number }\end{array}$ & $\begin{array}{c}\text { Radius } \\
\text { (ft) }\end{array}$ & $\begin{array}{l}\text { Angle } \\
\text { (deg) }\end{array}$ & $\begin{array}{l}\text { Elevation } \\
\text { Above Tank } \\
\text { Bottom } \\
\text { (in) }\end{array}$ & $\begin{array}{c}\text { Radial } \\
\text { Distance } \\
\text { from Mixer } \\
\text { Pump } 1 \\
\text { (ft) }\end{array}$ & $\begin{array}{c}\text { Radial } \\
\text { Distance } \\
\text { from Mixer } \\
\text { Pump 2 } \\
\text { (ft) }\end{array}$ \\
\hline 53 & 27 & 347.14 & 4 & 48.7 & 7.4 \\
\hline 55 & 27 & 39.58 & 4 & 46.1 & 17.2 \\
\hline 56 & 27 & 63.12 & 4 & 41.8 & 26 \\
\hline 57 & 27 & 88.34 & 4 & 35.3 & 34.3 \\
\hline 58 & 27 & 115.71 & 4 & 26.4 & 41.6 \\
\hline 59 & 34.75 & 146.25 & 140 & 20.5 & 54.4 \\
\hline 60 & 34.75 & 146.25 & 14 & 20.5 & 54.4 \\
\hline 61 & 34.75 & 146.25 & 4 & 20.5 & 54.4 \\
\hline 62 & 34.75 & 168.75 & 140 & 13.9 & 56.5 \\
\hline 63 & 34.75 & 168.75 & 14 & 13.9 & 56.5 \\
\hline 64 & 34.75 & 168.75 & 4 & 13.9 & 56.5 \\
\hline 65 & 34.75 & 258.75 & 140 & 37.3 & 44.6 \\
\hline 66 & 34.75 & 258.75 & 14 & 37.3 & 44.6 \\
\hline 67 & 34.75 & 258.75 & 4 & 37.3 & 44.6 \\
\hline 68 & 34.75 & 56.25 & 140 & 50.4 & 29 \\
\hline 69 & 34.75 & 56.25 & 14 & 50.4 & 29 \\
\hline 70 & 34.75 & 56.25 & 4 & 50.4 & 29 \\
\hline $72^{(\mathrm{b})}$ & 12.5 & 0 & 4 & 34.5 & 9.5 \\
\hline
\end{tabular}

\subsubsection{AZ-101 Sludge Weight Data}

Sludge weights, which are essentially a metal weight hung on a tape measure, are routinely used in the Hanford tank farms to measure the level of solids inside underground waste tanks. Sludge-weight deployments have been reported for the sediment level before and after the mixer pump operations in AZ-101. A discussion of sludge weight deployment is provided in $\mathrm{Hu}$ (2007). AZ-101 sludge weight data pertaining to the period of interest are provided in Table 3.2. ${ }^{\text {a) }}$ The date of deployment finer than one day has not been identified.

At risers 070 and 076 , the pre-mixer pump sediment levels of 16.75 and 18.75 inches were reduced to 1 and 0.75 inches, respectively. At risers 074 and 075, only an approximate 3 -inch decrease can be observed. Given the location of riser 070 in relation to the mixer pumps (Figure 3.1), it may be expected that the sediment at this location experienced significant interaction with the mixer pump jets. The similarity of orientation and disparity of response at risers 074,075 , and 076 is not as readily explained.

(a) Data taken from publically released spreadsheet SVF-1112 all solids R0.xls provided via e-mail from JM Conner, CH2M Hill to BE Wells, PNNL, on 3/14/08. 
Table 3.2. AZ-101 Sludge Weight Sediment Level

\begin{tabular}{|l|c|c|c|c||}
\hline Date & Riser 070 (in.) & Riser 074 (in.) & Riser 075 (in.) & Riser 076 (in.) \\
\hline $2 / 3 / 2000$ & 16.625 & 18 & 16.625 & 18.75 \\
\hline $4 / 18 / 2000$ & 16.75 & 17.75 & 16.5 & 18.75 \\
\hline $6 / 1 / 2000$ & 1 & 14.6875 & 13 & 0.75 \\
\hline $6 / 2 / 2000$ & 1.5 & 20 & 12.5 & 1 \\
\hline $6 / 5 / 2000$ & 4 & 22.25 & 19.5 & 4 \\
\hline $6 / 14 / 2000$ & 5.5 & 22 & 17 & $10^{(\text {a) }}$ \\
\hline $6 / 21 / 2000$ & 15.5 & 25 & 22 & 19 \\
\hline $6 / 28 / 2000$ & 16.75 & 26.5 & 22.5 & 15.5 \\
\hline $8 / 16 / 2000$ & 15.5 & 24 & 20 & 15 \\
\hline (a) First contact of the sludge weight was 11 inches higher. \\
\hline \multicolumn{5}{|l}{} \\
\hline
\end{tabular}

As indicated in Figure 3.2, the thermocouples in the vicinity of risers 074 and 075 reached the liquid temperature, indicating that the sediment was excavated (thermocouple 14, the closest to riser 076, was not operational). Carlson et al. (2001) reported that 95 to $100 \%$ of the sediment was mobilized. Thus, the sludge weight indications at risers 074 and 075 of a relatively thick layer (in comparison with the data at risers 070 and 076), in conjunction with the thermocouple data indicating that the sediment in these areas was excavated, suggest that the sediment material was rapidly settling or that portions of the sediment were "pushed" around the tank floor.

The risers in question (074 and 075) are at the outer radius of the tank (as is riser 076), possibly suggesting that material was pushed up against the tank wall. The disparity between the riser 076 and risers 074 and 075 measurements is thus of interest. Insight into this phenomenon may be gained by considering that the mixer pump in riser 003 , although operated substantially more than the mixer pump in riser 001 over the month of testing, ceased operation approximately 3.5 hours before cessation of mixer pump operation in riser 001 for the final mixing operations. Thus, rapidly settling or sliding sediment material may have cleared away from riser 001 to the other "half" of the tank, thereby resulting in the apparent anomaly of sludge weight sediment level measurements between the risers. Carlson et al. (2001) state that the stoppage of mixer pump 13.5 hours before mixer pump 2 resulted in a "larger accumulation of sludge to the half of the tank containing mixer pump 1."

The shear strength of the sediment required to support the sludge weight has been estimated as presented in Appendix B to be up to 370 Pa for typical Hanford sediment, and in-tank data for AW-101 suggest $160 \mathrm{~Pa}$. Based on this work, the sludge weight indicated shear strength herein is represented by nominally $200 \mathrm{~Pa}$. Thus, the "growth" of the sediment layer indicated in Table 3.2 for risers 070 and 076 is taken to indicate the level at which the sediment has a shear strength greater than or equal to $200 \mathrm{~Pa}$. The level reported at riser 076 on 6/14/2000 is noted to be the first indication of the solid-liquid interface; the "200 Pa" point was noted to be 11 inches below the reported value. The sludge weight data will be summarized with data from other measurements in Section 3.1.5.

The estimate of $200 \mathrm{~Pa}$ for the shear strength of the layer that will just support a sludge weight has a fairly large uncertainty. This uncertainty could be significantly reduced by experimentally determining the shear strength that will support a sludge weight for a range of simulants. 


\subsubsection{AZ-101 Gamma Scan Results}

As stated in Carlson et al. (2001), grab sample analysis, the suspended solids profiler (SSP), the gammamonitoring system, and the ultrasonic interface level analyzer (URSILLA) instruments indicate that "significant settling occurs as soon as the mixer pumps are turned off, and, for the most part, was complete in half a day." The gamma scan data of Carlson et al. (2001) is the most amenable to the current investigation, and is thus considered herein.

The gamma scan profiles provided in Figure 3.3 allow inference of the solid-liquid interface with time. Note that the gamma monitoring system is set such that the counts/second increase in the sediment (see Carlson et al. [2001], and note Gamma Rays Above $850 \mathrm{keV}$ in Figure 3.3). Profile (1) of Figure 3.3, taken from 0 to 73 minutes after cessation of mixer pump operation, shows a relatively uniform counting rate from 16 to 290 inches which indicates a uniform distribution of solids assuming that the counts/second of Profile (9) from 290 to 40 inches represent liquid. The solid-liquid interface can be inferred as will be summarized in Section 3.1.5.

\subsubsection{AZ-101 Sediment Shear Strength}

The pre-mixer pump operation shear strength of the AZ-101 sediment has been measured with a shear vane using waste samples from Cores 266 and 269. ${ }^{\text {(a) }}$ These measurements are compared to pre- and postmixer pump operation shear strength results determined via the "extrusion length" methodology. The extrusion length shear-strength estimates presented in Figure 3.4 below have not been reviewed nor previously published. As such, they are for information only.

As described in Section 2.2.1, the extrusion length methodology is an extension of the visual comparison of horizontal core extrusion methodology of Gauglitz and Aikin (1997) for estimating the shear strength of Hanford Waste developed in Rassat et al. (2003a). In summary, Gauglitz and Aikin horizontally extruded bentonite/water and kaolin/Ludox/water simulants of known shear strength and reported the length at which the extrusion exhibited "failure." In this approach, the shear strength of a material can be correlated directly to the functional form of the maximum tensile stress in a cantilever beam. This provides a means to compute the shear strength of a material given its density and the plastic failure length of a horizontal extrusion. Results with this methodology (termed "extrusion length") were generally within a factor of two or better of the ball rheometer measurements (typically accepted as being more representative of in situ waste conditions than laboratory measurements; Hedengren et al. 2000) for select saltcake DSTs. It was concluded that, in the absence of definitive in situ measurements, or in support of them, this extrusion length methodology is expected to produce representative results for the material's shear strength (Rassat et al. 2003a). A relatively favorable comparison of shear vane and extrusion length results can also be made for AY-102 sediment (see data in Onishi and Wells 2004), and the similarity of extrusion length and shear vane results in sludge is reported in Appendix F of $\mathrm{Hu}$ (2007).

(a) Fluor Global Services Memorandum 8D500-DBB-01-018, DB Bechtold to KE Bell et al., March 28, 2001. Subject: Correction of Shear Strength Measurements Reported by 222-S Laboratory. 

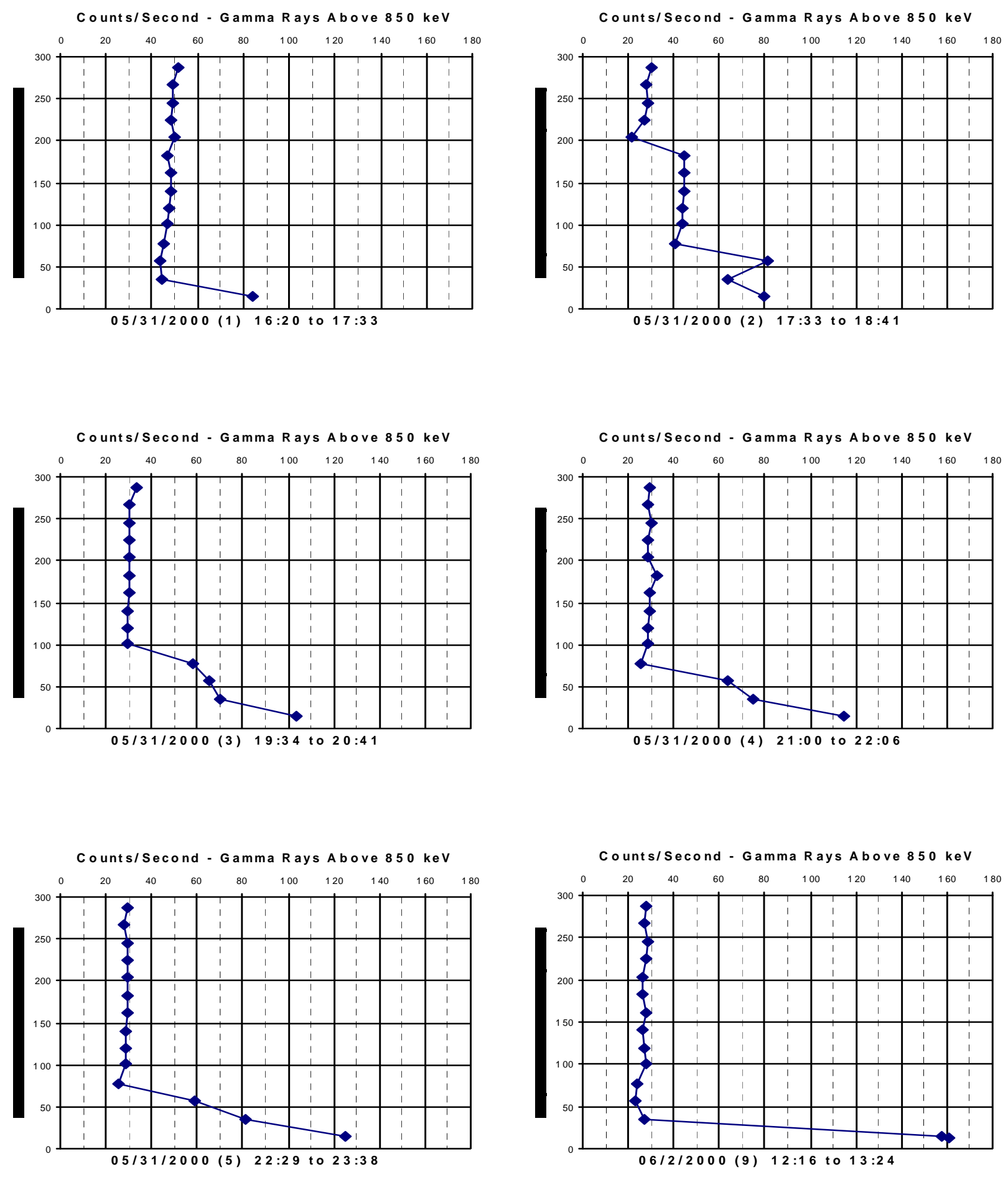

Figure 3.3. Gamma-Monitoring System Data 0 to 45 Hours after Pump Shutdown (Reproduced from Carlson et al. 2001; Y-Axis is Height Above Tank Bottom [inches])

Based on this extrusion length methodology, horizontal core extrusion videos from AZ-101 were investigated. Cores 266 and 269 were taken in October/November of 1999 (pre-mixer pump test), while core 283 was taken in August, 2000 (approximately 80 days after the end of the mixer pump test). 
Shear vane and extrusion length shear strength results are presented in Figure 3.4. The elevation of segment 16, cores 266 and 269, approximately corresponds to the elevation of segment 18 , core 283 . The approximate mid-point elevation of segment 16, cores 266 and 269, is 7 inches, segment 17, core 283, is 13.5 inches, and segment 18 , core 283 , is 2.5 inches. $^{\text {(a) }}$

The shear-vane shear-strength results are larger than the extrusion length estimates, with the same-coreand-segment shear vane result $60 \%$ and $50 \%$ larger than the median of the extrusion length best estimate and upper bound results, respectively. Insufficient data exist to reach a definitive conclusion regarding the shear-strength profile in the sediment; the extrusion length results from core 283 segments 18 and 18A bound the segment 17A result. There is no indication that limited sediment depth limits shear strength.

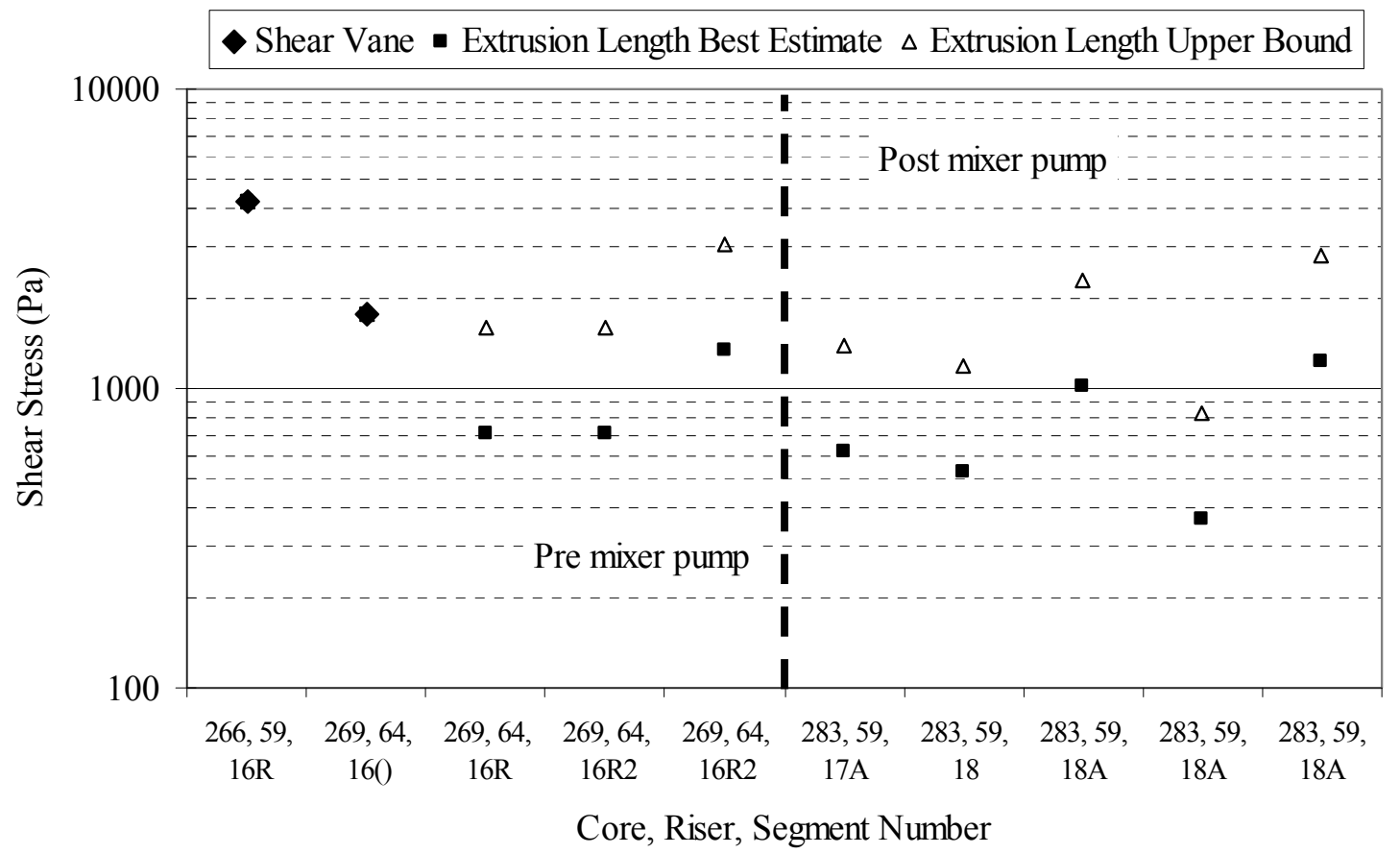

Figure 3.4. Sediment Shear Strength in AZ-101. Extrusion length shear strength estimates have not been reviewed or published; for information only.

There is no significant difference (710 $\mathrm{Pa}$ to $610 \mathrm{~Pa}$, median values) in the extrusion length results pre- and post-mixer pump operation, suggesting that the waste had regained its original shear strength in the intervening approximately 80 days from the completion of the mixer pump tests to the core 283 sampling event (no attempt is made to account for riser difference; the bulk of the sediment was mobilized; see Section 3.1.1). The available data thus suggest that mobilized AZ-101 sediment regained its initial shear strength within 80 days. Further, the shear strength attained in a 15 to 20 inch layer (see Section 3.1.2) may be as high as $4,190 \mathrm{~Pa}$ (core 266, segment 16R result).

(a) Inferred from AZ-101 Core Profile, TWINS: Tank Waste Information System database. http://twins.pnl.gov/twins3/twins.htm. 


\subsubsection{AZ-101 Sediment Settling Summary}

Figure 3.5 and Figure 3.6 show the time history of settling and shear strength of the mixer-pump-mobilized AZ-101 sediment from the data presented in Sections 3.1.1 through 3.1.4. Figure 3.5 is plotted in log-log scales to depict the various settling processes as indicated by the interface levels and their associated timescales, and Figure 3.6 is plotted on linear scales to highlight overall the specific trends on the growth and compaction of the sediment layer after mixer-pump operations were stopped.

The solid-liquid interface data (open square symbols) show this layer settling over time from an initial level of about 300 in. to a level of about 28 in. in about 2 days. As reported in Section 2, the solid-liquid interface data can be used, in conjunction with the pre-mixed condition of the tank, to estimate the solids content of the settled layer. The sludge-weight measurements show that, depending on the riser where the sludge weight was deployed, there was a settled layer with a shear strength of at least $200 \mathrm{~Pa}$ beginning as early as 1 day after mixing ceased. Poloski et al. (2007) estimate the sedimentation time scale for 10-mdeep vessels to be on the order of 1000 hours, so these AZ-101 results showing settling over a 20- to 40-hr period are more rapid than previously expected. The sludge-weight measurements showing rapid settling in risers 74 and 75, in comparison to the settling in risers 70 and 76, is considered further below.

The sludge-weight-indicated sediment growth upon cessation of mixing from Table 3.2 (and Figure 3.5) is re-plotted in Figure 3.6 in linear coordinates. As discussed in Section 3.1.2, the sediment was mobilized under each riser in which the sludge-weight was deployed. Insulating-concrete thermocouples 20 and 23, which are closest to the risers exhibiting the most rapid settling, risers 74 and 75 respectively, reached the supernatant liquid temperature, clearly demonstrating that the sediment was mobilized and that they were exposed to the supernatant liquid. In addition to AZ-101 (Carlson et al. 2001), the thermocouple response has been used to demonstrate sludge mobilization (removal of sediment and contact with supernatant liquid) and to track the solid-liquid interface in numerous Hanford waste tanks (see, for example, Cuta et al. 2000, Hu 2007, Stewart et al. 2005, Stewart et al. 1994).

Because the sediment was mobilized at risers 74 and 75, rapid settling, approaching 15 inches of sediment in one day, is indicated (Figure 3.6). The sludge-weight data in all four risers, as well as the solid-liquid interface from the Gamma-Monitoring System, indicate the completion of settling in approximately 25 days. The implication is therefore that the general settling behavior of the tank differs from that observed at risers 74 and 75, which may suggest that the rapid settling at risers 74 and 75 is localized. This phenomenon is supported by the mixer pump operations described in Section 3.1.2.

The period of nominally 25 days to the completion of settling (indicated by the maximum value in sediment depth) is followed by compaction of the layer. The shear strength of the sediment at 28 days, and before the compaction that occurred between 28 and 80 days, was estimated in Section 2.1.2 (see Figure 2.4) as $1605 \mathrm{~Pa}$. 


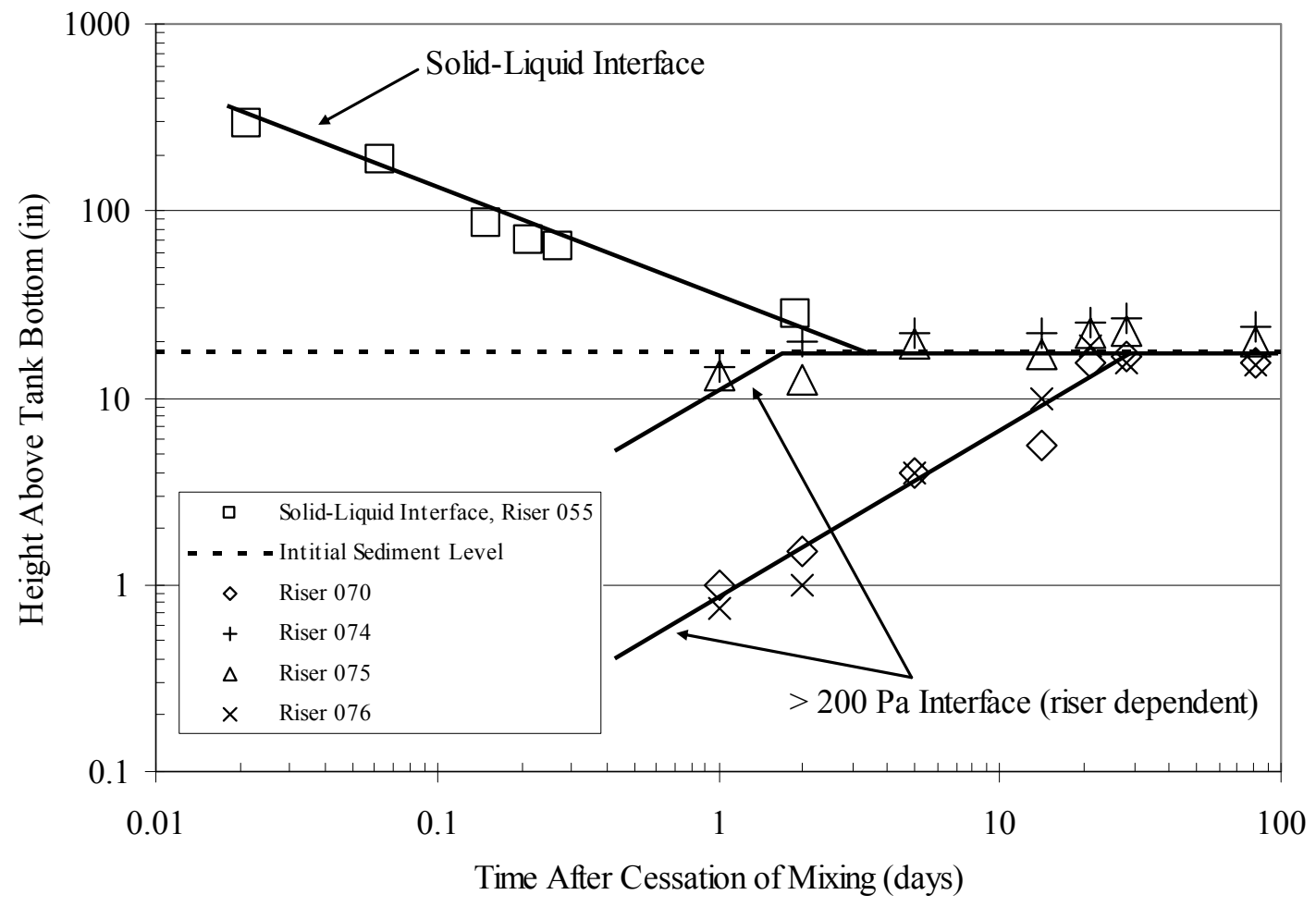

Figure 3.5. AZ-101 Sediment Level as a Function of Time after Mobilization. The solid-liquid interface is inferred from the Gamma-Monitoring System data of Figure 3.3. Data for risers 070, 074, 075, and 076 from sludge weight sediment level data, Table 3.2. Shear strength of the sediment at and below this level is greater than $200 \mathrm{~Pa}$ from sludge weight (Section 3.1.2). The shear strength of the sediment after 80 days may be up to $4190 \mathrm{~Pa}$ (see pre- and postmixer pump shear strength data in Figure 3.4 and shear-vane measurement on samples from core 266, segment 16R). 


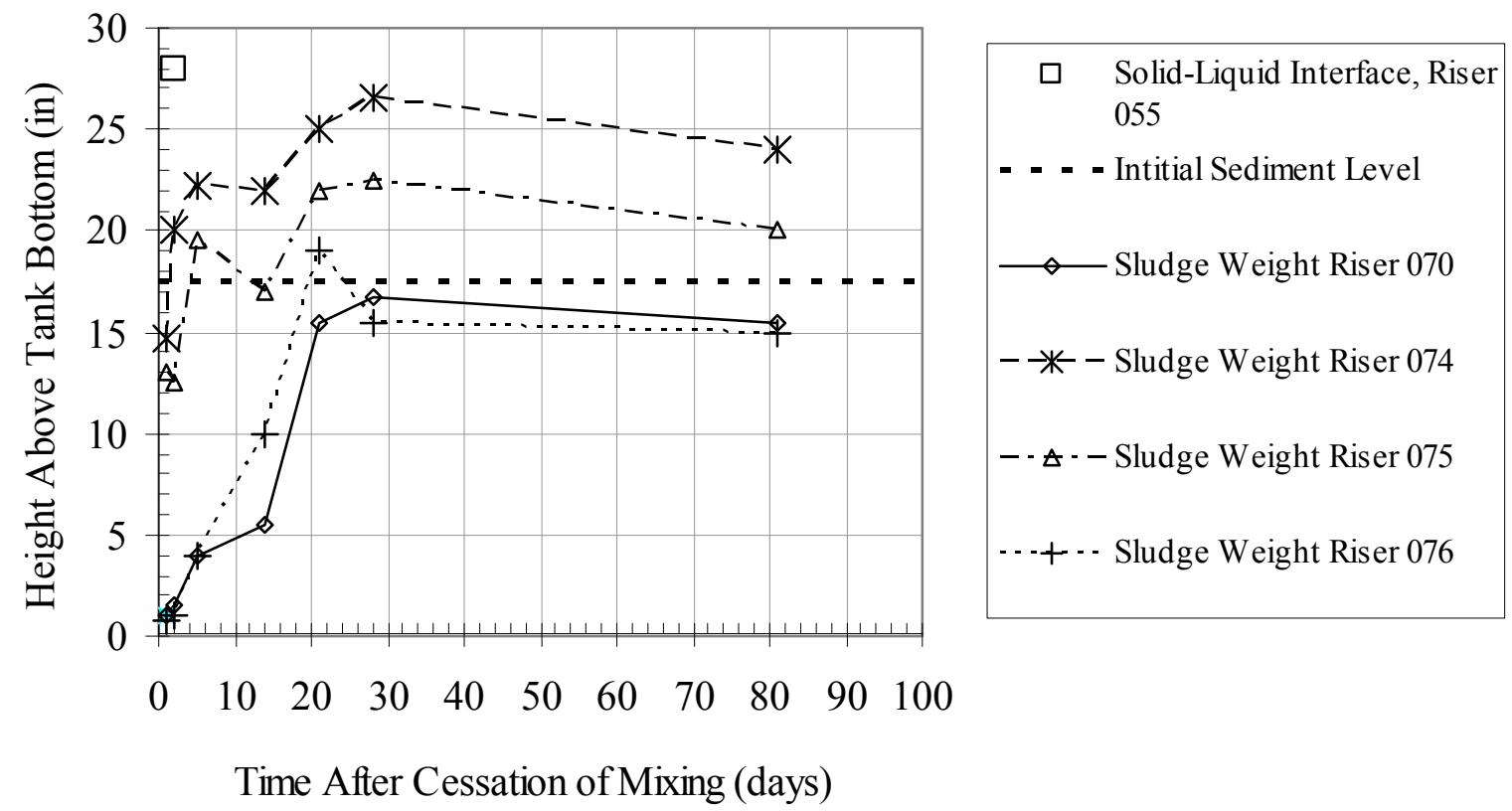

Figure 3.6. AZ-101 Sediment Level as a Function of Time after Mobilization. The solid-liquid interface is inferred from the Gamma-Monitoring System data of Figure 3.3. Data for risers 070, 074, 075, and 076 from sludge weight sediment level data (Table 3.2).

\subsection{AY-102}

Approximately $186 \mathrm{kgal}$ of sludge ( $\sim 97 \%$ of the initial inventory; sludge is relatively insoluble solids and interstitial liquid) was retrieved from C-106 using the Waste Retrieval Sluicing System and transferred to AY-102 via three sluicing campaigns from 11/98 through 10/99 (Cuta et al. 2000). Supernate from AY-102 was used as the sluicing fluid, and nominally $16 \%$ of the original sludge volume of C-106 was "lost" because of solids dissolution (Bailey 2000).

The sediment level in AY-102 was tracked with an Enraf densitometer ${ }^{(a)}$ (riser 15S) and temperature profiles (riser 5A), and four core sample profiles were taken shortly after the end of the last sluicing campaign, in 12/99 through 1/00 (cores 270 and 271, riser 15M, cores 272 and 273, riser 15G), which provide sediment property information. A riser map for AY-102 is provided in Figure 3.7.

Sediment level data are provided in Section 3.2.1, core sample data in Section 3.2.2, and a summary of the AY-102 data is provided in Section 3.2.3.

(a) The Enraf densitometer consists of a metal displacer (bob) of known mass that is held by a wire and moved vertically from the top to the bottom of the tank. The tension on the wire is continuously measured, and the density of the liquid surrounding the bob, and the presence of sediment layers, can be determined from the weight of the bob as it moves through different fluids. 


\subsubsection{AY-102 Sediment Level Data}

AY-102 initially contained approximately 9 inches of sediment (Cuta et al. 2000) and had nominally 67 inches of sediment after the completion of the sluicing campaigns as shown in Figure 3.8. The sediment level change of approximately 58 inches (from 9 to 67 inches) suggest that the solids settled in AY-102 to a similar condition as in C-106, as $186 \mathrm{kgal}$ minus $16 \%$ is nominally $155 \mathrm{kgal}$ of sludge transferred (see Section 3.2). With a tank diameter of $75 \mathrm{ft}$, this volume translates to approximately 56 inches, as compared to the 58 -inch difference (67 inches minus 9 inches). Comparing the $>500$-day measurements of the Enraf densitometer, riser 15S, and the temperature profiles on the opposite side of the tank, riser 5A, the sediment level is relatively uniform and does not appear to be a function of location in the tank.

The typical setting on the Enraf densitometer to detect a solids level is a decrease in tension equivalent to $25 \mathrm{~g}$ (displacer mass is $239 \mathrm{~g}$ ) (Hu 2007) and translates to a density difference greater than $0.1 \mathrm{~g} / \mathrm{mL}$. For temperature measurements, the sediment/liquid interface is determined from the temperature profiles by interpolation between the convective (liquid) and nonconvective (sediment). Thus, as relatively small density gradients inhibit convection, it is reasonable that the sediment levels indicated by the temperature profile measurements exceed the densitometer until settling/compaction is complete. This behavior can readily be discerned in Figure 3.8, in that the sediment level values inferred from the temperature profiles tend to be somewhat higher than the Enraf densitometer measurements, until about a 100 days after the end of the sluicing operations.

The retrieval batches (see Cuta et al. 2000) are evident in Figure 3.8, and periods of settling and compaction are apparent. The sediment level as determined from the batch volumes (minus $16 \%$ for dilution, see above) is included in Figure 3.8. With this data, the "lag" of the Enraf densitometer data to the transfers is apparent. Considering the relatively large single-day transfers at 109, 130, 163, 197, and 246 days since retrieval start, the median time to the maximum sediment level (as determined by the Enraf densitometer) is 5 days, ranging from 3 to 8 days. The subsequent sediment level decay via compaction took approximately 45 days to reach a decay rate of nominally 0.005 in./day from the transfer at 197 days. It took approximately 120 days for the settling rate to decrease to $0.008 \mathrm{in}$./day after the final transfer at 322 days. Note that the coarseness of the data collection interval after transfer completion may have dictated the latter result. The data indicate that the bulk of the material apparently settled in 5 days, and subsequent compaction occurred between 45 to 120 days. 


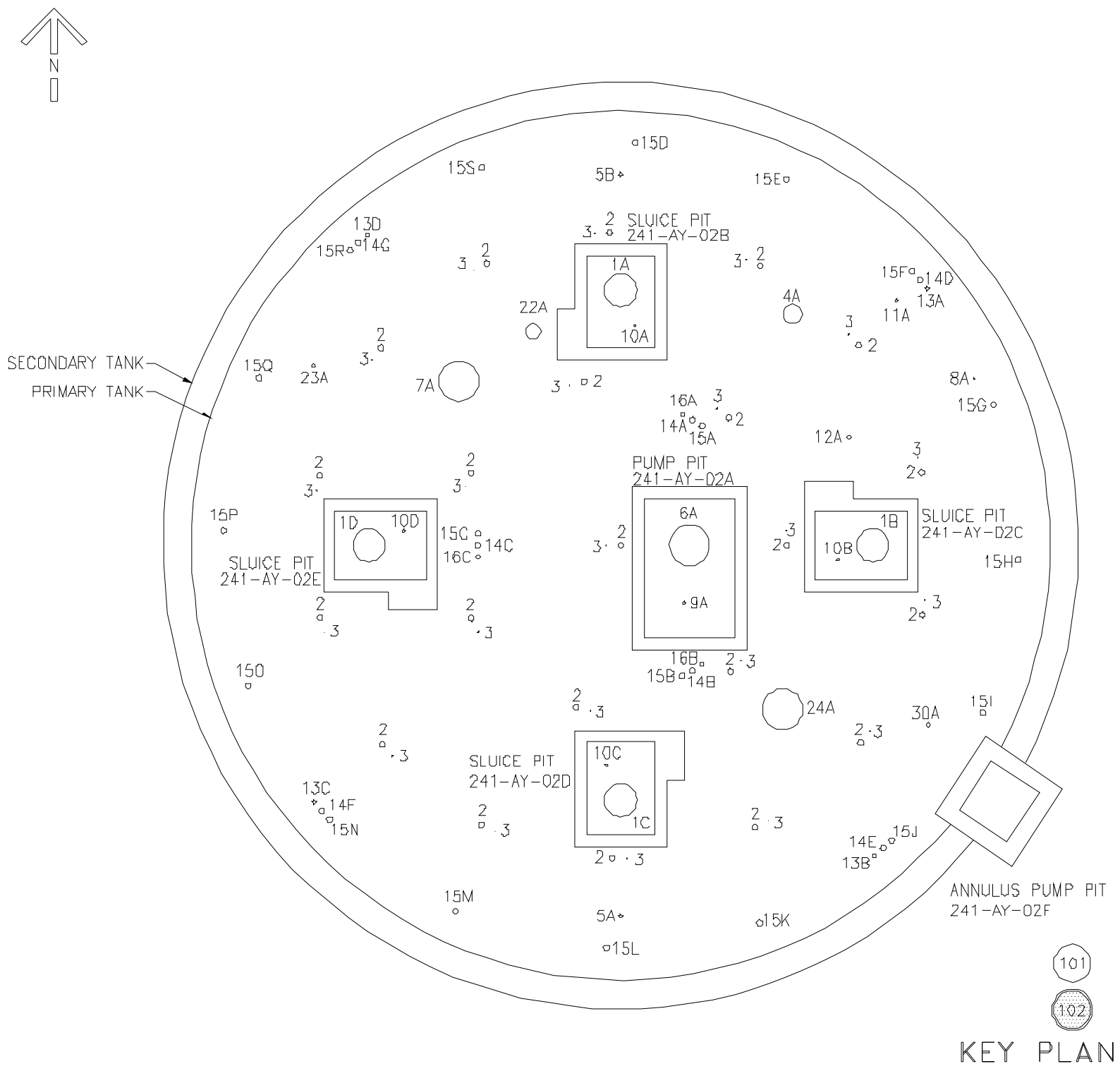

Figure 3.7. AY-102 Riser Map 


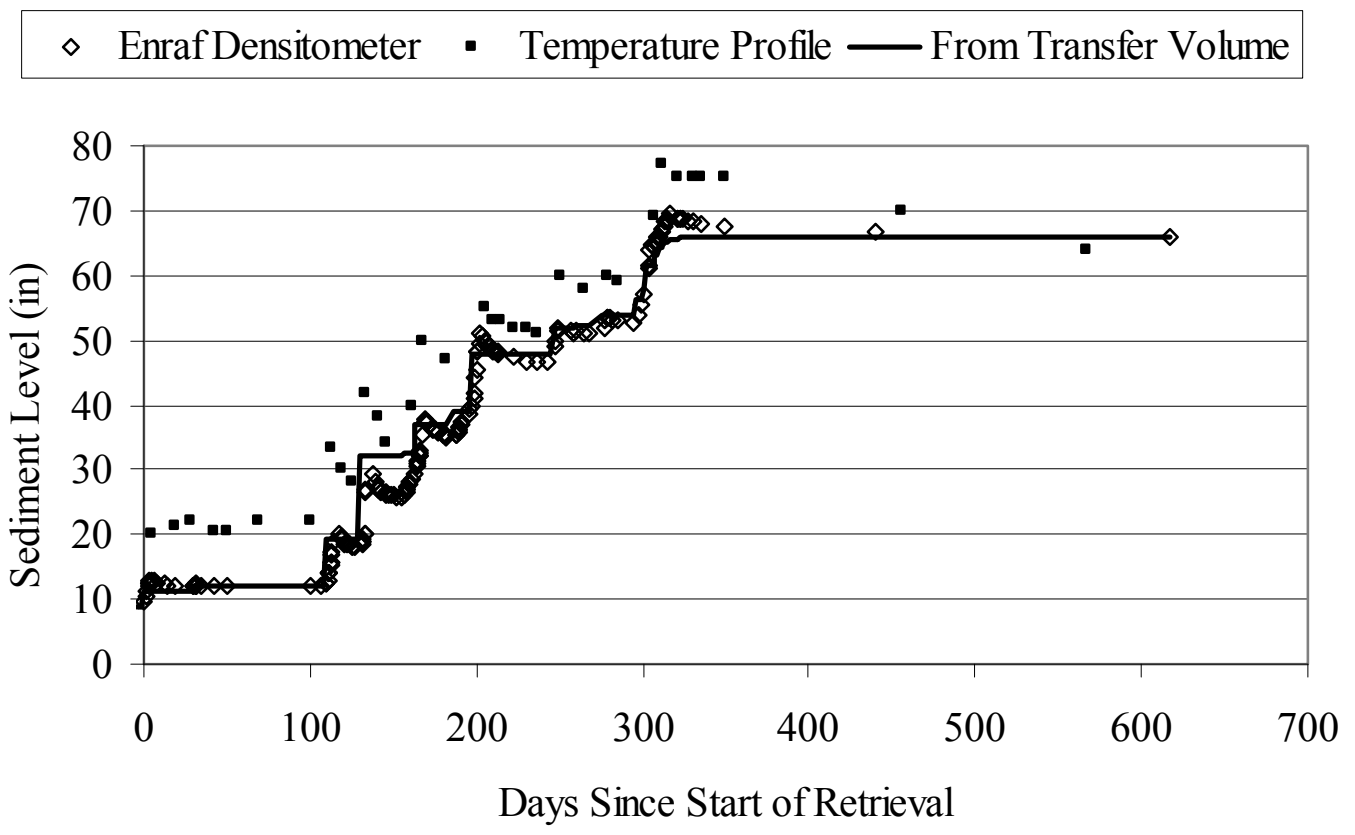

Figure 3.8. AY-102 Sediment Level History from Start of C-106 Retrieval Campaign

\subsubsection{AY-102 Core Sample Data}

Post-retrieval sediment property data are available from the four core sample profiles taken 12/99 through 1/00 (cores 270 and 271 at nominally 68 and 74 days, respectively, post-retrieval; riser 15M, cores 272 and 273, at nominally 87 and 91 days, respectively, post-retrieval; riser 15G). The shear strength of the cores was analyzed relatively extensively with a shear vane, with measurements for the upper and lower halves of the core segments. ${ }^{\text {(a) }}$ No shear-vane data are available for the original sediment of C-106. A comparison of the shear vane and core extrusion results for AY-102 is provided in Onishi and Wells (2004).

The shear-vane shear-strength data for AY-102 cores 270 through 273 are provided as a function of depth in the sediment in Figure 3.9. The depth in the sediment is determined via the TWINS core profile as the midpoint of the upper and lower halves of the core segments. ${ }^{(b)}$ The median value at the approximate nominal elevation from the tank bottom is also provided. The median of all measurements is $510 \mathrm{~Pa}$. No trend in shear strength with depth is apparent (note that the initial sediment level in AY-102 was 9 inches; see Section 3.2.1). The measurement location, risers $15 \mathrm{M}$ and $15 \mathrm{G}$, does not appear to influence the results. There is also no apparent impact from the "re-sampling," that is, core 271 followed 270 by approximately 6 days in riser 15M, and core 273 followed 272 by approximately 4 days in riser $15 \mathrm{G}$.

From Figure 3.8, it is evident that sediment was present at specific elevations earlier than at other elevations; see Figure 3.10. The nominal 4,400 days for the initial 9 inches of sediment is representative

(a) Fluor Global Services Memorandum 8D500-DBB-01-018, DB Bechtold to KE Bell et al., March 28, 2001. Subject: Correction of Shear Strength Measurements Reported by 222-S Laboratory.

(b) AY-102 Core Profile, TWINS: Tank Waste Information System database. http://twins.pnl.gov/twins3/twins.htm. 
of the reported 1989 sediment levels. ${ }^{(a)}$ Thus, the shear-strength data of Figure 3.9 can be plotted as a function of time; see Figure 3.11. The shear strength measurements are grouped by approximate nominal elevations. Shear strength appears to be independent of time. Thus, it is suggested that the minimum time for a given elevation, approximately 100 days, was sufficient for the material to reach its "final" shear strength. It is not possible to determine at what point during the initial 100 days the "final" shear strength was attained.

Percent water and density data for the sediment core segments for cores 270 and 273 are available. ${ }^{(b)}$ As evident from Figure 3.12, percent water and shear strength are not correlated. There is indication that percent water decreases with depth into the sediment (it is noted that core 273 segment 9 was nominally $50 \%$ sediment, 50\% supernatant); see Figure 3.13. The apparent anomaly of decreasing density with decreasing water content is explained by the initial sediment level of 9 inches as noted above in reference to Figure 3.9. Thus it is reasonable to expect that the waste properties from the bottom sediment core segment may not trend with those above.

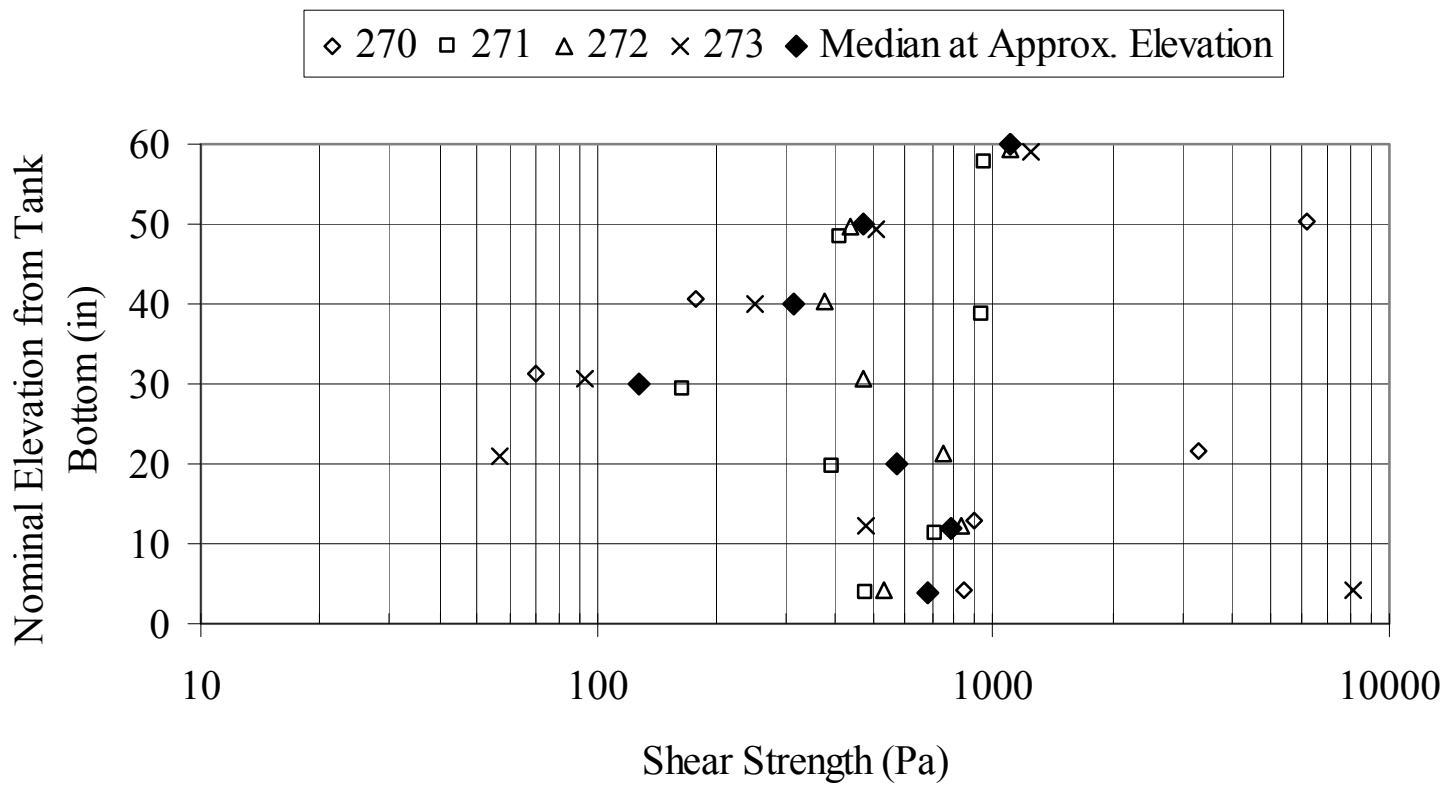

Figure 3.9. AY-102 Sediment Shear Strength for Waste Cores 270 Through 273

(a) TWINS: Tank Waste Information System database. http://twins.pnl.gov/twins3/twins.htm.

(b) TWINS: Tank Waste Information System database. http://twins.pnl.gov/twins3/twins.htm. 


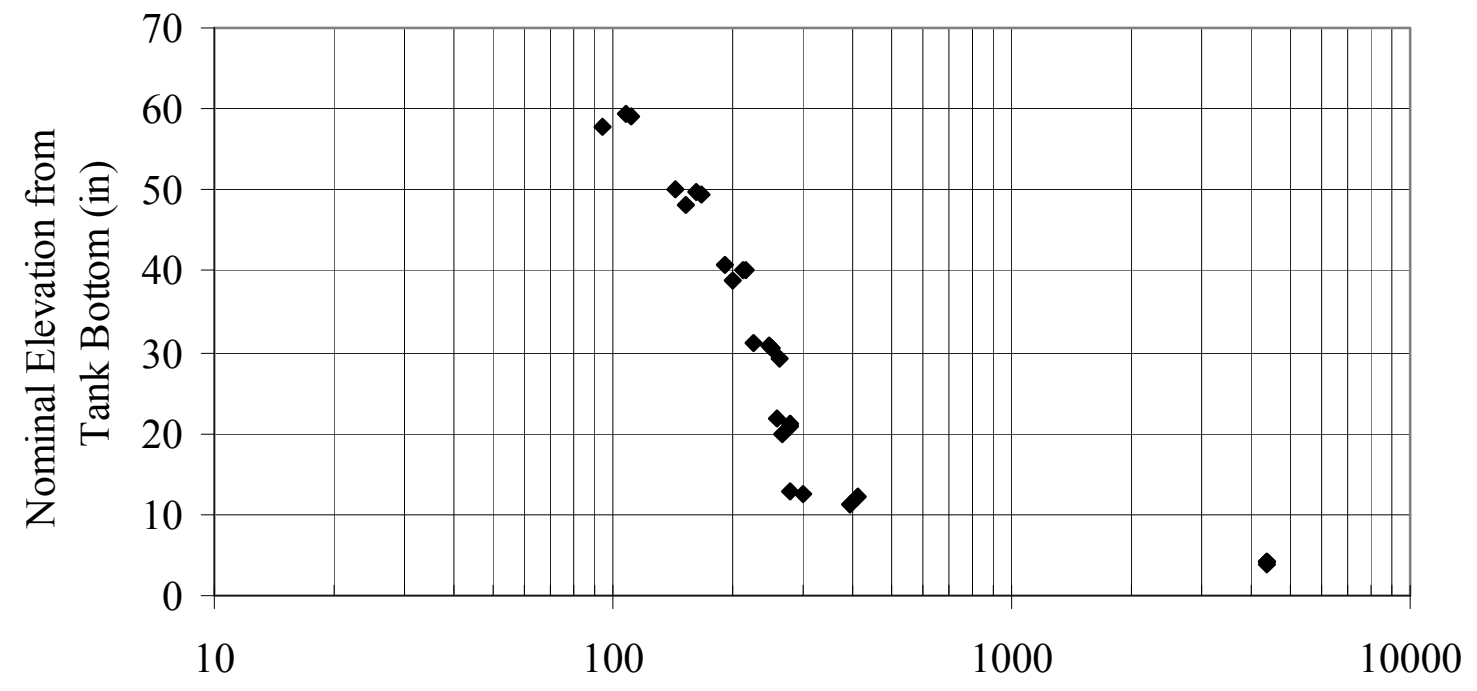

Time Until Sample by Elevation of Sediment (days)

Figure 3.10. Time Until Sample with Elevation of Sediment

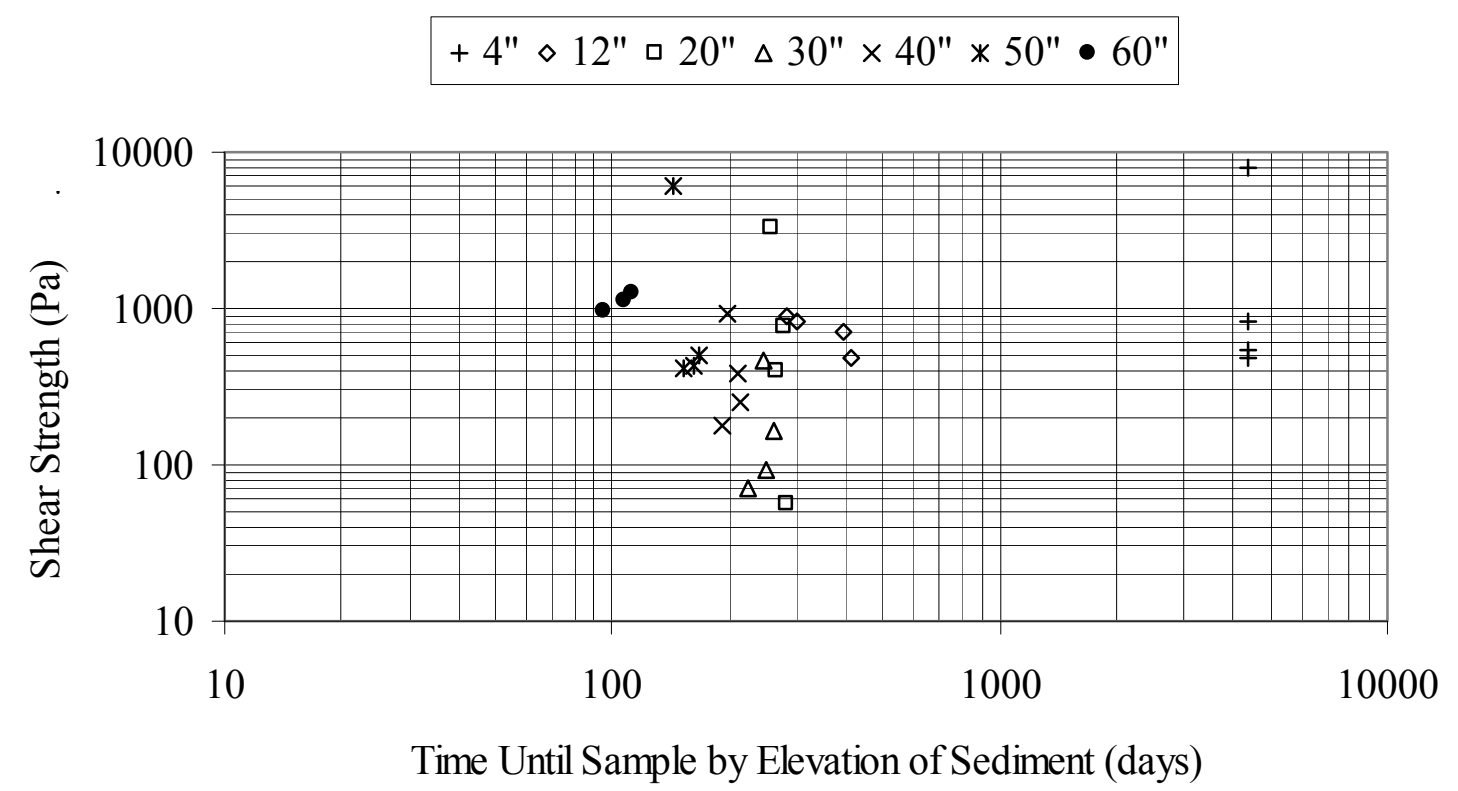

Figure 3.11. AY-102 Sediment Shear Strength for Waste Cores 270 Through 273 as a Function of Time. Legend indicates approximate nominal elevation from tank bottom. 
- Core 270, Shear Strength $\Delta$ Core 273, Shear Strength

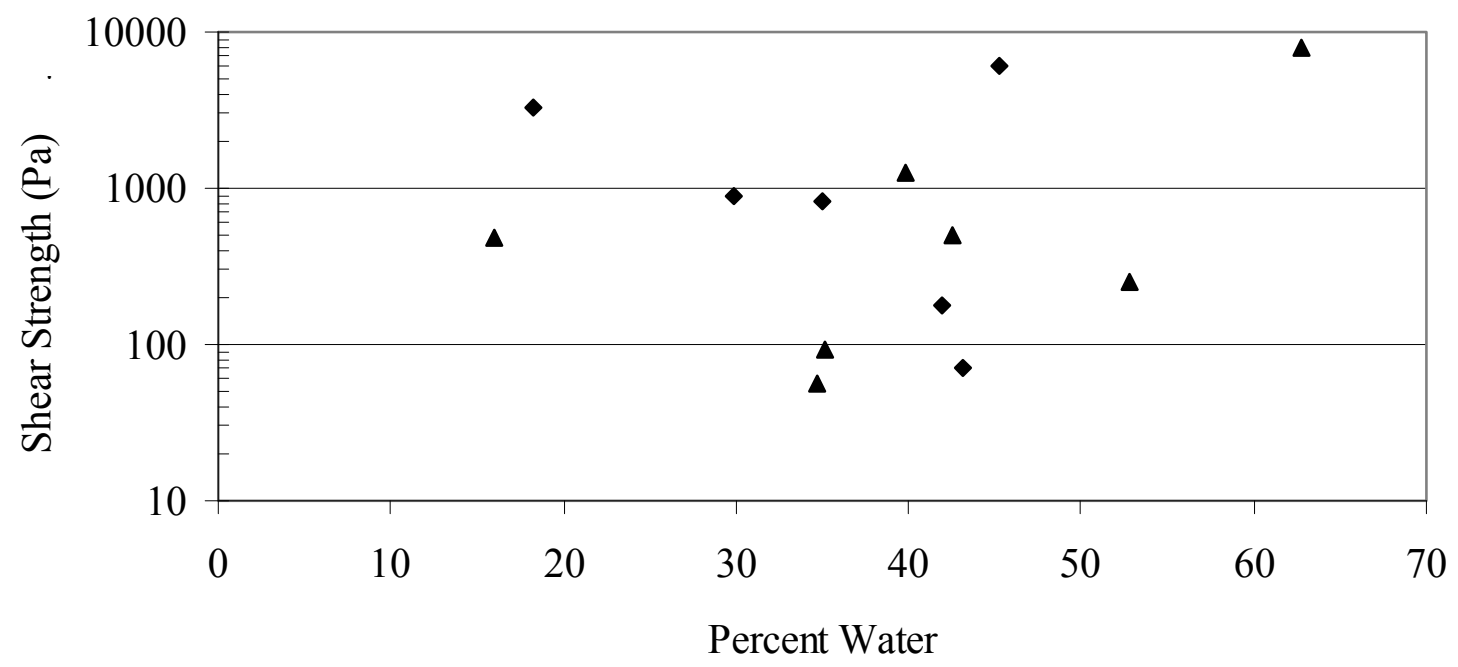

Figure 3.12. AY-102 Sediment Shear Strength as a Function of Percent Water for Sediment Core Segments from Waste Cores 270 and 273

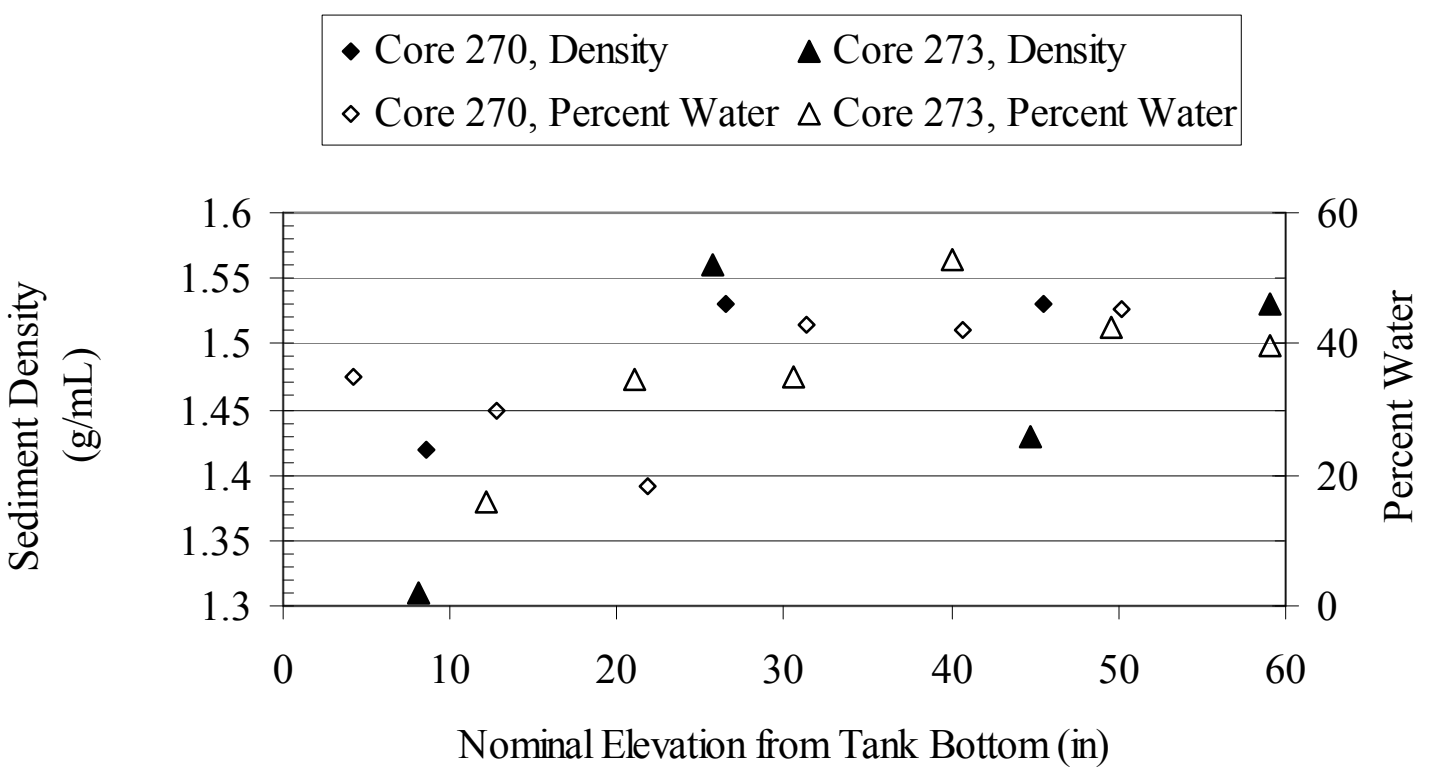

Figure 3.13. AY-102 Sediment Percent Water and Sediment Density for Sediment Core Segments from Waste Cores 270 and 273 


\subsubsection{AY-102 Sediment Settling Summary}

The data presented in Sections 3.2.1. and 3.2.2 indicate that the sediment material retrieved from C-106 and transferred into AY-102 settled rapidly, and the settled material has a median shear strength of approximately $510 \mathrm{~Pa}$ with measured values ranging from 60 to 8,100 $\mathrm{Pa}$. To summarize:

- The bulk of the sediment material apparently settled within 5 days, and subsequent compaction occurred between 45 to 120 days. There is no indication of radial non-uniformity.

- Shear strength is not correlated with depth in the sediment; shear strength is independent of water content. There is no indication of radial non-uniformity.

- The sediment reached its "final" shear strength (median $510 \mathrm{~Pa}$, ranging from 60 to 8,100 Pa) at or before approximately 100 days.

\subsection{SY-101 and SY-102}

The sediment layer in SY-101 was mobilized via tri-weekly mixer pump operations starting in 1993 and continuing through 4/2/00 (Johnson et al. 2000; Mahoney et al. 2000). Between 12/18/99 and 3/15/00, a series of three waste transfers removed slurry from SY-101 into SY-102. Most of the soluble sodium salts in SY-101 were dissolved by back-dilutions with water conducted during the series of transfers (Johnson et al. 2000).

In Section 3.3.1, the sediment in SY-101 is considered following the 4/2/00 cessation of the mixer pump operations. The material that subsequently settled had been mobilized essentially constantly for about 7 years, and the tank was diluted $40 \%$ by volume with water (the initial transfer removed undiluted waste, and the dilutions were conducted in sequence with transfers, so dilution water was removed by subsequent transfers).

SY-102 has historically served as a staging tank for cross-site transfers. Thus, waste levels in SY-102 have fluctuated with time. The sediment in SY-102 is considered in Section 3.3.2 during a period encompassing 12/18/99 to 3/15/00 when the tank received waste from SY-101.

\subsubsection{SY-101}

Starting in 1993 and continuing to April 2000, the initially nominally 5.33-m-thick sediment layer in SY-101 (0.26 undissolved solid volume fraction) was mobilized by a mixer pump in riser 12A (renumbered to riser 015) (see Johnson et al. 2000 for mixer pump, Stewart et al. 2005 for waste properties). Figure 3.14 provides the riser map for SY-101. ${ }^{\text {(a) }}$ The mixer pump was typically operated on a tri-weekly schedule and was incrementally rotated by approximately $30^{\circ}$ (mixer pump rotated incrementally for approximately $180^{\circ}$, then reversed incremental rotation back to starting position; "return" rotation offset by $15^{\circ}$ ) for each operation. Thus, regions away from the orientation of the mixer pump were "undisturbed" for nominal 30-day periods.

(a) TWINS: Tank Waste Information System database. http://twins.pnl.gov/twins3/twins.htm. 


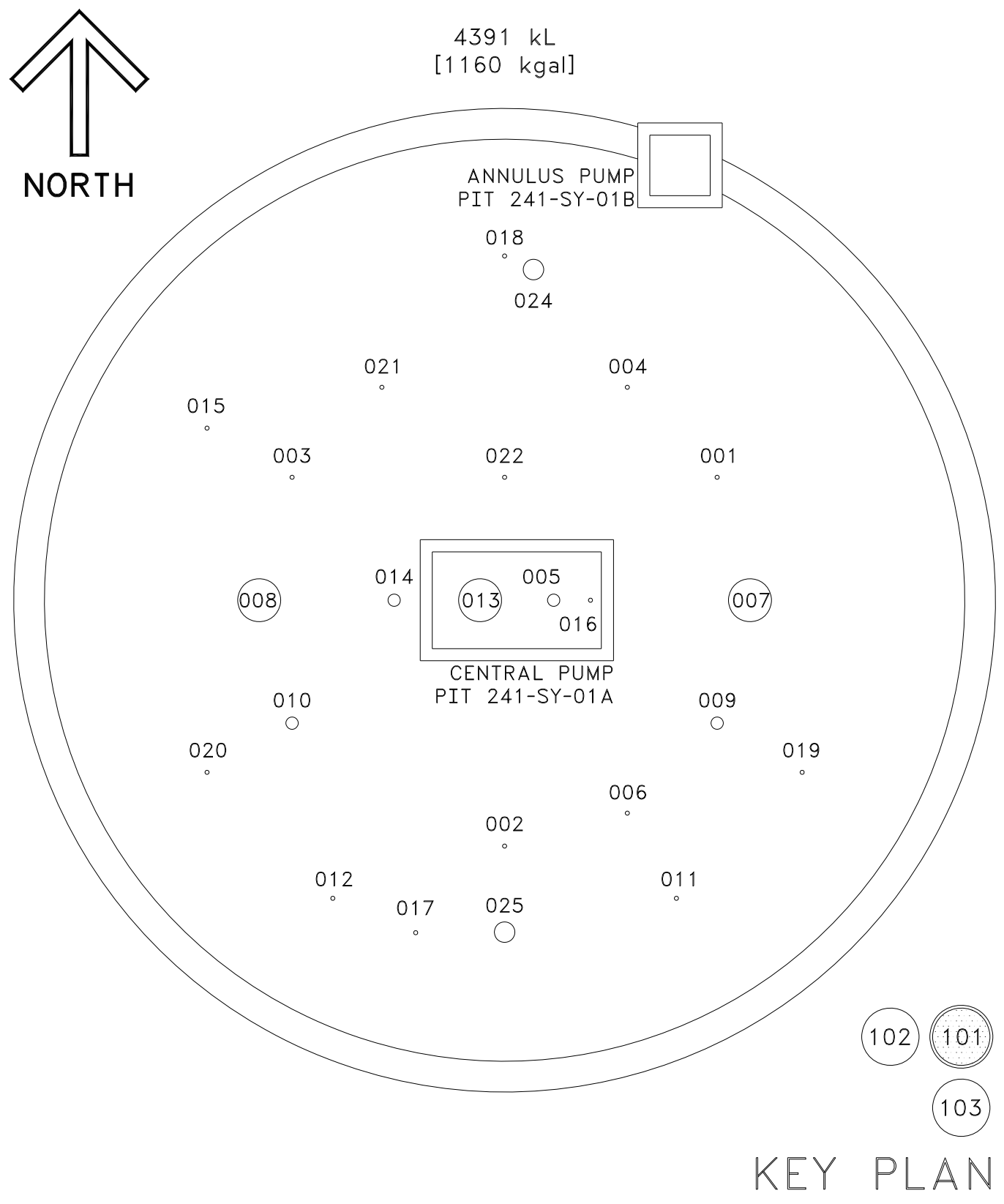

Figure 3.14. SY-101 Riser Map

The thermocouple profiles during the mixer pump operation time period clearly illustrate the mobilization and resettling of the sediment within a few days; the periodic mixer pump operations (and solids accumulation in the floating crust layer) resulted in a settled layer of approximately 50 inches in the "undisturbed" regions (Rassat et al. 2000). The yield stress of the settled layer, as measured with the ball rheometer in riser 4A (renumbered to riser 006), approximately 10 days after the mixer pump was directed at that location, was about $10 \mathrm{~Pa}$ at 24 inches above the tank bottom and $30 \mathrm{~Pa}$ at 6 inches (Stewart et al. 1995). The ball apparently did not reach the tank bottom, indicating that it was fully supported by the waste, which thus has a shear strength of at least $900 \mathrm{~Pa}$ (Meyer et al. 1997). 
The mixed slurry layer between the floating crust layer and settled sediment layer was "...clearly a fluid as evidenced by its uniform temperature profile, the operation of the mixer pump, and the fact that particles and bubbles can move within it....ball rheometer data...showed no yield stress..." (Rassat et al. 2000). Rassat et al. (2000) estimated the in situ solid volume fraction to be 0.15 . Core sample segments taken from this slurry region had to be "...stirred with a spatula for the material to be transferred..." to an alternative container. $^{(a)}$ This apparent inconsistency, in situ fluid to ex-tank "solid," can be attributed to the precipitation of solids from the liquid as the sample cooled upon removal from the tank.

The settling between mixing periods is not considered further herein. Instead, the solids settling and compaction following the 4/2/00 cessation of the mixer pump operations (after waste transfer and significant water dilution; see Section 3.3) is considered. The sediment level histories from the thermocouple trees in risers 17B and 17C (renumbered to risers 018 and 019 respectively) are discussed in Section 3.3.1.1 as well as data from the deployment of the zip cord in riser 6, Section 3.3.1.2. A summary of the data is provided in Section 3.3.1.3.

\subsubsection{SY-101 Thermocouple History}

The waste temperature profiles in SY-101 from April 2000 through August 2000 in risers 17B and 17C (renumbered 018 and 019, respectively) clearly show the decrease in the height of the settled solids layer with time; Figure 3.15 through Figure 3.18 (data from Figures 5.9 and 5.10 of Onishi et al. [2001]). Each trace represents a single thermocouple at the specified elevation; the tank fill level during this time period was approximately 350 inches. To distinguish each thermocouple in Figure 3.15 through Figure 3.18, it is was necessary to use solid colored lines given the large number of data for each data set. Because these figures may be copied in black and white, which would eliminate the ability to identify specific curves, these figures must be considered for information only. The relatively uniform temperature profile on $4 / 2 / 00$ when mixer pump operation was stopped indicates that the tank was relatively well mixed. The subsequent upper "cluster" of temperatures indicates the forming sediment layer; the lower cluster indicates the supernatant liquid. The departure of subsequently lower thermocouples from the sediment temperature to the liquid layer temperature indicates that the solid/liquid interface is below that elevation.

The times from cessation of the mixer pump operation to when a given thermocouple attained the liquid temperature as estimated from Figure 3.15 through Figure 3.18 are provided in Table 3.3 with computed settling/compaction rates. Reasonable agreement is evident between the instruments in the two risers. The solid/liquid interface is indicated to be decreasing at a rate of nominally $6 \mathrm{in}$./day at 12 days after cessation of mixer pump operation, approximately $3 \mathrm{in}$./day at 27 days, and less than $1 \mathrm{in}$./day after approximately 90 days. At 100 inches of sediment depth, the sediment is estimated to have a solid volume fraction of 0.17 (Johnson et al. 2000), which indicates that the well-mixed condition had a solid volume fraction of approximately 0.05 (in comparison to the pre-transfer, per-dilution condition of 0.15 ; see Section 3.3.1 above).

(a) Numatec Hanford Corporation Internal Memo 82100-99-017, Process Chemistry, JF O'Rourke, to JC Person, May 3, 1999. Subject: Results of Viscosity Measurements of Tank 241-SY-101 Samples. 


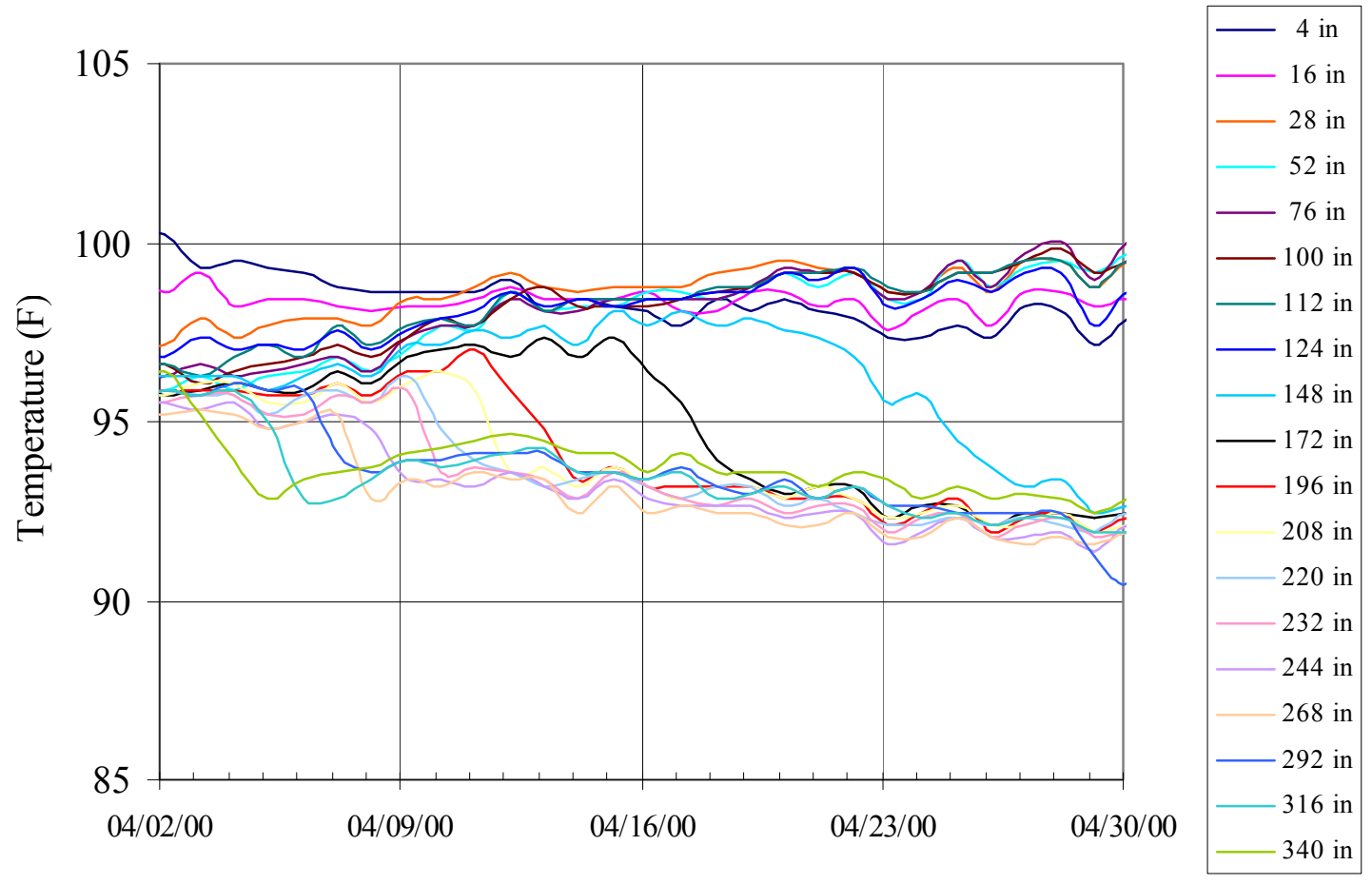

Figure 3.15. Temperature Profile History in Riser 17B, April 2000 (Information Only)

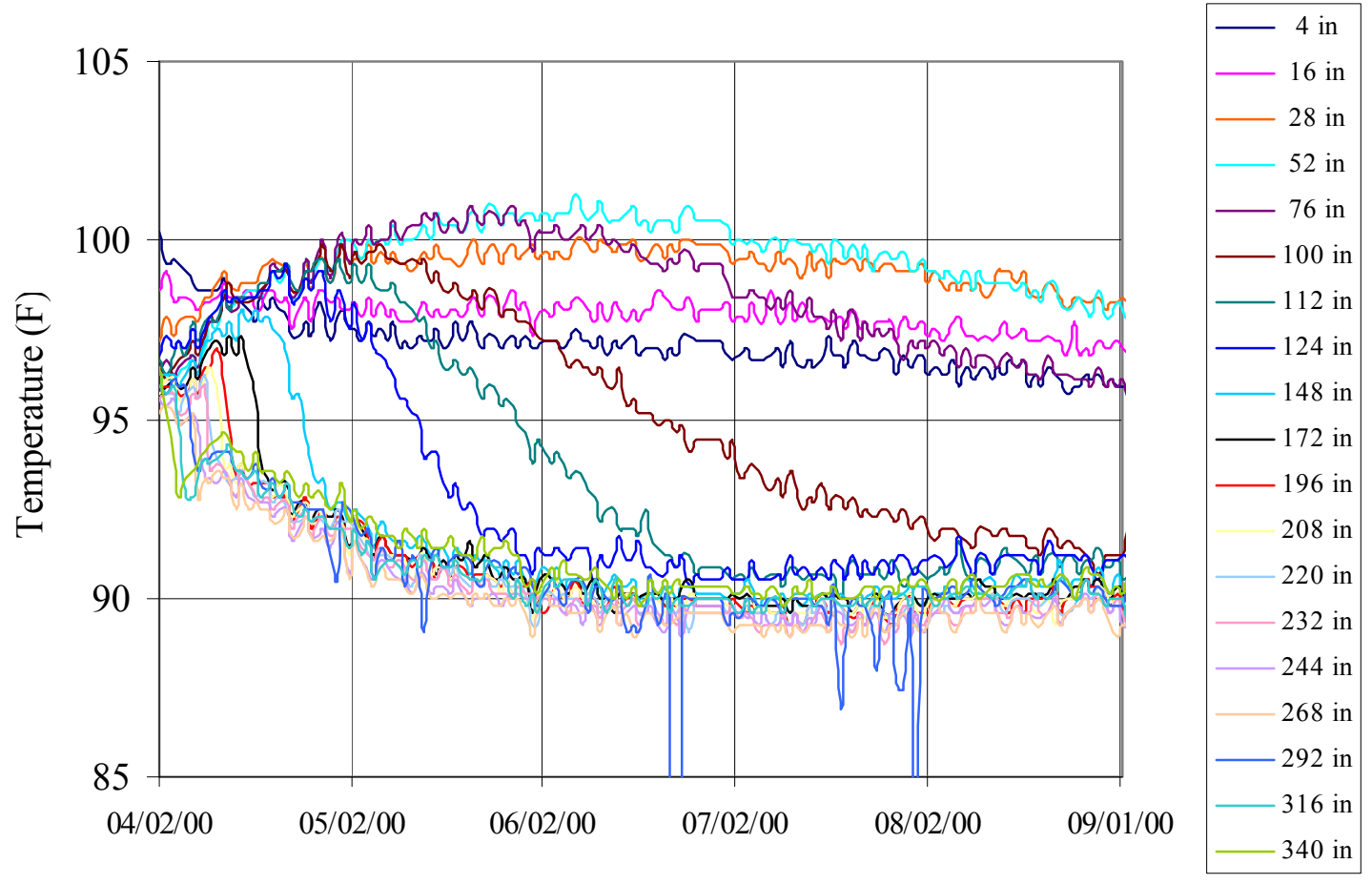

Figure 3.16. Temperature Profile History in Riser 17B, April 2000-August 2000 (Information Only) 


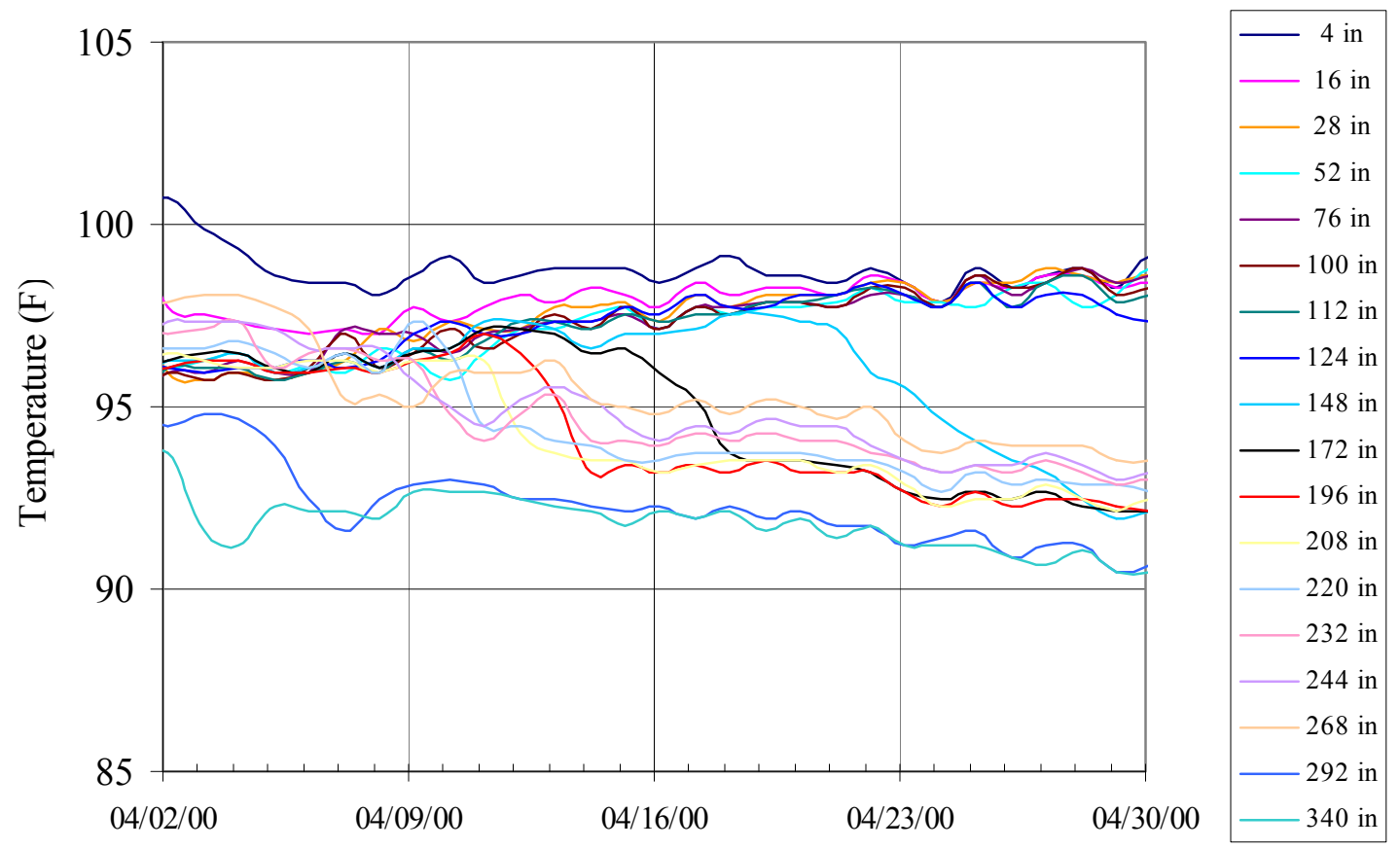

Figure 3.17. Temperature Profile History in Riser 17C, April 2000 (Information Only)

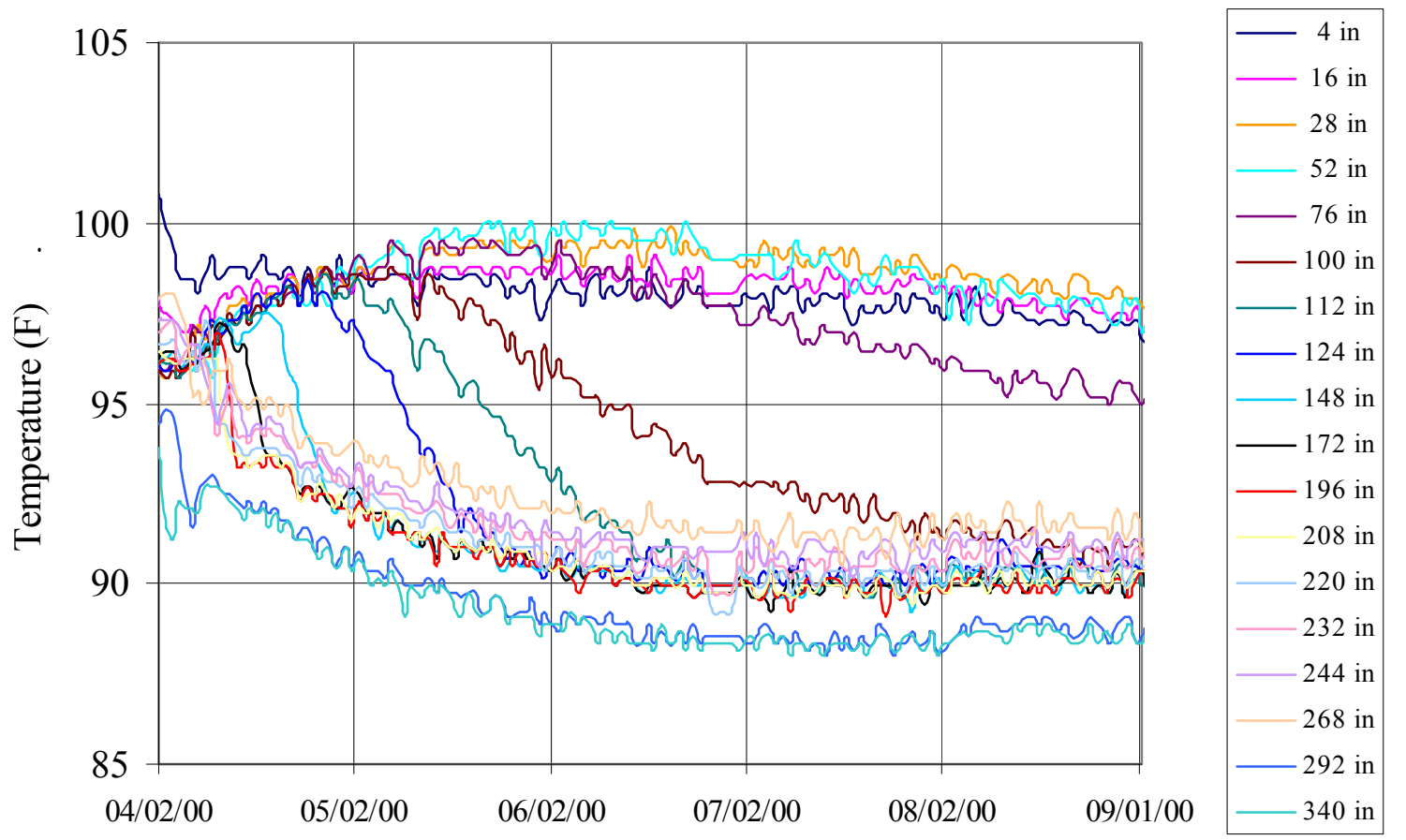

Figure 3.18. Temperature Profile History in Riser 17C, April 2000-August 2000 (Information Only) 
Table 3.3. Estimated Time for Thermocouples to Reach Supernatant Liquid Temperatures

\begin{tabular}{|c|c|c|c|c||}
\hline \multirow{2}{*}{$\begin{array}{c}\text { Thermocouple } \\
\text { Elevation (in) }\end{array}$} & \multicolumn{2}{|c|}{ Time (days) } & \multicolumn{2}{c|}{$\begin{array}{c}\text { Rate } \\
\text { (in./day) }\end{array}$} \\
\cline { 2 - 5 } & 17B & 17C & 17B & 17C \\
\hline 220 & 9 & 8 & - & - \\
\hline 208 & 10 & 10 & 12 & 6 \\
\hline 196 & 12 & 12 & 6 & 6 \\
\hline 172 & 17 & 16 & 4.8 & 6 \\
\hline 148 & 27 & 24 & 2.4 & 3 \\
\hline 124 & 57 & 47 & 0.8 & 1.0 \\
\hline 112 & 92 & 74 & 0.3 & 0.4 \\
\hline 100 & 147 & 130 & 0.2 & 0.2 \\
\hline
\end{tabular}

\subsubsection{SY-101 Zip Cord Data}

Intermittent zip cord data in SY-101 have been available after 4/2/00. The zip cords consist of a metal weight suspended on a measuring tape, similar to sludge weights, and are employed in a similar manner for solids level measurements. The zip cord plummet employed before 2004 was different than that used for the sludge weight shear strength estimates in Section 3.1.2 (see Hu 2007 regarding zip cord operation). However, the plummet geometry is such that the shear strength of the sediment required to support the zip cord plummet can also be estimated from Appendix B to be on the order of $200 \mathrm{~Pa}$. Zip cord data from riser 6 during and after the time period of interest is provided in Table 3.4. ${ }^{(\mathrm{a}, \mathrm{b})}$

Table 3.4. SY-101 Zip Cord Data

\begin{tabular}{|c|c|c||}
\hline Date & $\begin{array}{c}\text { Days Since } \\
\mathbf{4 / 2 / 0 0}\end{array}$ & $\begin{array}{c}\text { Sediment } \\
\text { Level (in) }\end{array}$ \\
\hline $4 / 4 / 2000$ & 2 & 10 \\
\hline $6 / 20 / 2000$ & 79 & 35 \\
\hline $9 / 19 / 2003$ & 1265 & 84.5 \\
\hline
\end{tabular}

\subsubsection{SY-101 Sediment Settling Summary}

The data presented in Sections 3.3.1.1 and 3.3.1.2 are combined to provide a time history of settling of the mixer-pump mobilized and water diluted SY-101 sediment in Figure 3.19. The data indicate that the sediment material in SY-101 settles and compacts from approximately 5\% solids by volume in a wellmixed condition to a sediment layer at approximately $17 \%$ solids by volume in approximately 130 days, essentially independent of radial location. The settled material reaches or exceeds a shear strength of approximately $200 \mathrm{~Pa}$ relatively slowly.

(a) Zip cord data taken from publically released spreadsheet SVF-1112 all solids R0.xls provided via e-mail from JM Conner, CH2M Hill to BE Wells, PNNL, on 3/14/08.

(b) It is assumed that the 11/02 transfers from SY-102 into SY-101 did not affect the sediment level in SY-101 given that the SY-102 transfer system employs a flex-and-float pump, i.e., initially pumped only supernatant liquid. 


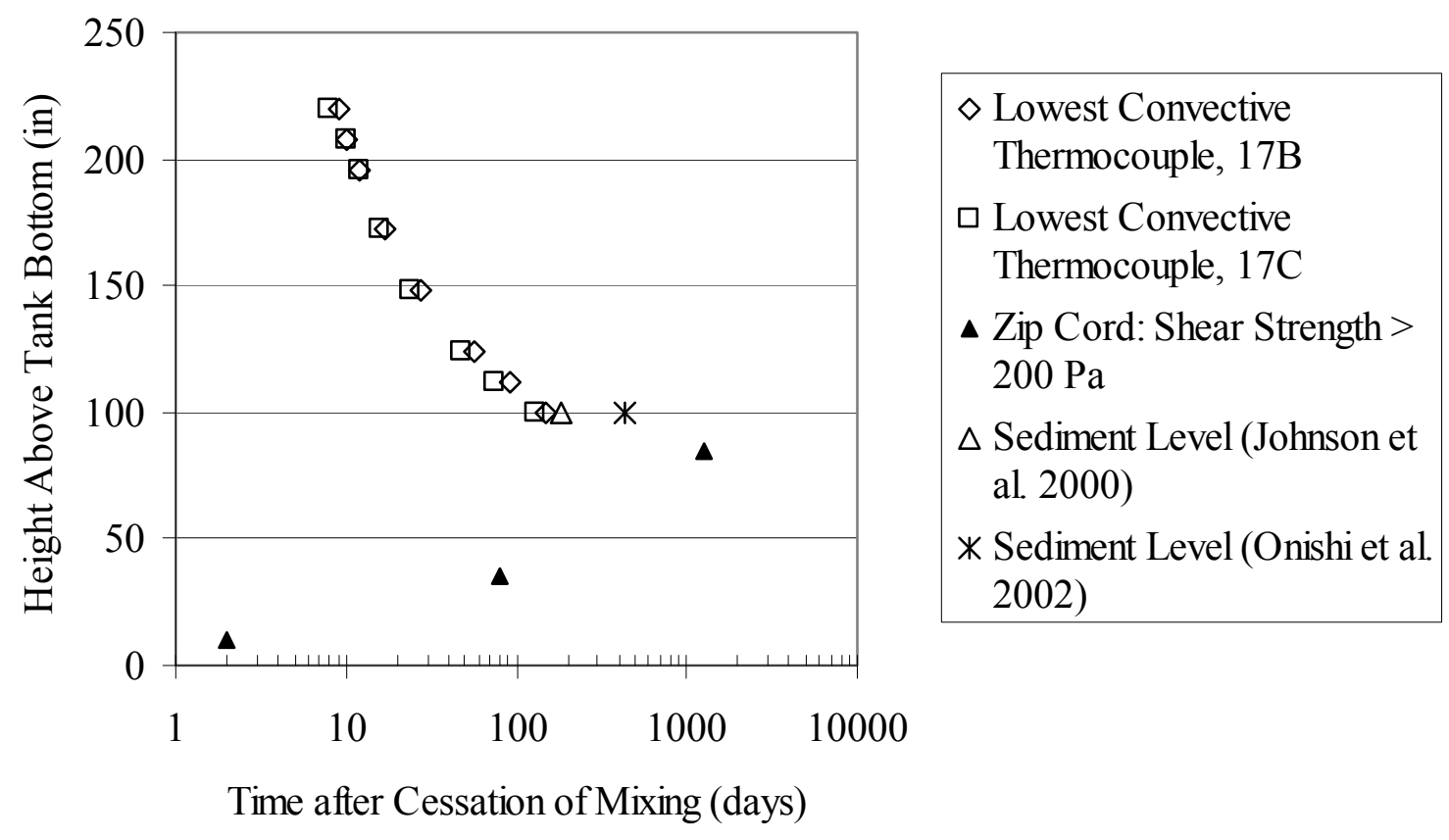

Figure 3.19. SY-101 Sediment History as a Function of Time after Mobilization and Dilution

\subsubsection{SY-102}

The sediment in SY-102 is considered during a period encompassing 12/18/99 to 3/15/00 when the tank received waste from SY-101 via three transfer campaigns. Mahoney et al. (2000) provide a summary of the SY-101 retrieval into SY-102. Given the solubility of SY-101 waste and the significant differences in the SY-101 waste as transferred (varied levels of dilution, gas content, etc.), the sediment in SY-102 is only considered with regard to the level indicated by zip cord deployment in risers 2, 3, and 21 without the estimate of received SY-101 solids volumes. Figure 3.20 provides the riser map for SY-102. ${ }^{\text {(a) }}$

To maintain operable waste levels in SY-102, waste was transferred out of SY-102 alternately with transfers from SY-101. The transfers out of SY-102 occurred 23, 16, and 19 days after the SY-101 transfers into SY-101 were completed. As the waste-removal system in SY-102 is a flex and float pump, it is unlikely that solids were removed. In addition, other wastes (U-103 interstitial liquid, U-105 interstitial liquid, etc.) were received in SY-102 during this period. ${ }^{(b)}$ The impact of other waste additions on the sediment in SY-102 is considered to be minimal given that the additions are insignificant in volume compared to the SY-101 transfers and are typically composed of dilute saltwell-pumped interstitial liquid.

Zip Cord data for SY-102 are presented in Section 3.3.2.1 and shear strength data in Section 3.3.2.2; the data are summarized in Section 3.3.2.3.

(a) TWINS: Tank Waste Information System database. http://twins.pnl.gov/twins3/twins.htm.

(b) TWINS: Tank Waste Information System database. http://twins.pnl.gov/twins3/twins.htm. 


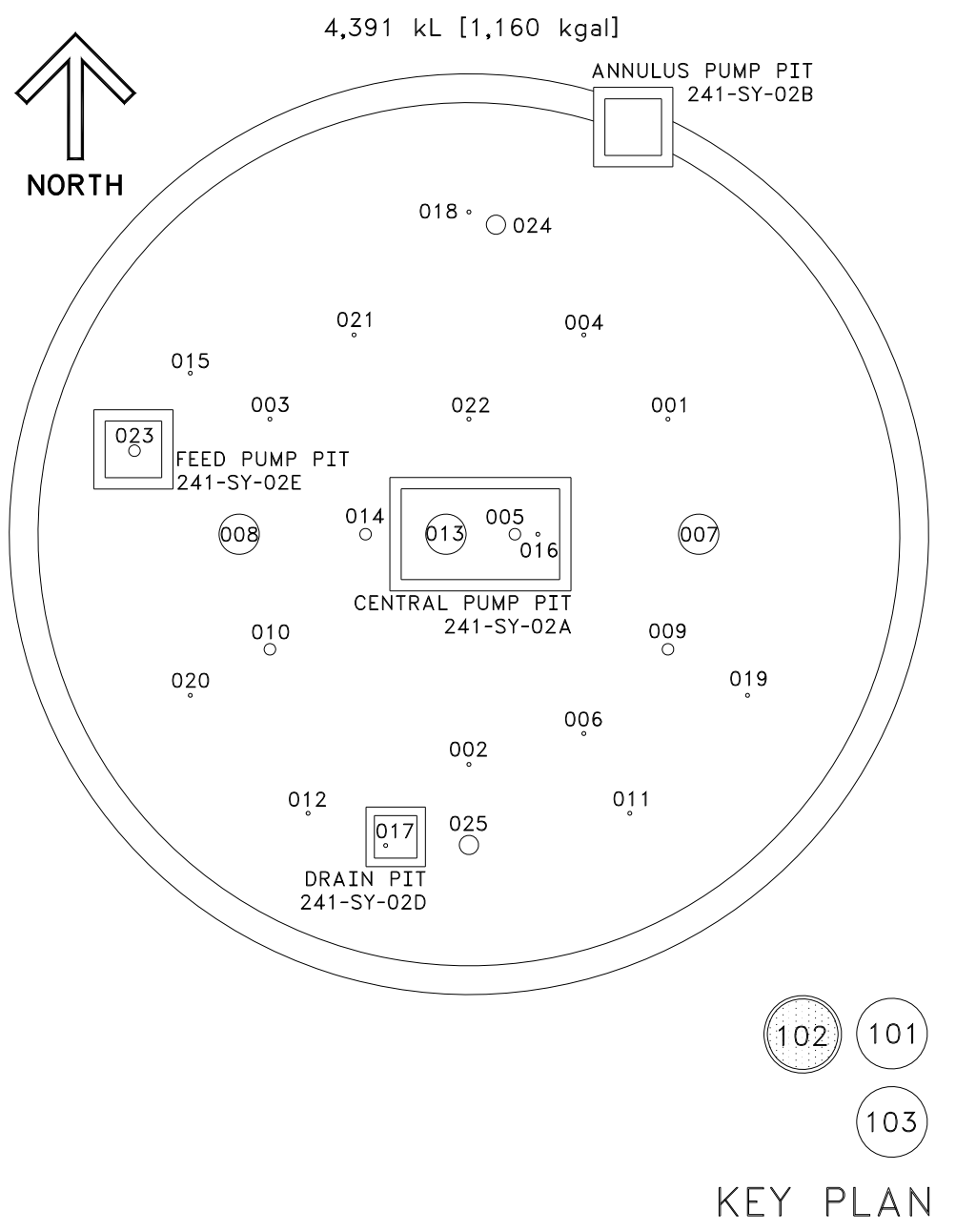

Figure 3.20. SY-102 Riser Map

\subsubsection{SY-102 Zip Cord Data}

Zip cord data are available from SY-102 before, during, and after the transfers from SY-101. A brief description of the zip cord is provided in Section 3.3.1.2; the shear strength of the sediment required to support the zip cord plummet is estimated to be on the order of $200 \mathrm{~Pa}$. Zip cord data are provided in Table 3.5. ${ }^{(a)}$

As indicated in Section 3.3.2, no attempt is made to correlate sediment volume. The transfer completion dates provided in Table 3.5 are from Mahoney et al. (2000). With an essentially constant sediment level after 40 days from the completion of the final transfer, the mixed, diluted, and transferred sediment from SY-101 apparently settled within the 40-day period to a condition with a shear strength equal to or greater than $200 \mathrm{~Pa}$.

(a) Zip cord data taken from publically released spreadsheet SVF-1112 all solids R0.xls provided via e-mail from JM Conner, CH2M Hill to BE Wells, PNNL, on 3/14/08. 
Table 3.5. SY-102 Zip Cord Data

\begin{tabular}{||c|c|c|c|c||}
\hline \hline $\begin{array}{c}\text { Transfer } \\
\text { Completion } \\
\text { Date }\end{array}$ & Zip Cord Date & $\begin{array}{c}\text { Time Since } \\
\text { Most Recent } \\
\text { SY-101 } \\
\text { Transfer } \\
\text { (days) }\end{array}$ & Riser & $\begin{array}{c}\text { Sediment } \\
\text { Level (in.) }\end{array}$ \\
\hline $12 / 19 / 1999$ & $9 / 9 / 1999$ & - & 2 & 10.3 \\
\hline & $1 / 10 / 2000$ & 22 & 3 & 11.5 \\
\hline $1 / 27 / 2000$ & $2 / 25 / 2000$ & 29 & 3 & 26.5 \\
\hline $3 / 2 / 2000$ & $4 / 11 / 2000$ & 40 & 3 & 40.5 \\
\hline & $10 / 3 / 2000$ & 215 & 3 & 40.5 \\
\hline & $10 / 10 / 2000$ & 222 & 21 & 40.1 \\
\hline & $8 / 15 / 2001$ & 531 & 3 & 43.5 \\
\hline
\end{tabular}

\subsubsection{SY-102 Sediment Shear Strength}

The sediment shear strength in SY-102 was measured with a shear vane using waste samples from Core 284 in riser 021 . $^{\text {(a) }}$ This core was taken 235 days after the final waste transfer from SY-101; there is minimal difference in the zip cord-indicated sediment level over this time interval; Table 3.5.

The SY-102 shear strength data are provided as a function of depth in the sediment in Figure 3.21. The depth in the sediment is determined via the TWINS core profile as the midpoint of the core segments. ${ }^{(b)}$ In the limited data set, there is no indication that the shear strength of the "new" sediment material from SY-101 is significantly different from that of the "original" SY-102 sediment (the initial sediment level in SY-102 was approximately 10 inches; see Table 3.5). The median of the measurements is $279 \mathrm{~Pa}$.

\subsubsection{SY-102 Sediment Settling Summary}

The time history of settling of the mixed, diluted, and transferred sediment from SY-101 in SY-102 is provided in Figure 3.22. It is indicated that the sediment material settled rapidly and has a shear strength of approximately $200 \mathrm{~Pa}$ up to $304 \mathrm{~Pa}$.

(a) TWINS: Tank Waste Information System database. http://twins.pnl.gov/twins3/twins.htm.

(b) AY-102 Core Profile, TWINS: Tank Waste Information System database. http://twins.pnl.gov/twins3/twins.htm. 


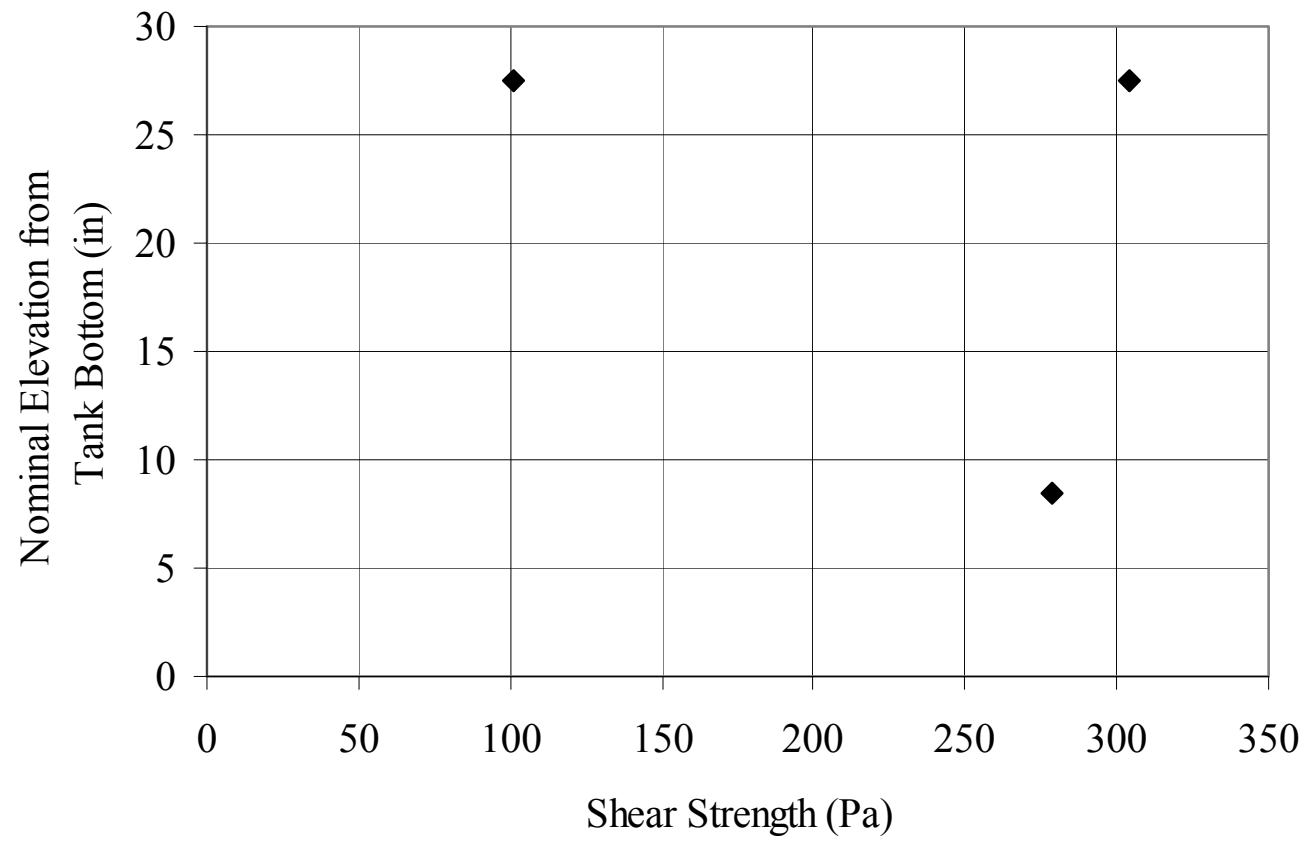

Figure 3.21. SY-102 Shear Strength 235 Days Post SY-101 Transfer

- Zip Cord: Shear Strength >200 Pa, < $304 \mathrm{~Pa}$ (may be time dependent) - - - - Core 284

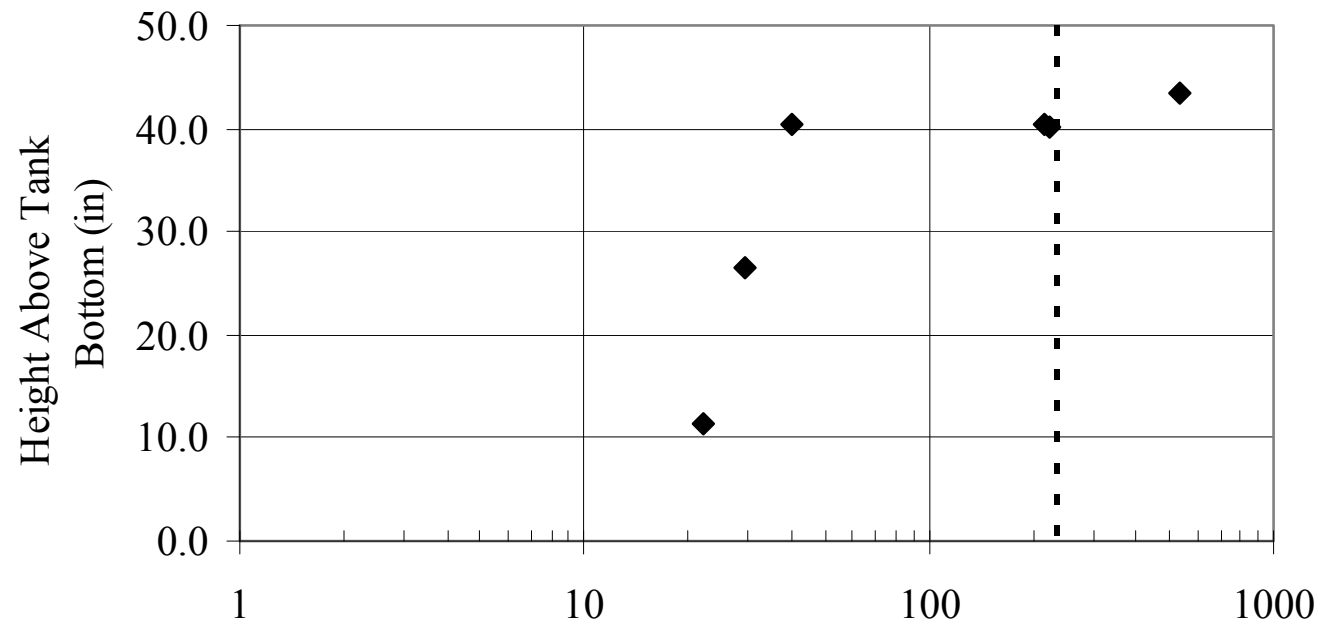

Time After Most Recent SY-101 Transfer (days)

Figure 3.22. SY-102 Sediment Level as a Function of Time Since Most Recent SY-101 Transfer (see Table 3.3) 


\subsection{PJM Mixing of Cohesive Layers}

PJM mixing of non-Newtonian (cohesive) materials that have a shear strength has been studied extensively. Many of the studies focused on quantifying mixing behavior and performance (Bontha et al. 2000, 2003a, 2003b; Enderlin et al. 2003; Johnson et al. 2003; Bates et al. 2003; Bamberger et al. 2005; Meyer et al. 2005; Johnson et al. 2005; Poloski et al. 2005; Bontha et al. 2007; and Kurath et al. 2007), and other studies focused on gas retention and release, but also provided improved understanding of PJM mixing performance (Stewart et al. 2007, 2006a, 2006b; Bontha et al. 2005; and Russell et al. 2005). These previous PJM studies were conducted with non-Newtonian simulants that did not settle, but they still provided a significant basis for understanding and estimating the performance of PJMs for mobilizing settling layers of cohesive materials. These previous studies were conducted in vessels that were filled with simulants that had uniform non-Newtonian fluid properties throughout the vessel, with the exception of the study by Bontha et al. (2000) that used a chemical simulant of AZ-101 that settled.

The general nature of the PJM mixing was that near the jets, the mobilization of the slurry was more intense, and the capability of the jet to mobilize the slurry decreased with distance from the jet. Stagnant regions in the slurry were observed when the jet was not sufficiently strong to mobilize the slurry, and the size of these regions depended on the mixing system, operational parameters, and slurry rheology. A key behavior that was modeled and evaluated with experimental results was the formation of a cavern within which the slurry was mobilized by the PJMs. The previous work also focused on determining the conditions when this cavern would reach the top, or break through, the upper surface of the slurry.

The objective of this section is to predict the waste properties of settled cohesive layers, specifically the shear strength and thickness, which can be mobilized by PJMs based on analyses of existing data and models from previous studies. Jet mixing of cohesive materials has been studied for both PJM and horizontal jets, but some assumptions and simplifications are needed to apply these results to PJM mixing of cohesive layers. Figure 4.1 shows the range of configurations for settled cohesive layers that can be expected in WTP vessels. For feeds with solids loading near $15 \mathrm{wt} \%$ undissolved solids, and assuming solids settle only a small amount and create a slurry with a shear strength at this solids loading, the waste configuration will be a vessel essentially full with the cohesive layer. This configuration is shown in Figure 4.1A. For lower solids loading, or if the waste forms a layer at a higher fraction of solids, a configuration of a thick cohesive layer of settled waste will occur as shown in Figure 4.1B. At much lower solids loading or with very compact settled layers, the thin-layer configuration shown in Figure $4.1 \mathrm{C}$ will occur. Each of these configurations will be addressed by the models presented below.
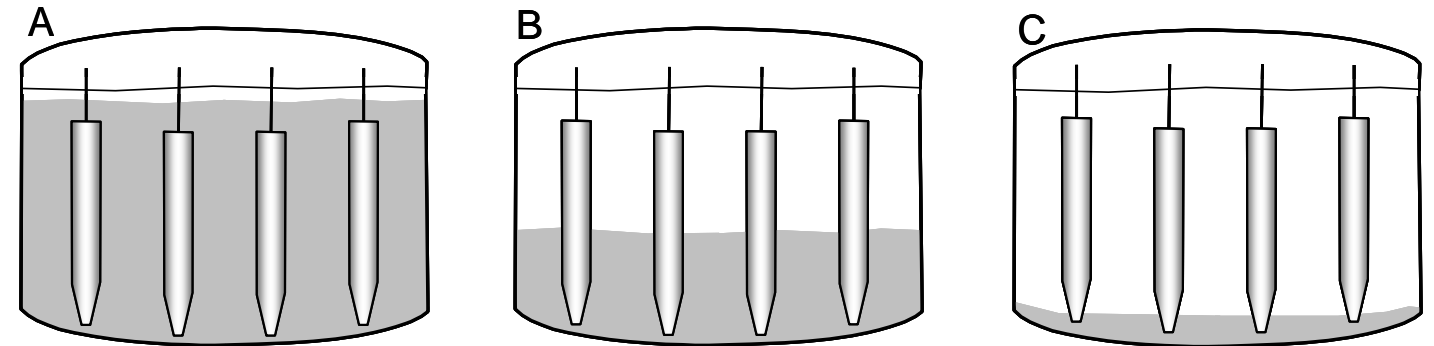

Figure 4.1. Representative Configurations for Settled Layers of Cohesive Waste: A) Full Tank, B) Thick Layer, and C) Thin Layer 


\subsection{Cavern Breakthrough Model}

In the study by Bamberger et al. (2005), the mechanism of cavern breakthrough due to upwelling in the center of a ring of PJMs was described, and testing results at multiple velocity scales with a range of simulants were reported. The general configuration of cavern breakthrough is depicted in Figure 4.2. The upward velocity where the jets from multiple PJMs meet in the center and where there is upwelling of mobilized slurry in the center of the central ring is the notable feature of this mixing mechanism. While the center upwelling was a prominent feature in previous studies and is expected in settled layers, center breakthrough has not yet been observed in the settled layer configuration. The objective of this section is to model the center upwelling and the resulting cavern height, $\mathrm{H}_{\mathrm{C}}$.

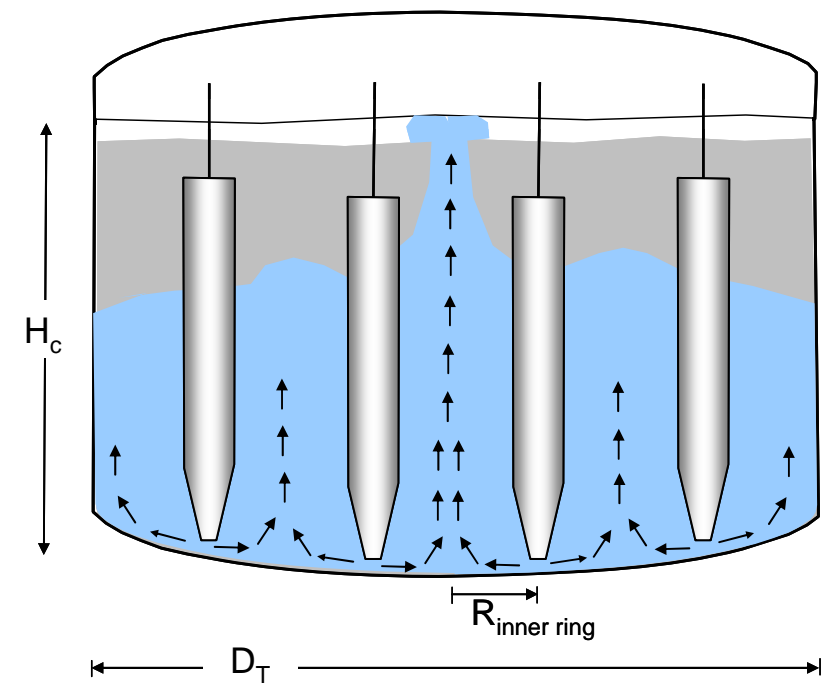

Figure 4.2. Cavern Breakthrough due to Central Upwelling in the Center of a Ring of PJMs

Bamberger et al. (2005) $)^{(a)}$ presented a correlation for cavern height, in terms of a number of parameters, with the coefficients determined from single-jet experiments with Laponite clay simulants. Figure 4.3 shows the cavern height and tank diameter with a single jet. For a steady jet, or a pulsed jet in the limit of large pulse fractions, the correlation is the following

$$
\frac{\mathrm{H}_{\mathrm{C}}}{\mathrm{D}_{\mathrm{T}}}=1.67 \frac{\mathrm{d}_{0}}{\mathrm{D}_{\mathrm{T}}} \mathrm{Re}_{\tau}^{1 / 2}-\frac{1}{2}
$$

In this equation, $H_{C}$ is the cavern height, $d_{0}$ is the jet diameter, $D_{T}$ is the tank diameter, and the yield Reynolds number, $\mathrm{Re}_{\tau}$, is defined as

$$
\operatorname{Re}_{\tau}=\frac{\rho \mathrm{u}_{0}^{2}}{\tau_{\mathrm{s}}}
$$

As discussed in Bamberger et al. (2005), Equation 4.1 is a valid approximation when the $\operatorname{Re}_{\tau}$ is small compared to $V_{P} / d_{0}{ }^{3}$, where $V_{P}$ is the pulse volume. This limiting behavior is for when the effects of

(a) See Equation 3.31 and Figures 3.7 and 3.9 of Bamberger et al. (2005). 
pulsation are negligible and the maximum cavern height from steady jets occurs. When pulsation is important, the cavern height becomes smaller (Bamberger et al., 2005).

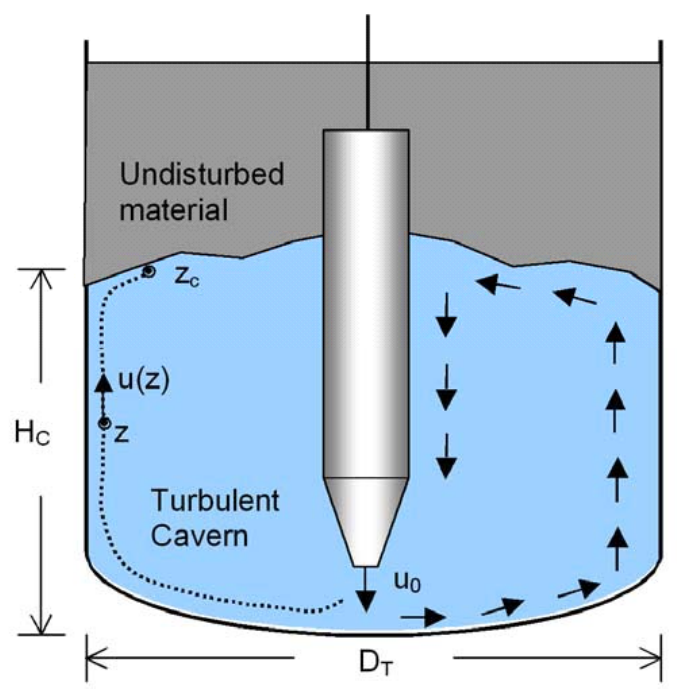

Figure 4.3. A Single Jet in a Vessel with a Non-Newtonian Slurry as Depicted by Bamberger et al. (2005)

This single jet model can be modified to predict the cavern height created inside the central ring of a multi-jet PJM mixing system. The first modification is that each PJM operates primarily within only a portion of the vessel, so $\mathrm{D}_{\mathrm{T}}$ in Equation 4.1 needs to be replaced with an effective diameter. For the jets in the inner ring, as shown in Figure 4.2, the effective tank diameter can be approximated as $2 \mathrm{R}_{\text {inner ring. }}$. The second modification is to note that the upward velocity in the center of the inner ring of PJMs has a contribution from all of the inner ring jets. A simple model can be used to determine how to combine the contribution of multiple jets into a jet with an effective jet diameter that creates the upward velocity and flow. If multiple adjacent jets are acting in the same direction and at the same velocity, the combination of the individual jets is an effective jet with the same velocity but with a total flow that is the sum of all the individual jets. If the volumetric flow from each jet is $\mathrm{u}_{0} \pi \mathrm{d}_{0}{ }^{2} / 4$, the diameter of a single effective jet that has the same total flow is $\mathrm{N}_{\mathrm{j}-\mathrm{CR}}^{1 / 2} \mathrm{~d}_{0}$, where $\mathrm{N}_{\mathrm{j}-\mathrm{CR}}$ is the number of jets. The third modification is to replace the coefficient 1.67 that was determined from single-jet Laponite tests with a coefficient that is determined from cavern breakthrough tests. Taking Equation 4.1 and replacing $\mathrm{D}_{\mathrm{T}}$ with $2 \mathrm{R}_{\text {inner ring }}, \mathrm{d}_{0}$ with $\mathrm{N}_{\mathrm{j}-\mathrm{CR}}^{1 / 2} \mathrm{~d}_{0}$ and 1.67 with an unknown coefficient $\mathrm{C}$ gives the following.

$$
\mathrm{H}_{\mathrm{C}}=\mathrm{Cd}_{0} \mathrm{~N}_{\mathrm{j}-\mathrm{CR}}^{1 / 2} \mathrm{Re}_{\tau}^{1 / 2}-\mathrm{R}_{\text {inner ring }}
$$

This equation can now be scaled by the actual tank diameter, $\mathrm{D}_{\mathrm{T}}$, to give the following:

$$
\frac{\mathrm{H}_{\mathrm{C}}}{\mathrm{D}_{\mathrm{T}}}=\mathrm{C} \frac{\mathrm{d}_{0}}{\mathrm{D}_{\mathrm{T}}} \mathrm{N}_{\mathrm{j}-\mathrm{CR}}^{1 / 2} \mathrm{Re}_{\tau}^{1 / 2}-\frac{\mathrm{R}_{\text {inner ring }}}{\mathrm{D}_{\mathrm{T}}}
$$


The coefficient $\mathrm{C}$ can now be determined from breakthrough experiments. Bamberger et al. (2005) reported results for cavern breakthrough for PJM tests with a range of clay mixtures and vessels. For determining an estimate for $\mathrm{C}$, the test results for a mixture of kaolin and bentonite clays conducted in the 336 Large-Scale 4PJM Test Stand are used because this clay mixture was the most realistic simulant, and the test stand was the largest used. Table 4.1 shows the parameters and specific test data from various sources in Bamberger et al. (2005). The test data reported $\mathrm{Re}_{\tau}$ when breakthrough just occurred from central upwelling, which is Mode 2 mixing as shown in Figure 5.1 of Bamberger et al. (2005). Mode 3 mixing, which is considered minimal mixing, occurs at a higher velocity, but specific test data are not available for Mode 3 mixing. There are no specific data to estimate the additional jet velocity needed to achieve Mode 3 mixing in comparison to Mode 2 (breakthrough), but a 50\% higher velocity was assumed as a reasonable estimate. In Table $4.1, \operatorname{Re}_{\tau}$ for this minimal mixing is given based on this assumption. With this value for $\mathrm{Re}_{\tau}$, the coefficient $\mathrm{C}$ is determined to be 0.39 , and the cavern breakthrough correlation, which assumes the limiting steady-jet behavior, becomes

$$
\frac{\mathrm{H}_{\mathrm{C}}}{\mathrm{D}_{\mathrm{T}}}=0.39 \frac{\mathrm{d}_{0}}{\mathrm{D}_{\mathrm{T}}} \mathrm{N}_{\mathrm{j}-\mathrm{CR}}^{1 / 2} \operatorname{Re}_{\tau}^{1 / 2}-\frac{\mathrm{R}_{\text {inner ring }}}{\mathrm{D}_{\mathrm{T}}}
$$

Table 4.1. Test Parameters and Results Used to Estimate the Coefficient $\mathrm{C}$

\begin{tabular}{|c|c|l||}
\hline Parameter & Value & \multicolumn{1}{|c|}{$\begin{array}{c}\text { Data Source in } \\
\text { Bamberger et al. (2005) }\end{array}$} \\
\hline $\begin{array}{c}\mathrm{Re}_{\tau} \\
\text { at breakthrough }\end{array}$ & 1,600 & $\begin{array}{l}\text { Table 5.5 } \\
\text { Average of "Peak Average Re" } \\
\text { values for L18 and L19\&L-20 }\end{array}$ \\
\hline $\mathrm{D}_{\mathrm{T}}$ & $12.75 \mathrm{ft}$ & Section 4.1.1 (internal diameter) \\
\hline $\mathrm{d}_{0}$ & 4 inches & Section 4.1.1 \\
\hline $\mathrm{R}_{\text {inner ring }}$ & $3.99 \mathrm{ft}$ & Average radius from Figure A.2 \\
\hline $\mathrm{N}_{\mathrm{j}-\mathrm{CR}}$ & 4 & Section 4.1.1 \\
\hline $\mathrm{H}_{\mathrm{C}} / \mathrm{D}_{\mathrm{T}}$ & 0.9 & $\begin{array}{l}\text { Table 5.5 } \\
\text { H/D } \mathrm{D}_{\mathrm{T}} \text { value for L18 and L19\&L-20 }\end{array}$ \\
\hline $\begin{array}{c}\text { Re } \\
\text { for minimal } \\
\text { mixing }\end{array}$ & 3600 & $\begin{array}{l}\text { Calculated Values } \\
\text { Assumes minimal mixing occurs at } \\
\text { a velocity that is 1.5 times the } \\
\text { velocity for breakthrough }\end{array}$ \\
\hline $\mathrm{C}$ & 0.39 & Calculated from Equation 4.4 \\
\hline
\end{tabular}

The cavern breakthrough correlation given by Equation 4.5 was developed specifically for when the central cavern height is at the full depth of the waste, and this is where the correlation is most accurate. Equation 4.5 does predict how the cavern height varies with the mixing parameters, but the purpose of this correlation is to predict breakthrough sufficient to give Mode 3 mixing.

Figure 4.4 shows predictions for cavern height as a function of shear strength from this cavern breakthrough correlation with parameters for WTP vessel HLP-22. As stated above, this correlation 
assumes the limiting behavior of steady jets, which give the maximum cavern height. The model is based on having a uniform density slurry, which does not occur with settling slurries, and the impact of this assumption has not yet been determined. Results are shown for jet velocities of $8 \mathrm{~m} / \mathrm{s}$ and $12 \mathrm{~m} / \mathrm{s}$. With the $8 \mathrm{~m} / \mathrm{s}$ jet, the results show that breakthrough and full-tank mobilization occur when the shear strength is below about $4.8 \mathrm{~Pa}$. With a $12 \mathrm{~m} / \mathrm{s}$ jet, shear strengths up to $11 \mathrm{~Pa}$ can be mobilized. At higher strengths, cavern breakthrough and full-tank mobilization do not occur. Figure 4.3 also shows how the cavern breakthrough model predicts that it is easier to mix settled layers as the layers become less deep. One example identified in Figure 4.4 is that the strength must be below about $13 \mathrm{~Pa}$ to mobilize a settled layer that is half the depth of the full tank for $8 \mathrm{~m} / \mathrm{s}$ jets and less than $30 \mathrm{~Pa}$ for $12 \mathrm{~m} / \mathrm{s}$ jets.

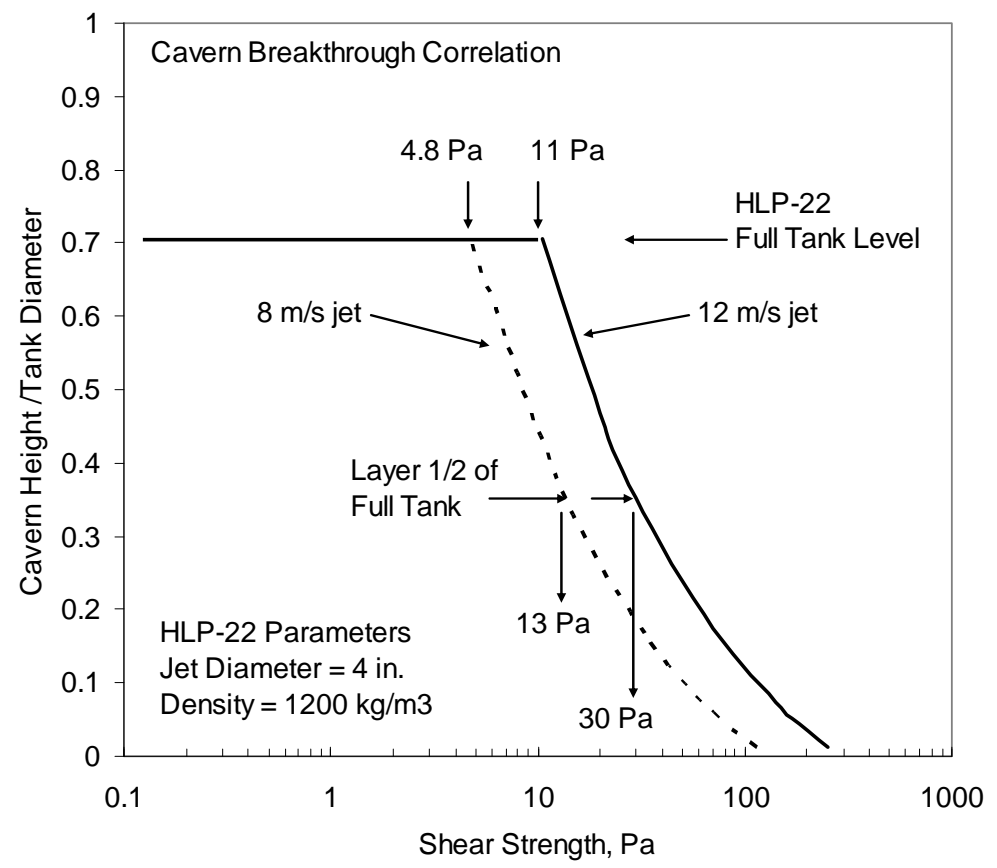

Figure 4.4. Cavern Breakthrough Correlation Predications for Cavern Height and Breakthrough, Which Assumes the Limiting Steady-Jet Behavior and a Uniform Slurry Density, as a Function of Shear Strength for HLP-22 Parameters and a Slurry Density of $1200 \mathrm{~kg} / \mathrm{m}^{3}$

Table 2.1 gives estimates for the range of shear strength of settled layers that could occur in WTP process vessels, depending on how long the layer has been allowed to settle. Unfortunately, there are no estimates for very recently settled waste ( 0 to 10 hours) that can be used to compare with the model predictions in Figure 4.4. For waste settled 10 to 24 hours, Table 2.1 gives $30 \mathrm{~Pa}$ as a typical value and $200 \mathrm{~Pa}$ as a reasonable, though uncertain, upper bound. The model results in Figure 4.4 show that $12-\mathrm{m} / \mathrm{s}$ jets would not mobilize a 200-Pa layer if it filled half the vessel, but a thin layer of 200-Pa material would be mobilized. The worst-case shear strength is for compacted waste, and Table 2.1 gives estimates for these strengths.

\subsection{Cavern Height Model}

The single jet model for cavern height in Laponite clay developed by Bamberger et al. (2005), and given by Equation 4.1, can be modified by an alternate method to predict a multi-PJM mixing system. In this alternate method, two modifications are needed. First, $\mathrm{D}_{\mathrm{T}}$ in the single jet model is replaced with an 
effective diameter of $\mathrm{D}_{\mathrm{T}} / \mathrm{N}_{\mathrm{j}}^{1 / 2}$, where this effective diameter corresponds to the average equivalent circular area for each PJM in a tank with $\mathrm{N}_{\mathrm{j}}$ PJMs. The second modification is to adjust the coefficient of 1.67, which was determined for Laponite clay, to represent kaolin/bentonite clay behavior, which is a more realistic simulant. The same tests used in Table 4.1 can also be used to make this adjustment. Table 4.2 shows $\operatorname{Re}_{\tau}$ at breakthrough for kaolin/bentonite clay and Laponite clay. The kaolin/bentonite clay required a $\operatorname{Re}_{\tau}$ about 5-fold larger than for Laponite, so $\operatorname{Re}_{\tau}$ in Equation 4.1 is replaced with $\operatorname{Re}_{\tau} / 5$. Taking Equation 4.1 and replacing $\mathrm{D}_{\mathrm{T}}$ with $\mathrm{D}_{\mathrm{T}} / \mathrm{N}_{\mathrm{j}}^{1 / 2}$ and $\mathrm{Re}_{\tau}$ with $\mathrm{Re}_{\tau} / 5$ gives the following cavern height correlation.

$$
\frac{\mathrm{H}_{\mathrm{C}}}{\mathrm{D}_{\mathrm{T}}}=\frac{1.67}{5^{1 / 2}}\left(\frac{\mathrm{d}_{0}}{\mathrm{D}_{\mathrm{T}}}\right) \operatorname{Re}_{\tau}^{1 / 2}-\frac{1}{2 \mathrm{~N}_{\mathrm{j}}^{1 / 2}}
$$

Similar to Equation 4.5, this cavern height correlation assumes the limiting steady-jet behavior that gives the maximum cavern height.

Table 4.2. Test Parameters used to Determine the Cavern Height Model Coefficient

\begin{tabular}{||c|c|c|l||}
\hline \hline Parameter & Simulant & Value & \multicolumn{1}{c||}{$\begin{array}{c}\text { Data Source in } \\
\text { Bamberger et al. (2005) }\end{array}$} \\
\hline $\begin{array}{c}\operatorname{Re}_{\tau} \\
\text { at breakthrough }\end{array}$ & $\begin{array}{c}\text { Kaolin/Bentonite } \\
\text { Clay }\end{array}$ & 1,600 & $\begin{array}{l}\text { Table 5.5 } \\
\text { Average of "Peak Average Re" } \\
\text { values for L18 and L19\&L-20 }\end{array}$ \\
\hline $\begin{array}{c}\operatorname{Re}_{\tau} \\
\text { at breakthrough }\end{array}$ & Laponite Clay & 325 & $\begin{array}{l}\text { Table 5.5 } \\
\text { Average of "Peak Average Re" } \\
\text { values for L2 and L4 }\end{array}$ \\
\hline $\begin{array}{c}\text { Matio of } \mathrm{Re}_{\tau} \\
\text { Coefficient }\end{array}$ & & $\sim 5$ & Calculated Values \\
\hline \hline
\end{tabular}

The coefficient of 1.67 in Equations 4.6 and 4.1 was determined by fitting data over a range of cavern heights. In comparison, the coefficient in Equation 4.5 was determined from breakthrough data. When the coefficients in Equation 4.6 are compared to the cavern breakthrough model given by Equation 4.5, it is easy to show that these two models are effectively identical for HLP-22 parameters. This agreement of different approaches to modifying the single jet model shows that the results are consistent.

\subsection{Thin Cohesive Layer Models}

Figure 4.5 depicts a thin cohesive layer being mobilized and mixed by PJMs. In this waste configuration, the jet only needs to mobilize waste radially outward from the PJM, and not vertically, because the vertical distance the jet needs to travel is insignificant.

For thin cohesive layers, correlations can be developed from both previous PJM results and from studies of waste mobilization in Hanford DSTs using steady horizontal jets. For thin layers, the single jet 
correlation from Bamberger (2005), Equation 4.1, can be rearranged to determine the effective cleaning radius (ECR) around a PJM. The PJM correlation for Laponite clay, assuming large pulse volumes, is the following.

$$
\frac{\mathrm{ECR}}{\mathrm{d}_{0}}=1.67 \mathrm{Re}_{\tau}^{1 / 2}
$$

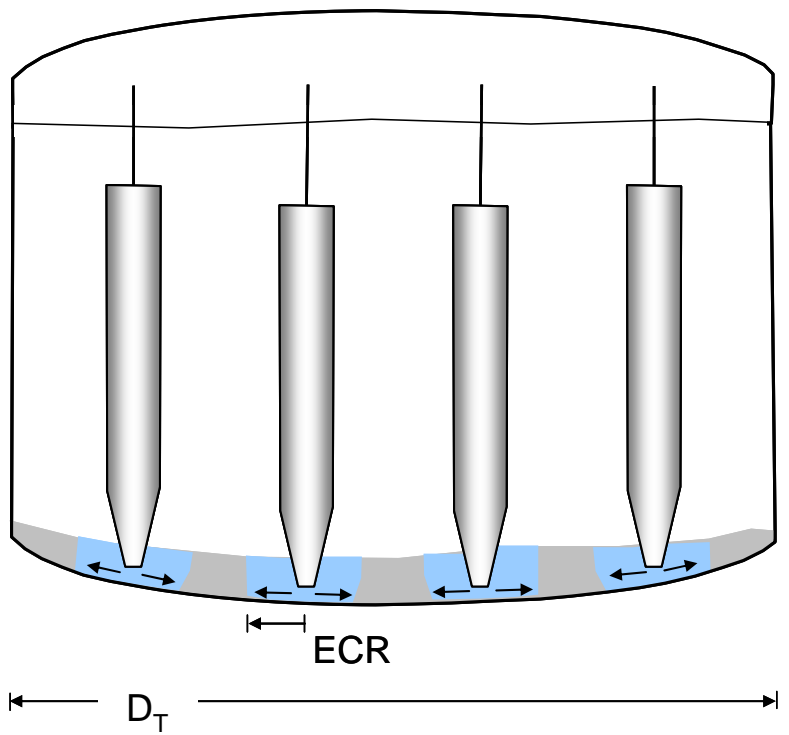

Figure 4.5. PJMs Mobilizing Cohesive Layers around each PJM

Similar to Section 4.2, an improved correlation can be obtained by adjusting the coefficient 1.67 to represent kaolin/bentonite clay behavior. There are no cleaning radius data directly comparing Laponite and kaolin/bentonite clays, so the same adjustment used in Section 4.2 will be used here. Reducing the coefficient from 1.67 to $1.67 / 5^{1 / 2}$ in Equation 4.7 gives a second result for thin layers, which will be called the PJM correlation scaled to clay.

$$
\frac{\mathrm{ECR}}{\mathrm{d}_{0}}=\frac{1.67}{5^{1 / 2}} \operatorname{Re}_{\tau}^{1 / 2}
$$

A series of studies were performed by Powell et al. (1995a, 1995b, 1997) to develop correlations to predict the ECR of jet mixer pumps in Hanford waste storage tanks. In these studies, jets were directed horizontally from the center of a tank, and the nozzle was a few jet nozzle diameters above the tank bottom. This geometry is different from a typical PJM geometry where the jet is directed downward, impinges on the tank bottom, and is re-directed outward in a radial direction from the point of impingement. There are studies in the literature that have described the behavior of horizontal circular jets and also impinging circular jets, and these studies provide the relationships that allow the horizontal jet results of Powell to be scaled to the impinging jet geometry of a PJM. The method for doing this scaling is summarized below. 
Powell et al. (1997) summarized the key findings, recommended correlations from the original studies, and recommended the following correlation for the ECR with the parameters as defined in this section:

$$
\operatorname{ECR}(\mathrm{cm})=4.0 \mathrm{u}_{0} \mathrm{~d}_{0} \tau_{\mathrm{s}}^{-0.46}
$$

It is important to note that cgs units must be used in this correlation (ECR in $\mathrm{cm}$, jet diameter $\mathrm{d}_{0}$ in $\mathrm{cm}$, undisturbed sludge strength $\tau_{\mathrm{s}}$ in dynes $/ \mathrm{cm}^{2}$, and jet velocity $\mathrm{u}_{0}$ in $\mathrm{cm} / \mathrm{s}$ ). Based on the uncertainty in the measurements, Powell et al. (1997) recommended using a proportionality coefficient of 3.0 if a conservative (lower) estimate of the ECR was needed, rather than using the 4.0 that best fit the data. For predicting PJM results, we will use the correlation with a coefficient of 4.0. The correlation given by Equation 4.9 has dimensions, and specifically has a $\tau_{\mathrm{s}}^{-0.46}$ dependence that is slightly different from the shear strength dependence of $\tau_{\mathrm{s}}^{-0.5}$ given in Equations 4.7 and 4.8 via the yield Reynolds number shown as $\mathrm{Re}_{\tau}^{1 / 2}$. One approach for obtaining a direct comparison of Powell's correlation with the PJM correlations is to create a correlation from Powell's results that has a shear-strength dependence of $\tau_{\mathrm{s}}^{-0.5}$ and then rewrite the correlation in dimensionless form. The following correlation does this and exactly matches Equation 4.9 when the shear strength is $1000 \mathrm{~Pa}$ :

$$
\frac{\mathrm{ECR}}{\mathrm{d}_{0}}=5.78 \mathrm{Re}_{\tau}^{1 / 2}
$$

In determining Equation 4.10, a density of $1.0 \mathrm{~g} / \mathrm{cm}^{3}$ was used because water jets were used by Powell in developing Equation 4.9. In comparison to Equation 4.9 of Powell et al. (1997), Equation 4.10 predicts an ECR that is larger by $10 \%$ at $100 \mathrm{~Pa}$ and smaller by $9 \%$ at $10,000 \mathrm{~Pa}$. This is a small difference considering the uncertainty in the data used to create the original correlation.

Equation 4.9 is for a horizontal jet and must be further modified to account for the different geometry of a downward impinging jet, such as a steady PJM jet, in comparison to a horizontal jet. To modify Powell's correlation to represent a downward impinging jet, we begin with the derivation of Equation 4.1 presented in Bamberger et al. (2005). Equation 3.8 of Bamberger et al. (2005), which refers to Rajaratnam (1976), relates the maximum time averaged velocity $\mathrm{u}(\mathrm{z})$ at a distance $\mathrm{z}$ from the jet as follows:

$$
\mathrm{u}(\mathrm{z})=\mathrm{c}_{\mathrm{J}} \frac{\mathrm{u}_{0} \mathrm{~d}_{0}}{\mathrm{z}}
$$

For a Newtonian turbulent circular free jet the coefficient $c_{J}$ is about 5 to 6 (in the remainder of this discussion, a factor of 5 will be used).

Beltaos and Rajaratnam (1977) analyzed an impinging jet and found that the relationship between the radial velocity of the jet as a function of radial position from where the jet impinges on a wall can be approximated with an equation equivalent to Equation 4.11,

$$
\mathrm{u}(\mathrm{r})=\mathrm{c}_{\mathrm{u}} \frac{\mathrm{u}_{0} \mathrm{~d}_{0}}{\mathrm{r}}
$$


where the coefficient $c_{u}$ is about 1 . Equations 4.11 and 4.12 for jet velocity have the same dependence on distance, but the coefficient is $\sim 1$ for an impinging jet rather than $\sim 5$ for a horizontal free jet. The physical meaning of this result is that the velocity of a horizontal circular free jet at a specific distance is $\sim 5$ times larger than if the same jet impinged on the bottom of a vessel and moved in a radial direction to the same distance. In Equation 4.10, the velocity dependence is included in the yield Reynolds number, $\operatorname{Re}_{\tau}^{1 / 2}=\left(\rho u_{0}^{2} / \tau_{s}\right)^{1 / 2}$. For an impinging jet, the effective velocity is $1 / 5$ the horizontal jet velocity.

Taking Equation 4.10 for horizontal jets and replacing the jet velocity with an effective velocity of $\mathrm{u}_{0} / 5$ gives the following correlation.

$$
\frac{\mathrm{ECR}}{\mathrm{d}_{0}}=\frac{5.78}{5} \mathrm{Re}_{\tau}^{1 / 2}
$$

This correlation will be referred to as the horizontal jet scaled to be an impinging jet.

Figure 4.6 shows the results for the ECR of a PJM from the three correlations given by Equations. 4.7, 4.8, and 4.13. These results all assume that the pulse volume fraction is sufficiently large that the correction term for unsteady jets is negligible. An important observation of the three results shown in Figure 4.6 is that the ECR scales with jet diameter and yield Reynolds number in an identical manner. It is also significant that the ECR results for the horizontal jet (scaled to be an impinging jet) is only about $50 \%$ larger than the PJM result scaled for "clay". Given the uncertainly in the data used to create these correlations, this is reasonable agreement between these two approaches.

Of the three correlations, Equation 4.8 gives the most conservative prediction of ECR, which is the PJM result scaled to "clay". This correlation was developed directly from PJM tests, so it is probably more appropriate as well. Until test data are collected specifically for PJM mobilization of thin settled layers of cohesive materials, Equation 4.8 is the best correlation for estimating PJM performance for this waste configuration.

Equation 4.8 can be plotted in a number of different ways to show PJM performance in specific vessels. One useful way to evaluate PJM performance is to estimate the needed cleaning radius for a specific vessel and then compare the ECR correlation to the needed ECR. One estimate of the needed ECR is the following

$$
\text { Needed } E C R=\frac{\left(D_{T} / 2\right)}{N_{j}^{1 / 2}}
$$

where this radius corresponds to the average equivalent circular area for each of PJM in a vessel with $\mathrm{N}_{\mathrm{j}}$ PJMs. For HLP-22, the vessel diameter is $38 \mathrm{ft}$. and $\mathrm{N}_{\mathrm{j}}$ is 12 ; the Needed ECR is $5.5 \mathrm{ft}$. Note that this is based on the cross-sectional tank area, not the area of the floor. For any PJM layout, there will be regions of the tank that are farther from a PJM than this average radius, so this estimate of a needed ECR is not the maximum value. 


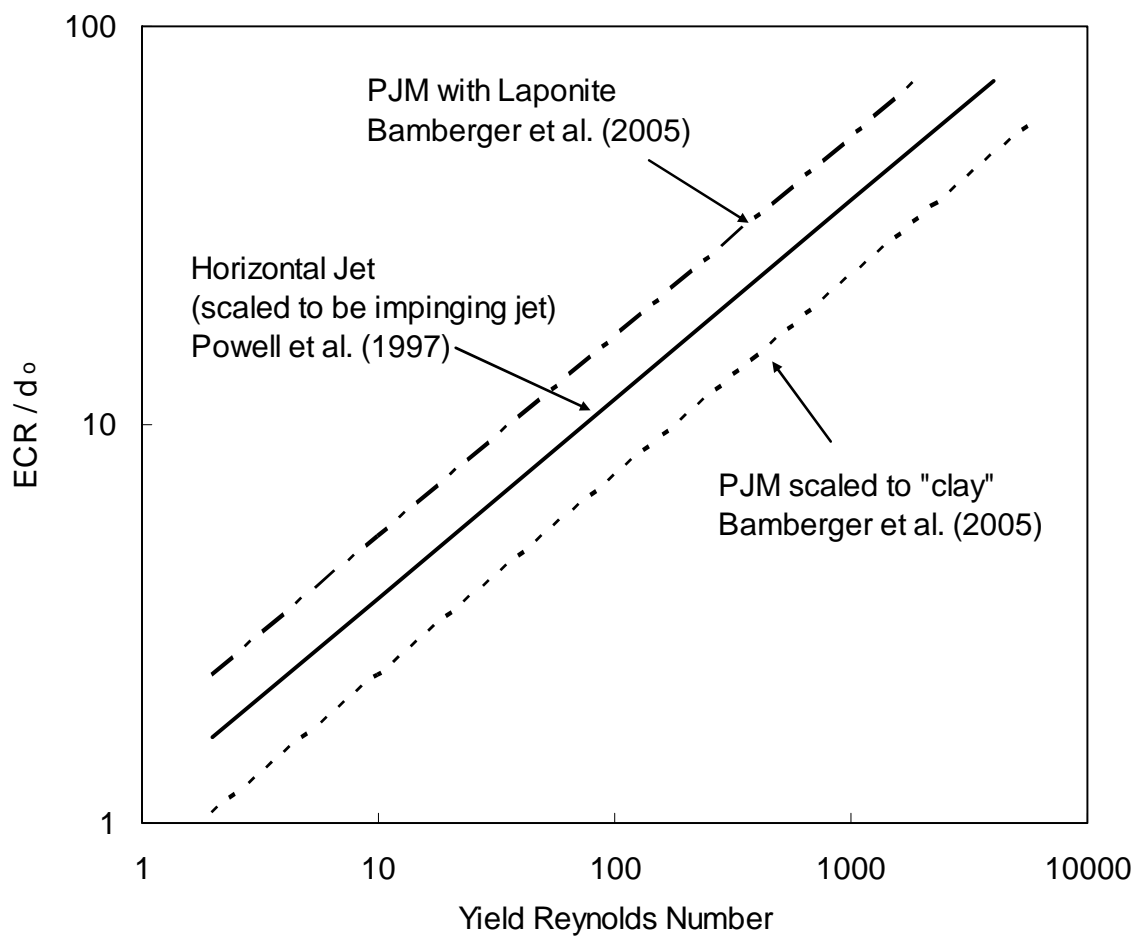

Figure 4.6. Effective Cleaning Radius Correlations for Impinging Jets

Figure 4.7 shows the ratio of the ECR scaled by the needed ECR as a function of waste strength for jet velocities of $8 \mathrm{~m} / \mathrm{s}$ and $12 \mathrm{~m} / \mathrm{s}$. The results show that an $8 \mathrm{~m} / \mathrm{s}$ jet will effectively mobilize a thin $30 \mathrm{~Pa}$ layer beyond the needed distance of $5.5 \mathrm{ft}$. The correlation predicts that $8 \mathrm{~m} / \mathrm{s}$ jets will just mobilize a thin $157 \mathrm{~Pa}$ layer to $5.5 \mathrm{ft}$ (note that this shear strength corresponds exactly to when the cavern height correlation given by Equation 4.6 predicts the cavern height is zero). Increasing the jet velocity to $12 \mathrm{~m} / \mathrm{s}$ noticeably improves the PJM performance.

\subsection{Cohesive Layer Mobilization Summary and Comparison of Predicted PJM Performance with Estimated Settled Layers}

Previous PJM testing with non-Newtonian simulants provides a basis for estimating the performance of PJMs for mobilizing settled layers of cohesive materials. Mixing deep settled layers of cohesive materials becomes significantly more difficult with increasing layer depth. For a full tank of cohesive material, the cavern breakthrough correlation for HLP-22 with 4-inch diameter and 8-m/s jets predicts that the shear strength of the material must be less than about $5 \mathrm{~Pa}$ for effective mixing of the $27 \mathrm{ft}$ thick layer and about $13 \mathrm{~Pa}$ for a layer that is half this thickness. In contrast, the thin-layer correlation predicts that a thin cohesive layer of $157 \mathrm{~Pa}$ material could be mixed to a radius of $5.5 \mathrm{ft}$ around each PJM, which is the radius of average circular area for each PJM. The underlying reason for this difference is the distance the jet needs to travel to mix a thin layer is substantially less $(5.5 \mathrm{ft})$ than the distance needed to reach to top of the waste in a full vessel $(5.5+27=32.5 \mathrm{ft})$. 


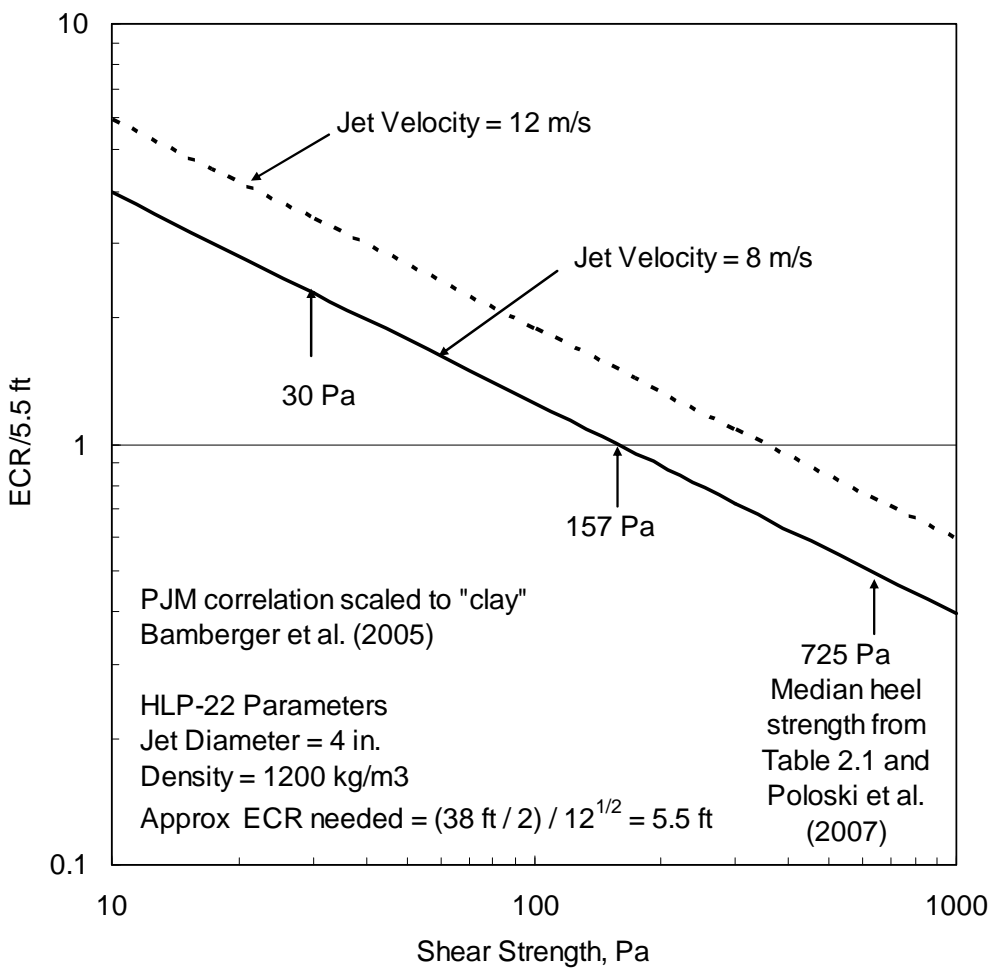

Figure 4.7. Effective Cleaning Radius Correlations for Impinging Jets on Thin Cohesive Layers (based on a slurry density of $1200 \mathrm{~kg} / \mathrm{m}^{3}$ )

In Section 2, results were present for the strength (or yield stress) of settled and stratified layers, and these results can be compared with the predicted PJM performance developed in this section. Figure 4.8 shows a comparison of the PJM performance given in Figure 4.4 for 4 -inch diameter, $12-\mathrm{m} / \mathrm{s}$ jets with the settled-layer strength from Figure 2.6. When the settled-layer strength is less than (or to the left of) the PJM performance curve, the PJM performance is sufficient to overcome the cohesive properties of the material and mobilize the layer. Conversely, when the settled-layer strength exceeds (or is to the right of) the PJM performance curve, the PJM performance is insufficient to overcome the strength of the layer. Where a settling curve crosses, the PJM performance curve gives the specific settled layer height and strength that can just be mobilized. For Cases 1 through 3 and the kaolin example, the beginning point is a 1-Pa unsettled layer. The PJM performance curve is $11 \mathrm{~Pa}$ for this layer thickness, which comfortably exceeds the 1-Pa unsettled layer. For Cases 1 through 3 and kaolin, Figure 4.8 shows that the settledlayer strength exceeds the PJM performance when the layers reach a scaled height between 0.3 and 0.4 and about $30 \mathrm{~Pa}$. For the models of settling and PJM performance used here, this condition defines when the PJM operation is insufficient to overcome the cohesive properties. There are no large-scale settling and strength data for actual waste, kaolin, or a material representing Cases 1 through 3 to estimate how long it would take to reach this condition, though the data in Figure 2.4 give some information on the time scale.

The PJM performance shown in Figure 4.4 and Figure 4.8 shows that higher strength layers can be mobilized if they are thin. For a layer that is $200 \mathrm{~Pa}$, the PJM performance curve in Figure 4.8 shows that a layer with a scaled height of about 0.03 could just be mobilized. The result for the Case 2 slurry diluted to $0.1 \mathrm{~Pa}$ shows that dilution gives a layer that crosses the PJM performance at a higher shear strength in 
comparison to the undiluted Case 2, suggesting that dilution can improve mobilization. For example, the Case 2 slurry that begins at a scaled height of 0.7 and a 1-Pa shear strength crosses the PJM performance curve at a scaled height of 0.37 and shear strength of about $30 \mathrm{~Pa}$. For the diluted Case 2 slurry that begins at a scaled height of 0.7 and a 0.1-Pa shear strength, it crosses the PJM performance curve at a scaled height of 0.15 and a shear strength of $80 \mathrm{~Pa}$. The effect of dilution on the time scale for settling, which is not included in Figure 4.8, still needs to be considered.

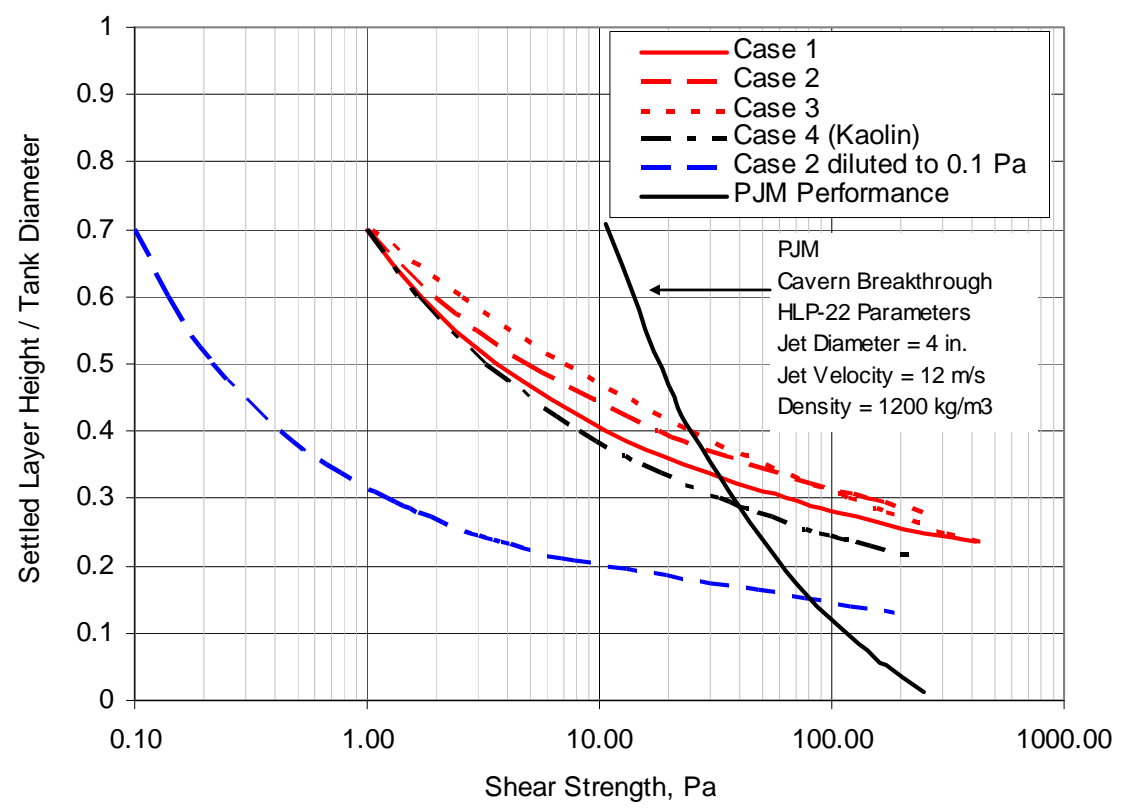

Figure 4.8. Comparison of the Estimated Shear Strength of Settling Layers with the PJM Performance Predicted by the Cavern Breakthrough Correlation, which Assumes the Limiting Steady-Jet Behavior, a Uniform Slurry Density, and HLP-22 Parameters with a Slurry Density of $1200 \mathrm{~kg} / \mathrm{m}^{3}$

The comparison given in Figure 4.8 highlights the critical importance of knowing both the strength of the settling layer as a function of depth and time and the PJM performance curve as a function of layer depth and strength. Assuming the PJM performance prediction is accurate, the PJM systems will fully mobilize a 1-Pa slurry that is uniform. If a thin layer does not exceed $200 \mathrm{~Pa}$, the PJM system should also mobilize this layer. The most challenging situation based on this analysis appears to be material that settles to form a relatively thick layer (say 0.35 in Figure 4.8) that exceeds $30 \mathrm{~Pa}$. While previous studies provide wellvalidated models to adapt for predicting the performance of PJM systems with settled layers of cohesive materials, there are too few data on PJM mobilization of settled cohesive layers to confirm the validity of the proposed model or to estimate the accuracy of the predictions. The technical uncertainty listed below addresses this need for information.

Uncertainty 4.1 PJM performance behavior for off-normal events with settled cohesive layers has technical uncertainty based on existing data and models. The uncertainty includes quantifying the role of settled-layer properties (rheology and density) and determining how existing PJM correlations for non-settling cohesive slurries need to be modified for settling slurries. The effect of PJM operational parameters and geometries also needs to be developed. 
Figure 4.9 shows a comparison between the PJM performance given in Figure 4.4 for 4-inch-diameter, $12-\mathrm{m} / \mathrm{s}$ jets with the shear strength (or yield stress) of a stratified layer during PJM operation shown previously in Figure 2.7. This comparison shows that for sufficiently low cloud heights, the shear strength (or yield stress) at the vessel bottom will at some point exceed the PJM performance. For the models of stratification and PJM performance used here, this condition defines when the PJM operation is insufficient to overcome the cohesive properties and occurs at a scaled cloud height between 0.5 and 0.6. For example, the Case 2 slurry with a scaled cloud height of 0.6 has a shear strength of just above $0.01 \mathrm{~Pa}$ at a scaled height of 0.6 and a shear strength at the vessel bottom of just over $100 \mathrm{~Pa}$. The PJM performance curve is always at a higher shear strength, or to the right, than the stratified layer shear strength. Similar to the discussion of Figure 4.8, when the stratified layer strength crosses the PJM performance curve, a situation exists where the PJM performance is no longer sufficient to mobilize the stratified layer. For the Case 2 slurry at a cloud height of 0.5 , the stratified layer strength crosses the PJM performance curve at a scaled height of 0.08 and a shear strength just above $100 \mathrm{~Pa}$. Accordingly, for the Case 2 slurry and the PJM performance curve used here, the scaled cloud height needs to stay above 0.5 for the slurry to be mobilized at all elevations.

Recent work by Meyer et al. (2009) can be used to estimate the cloud height, although this study focused on noncohesive materials rather than cohesive materials. There are too few data on PJM mobilization of settling cohesive materials forming stratified layers to confirm the validity of the proposed model or to estimate the accuracy of the predictions. The technical uncertainty listed below addresses this need for information.

Uncertainty 4.2 PJM performance behavior for normal operations with settling cohesive slurries that form stratified layers has technical uncertainty, including a lack of data and models to quantify the role of slurry rheology and density and to determine how existing PJM correlations for noncohesive slurries need to be modified for settling cohesive slurries. The effect of PJM operational parameters and geometries also needs to be developed. If the performance of a PJM system is shown to be sufficient to mobilize a completely settled layer following an off-norma event, through addressing uncertainty 4.1, this PJM system should be sufficient under normal operations. 


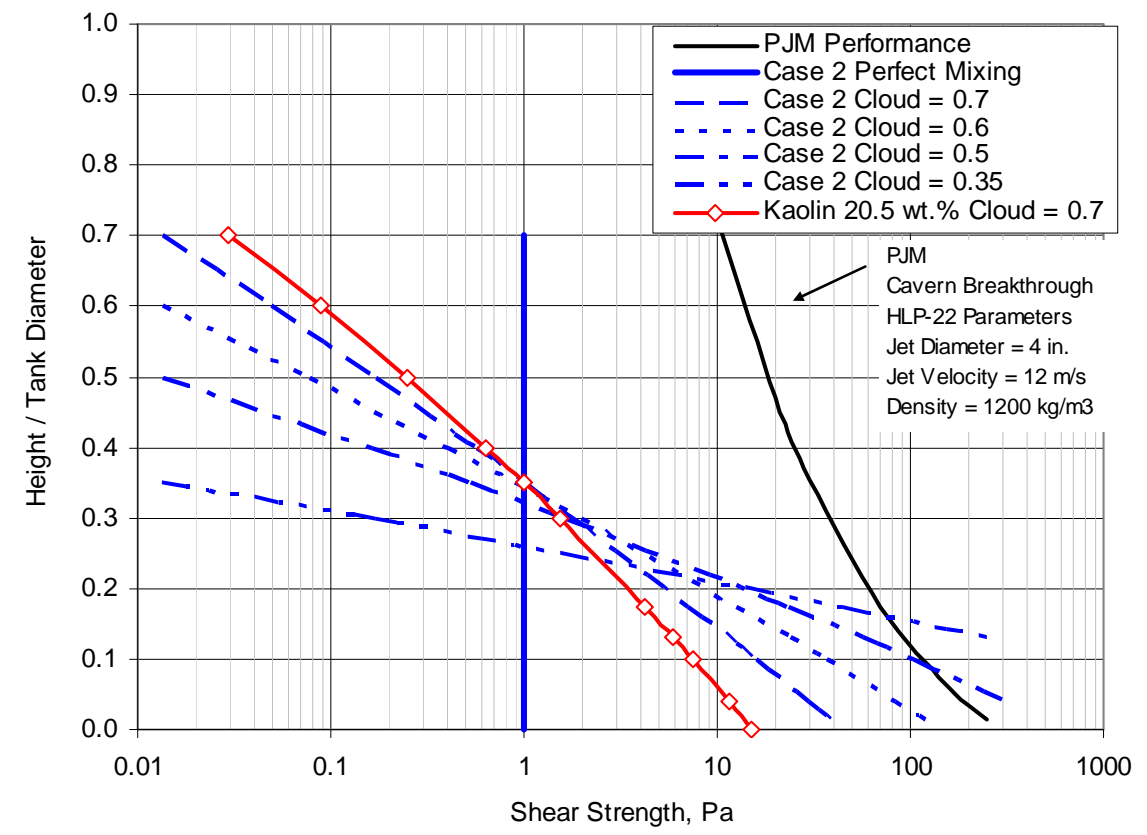

Figure 4.9. Comparison of the Estimated Shear Strength (or Yield Stress) of Stratified Layers During Normal PJM Operation with the PJM Performance Predicted by the Cavern Breakthrough Correlation, Which Assumes the Limiting Steady-Jet Behavior, a Uniform Slurry Density, and HLP-22 Parameters with a Slurry Density of $1200 \mathrm{~kg} / \mathrm{m}^{3}$ 


\subsection{Steady-State and Stagnant Zone Holdup for M3 Vessels}

A number of previous studies measured the steady-state gas holdup in scaled tests with a range of simulant properties, PJM configurations and operations, and gas-generation rates (Stewart et al. 2007, 2006a, 2006b; Bontha et al. 2005; Russell et al. 2005). The correlations developed in these studies can be used to predict the gas holdup in WTP vessels at plant conditions. WTP (2008) gives a listing of vessels and information associated with the M3 issue. The key scaling relationship from these studies is a gasbubble holdup model that shows that the steady-state holdup is the ratio of the gas-generation superficial velocity to the effective bubble-rise velocity. Following the nomenclature of Stewart et al. (2007), this relationship is

$$
\alpha_{\mathrm{Gss}}=\frac{\mathrm{U}_{\mathrm{Gs}}}{\mathrm{U}_{\mathrm{Gf}}}
$$

where $\alpha_{\text {Gss }}$ is the steady-state gas holdup (in percent), $\mathrm{U}_{\mathrm{Gs}}$ is the superficial velocity of gas generation, and $\mathrm{U}_{\mathrm{Gf}}$ is the effective generated gas bubble-rise velocity at the surface. It is important to note that the bubble-rise velocity in Equation 5.1 is a nonlinear function of the holdup, and thus indirectly dependent on $\mathrm{U}_{\mathrm{Gs}}$, in addition to being dependent on the vessel mixing and slurry properties. However, Equation 5.1 provides a direct method for scaling laboratory-scale testing results to full tank behavior at WTP conditions once testing results quantify the scaling behavior of $\mathrm{U}_{\mathrm{Gs}}$.

In the previous work, the superficial velocity of gas generation is often shown as the product $\mathrm{g}_{\mathrm{v}} \mathrm{H}$, where $\mathrm{g}_{\mathrm{v}}$ is the volume of gas generated per unit volume of slurry per unit time, and $\mathrm{H}$ is the effective slurry depth in the vessel. It is important to note that the correlation for gas holdup predicts the total gas holdup based on the total gas-generation rate, not just the generation rate of single species such as hydrogen. Information on gas generation in WTP vessels is often reported as the total volume of $\mathrm{H}_{2}$ generated in a completely full vessel per unit time. The gas-generation superficial velocity for hydrogen is the ratio of the total volumetric generation rate of hydrogen in a vessel scaled by the cross-sectional area of the vessel.

$$
\mathrm{U}_{\mathrm{Gs}}=\mathrm{g}_{\mathrm{v}} \mathrm{H}=\frac{\mathrm{G}_{\mathrm{v}}}{\mathrm{A}}
$$

where $A$ is the cross sectional area of the vessel, and $G_{v}$ is the total gas-generation rate in the vessel. Hydrogen is known to be only a portion of the gas that is generated within the waste, and for predictions using holdup correlations, we follow Stewart et al. (2007) and assume that hydrogen is $25 \mathrm{vol} \%$ of the total generated gas. In a study of the retained gas composition in Hanford tank waste, Mahoney et al. (1999) concluded that the gas retained in the convective layer of the waste was less than or equal to $25 \mathrm{~mol} \%$, which is equivalent to $25 \mathrm{vol} \%$, hydrogen. Mahoney also noted that the gas in the nonconvective (sediment) layer had consistently higher hydrogen, so the value of $25 \%$ hydrogen is not a bounding value. With the assumption of $25 \mathrm{vol} \%$ hydrogen in the retained gas, the total gas-generation superficial velocity is 4 times the hydrogen generation superficial velocity. 
In the most recent study by Stewart et al. (2007), gas-holdup tests were conducted in scaled lag-storage vessels filled with either AZ-101 chemical simulant with AFA or with a mixture of kaolinite and bentonite clay. In these tests, the gas-generation superficial velocity was varied and its scaling behavior quantified for scaled lag-storage vessels that were well mixed with both air spargers and PJMs. In conducting the measurements for gas holdup, the holdup of injected air bubbles was subtracted from the overall holdup, so the correlations represent the holdup of only the gas bubbles that were generated in situ during the tests.

Stewart et al. (2007) (see Figure 5.13 in Stewart et al.) gave the following correlation for holdup in a scaled lag-storage vessel with $30 \mathrm{~Pa}$ AZ-101 simulant and AFA,

$$
\alpha_{\mathrm{Gss}}=6.779 \mathrm{U}_{\mathrm{Gs}}^{0.559}
$$

With an estimate for the total gas-generation superficial velocity, $\mathrm{U}_{\mathrm{Gs}}$ at plant conditions, this correlation can predict the steady-state gas holdup in a fully mixed vessel containing a non-Newtonian slurry. For settling cohesive slurries, which is the focus of this study, this correlation can be applied, but the accuracy of the correlation for this waste behavior has not been determined. Note that the coefficients for this correlation were determined with the gas-generation superficial velocity taken at the average gas pressure in the vessel, which can be approximated as the pressure at half the depth of the waste. Similarly, the steady-state gas-holdup fraction is at the average gas pressure. The reason for selecting this correlation, which is based on testing with higher yield stress materials, is that the predicted holdup is higher than for the other correlations presented by Stewart et al. (2007). While this correlation is not a rigorous upper bound, it does reflect the higher level of holdup that is predicted. Figure 5.1 shows the predicted gas holdup (in percent) for a range of gas-generation superficial velocities. The laboratory testing by Stewart et al. (2007) was conducted between 0.01 and $0.1 \mathrm{~mm} / \mathrm{s}$ gas-generation superficial velocity while typical plant conditions are a factor of 10 to 100 times smaller. Accordingly, there is a significant extrapolation needed to predict plant-scale gas holdup.

Figure 5.1 also shows two different holdup correlations for vessels filled with mixtures of kaolinite and bentonite clays. The correlation for 30 Pa clay by Stewart et al. (2007) ${ }^{(a)}$ was developed from testing done with the same vessels and PJM/sparger systems as used in the AZ-101/AFA testing. The 30-Pa AZ-101 simulant and the 30-Pa clay simulant had essentially similar rheological behavior, but the AZ-101/AFA simulant consistently had higher holdup. This result shows that there are important interactions, other than just the rheological behavior of the slurry, that affect the gas holdup.

Stewart et al. (2006b) analyzed the data from Russell et al. (2005) and concluded that the holdup behavior of a wide-range of tests fell into two distinct groups. One group correlated with a lower holdup, and it was inferred that the vessels for these tests were very well mixed throughout. In the second group, which correlated with a higher holdup, they noted that they believed the vessels had stagnant regions and were not well mixed throughout. Holdup tests in a 1:4.9 scale vessel (UFP-2) with a 36 Pa yield stress clay simulant, for example, were part of this higher holdup group. The group of well-mixed tests included vessels with spargers, PJMs with upward-pointing nozzles in addition to the normal downward-pointing nozzles, and tests with lower yield stress simulants. The correlation given by Stewart et al. (2006b) for these well mixed vessels is

(a) Figure 5.12 of Stewart et al. (2007) gives $\alpha_{\mathrm{Gss}}=7.964 \mathrm{U}_{\mathrm{Gs}}^{0.794}$ as the correlation for 30 Pa Clay. 


$$
\alpha_{\mathrm{Gss}}=17.01 \mathrm{U}_{\mathrm{Gs}}
$$

where $\mathrm{U}_{\mathrm{Gs}}$ is the gas-generation superficial velocity (in $\mathrm{mm} / \mathrm{s}$ ) and the $\alpha_{\mathrm{Gss}}$ is the gas holdup in percent. ${ }^{\text {(a) }}$ Similar to Equation 5.3, this correlation was developed from testing with non-Newtonian slurries that filled an entire vessel, and not settling slurries being considered here. This correlation is similar to Equation 5.3, but with a different dependence on the gas-generation superficial velocity. Figure 5.1 shows the correlation given by Equation 5.4 (Stewart et al. 2006b), and the predicted gas holdup from this correlation compares well with the correlation from Stewart et al. (2007) at higher gas-generation rates and predicts lower gas holdup at lower gas-generation rates.

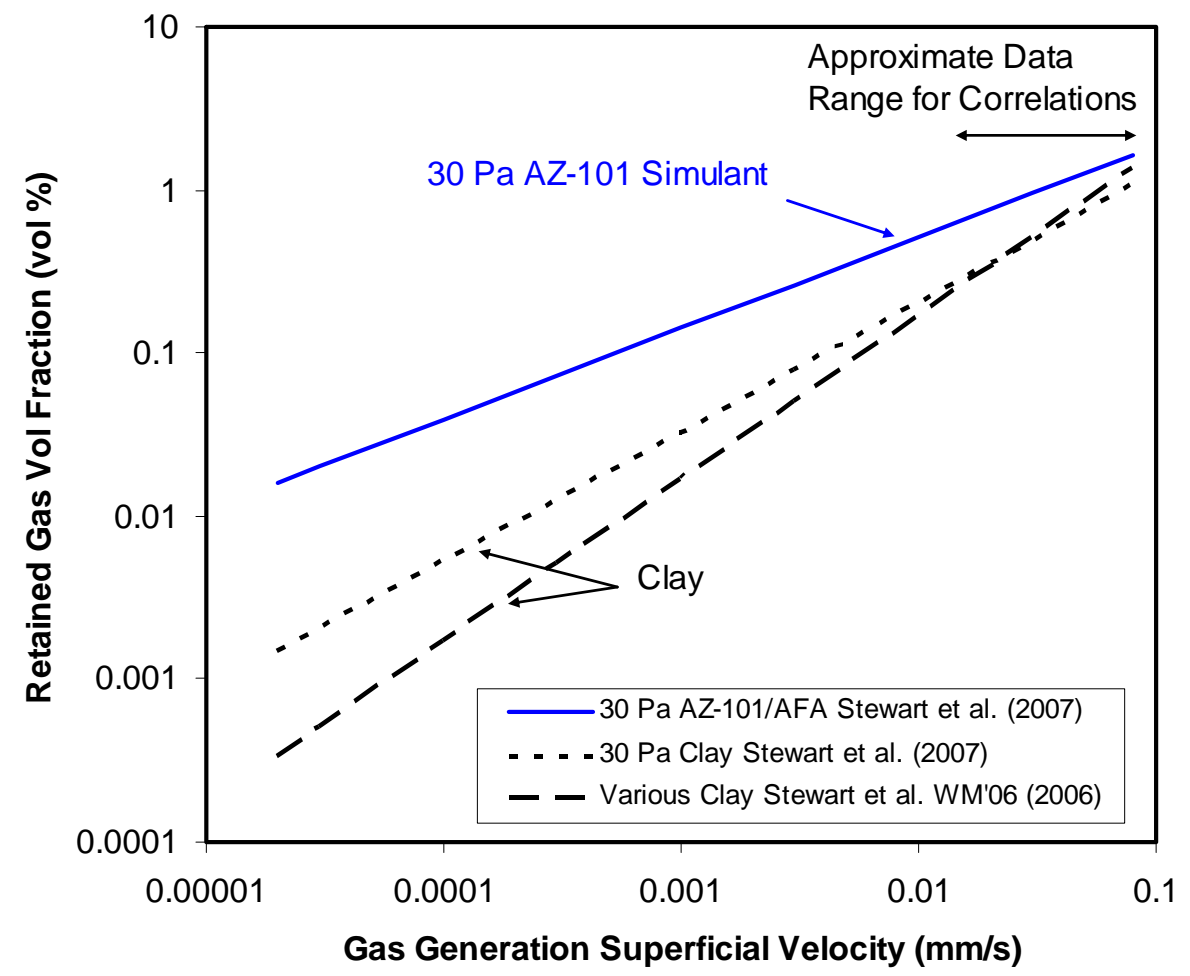

Figure 5.1. Retained Gas Fraction (total gas, not just hydrogen) as a Function of the Total GasGeneration Rate

With a correlation for total gas holdup, such as Equation 5.3, the steady-state holdup can be predicted for WTP vessels at plant conditions once the total gas-generation superficial velocity is known for each vessel. This correlation should be insensitive to geometry, provided the entire vessel is well mixed The predicted holdup is for all the gas, not just hydrogen, and the gas is at the average hydrostatic pressure in the vessel. The volume of hydrogen gas that could be released to the headspace can be determined by estimating the averaged depth of the waste and again assuming that hydrogen is $25 \mathrm{vol} \%$ of the retained gas. Appendix $\mathrm{C}$ provides details on the input parameters and the calculation of these results. Once the

(a) Figure 4 of Stewart et al. (2006b) gives $U_{R}=0.351$, and in this report, $U_{R}$ is $U_{G f}$. Note that the value of 0.351 in Figure 4 is incorrect and should be 3.51. Changing this equation from using the gas-generation rate in the units of $\mathrm{mm} / \mathrm{min}$ to $\mathrm{mm} / \mathrm{s}$ gives Eq. 5.3 with the coefficient of 17.01 and $\alpha_{\mathrm{Gss}}$ in percent. 
holdup of hydrogen is estimated, it is instructive to compare this steady-state holdup to the maximum allowed retention in a vessel (see Section 1.3 for a discussion of how the steady-state holdup compares to the maximum allowed holdup). Table 5.1 shows a summary of the hydrogen holdup and the comparison to the maximum allowed hold up for a selection of vessels with settling slurries. These vessels are a subset of the vessels listed in the mixing requirements document that are associated with the M3 issue and have an average concentration of solids greater than zero. The calculated holdup assumes that gas is retained throughout all the waste, but this neglects the fact that the waste will settle and will only retain gas in the portion of the vessel where the solids concentration is sufficiently high to create a yield stress. Accordingly, the predicted holdup is higher than what will actually occur with settling solids. The final column in Table 5.1 shows the ratio of the steady-state holdup to the maximum allowed release. An important conclusion from this analysis is that the steady-state holdup can be nearly $25 \%$ of the allowed release, with UFP-VSL-00001A/B being the highest vessel at 18.6\%. As mentioned previously, the correlation used in these calculations was developed from Non-Newtonian testing, and this correlation is being applied to the different situation of vessels with settling slurries. 
Table 5.1. Summary of Steady State Gas Holdup for Selected Vessels with Settling Slurries and a Comparison to the Maximum Allowed Release

\begin{tabular}{|c|c|c|c|c|c|c|c|c|}
\hline WTP Vessel & \begin{tabular}{|c|} 
Hydrogen \\
Generation Rate \\
(liter H2 @ 1 atm, \\
@temp, per hour) \\
(L) \\
\end{tabular} & $\begin{array}{c}\text { Time to } \\
\text { LFL } \\
\text { (hours) }\end{array}$ & \begin{tabular}{|c|} 
Maximum Allowed \\
Hydrogen Release \\
(at 1 atm and \\
vessel temp) \\
(gal)
\end{tabular} & \begin{tabular}{|c|} 
Total Gas \\
Generation \\
Superficial \\
Velocity \\
$(\mathrm{mm} / \mathrm{sec})$ \\
\end{tabular} & $\begin{array}{l}\text { Predicted } \\
\text { Total Gas } \\
\text { Holdup } \\
\text { Fraction } \\
\text { (percent) }\end{array}$ & $\begin{array}{l}\text { Predicted } \\
\text { Total } \\
\text { Gas Holdup } \\
\text { at } 1 \text { atm } \\
\text { (gal) }\end{array}$ & $\begin{array}{c}\text { Predicted } \\
\text { Steady-State } \\
\text { Hydrogen Holdup } \\
\text { at } 1 \text { atm } \\
\text { (gal) }\end{array}$ & $\begin{array}{c}\text { Steady-State Holdup } \\
\text { / } \\
\text { Max Allowed } \\
\text { Release } \\
\text { (percent) }\end{array}$ \\
\hline & Ref 1 & Ref 1 & & Comment 1 & $\begin{array}{c}\text { Ref } 4 \\
\text { Comment } 2 \\
\end{array}$ & Comment 2 & Comment 1 & Comment 1 \\
\hline UFP-VSL-00001A/B & 130 & 10 & 343 & 0.00495 & 0.2815 & 256 & 64 & 18.6 \\
\hline HLP-VSL-00022 & 280 & 22 & 1627 & 0.00295 & 0.2125 & 660 & 165 & 10.1 \\
\hline FEP-VSL-00017A/B & 22 & 89 & 517 & 0.00069 & 0.0954 & 92 & 23 & 4.4 \\
\hline FRP-02A/B/C/D & 16 & 508 & 2147 & 0.00011 & 0.0325 & 206 & 51 & 2.4 \\
\hline RLD-VSL-00008 & 0.38 & 974 & 98 & 0.00003 & 0.0196 & 2.5 & 0.6 & 0.6 \\
\hline $\begin{array}{l}\text { Comment } 1 \\
\text { Comment } 2\end{array}$ & \multicolumn{8}{|c|}{$\begin{array}{l}\text { Hydrogen is assumed to be } 1 / 4 \text { of total gas } \\
\text { Gas pressure is at average waste depth. }\end{array}$} \\
\hline $\begin{array}{l}\text { Reference } 1 \\
\text { Reference } 4\end{array}$ & \multicolumn{8}{|c|}{ Eager (2008); see Table 8-1 and 8-2. } \\
\hline
\end{tabular}


Even though the previous work and correlations on gas holdup can be used, there are a number of technical gaps that cause uncertainty in the predicted results for the situation of gas retention and release from slurries that settle. In Section 1.6.2 on the mechanisms of bubble release, we have asserted that when a cohesive slurry is mobilized, and we assume that a mobilized slurry is also sheared, any retained bubbles gas are free to rise and be released. However, for sufficiently short periods of shearing due to the pulsing of the PJMs or if the shearing is sufficiently small, it is likely that the bubble release will be negligible. The technical uncertainty is focused on quantifying how little shearing is sufficient to release bubbles.

Uncertainty 5.1 Determine if low shear at the design distance from PJM is sufficient to release bubbles. Slow release in poorly mixed regions is an unresolved issuecohesive layer mixing studies might resolve this.

Finally, the correlations used in this section for estimating gas holdup were developed from experiments using simulants with shear strengths below about $40 \mathrm{~Pa}$ and also used spargers together with PJMs. If settled layers have higher strengths, extrapolating the existing correlations is a source of uncertainty. Accordingly, the following gap exists.

Uncertainty 5.2 Extend existing correlations for gas holdup to fully account for settling cohesive materials that can form layers with shear strengths higher than about $40 \mathrm{~Pa}$. Gas holdup in vessels without spargers has received less study than mixing systems with PJMs and spargers. Depending on the testing results for mixing performance with settling waste, additional gas retention and release studies may be needed to reduce the uncertainty in holdup predictions.

The following technical uncertainty was listed previously in Section 1.6.1 and is shown here because it affects the holdup of gas.

Uncertainty 1.1 The foaming behavior of untreated actual wastes should be characterized to determine if there is a potential gas-retention mechanism in these waste materials prior to waste transfer to the WTP. 


\subsection{Summary of Technical Uncertainties}

In previous sections of this report, technical uncertainties have been called out as they were identified, and Table 6.1 lists all of the specific uncertainties. The uncertainties are grouped in two categories; the first category is Technical Uncertainties for PJM Behavior with Settling Slurries, and the second category is Technical Uncertainties for Waste Characterization. For PJM behavior, the two most significant uncertainties are associated with the current status that that there has been very little testing of the PJM performance on settled or stratified cohesive layers, and it is unclear if the existing correlations developed for vessels without layers can be used for settling waste. While the previous studies on PJM mixing of uniform non-Newtonian materials quantified many aspects of the PJM performance, data to quantify the roles of important operational parameters (jet velocity, pulse size, and duty cycle) and geometry (\# of PJM tubes, nozzle size, bottom shape) are absent. For waste characterization, the most significant uncertainty is that existing models and data on settling dynamics and the strength of settled layers as a function of depth have not included experimental testing to confirm the scaling behavior or the strength as a function of depth into a settled layer. It is expected that a sound understanding of settling dynamics will be needed to manage the strength and thickness of settled layers. The accuracy of the estimates for waste strength as a function of depth and time and the accuracy of the estimates for the capability of PJM systems to mobilize the waste needs to be determined to address these uncertainties. 
Table 6.1. Key Technical Uncertainties

\begin{tabular}{|c|c|}
\hline $\begin{array}{l}\text { Uncertainty No. } \\
\text { (Section) }\end{array}$ & Technical Uncertainties for PJM Behavior with Settling Slurries \\
\hline$(4.4)$ & $\begin{array}{l}\text { PJM performance behavior for off-normal events with settled cohesive layers has } \\
\text { technical uncertainty based on existing data and models. The uncertainty includes } \\
\text { quantifying the role of settled-layer properties (rheology and density) and determining } \\
\text { how existing PJM correlations for non-settling cohesive slurries need to be modified } \\
\text { for settling slurries. The effect of PJM operational parameters and geometries also } \\
\text { needs to be developed. }\end{array}$ \\
\hline$(4.4)$ & $\begin{array}{l}\text { PJM performance behavior for normal operations with settling cohesive slurries that } \\
\text { form stratified layers has technical uncertainty, including a lack of data and models to } \\
\text { quantify the role of slurry rheology and density and to determine how existing PJM } \\
\text { correlations for noncohesive slurries need to be modified for settling cohesive slurries. } \\
\text { The effect of PJM operational parameters and geometries also needs to be developed. } \\
\text { If the performance of a PJM system is shown to be sufficient to mobilize a completely } \\
\text { settled layer following an off-normal event, through addressing uncertainty 4.1, this } \\
\text { PJM system should be sufficient under normal operations. }\end{array}$ \\
\hline 5.1 & $\begin{array}{l}\text { Determine if low shear at the design distance from the PJM is sufficient to release } \\
\text { bubbles. A slow release in poorly mixed regions is an unresolved issue - cohesive } \\
\text { layer mixing studies might resolve this. }\end{array}$ \\
\hline \multirow[t]{2}{*}{5.2} & $\begin{array}{l}\text { Extend existing correlations for gas holdup to fully account for settling cohesive } \\
\text { materials that can form layers with shear strengths higher than about } 40 \text { Pa. Gas } \\
\text { holdup in vessels without spargers has received less study than mixing systems with } \\
\text { PJMs and spargers. Depending on the testing results for mixing performance with } \\
\text { settling waste, additional gas retention and release studies may be needed to reduce the } \\
\text { uncertainty in holdup predictions. }\end{array}$ \\
\hline & Technical Uncertainties for Waste Characterization \\
\hline (2.1) & $\begin{array}{l}\text { Scaling behavior, including the role of vessel size, of the settling dynamics and the } \\
\text { buildup of strength in the settled layer, with a particular emphasis on shorter settling } \\
\text { times and strength increase with depth into a layer is not well quantified with existing } \\
\text { data and analysis. The best current estimates are presented in this report, but these } \\
\text { estimates have uncertainty. Accurate predictions of the settling behavior and strength } \\
\text { formation are needed, so the mixing system is designed to prevent settled layers that } \\
\text { will exceed remobilization capabilities. Tank-farm studies of full-scale settling have } \\
\text { shown substantially faster settling than expected based on laboratory tests. This } \\
\text { inconsistency needs to be understood. }\end{array}$ \\
\hline $\begin{array}{c}1.1 \\
(1.6 .1)\end{array}$ & $\begin{array}{l}\text { The foaming behavior of untreated actual wastes should be characterized to determine } \\
\text { if there is a potential gas-retention mechanism in these waste materials prior to waste } \\
\text { transfer to the WTP. }\end{array}$ \\
\hline
\end{tabular}




\subsection{References}

Ali SA, PA Gauglitz, and WR Rossen. 2000. "Stability of Solids-Coated Liquid Layers between Bubbles." Industrial and Engineering Chemical Research 39(8):2742-2745.

Aronson MP. 1986. "Influence of Hydrophobic Particles on the Foaming of Aqueous Surfactant Solutions.” Langmuir 2(5):653-659.

Aveyard R, BP Binks, PDI Fletcher, TG Beck, and CE Rutherford. 1994. "Aspects of Aqueous Foam Stability in the Presence of Hydrocarbon Oils and Solid Particles." Advances in Colloid and Interface Science 48:93-120.

Bailey JW. 2000. Waste Retrieval Sluicing System (WRSS) and Project W-320, Tank 241-C-106 Sluicing, Lessons Learned. RPP-5687, Rev. 0, CH2M HILL Hanford Group, Richland, Washington.

Bamberger JA, PA Meyer, JR Bontha, CW Enderlin, DA Wilson, AP Poloski, JA Fort, ST Yokuda, HD Smith, F Nigl, MA Friedrich, DE Kurath, GL Smith, JM Bates, and MA Gerber. 2005. Technical Basis for Testing Scaled Pulse Jet Mixing Systems for Non-Newtonian Slurries. PNWD-3551 (WTP-RPT-113 Rev. 0), Battelle-Pacific Northwest Division, Richland, Washington.

Bates JM, JW Brothers, JM Alzheimer, DE Wallace, and PA Meyer. 2003. Test Results for Pulse Jet Mixers in Prototypic Ultrafiltration Feed Process and High-Level Waste Lag Storage Vessels. WTPRPT-110, Rev. 0, Bechtel National, Inc., Richland, Washington.

Beltaos S, and N Rajaratnam. 1977. "Impingement of Axisymmetric Developing Jets." J. Hydraulic Research 15(4):311-325.

Bindal S, AD Nikolov, DT Wasan, DP Lambert, and DC Koopman. 2001. "Foaming in Simulated Radioactive Waste.” Journal of Environmental Science and Technology 35:3941-3947.

Bindal SK, G Sethumadhavan, AD Nikolov, and DT Wasan. 2002. "Foaming Mechanisms in Surfactant Free Particle Suspensions.” AIChE Journal 48(10):2307-2314.

Bontha JR, CW Stewart, DE Kurath, PA Meyer, ST Arm, CE Guzman-Leong, MS Fountain, M Friedrich, SA Hartley, LK Jagoda, CD Johnson, KS Koschik, DL Lessor, F Nigl, RL Russell, GL Smith, W Yantasee, and ST Yokuda. 2005. Technical Basis for Predicting Mixing and Flammable Gas Behavior in the Ultrafiltration Feed Process and High-Level Waste Lag Storage Vessels with Non-Newtonian Slurries. PNWD-3676 (WTP-RPT-132, Rev. 0), Pacific Northwest National Laboratory, Richland, Washington.

Bontha JR, DE Kurath, AP Poloski, WC Buchmiller, WH Combs, ED Johnson, HC Webber, and KL Herman. 2007. Pulse Jet Mixer Controller and Instrumentation Testing. PNWD-3828 (WTP-RPT-146, Rev. 0). Pacific Northwest National Laboratory, Richland, Washington.

Bontha JR, GR Golcar, and N Hannigan. 2000. Demonstration and Optimization of BNFL's Pulsed Jet Mixing and RFD Sampling Systems Performance Using NCAW Simulant. PNWD-3054 (BNFL-RPT-048 Rev. 0), Battelle-Pacific Northwest Division, Richland, Washington. 
Bontha JR, JM Bates, CW Enderlin, and MG Dodson. 2003b. Large Tank Experimental Data for Validation of the FLUENT CFD Model of Pulsed Jet Mixers. PNWD-3303 (WTP-RPT-081, Rev. 0), Pacific Northwest National Laboratory, Richland, Washington.

Bontha JR, TE Michener, DS Trent, JM Bates, and MD Johnson. 2003a. Development and Assessment of the TEMPEST CFD Model of the Pulsed Jet Mixing Systems. PNWD-3261 (WTP-RPT-061), Pacific Northwest National Laboratory, Richland, Washington.

Bredt PR, and SM Tingey. 1996. The Effect of Dilution on the Gas Retention Behavior of Tank 241-SY-103 Waste. PNNL-10893, Pacific Northwest National Laboratory, Richland, Washington.

Bredt PR, SM Tingey, and EH Shade. 1995. The Effect of Dilution on the Gas Retention Behavior of Tank 241-SY-101 Waste. PNL-10781, Pacific Northwest Laboratory, Richland, Washington.

Brooks KP, DR Rector, and PA Smith. 1999. “Gravity Settling of Hanford Single-Shell Tank Sludges." Separations Science and Technology 34(6, 7):1351-1370.

Brooks KP, JR Bontha, GR Golcar, RL Meyers, KG Rappe, and DR Rector. 1998. Bench-Scale Enhanced Sludge Washing and Gravity Settling of Hanford Tank S-107 Sludge. PNNL-12010, Pacific Northwest National Laboratory, Richland, Washington.

Bryan SA, LR Pederson, and RD Scheele. 1992a. "Crust Growth and Gas Retention in Synthetic Hanford Waste." In: Proceedings of Waste Management '92 Conference Proceedings, pp. 829-834, March 1992, Tucson, Arizona.

Bryan SA, LR Pederson, JL Ryan, RD Scheele, and JM Tingey. 1992b. Slurry Growth, Gas Retention, and Flammable Gas Generation by Hanford Radioactive Waste Tanks: Synthetic Waste Studies, FY 1991. PNL-8169, Pacific Northwest National Laboratory, Richland, Washington.

Bryan SA, RD Scheele, LR Pederson, and SR Adami. 1993. In: Proceedings of the 4th Annual International Conference on High Level Radioactive Waste Management, pp. 1348-1354, Las Vegas, Nevada.

Burket PR, TM Jones, TL White, CL Crawford, and TB Calloway. 2005. Evaluation of Foaming and Antifoam Effectiveness during the WTP Oxidative Leaching Process. WSRC-TR-2005-00263, Rev. 0, Westinghouse Savannah River Company, Aiken, South Carolina.

Callaway, WS. 2000. Results of Retrieval Testing of Sludge from Tank 241-AZ-101. HNF-7078, Rev. 0, Fluor Hanford, Richland, Washington.

Carlson AB, PJ Certa, TM Hohl, JR Bellomy III, TW Crawford, DC Hedengren, AM Templeton, HS Fisher, SJ Greenwood, DG Douglas, and WJ Ulbright Jr. 2001. Test Report, 241-AZ-101 Mixer Pump Test. RPP-6548, Rev. 1, Numatec Hanford Corporation, Richland, Washington.

Cheremisinoff NP, and R Gupta. 1983. Handbook of Fluids in Motion, pp. 546-547, Ann Arbor Science, Ann Arbor, Michigan.

Chhabra RP. 1993. Bubbles, Drops, and Particles in Non-Newtonian Fluids. CRC Press, Boca Raton, Florida. 
Crowder ML, CL Crawford, EK Hansen, and F Fondeur. 2003. Evaporation of Pretreated Hanford Tank AW-101 Sample Mixed with Recycle. WSRC-TR-2003-00218 (SRT-RPP-2003-00156) Rev. 0, Westinghouse Savannah River Company, Aiken, South Carolina.

Crowder ML, CL Crawford, HH Saito, TB Calloway Jr., LV Gibson, Jr., MA Burdette, and SL Crump. 2001. Bench-Scale Evaporation of a Large Hanford Envelope C Sample (Tank 241-AN-102). WSRCTR-2000-00469 (SRT-RPP-2000-00043) Rev. 1, Westinghouse Savannah River Company, Aiken, South Carolina.

Crowder ML, EK Hansen, CL Crawford, WE Daniel Jr., RF Schumacher, PR Burket, and TB Calloway, Jr. 2004. Evaporation, Rheology, and Vitrification of a Pretreated Radioactive Hanford Tanks 241-AN104 Sample Mixed with Simulated LAW SBS Recycle. WSRC-TR-2004-00232 (SRNL-RPP-2004-00044) Rev. 0, Westinghouse Savannah River Company, Aiken, South Carolina.

Cuta JM, KG Carothers, DW Damschen, WL Kuhn, JA Lechelt, K Sathyanarayana, and LA Stauffer. 2000. Review of Waste Retrieval Sluicing System Operations and Data for Tanks 241-C-016 and 241AY-102. PNNL-13319, Pacific Northwest National Laboratory, Richland, Washington.

Dippenaar A. 1982a. "The Destabilization of Froth by Solids. I. The Mechanism of Film Rupture." International Journal of Mineral Processing 9:1-14.

Dippenaar A. 1982b. "The Destabilization of Froth by Solids. II. The Rate-Determining Step." International Journal of Mineral Processing 9:15-22.

Eager K. 2008. Calculation of Hydrogen Generation Rates and Times to Lower Flammability Limit for WTP. Calculation Sheet, ECCN No: 24590-WTP-M4E-V11T-00007, January 16, 2008, Bechtel National, Inc., Richland. Washington.

Edwards MK, AM Casella, LK Jagoda, RW Shimskey, JM Billing, JV Crum, ED Jenson, LA Snow, DL Blanchard, RC Daniel, AE Kozelisky, RG Swoboda, EC Buck, KE Draper, PJ MacFarlan, AJ Casella, SK Fiskum, and RA Peterson. 2009. Characterization, Leaching, and Filtration Testing for Tributyl Phosphate (TBP, Group 7) Actual Waste Sample Composites. PNNL-18119 (WTP-RPT-169, Rev 0), Pacific Northwest National Laboratory, Richland, Washington.

Enderlin CW, MG Dodson, F Nigl, J Bontha, and JM Bates. 2003. Results of Small-Scale Particle Cloud Tests and Non-Newtonian Fluid Cavern Tests. PNWD-3360 (WTP-RPT-078), Pacific Northwest Laboratory, Richland, Washington.

Fiskum SK, EC Buck, RC Daniel, K Draper, MK Edwards, TL Hubler, LK Jagoda, ED Jenson, AE Kozelisky, GJ Lumetta, PJ MacFarlan, BK McNamara, RA Peterson, SI Sinkov, LA Snow, and RG Swoboda. 2008. Characterization and Leaching Testing for REDOX Sludge and S-Saltcake Actual Waste Sample Composites. PNNL-17368 (WTP-RPT-157), Pacific Northwest National Laboratory, Richland, Washington.

Fiskum SK, MK Edwards, EC Buck, JM Billing, RW Shimskey, KE Draper, JV Crum, RA Peterson, AE Kozelisky, RC Daniel, and PJ MacFarlan. 2009. Characterization, Leaching, and Filtration Testing of Ferrocyanide Tank Sludge (Group 8) Actual Waste Composite. PNNL-18120 (WTP-RPT-170, Rev. 0), Pacific Northwest National Laboratory, Richland, Washington. 
Frye GC, and JC Berg. 1989a. "Antifoam Action by Solid Particles.” Journal of Colloid and Interface Science 127(1):222-238.

Frye GC, and JC Berg. 1989b. "Mechanisms for the Synergistic Antifoam Action by Hydrophobic Solid Particles in Insoluble Liquids." Journal of Colloid and Interface Science 130(1):54-59.

Garrett PR. 1979. "The Effect of Polytetrafluoroethylene Particles on the Foamability of Aqueous Surfactant Solutions.” Journal of Colloid and Interface Science 69(1):107-121.

Gauglitz PA, and G Terrones. 2002. Estimated Maximum Gas Retention from Uniformly Dispersed Bubbles in K Basin Sludge Stored in Large-Diameter Containers. PNNL-13893, Pacific Northwest National Laboratory, Richland, Washington.

Gauglitz PA, and JT Aikin. 1997. Waste Behavior During Horizontal Extrusion: Effect of Waste Strength for Bentonite and Kaolin/Ludox Simulants and Strength Estimates for Wastes from Hanford Tanks 241-SY-103, AW-101, AN-103, and S-102. PNNL-11706, Pacific Northwest National Laboratory, Richland, Washington.

Gauglitz PA, G Terrones, SJ Muller, MM Denn, and WR Rossen. 2001. Mechanics of Bubbles in Sludges and Slurries: Final Report for U.S. Department of Energy. PNNL-13748, Pacific Northwest National Laboratory, Richland, Washington.

Gauglitz PA, LA Mahoney, DP Mendoza, and MC Miller. 1994. Mechanisms of Gas Bubble Retention. PNL-10120, Pacific Northwest Laboratory, Richland, Washington.

Gauglitz PA, SD Rassat, MR Powell, RR Shah, and LA Mahoney. 1995. Gas Bubble Retention and its Effect on Waste Properties: Retention Mechanisms, Viscosity, and Tensile and Shear Strength. PNL-10740, Pacific Northwest Laboratory, Richland, Washington.

Gauglitz PA, SD Rassat, PR Bredt, JH Konynenbelt, SM Tingey, and DP Mendoza. 1996. Mechanisms of Gas Bubble Retention and Release: Results for Hanford Waste Tanks 241-S-102 and 241-SY-103 and Single-Shell Tank Simulants. PNNL-11298, Pacific Northwest National Laboratory, Richland, Washington.

Geeting JGH, RT Hallen, LK Jagoda, AP Poloski, RD Scheele, and DR Weier. 2003. Filtration, Washing, and Caustic Leaching of Hanford Tank AZ-101 Sludge. PNWD-3206, Rev 1 (WTP-RPT-043, Rev 1), Pacific Northwest National Laboratory, Richland, Washington.

Gray WJ, ME Peterson, RD Scheele, and JM Tingey. 1999. Characterization of the Second Core Sample of Neutralized Current Acid Waste from Double-Shell Tank 101-AZ. PNNL-13027, Pacific Northwest National Laboratory, Richland, Washington.

Guerrero HN, CL Crawford, MD Fowley, RA Leishear, and ML Restivo. 2007. Effects of Alternate Antifoam Agents, Noble Metals, Mixing Systems and Mass Transfer on Gas Holdup and Release from Non-Newtonian Slurries. WSRC-STI-2007-00537, Rev. 0, Savannah River National Laboratory, Aiken, South Carolina.

Hassander H, B Johansson, and B Tornell. 1989. "The Mechanism of Emulsion Stabilization by Small Silica (Ludox) Particles." Colloids and Surfaces 40:93-105. 
Hedengren DC, KM Hodgson, WB Barton, CW Stewart, JM Cuta, and BE Wells. 2000. Data Observations on Double-Shell Flammable Gas Watch List Tank Behavior. RPP-6655, CH2MHILL Hanford Group, Inc., Richland, Washington.

Hu TA. 2007. Methodology and Calculations for the Assignment of Waste Groups for the Large Underground Waste Storage Tanks at the Hanford Site. RPP-10006, Rev. 6., CH2M HILL Hanford Group, Inc., Richland, Washington.

Hudales JBM, and HN Stein. 1990. "The Influence of Solid Particles on Foam and Film Drainage." Journal of Colloid and Interface Science 140(2):307-313.

ICD 19. 2008. ICD 19 - Interface Control Document for Waste Feed, 24590-WTP-ICD-MG-01-019, Rev 4, River Protection Project, Richland, Washington.

Johnson GD, DC Hedengren, JM Grigsby, CW Stewart, JJ Zach, and LM Stock. 2001. Flammable Gas Safety Issue Resolution. RPP-7771 Rev. 0-A, CH2M HILL Hanford Group, Richland, Washington.

Johnson GD, NW Kirch, RE Bauer, JM Conner, CW Stewart, BE Wells, and JM Grigsby. 2000. Evaluation of Hanford High-Level Waste Tank 241-SY-101. RPP-6517, Rev. 0, CH2MHILL Hanford Group, Inc., Richland, Washington.

Johnson GD, WB Barton, JW Brothers, SA Bryan, PA Gauglitz, RC Hill, LR Pederson, CW Stewart, and LM Stock. 1997. Flammable Gas Project Topical Report. HNF-SP-1193, Rev. 2, Richland, Washington.

Johnson MD, JR Bontha, and JM Bates. 2003. Demonstration of Ability to Mix in a Small-Scale PulsedJet Mixer Test Facility. PNWD-3273 (WTP-RPT-077), Pacific Northwest Laboratory, Richland, Washington.

Johnson MD, MA Gerber, JR Bontha, AP Poloski, RT Hallen, SK Sundaram, and DE Wallae. 2005. Hybrid Mixing System Test Results for Prototype Ultrafiltration Feed Process and High-Level Waste Lag Storage Vessels. PNWD-3586 (WTP-RPT-128, Rev. 0), Pacific Northwest Laboratory, Richland, Washington.

Josephs J, and TB Calloway. 2001. Foaming in Hanford River Protection Project Waste Treatment Plant LAW Evaporation Processes - FY01 Summary Report. WSRC-TR-2001-00561, Rev. 0, Westinghouse Savannah River Company, Aiken, South Carolina.

Koczo K, JK Koczone, and DT Wasan. 1994. "Mechanisms for Antifoaming Action in Aqueous Systems by Hydrophobic Particles and Insoluble Liquids." Journal of Colloid and Interface Science 166:225-238.

Kulkarni RD, ED Goddard, and B Kanner. 1977. "Mechanism of Antifoaming: Role of Filler Particle." Industrial and Engineering Chemistry Fundamentals 16(4):472-474.

Kurath DE, PA Meyer, JR Bontha, AP Poloski, JA Fort, WH Combs, WC Buchmiller, ID Welch, and MD Bleich. 2007. Assessment of Pulse Tube Mixing for Vessels Containing Non-Newtonian Slurries. PNWD-3827 (WTP-RPT-155, Rev. 0), Pacific Northwest National Laboratory, Richland, Washington. 
Levine S BD Bowen, and SJ Partridge. 1989a. "Stabilization of Emulsions by Fine Particles. I. Partitioning of Particles Between Continuous Phase and Oil/water Interface." Colloids and Surfaces $38: 325-343$.

Levine S BD Bowen, and SJ Partridge. 1989b. "Stabilization of Emulsions by Fine Particles. II. Capillary and Van Der Waals Forces Between Particles.” Colloids and Surfaces 38:34-364.

Lumetta GJ, MK Edwards, ED Jenson, RW Shimskey,EC Buck, SK Fiskum, AE Kozelisky, SI Sinkov, RC Daniel, RT Hallen, PJ MacFarlan, LA Snow, K Draper, LK Jagoda, and RA Peterson. 2009.

Characterization, Leaching, and Filtration Testing for Bismuth Phosphate Sludge (Group 1) and Bismuth Phosphate Saltcake (Group 2) Actual Waste Sample Composites. PNNL-17992 (WTP-RPT-166, Rev 0), Pacific Northwest National Laboratory, Richland, Washington.

MacLean GT. 1999. The Settling and Compaction of Nuclear Waste Slurries. HNF-5177, Rev. 0, including errata dated 11/15/99 replacing page 5, Numatec Hanford Corporation, Richland, Washington.

Mahoney LA, ZI Antoniak, WB Barton, JM Conner, NW Kirch, CW Stewart, and BE Wells. 2000. Results of Transfer and Back-Dilution Sequences in Tanks 241-SY-101 and 241-SY-102. TWS00.38. Pacific Northwest National Laboratory, Richland, Washington.

Mahoney LA, ZI Antoniak, JM Bates, and ME Dahl. 1999. Retained Gas Sampling Results for the Flammable Gas Program. PNNL-13000, Pacific Northwest National Laboratory, Richland, Washington.

Meyer PA, JA Bamberger, CW Enderlin, JA Fort, BE Wells, SK Sundaram, PA Scott, MJ Minette, GL Smith, CA Burns, MS Greenwood, GP Morgen,EBK Baer, SF Snyder, M White, GF Piepel, BG Amidan, and A Heredia-Langner. 2008. Pulse Jet Mixing Tests with Noncohesive Solids. PNNL-18098 (WTPRPT-182, Rev. 0), Pacific Northwest National Laboratory, Richland, Washington.

Meyer PA ME Brewster, SA Bryan, G Chen, LR Pederson, CW Stewart, and G Terrones. 1997. Gas Retention and Release Behavior in Hanford Double-Shell Waste Tanks. PNNL-11536, Rev. 1, Pacific Northwest National Laboratory, Richland, Washington.

Meyer PA, DE Kurath, and CW Stewart. 2005. Overview of the Non-Newtonian Pulse Jet Mixer Test Program. PNWD-3677 (WTP-RPT-127, Rev. 0), Pacific Northwest National Laboratory, Richland, Washington.

Ohshima S, T Takematsu, Y Kuriki, K Shimada, M Suzuki, and J Kato. 1976. Journal of Chemical Engineering of Japan 9:29.

Onishi Y, and BE Wells. 2004. Feasibility Study on Using Two Mixer Pumps for Tank 241-AY-102 Waste Mixing. PNNL-14763, Pacific Northwest National Laboratory, Richland, Washington.

Onishi Y, BE Wells, SA Hartley, and SK Cooley. 2001. Pipeline Cross-Site Transfer Assessment for Tank 241-SY-101. PNNL-13650, Pacific Northwest National Laboratory, Richland, Washington.

Peterson ME, RD Scheele, and JM Tingey. 1989. Characterization of the First Core Sample of Neutralized Current Acid Waste from Double-Shell Tanks 101-AZ. PNL-7758, Pacific Northwest Laboratory, Richland, Washington. 
Poloski AP, BE Wells, JM Tingey, LA Mahoney, MN Hall, SL Thomson, GL Smith, ME Johnson, JE Meacham, MA Knight, MG Thien, JJ Davis, and Y Onishi. 2007. Estimate of Hanford Waste Rheology and Settling Behavior. PNNL-16857 (WTP-RPT-154 Rev. 0), Pacific Northwest National Laboratory, Richland, Washington.

Poloski AP, PR Bredt, JW Chenualt, RG Swoboda. 2003. Rheological and Physical Properties of AZ101 HLW Pretreated Sludge and Melter Feed. PNWD-3366 (WTP-RPT-096, Rev. 0), Pacific Northwest National Laboratory, Richland, Washington.

Poloski AP, RC Daniel, DR Rector, PR Bredt, and BC Buck. 2006b. Characterization and Correlation of Particle-Level Interactions to the Macroscopic Rheology of Powders, Granular Slurries, and Colloidal Suspensions. PNNL-16133, Pacific Northwest National Laboratory, Richland, Washington.

Poloski AP, ST Arm, JA Bamberger, B Barnett, R Brown, BJ Cook, CW Enderlin, MS Fountain, M Friedrich, BG Fritz, RP Mueller, F Nigl, Y Onishi, LA Schienbein, LA Snow, S Tzemos, M White, and JA Vucelick. 2005. Technical Basis for Scaling of Air Sparging Systems for Mixing in Non-Newtonian Slurries. PNWD-3541 (WTP-RPT-129, Rev. 0), Pacific Northwest National Laboratory, Richland, Washington.

Poloski AP, ST Arm, OP Bredt, TB Calloway, Y Onishi, RA Peterson, GL Smith, and HD Smith. 2006a. Final Report: Technical Basis for HLW Vitrification Stream Physical and Rheological Property Bounding Conditions. PNWD-3675 (WTP-RPT-112, Rev. 0), Pacific Northwest National Laboratory, Richland, Washington.

Powell MR, CM Gates, CR Hymas, MA Sprecher, and NJ Morter. 1995a. Fiscal Year 1994 1/25 ${ }^{\text {th }}$-Scale Sludge Mobilization Testing. PNL-10582, Pacific Northwest National Laboratory, Richland, Washington.

Powell MR, GR Golcar, CR Hymas, and RL McKay. 1995b. Fiscal Year 1993 1/25 ${ }^{\text {th }}$-Scale Sludge Mobilization Testing. PNL-10464, Pacific Northwest National Laboratory, Richland, Washington.

Powell MR, Y Onishi, and R Shekarriz. 1997. Research on Jet Mixing of Settled Sludges in Nuclear Waste Tanks at Hanford and Other DOE Sites: A Historical Perspective. PNNL-11686, Pacific Northwest National Laboratory, Richland, Washington.

Rajaratnam N. 1976. Turbulent Jets. Elsevier Science Publishers, New York.

Rassat SD, CW Stewart, BE Wells, WL Kuhn, ZI Antoniak, JM. Cuta, KP Recknagle, G Terrones, VV Viswanathan, JH Sukamto, and DP Mendoza. 2000. Dynamics of Crust Dissolution and Gas Release in Tank 241-SY-101. PNNL-13112, Pacific Northwest National Laboratory, Richland, Washington.

Rassat SD, LA Mahoney, BE Wells, DP Mendoza, and DD Caldwell. 2003a. Assessment of Physical Properties of Transuranic Waste in Hanford Single-Shell Tanks. PNNL-14221, Pacific Northwest National Laboratory, Richland, Washington.

Rassat SD, LM Bagaasen, LA Mahoney, RL Russell, DD Caldwell, and DP Mendoza. 2003b. Physical Properties and Liquid Chemical Simulant Formulations for Transuranic Waste in Hanford Single-Shell Tanks. PNNL-14333, Pacific Northwest National Laboratory, Richland, Washington. 
Rassat SD, PA Gauglitz, PR Bredt, LA Mahoney, SV Forbes, and SM Tingey. 1997. Mechanisms of Gas Bubble Retention and Release: Experimental Results for Hanford Waste Tanks 241-AW-101 and 241-AN103. PNNL-11642, Pacific Northwest National Laboratory, Richland, Washington.

Rassat SD, PA Gauglitz, SM Caley, LA Mahoney, and DP Mendoza. 1999. A Discussion of SY-101 Crust Gas Retention and Release Mechanisms. PNNL-12092, Pacific Northwest National Laboratory, Richland, Washington.

Rassat SD, SM Caley, PR Bredt, PA Gauglitz, DE Rinehart, and SV Forbes. 1998. Mechanisms of Gas Bubble Retention and Release: Experimental Results for Hanford Single Shell Waste Tanks 241-A-101, 241-S-106, and 241-U-103. PNNL-11981, Pacific Northwest National Laboratory, Richland, Washington.

Rector DR, and BC Bunker. 1995a. Sedimentation Models. PNNL-10754, Pacific Northwest National Laboratory, Richland, Washington.

Rector DR, and BC Bunker. 1995b. Effect of Colloidal Aggregation on the Sedimentation and Rheological Properties of Tank Waste. PNNL-10761, Pacific Northwest National Laboratory, Richland, Washington.

Rossen WR, and SI Kam. 1996. Mechanisms of Stability of Armored Bubbles: FY 1996 Final Report. PNNL-11416, Prepared by the Department of Petroleum and Geosystems Engineering, The University of Texas at Austin for the Pacific Northwest National Laboratory, Richland, Washington.

Rossen WR, and SK Das. 1996. Mechanisms of Stability of Armored Bubbles: FY 1995 Progress Report. PNNL-11133, Prepared by the Department of Petroleum and Geosystems Engineering, The University of Texas at Austin for the Pacific Northwest National Laboratory, Richland, Washington.

Russell RL, CW Stewart, SD Rassat, CD Johnson, ST Arm, PA Meyer, MS Fountain, CE GuzmanLeong, and BK Hatchell. 2005. Final Report: Gas Retention and Release in Hybrid Pulse Jet Mixed Tanks Containing Non-Newtonian Waste Simulants. PNWD-3552 (WTP-RPT-114 Rev 1), Pacific Northwest National Laboratory, Richland, Washington.

Shekarriz A, KJ Hammad, MR Powell. 1997. Evaluation of Scaling Correlations for Mobilization of Double-Shell Tank Waste. PNNL-11737, Pacific Northwest National Laboratory, Richland, Washington.

Snow, LA, EC Buck, AJ Casella, JV Crum, RC Daniel, KE Draper, MK Edwards, SK Fiskum, LK Jagoda, ED Jenson, AE Kozelisky, PJ MacFarlan, RA Peterson, and RG Swoboda. 2008. Characterization and Leach Testing for PUREX Cladding Waste Sludge (Group 3) and REDOX Cladding Waste Sludge (Group 4) Actual Waste Sample Composites. PNNL-18054 (WTP-RPT-167, Rev. 0), Pacific Northwest National Laboratory, Richland, Washington.

Stewart CS, PA Meyer, DE Kurath, and SM Barnes. 2006b. "Scaling Laws for Reduced-Scale Tests of Pulse Jet Mixing Systems in Non-Newtonian Slurries: Gas Retention and Release Behavior." In: Proceedings of Waste Management 2006. February 26-March 2, Tucson, Arizona.

Stewart CW, CL Shepard, JM Alzheimer, TI Stokes, and G Terrones. 1995. In Situ Determination of Rheological Properties and Void Fraction in Hanford Waste Tank 241-SY-101. PNL-10682, Pacific Northwest National Laboratory, Richland, Washington. 
Stewart CW, JG Fadeff, JD Hudson, LF Efferding, JR Friley, TE Michener, FE Panisko, NW Kirch, ZI Antoniak, DA Reynolds, and JJ Irwin. 1994. Mitigation of Tank 241-SY-101 by Pump Mixing: Results of Full-Scale Testing. PNL-9959, Pacific Northwest National Laboratory, Richland, Washington.

Stewart CW, JM Alzheimer, ME Brewster, G Chen, RE Mendoza, HC Reid, CL Shepard, and G Terrones. 1996. In Situ Rheology and Gas Volume in Hanford Double-Shell Waste Tanks. PNL-11296, Pacific Northwest National Laboratory, Richland, Washington.

Stewart CW, LA Mahoney, CE Guzman-Leong, JM Alzheimer, ST Arm, JA Bailey, MG Butcher, SK Cooley, EC Golovich, DE Hurley, LK Jagoda, CD Johnson, WR Park, LD Reid, RW Slaugh, HD Smith, Y Su, BE Wells, C Wend, and ST Yokuda. 2007. Results from Large-Scale Testing on Effects of AntiFoam Agent on Gas Retention and Release. PNNL-17170 (WTP-RPT-156 Rev 0), Pacific Northwest National Laboratory, Richland, Washington.

Stewart CW, PA Meyer, MS Fountain, CE Guzman-Leong, SA Hartley-McBride, JL Huckaby, and BE Wells. 2006a. Effect of Anti-Foam Agent on Gas Retention and Release Behavior in Simulated HighLevel Waste. PNWD-3786 (WTP-RPT-147), Pacific Northwest National Laboratory, Richland, Washington.

Stewart CW, SA Hartley, PA Meyer, and BE Wells. 2005. Predicting Peak Hydrogen Concentrations from Spontaneous Gas Releases in Hanford Waste Tanks. PNNL-15238, Pacific Northwest National Laboratory, Richland, Washington.

Symons GA. 1996. Mixer Pump Test Plan for Double-Shell Tank AZ-101. WHC-SD-WM-PTP-027, Rev. 1., Westinghouse Hanford Company, Richland, Washington.

Tambe DE, and MM Sharma. 1994. "Factors Controlling the Stability of Colloid-stabilized Emulsions. II. A Model for the Rheological Properties of Colloid-Laden Interfaces." Journal of Colloid and Interface Science 162:1-10.

Tambe DE, and MM Sharma. 1995. "Factors Controlling the Stability of Colloid-Stabilized Emulsions. III. Measurement of the Rheological Properties of Colloid Laden Interfaces." Journal of Colloid and Interface Science 171:456-462.

Tang FQ, Z Xiao, J Tang, and L Jiang. 1989. “The Effect of $\mathrm{SiO}_{2}$ Particles upon Stabilization of Foam.” Journal of Colloid and Interface Science 131(2):498-502.

Thomas, AD. 1979. "Settling of Particles in a Horizontally Sheared Bingham Plastic." First National Conference on Rheology, Melbourne, May 30 - June 1, 1979.

Tingey JM, J Gao, CH Delegard, LM Bagaasen, and BE Wells. 2003. Physical Property and Rheological Testing of Actual Transuranic Waste from Hanford Single-Shell Tanks. PNNL-14365, Pacific Northwest National Laboratory, Richland, Washington.

Urie MW, GM Mong, PR Bredt, AP Poloski, JA Campbell, RD Scheele, OT Farmer, CZ Soderquist, SK Fiskum, RG Swoboda, LR Greenwood, MP Thomas, EW Hoppe, JJ Wagner, and LK Jagoda. 2004. Chemical Analysis and Physical Property Testing of 241-AZ-101Tank Waste-Supernatant and Centrifuged Solids. PNWD-3215, Rev 1 (WTP-RPT-048, Rev 1), Pacific Northwest National Laboratory, Richland, Washington. 
Van Boekel MAJS, and P Walstra. 1981. "Stability of Oil-in-water Emulsions with Crystals in the Disperse Phase." Colloids and Surfaces 3:109-118.

Walker DD, CL Crawford, and NE Bibler. 1994. "Radiolytic Bubble Formation and Level Changes in Simulated High-Level Waste Salts and Sludges-Application to HLW Storage Tanks.” In: Proceedings of Waste Management 1994, Tucson, Arizona, pp. 393-396.

Wasan D, A Nikolov, and A Shah. 2004. "Foaming and Antifoaming in Boiling Suspensions." Industrial and Engineering Chemistry Research 43:3812-3816.

Waste Treatment Plant (WTP). 2008. Waste Treatment and Immobilization Project Doc. No. 24590WTP-ES-PT-08-002, Rev 1, "Determination of Mixing Requirements for Pulse-Jet-Mixed Vessels in the Waste Treatment Plant,” Initial Issue March 7, 2008. Bechtel National, Inc., Richland, Washington.

Wheeler SJ. 1990. "Movement of Large Gas Bubbles in Unsaturated Fine-Grained Sediments." Marine Geotechnology (9):113-129. 
Appendix A

Data Table for Shear Strength 



\section{Appendix A: Data Table for Shear Strength}

The shear strength data considered in this report are provided in Tables A.1 and A.2 for the shear vane and core extrusion data respectively. Tank name, data reference, and sample identification are provided.

Table A.1. Shear Vane Data

\begin{tabular}{|c|c|c|c|c|}
\hline Tank & Reference & Sample & $\begin{array}{c}\text { Shear Strength } \\
\text { (Pa) }\end{array}$ & Comment \\
\hline \multirow[t]{3}{*}{ AN-103 } & 1 & & 5000 & $\begin{array}{c}320 \mathrm{~cm} \text { from tank } \\
\text { bottom }\end{array}$ \\
\hline & & & 6000 & $\begin{array}{c}320 \mathrm{~cm} \text { from tank } \\
\text { bottom }\end{array}$ \\
\hline & & & 8000 & $\begin{array}{c}320 \mathrm{~cm} \text { from tank } \\
\text { bottom }\end{array}$ \\
\hline \multirow[t]{6}{*}{ AN-102 } & 2 & $\begin{array}{l}\text { Core } 307 \text {, Segment } 19 \\
\text { Solids, Settled Solids, } \\
\text { Measurement made on the } \\
\text { lower } 1 / 2 \text { portion of } \\
\text { sample jar } 19686\end{array}$ & 1450 & \\
\hline & & $\begin{array}{l}\text { Core } 307, \text { Segment } 20 \\
\text { Solids, Settled Solids, } \\
\text { Measurement made on the } \\
\text { lower } 1 / 2 \text { portion of } \\
\text { sample jar } 19685\end{array}$ & 560 & \\
\hline & & $\begin{array}{c}\text { Core } 307 \text {, Segment 21A } \\
\text { Solids, Measurement } \\
\text { made on the lower } 1 / 2 \\
\text { portion of sample jar } \\
19659\end{array}$ & 955 & \\
\hline & & $\begin{array}{l}\text { Core } 307, \text { Segment } 20 \\
\text { Solids, Settled Solids, } \\
\text { Measurement made on the } \\
\text { upper } 1 / 2 \text { portion of } \\
\text { sample jar } 19685\end{array}$ & 874 & \\
\hline & & $\begin{array}{c}\text { Core } 307 \text {, Segment 21A } \\
\text { Solids, Measurement } \\
\text { made on the upper } 1 / 2 \\
\text { portion of sample jar } \\
19659 \\
\end{array}$ & 337 & \\
\hline & & $\begin{array}{l}\text { Core } 307, \text { Segment } 19 \\
\text { Solids, Settled Solids, } \\
\text { Measurement made on the } \\
\text { upper } 1 / 2 \text { portion of } \\
\text { sample jar } 19686\end{array}$ & 187 & \\
\hline
\end{tabular}


Table A.1 (cont'd)

\begin{tabular}{|c|c|c|c|c|}
\hline Tank & Reference & Sample & $\begin{array}{c}\text { Shear Strength } \\
\text { (Pa) }\end{array}$ & Comment \\
\hline \multirow[t]{8}{*}{ AN-107 } & 2 & $\begin{array}{c}\text { Core 304, Segment 18R } \\
\text { Lower Half Solids: Jar } \\
19472 \text { - 3rd Shear } \\
\text { Strength measurement. } \\
\text { Probe in bottom portion of } \\
\text { sample jar. }\end{array}$ & 3 & \\
\hline & & $\begin{array}{l}\text { Core 304, Segment 19R } \\
\text { Solids: Jar } 19027 \text { - 1st } \\
\text { Shear Strength } \\
\text { measurement. Probe in } \\
\text { top portion of sample jar. }\end{array}$ & 33 & \\
\hline & & $\begin{array}{l}\text { Core 304, Segment 19R } \\
\text { Solids: Jar } 19027 \text { - 2nd } \\
\text { Shear Strength } \\
\text { measurement. Probe in } \\
\text { middle portion of sample } \\
\text { jar. }\end{array}$ & 46 & \\
\hline & & $\begin{array}{l}\text { Core 304, Segment 19R } \\
\text { Solids: Jar } 19027 \text { - 3rd } \\
\text { Shear Strength } \\
\text { measurement. Probe in } \\
\text { bottom portion of sample } \\
\text { jar. }\end{array}$ & 42 & \\
\hline & & $\begin{array}{l}\text { Core 304, Segment 19R } \\
\text { Solids: Jar } 19027 \text { - 4th } \\
\text { Shear Strength } \\
\text { measurement. Probe } \\
\text { closer to bottom of sample } \\
\text { jar. }\end{array}$ & 42 & \\
\hline & & $\begin{array}{l}\text { Core 304, Segment } 20 \\
\text { Solids: Jar } 19465 \text { - 1st } \\
\text { Shear Strength } \\
\text { measurement. Probe in } \\
\text { top portion of sample jar. }\end{array}$ & 206 & \\
\hline & & $\begin{array}{l}\text { Core 304, Segment } 20 \\
\text { Solids: Jar } 19465 \text { - 2nd } \\
\text { Shear Strength } \\
\text { measurement. Probe in } \\
\text { middle portion of sample } \\
\text { jar. }\end{array}$ & 258 & \\
\hline & & $\begin{array}{l}\text { Core 304, Segment } 20 \\
\text { Solids: Jar } 19465 \text { - 3rd } \\
\text { Shear Strength } \\
\text { measurement. Probe in } \\
\text { bottom portion of sample } \\
\text { jar. }\end{array}$ & 323 & \\
\hline
\end{tabular}


Table A.1 (cont'd)

\begin{tabular}{|c|c|c|c|c|}
\hline Tank & Reference & Sample & $\begin{array}{c}\text { Shear Strength } \\
\text { (Pa) }\end{array}$ & Comment \\
\hline & & $\begin{array}{l}\text { Core 304, Segment 21A } \\
\text { Solids: Jar } 19467 \text { - 1st } \\
\text { Shear Strength } \\
\text { measurement. Probe in } \\
\text { top portion of sample jar. }\end{array}$ & 106 & \\
\hline & & $\begin{array}{l}\text { Core 304, Segment 21A } \\
\text { Solids: Jar } 19467 \text { - 2nd } \\
\text { Shear Strength } \\
\text { measurement. Probe in } \\
\text { middle portion of sample } \\
\text { jar. }\end{array}$ & 411 & \\
\hline & & $\begin{array}{l}\text { Core 304, Segment 21A } \\
\text { Solids: Jar } 19467 \text { - 3rd } \\
\text { Shear Strength } \\
\text { measurement. Probe in } \\
\text { bottom portion of sample } \\
\text { jar. }\end{array}$ & 610 & \\
\hline & & $\begin{array}{l}\text { Core 304, Segment 21B } \\
\text { Solids: Jar } 19471 \text { - 1st } \\
\text { Shear Strength } \\
\text { measurement. Probe in } \\
\text { bottom portion of sample } \\
\text { jar. }\end{array}$ & 60 & \\
\hline & & $\begin{array}{l}\text { Core 304, Segment 21B } \\
\text { Solids: Jar } 19471 \text { - 2nd } \\
\text { Shear Strength } \\
\text { measurement. Probe in } \\
\text { deeper bottom portion of } \\
\text { sample jar. }\end{array}$ & 56 & \\
\hline \multirow[t]{3}{*}{ AW-101 } & 1 & & 1600 & $\begin{array}{c}25 \mathrm{~cm} \text { from tank } \\
\text { bottom }\end{array}$ \\
\hline & & & 350 & $\begin{array}{l}75 \mathrm{~cm} \text { from tank } \\
\text { bottom }\end{array}$ \\
\hline & & & 550 & $\begin{array}{c}175 \mathrm{~cm} \text { from tank } \\
\text { bottom }\end{array}$ \\
\hline \multirow[t]{11}{*}{ AW-103 } & 3 & Core 265, Segment 5 & 456 & \\
\hline & & Core 265, Segment 6 & 913 & \\
\hline & & Core 265, Segment 7 & 931 & \\
\hline & & Core 265, Segment 8 & 521 & \\
\hline & & Core 265 , Segment 9 & 1769 & \\
\hline & & Core 265 , Segment 10 & 3538 & \\
\hline & & Core 267, Segment 5 & 279 & \\
\hline & & Core 267, Segment 6 & 521 & \\
\hline & & Core 267, Segment 7 & 1583 & \\
\hline & & Core 267, Segment 8 & 326 & \\
\hline & & Core 267, Segment 9 & 587 & \\
\hline
\end{tabular}


Table A.1 (cont'd)

\begin{tabular}{|c|c|c|c|c|}
\hline Tank & Reference & Sample & $\begin{array}{c}\text { Shear Strength } \\
\text { (Pa) }\end{array}$ & Comment \\
\hline \multirow[t]{13}{*}{ AY-101 } & 3 & Core 276, Segment $3 \mathrm{UH}$ & 2720 & \\
\hline & & Core 276, Segment $3 \mathrm{LH}$ & 6745 & \\
\hline & & Core 276, Segment 3R & 1193 & \\
\hline & & Core 278, Segment $2 \mathrm{LH}$ & 402 & \\
\hline & & Core 278, Segment $3 \mathrm{UH}$ & 18288 & \\
\hline & & Core 275, Segment 3 & 1442 & \\
\hline & & Core 275, Segment $2 \mathrm{LH}$ & 420 & \\
\hline & & Core 277, Segment $2 \mathrm{LH}$ & 302 & \\
\hline & & Core 277, Segment 3 & 1050 & \\
\hline & & Core 277, Segment 2 UH & 9 & \\
\hline & & Core 276, Segment $2 \mathrm{LH}$ & 3695 & \\
\hline & & Core 278, Segment 3 LH & 2598 & \\
\hline & & Core 278, Segment $2 \mathrm{UH}$ & 45 & \\
\hline \multirow[t]{11}{*}{ AY-102 } & 3 & $\begin{array}{c}\text { Core 270, Segment } 10 \\
\text { Upper Half Solids, } \\
\text { Homogenized }\end{array}$ & 6189 & \\
\hline & & $\begin{array}{l}\text { Core 270, Segment } 10 \\
\text { Lower Half Solids, } \\
\text { Homogenized } \\
\end{array}$ & 177 & \\
\hline & & $\begin{array}{l}\text { Core 270, Segment } 11 \\
\text { Upper Half Solids, } \\
\text { Homogenized }\end{array}$ & 70 & \\
\hline & & $\begin{array}{l}\text { Core } 270, \text { Segment } 1 \\
\text { Lower Half Solids, } \\
\text { Homogenized }\end{array}$ & 3318 & \\
\hline & & $\begin{array}{l}\text { Core 270, Segment } 12 \\
\text { Upper Half Solids, } \\
\text { Homogenized } \\
\end{array}$ & 890 & \\
\hline & & $\begin{array}{l}\text { Core 270, Segment } 1 \\
\text { Lower Half Solids, } \\
\text { Homogenized }\end{array}$ & 839 & \\
\hline & & $\begin{array}{l}\text { Core 273, Segment } 9 \\
\text { Solids, Homogenized }\end{array}$ & 1251 & \\
\hline & & $\begin{array}{l}\text { Core 273, Segment } 10 \\
\text { Upper Half Solids, } \\
\text { Homogenized }\end{array}$ & 507 & \\
\hline & & $\begin{array}{l}\text { Core 273, Segment } 10 \\
\text { Lower Half Solids, } \\
\text { Homogenized }\end{array}$ & 250 & \\
\hline & & $\begin{array}{l}\text { Core 273, Segment } 12 \\
\text { Upper Half Solids, } \\
\text { Homogenized }\end{array}$ & 474 & \\
\hline & & $\begin{array}{l}\text { Core } 273, \text { Segment } 12 \\
\text { Lower Half Solids, } \\
\text { Homogenized }\end{array}$ & 8096 & \\
\hline
\end{tabular}


Table A.1 (cont'd)

\begin{tabular}{|c|c|c|c|c|}
\hline Tank & Reference & Sample & $\begin{array}{l}\text { Shear Strength } \\
\text { (Pa) }\end{array}$ & Comment \\
\hline & & $\begin{array}{l}\text { Core } 271, \text { Segment } 9 \\
\text { Solids, Homogenized }\end{array}$ & 953 & \\
\hline & & $\begin{array}{l}\text { Core 271, Segment } 10 \\
\text { Upper Half Solids, } \\
\text { Homogenized }\end{array}$ & 414 & \\
\hline & & $\begin{array}{l}\text { Core 271, Segment } 10 \\
\text { Lower Half Solids, } \\
\text { Homogenized }\end{array}$ & 940 & \\
\hline & & $\begin{array}{l}\text { Core 271, Segment } 11 \\
\text { Upper Half Solids, } \\
\text { Homogenized }\end{array}$ & 164 & \\
\hline & & $\begin{array}{l}\text { Core 271, Segment } 11 \\
\text { Lower Half Solids, } \\
\text { Homogenized }\end{array}$ & 392 & \\
\hline & & $\begin{array}{l}\text { Core 273, Segment } 11 \\
\text { Upper Half Solids, } \\
\text { Homogenized }\end{array}$ & 93 & \\
\hline & & $\begin{array}{l}\text { Core 273, Segment } 11 \\
\text { Lower Half Solids, } \\
\text { Homogenized }\end{array}$ & 57 & \\
\hline & & $\begin{array}{l}\text { Core 272, Segment } 9 \\
\text { Solids, Homogenized }\end{array}$ & 1104 & \\
\hline & & $\begin{array}{l}\text { Core 271, Segment } 12 \\
\text { Upper Half Solids, } \\
\text { Homogenized }\end{array}$ & 720 & \\
\hline & & $\begin{array}{l}\text { Core 271, Segment } 12 \\
\text { Lower Half Solids, } \\
\text { Homogenized }\end{array}$ & 479 & \\
\hline & & $\begin{array}{c}\text { Core 272, Segment } 10 \\
\text { Upper Half Solids, } \\
\text { Homogenized }\end{array}$ & 435 & \\
\hline & & $\begin{array}{l}\text { Core 272, Segment } 10 \\
\text { Lower Half Solids, } \\
\text { Homogenized }\end{array}$ & 378 & \\
\hline & & $\begin{array}{l}\text { Core 272, Segment } 11 \\
\text { Upper Half Solids, } \\
\text { Homogenized }\end{array}$ & 470 & \\
\hline & & $\begin{array}{l}\text { Core 272, Segment } 11 \\
\text { Lower Half Solids, } \\
\text { Homogenized }\end{array}$ & 751 & \\
\hline & & $\begin{array}{l}\text { Core 272, Segment } 12 \\
\text { Upper Half Solids, } \\
\text { Homogenized }\end{array}$ & 835 & \\
\hline & & $\begin{array}{l}\text { Core 272, Segment } 12 \\
\text { Lower Half Solids, } \\
\text { Homogenized }\end{array}$ & 533 & \\
\hline
\end{tabular}


Table A.1 (cont'd)

\begin{tabular}{|c|c|c|c|c|}
\hline Tank & Reference & Sample & $\begin{array}{l}\text { Shear Strength } \\
\text { (Pa) }\end{array}$ & Comment \\
\hline \multirow[t]{2}{*}{ AZ-101 } & 3 & $\begin{array}{c}\text { Core 266, Segment 16R } \\
\text { Solids }\end{array}$ & 4190 & \\
\hline & & $\begin{array}{c}\text { Core 269, Segment } 16 \\
\text { Solids }\end{array}$ & 1769 & \\
\hline AZ-101 & 4 & Core $2, \mathrm{~S} 1,30 \mathrm{C}$ & 1500 & \\
\hline \multirow[t]{7}{*}{ AZ-102 } & 3 & $\begin{array}{c}\text { Core 262, Segment } 18 \\
\text { Solids }\end{array}$ & 866 & \\
\hline & & $\begin{array}{c}\text { Core 262, Segment 18R } \\
\text { Solids }\end{array}$ & 345 & \\
\hline & & $\begin{array}{c}\text { Core 268, Segment } 16 \\
\text { Solids }\end{array}$ & 736 & \\
\hline & & $\begin{array}{c}\text { Core 268, Segment } 17 \\
\text { Solids }\end{array}$ & 8194 & \\
\hline & & $\begin{array}{c}\text { Core 268, Segment 17R } \\
\text { Solids }\end{array}$ & 12105 & \\
\hline & & $\begin{array}{l}\text { Core 268, Segment } 18 \\
\text { Upper Half Solids }\end{array}$ & 1117 & \\
\hline & & $\begin{array}{c}\text { Core 268, Segment } 18 \\
\text { Lower Half Solids }\end{array}$ & 549 & \\
\hline \multirow[t]{2}{*}{ B-111 } & 2 & Core 29, Segment 3 Solids & 30 & \\
\hline & & Core 29, Segment 5 Solids & 90 & \\
\hline \multirow[t]{3}{*}{ B-201 } & 2 & Core 26 , Segment 8 Solids & 1220 & \\
\hline & & Core 26, Segment 2 Solids & 1410 & \\
\hline & & Core 26, Segment 5 Solids & 1310 & \\
\hline \multirow[t]{6}{*}{ B-202 } & & $\begin{array}{c}\text { Tank B-202, Core 24, } \\
\text { Segment } 2\end{array}$ & 200 & \\
\hline & & $\begin{array}{l}\text { Tank B-202, Core 24, } \\
\text { Segment } 4\end{array}$ & 750 & \\
\hline & & $\begin{array}{c}\text { Tank B-202, Core 24, } \\
\text { Segment } 6\end{array}$ & 670 & \\
\hline & & Core 25, Segment 3 Solids & 270 & \\
\hline & & Core 25, Segment 5 Solids & 470 & \\
\hline & & Core 25 , Segment 7 Solids & 270 & \\
\hline B-203 & 5 & Composite & 2280 & Composite, $25 \mathrm{C}$ \\
\hline \multirow[t]{5}{*}{ C-104 } & 3 & $\begin{array}{l}\text { Core 247, Segment } 3 \\
\text { Subsegment B Solids }\end{array}$ & 1304 & \\
\hline & & $\begin{array}{l}\text { Core 247, Segment } 3 \\
\text { Subsegment C Solids }\end{array}$ & 791 & \\
\hline & & $\begin{array}{l}\text { Core } 247, \text { Segment } 3 \\
\text { Subsegment D Solids }\end{array}$ & 2607 & \\
\hline & & $\begin{array}{l}\text { Core 247, Segment } 4 \\
\text { Upper Half Solids }\end{array}$ & 810 & \\
\hline & & $\begin{array}{c}\text { Core 247, Segment } 4 \\
\text { Lower Half Solids }\end{array}$ & 7077 & \\
\hline
\end{tabular}


Table A.1 (cont'd)

\begin{tabular}{|c|c|c|c|c|}
\hline Tank & Reference & Sample & $\begin{array}{c}\text { Shear Strength } \\
\text { (Pa) }\end{array}$ & Comment \\
\hline & & $\begin{array}{l}\text { Core 247, Segment } 1 \\
\text { Upper Half Solids }\end{array}$ & 345 & \\
\hline & & $\begin{array}{l}\text { Core } 247, \text { Segment } 1 \\
\text { Lower Half Solids }\end{array}$ & 289 & \\
\hline & & $\begin{array}{c}\text { Core 247, Segment } 2 \\
\text { Upper Half Solids }\end{array}$ & 521 & \\
\hline & & $\begin{array}{c}\text { Core 247, Segment } 2 \\
\text { Lower Half Solids }\end{array}$ & 2421 & \\
\hline & & $\begin{array}{l}\text { Core 247, Segment } 3 \\
\text { Subsegment A Solids }\end{array}$ & 885 & \\
\hline \multirow[t]{13}{*}{ C-107 } & 2 & $\begin{array}{c}\text { Core 287, Segment } 3 \\
\text { Solids }\end{array}$ & 1183 & \\
\hline & & $\begin{array}{c}\text { Core 287, Segment } 2 \\
\text { Solids }\end{array}$ & 1149 & \\
\hline & & $\begin{array}{c}\text { Core 287, Segment } 4 \\
\text { Solids }\end{array}$ & 7826 & \\
\hline & & $\begin{array}{c}\text { Core 287, Segment 4R } \\
\text { Solids }\end{array}$ & 228 & \\
\hline & & $\begin{array}{c}\text { Core 287, Segment 5R } \\
\text { Solids }\end{array}$ & 1087 & \\
\hline & & $\begin{array}{c}\text { Core 288, Segment } 1 \\
\text { Solids }\end{array}$ & 350 & \\
\hline & & $\begin{array}{c}\text { Core 288, Segment } 2 \\
\text { Solids }\end{array}$ & 432 & \\
\hline & & $\begin{array}{c}\text { Core 288, Segment } 3 \\
\text { Solids }\end{array}$ & 1050 & \\
\hline & & $\begin{array}{c}\text { Core 288, Segment 4R1 } \\
\text { Solids }\end{array}$ & 1230 & \\
\hline & & $\begin{array}{l}\text { Core 288, Segment 3R } \\
\text { Solids }\end{array}$ & 1119 & \\
\hline & & $\begin{array}{c}\text { Core 288, Segment 3R1 } \\
\text { Solids }\end{array}$ & 1014 & \\
\hline & & $\begin{array}{c}\text { Core 288, Segment 5R } \\
\text { Solids }\end{array}$ & 75 & \\
\hline & & $\begin{array}{c}\text { Core 287, Segment } 1 \\
\text { Solids }\end{array}$ & 650 & \\
\hline \multirow[t]{3}{*}{ SY-101 } & 2 & $\begin{array}{l}\text { Window C Core 22, } \\
\text { Segment 15, Direct }\end{array}$ & 730 & $50 \mathrm{C}$ \\
\hline & & $\begin{array}{l}\text { Window C Core 22, } \\
\text { Segment 19, Direct }\end{array}$ & 640 & $50 \mathrm{C}$ \\
\hline & & $\begin{array}{l}\text { Window C Core 22, } \\
\text { Segment 22, Direct }\end{array}$ & 2400 & $50 \mathrm{C}$ \\
\hline \multirow[t]{2}{*}{ SY-102 } & 2 & $\begin{array}{l}\text { Core 284, Segment } 17 \\
\text { Solids }\end{array}$ & 304 & \\
\hline & & $\begin{array}{l}\text { Core 284, Segment } 16 \\
\text { Subsegment A }\end{array}$ & 279 & \\
\hline
\end{tabular}


Table A.1 (cont'd)

\begin{tabular}{|c|c|c|c|c|}
\hline Tank & Reference & Sample & $\begin{array}{c}\text { Shear Strength } \\
\text { (Pa) }\end{array}$ & Comment \\
\hline & & $\begin{array}{l}\text { Core } 284, \text { Segment } 16 \\
\text { Subsegment B }\end{array}$ & 101 & \\
\hline SY-103 & 1 & & 2000 & $\begin{array}{l}70 \mathrm{~cm} \text { from tank } \\
\text { bottom }\end{array}$ \\
\hline & & & 1400 & $\begin{array}{l}120 \mathrm{~cm} \text { from tank } \\
\text { bottom }\end{array}$ \\
\hline & & & 2000 & $\begin{array}{l}160 \mathrm{~cm} \text { from tank } \\
\text { bottom }\end{array}$ \\
\hline & & & 1300 & $\begin{array}{l}220 \mathrm{~cm} \text { from tank } \\
\text { bottom }\end{array}$ \\
\hline & & & 1000 & $\begin{array}{l}270 \mathrm{~cm} \text { from tank } \\
\text { bottom }\end{array}$ \\
\hline T-107 & 2 & $\begin{array}{c}\text { Core } 50, \text { Segment } 2 \\
\text { Solids, Homogenized }\end{array}$ & 720 & \\
\hline T-204 & 5 & & 1520 & Composite, $25 \mathrm{C}$ \\
\hline T-203 & 5 & & 3770 & Composite, $25 \mathrm{C}$ \\
\hline U-107 & 2 & $\begin{array}{l}\text { Core } 245, \text { Segment } 4 \\
\text { Upper Half Solids }\end{array}$ & 51 & \\
\hline \multicolumn{5}{|c|}{$\begin{array}{l}\text { References: } \\
\text { 1. Gauglitz PA, and JT Aikin. 1997. Waste Behavior During Horizontal Extrusion: Effect of Waste } \\
\text { Strength for Bentonite and Kaolin/Ludox Simulants and Strength Estimates for Wastes from Hanford } \\
\text { Tanks 241-SY-103, AW-101, AN-103, and S-102. PNNL-11706. Pacific Northwest National Laboratory, } \\
\text { Richland, Washington. } \\
\text { 2. TWINS, Tank Waste Information System, http://twins.pnl.gov/twins3/twins.htm. } \\
\text { 3. Memorandum from DB Bechtold to KE Bell, RA Esch, and FH Steen. Correction of Shear Strength } \\
\text { Measurements Reported by 222S Laboratory. March 28, 2001. 8D500-DBB-01-018. Fluor Hanford, } \\
\text { Richland, WA. } \\
\text { 4. Gray WJ, ME Peterson, RD Scheele, and JM Tingey. 1993. Characterization of the Second Core } \\
\text { Sample of Neutralized Current Acid Waste from Double-Shell Tank 101-AZ. PNNL-13027. Pacific } \\
\text { Northwest National Laboratory, Richland, WA. } \\
\text { 5. Tingey JM, J Gao, CH Delegard, LM Bagaasen, and BE Wells. 2003. Physical Property and } \\
\text { Rheological Testing of Actual Transuranic Waste from Hanford Single-Shell Tanks. PNNL-14365. Pacific } \\
\text { Northwest National Laboratory, Richland, Washington. }\end{array}$} \\
\hline
\end{tabular}


Table A.2. Core Extrusion Data

\begin{tabular}{|c|c|c|c|c|}
\hline Tank & Reference & $\begin{array}{c}\text { Lower Bound Shear } \\
\text { Strength (Pa) }\end{array}$ & $\begin{array}{c}\text { Upper Bound } \\
\text { Shear Strength } \\
\text { (Pa) }\end{array}$ & Comment \\
\hline \multirow[t]{17}{*}{ A-101 } & 1 & 30 & 30 & 345 inches above tank bottom \\
\hline & & 70 & 70 & 180 inches above tank bottom \\
\hline & & 250 & 500 & 218 inches above tank bottom \\
\hline & & 340 & 440 & 270 inches above tank bottom \\
\hline & & 340 & 440 & 280 inches above tank bottom \\
\hline & & 390 & 800 & 237 inches above tank bottom \\
\hline & & 540 & 800 & 256 inches above tank bottom \\
\hline & & 495 & 890 & 295 inches above tank bottom \\
\hline & & 295 & 590 & 313 inches above tank bottom \\
\hline & & 75 & 150 & 175 inches above tank bottom \\
\hline & & 190 & 250 & 256 inches above tank bottom \\
\hline & & 95 & 120 & 327 inches above tank bottom \\
\hline & & 250 & 300 & 295 inches above tank bottom \\
\hline & & 340 & 445 & 336 inches above tank bottom \\
\hline & & 295 & 590 & 333 inches above tank bottom \\
\hline & & 340 & 590 & 232 inches above tank bottom \\
\hline & & 500 & 900 & 193 inches above tank bottom \\
\hline \multirow[t]{5}{*}{ AN-103 } & 2 & 50 & 150 & $386 \mathrm{~cm}$ above tank bottom \\
\hline & & 100 & 200 & $338 \mathrm{~cm}$ above tank bottom \\
\hline & & 700 & 1400 & $241 \mathrm{~cm}$ above tank bottom \\
\hline & & 500 & 1000 & $193 \mathrm{~cm}$ above tank bottom \\
\hline & & 700 & 1400 & $97 \mathrm{~cm}$ above tank bottom \\
\hline \multirow[t]{3}{*}{ AW-101 } & 2 & 50 & 150 & $241 \mathrm{~cm}$ above tank bottom \\
\hline & & 50 & 150 & $145 \mathrm{~cm}$ above tank bottom \\
\hline & & 50 & 150 & $48 \mathrm{~cm}$ above tank bottom \\
\hline \multirow[t]{12}{*}{ S-102 } & 2 & 40 & 100 & $483 \mathrm{~cm}$ above tank bottom \\
\hline & & 150 & 300 & $434 \mathrm{~cm}$ above tank bottom \\
\hline & & 250 & 500 & $386 \mathrm{~cm}$ above tank bottom \\
\hline & & 300 & 1600 & $338 \mathrm{~cm}$ above tank bottom \\
\hline & & 100 & 200 & $290 \mathrm{~cm}$ above tank bottom \\
\hline & & 250 & 500 & $290 \mathrm{~cm}$ above tank bottom \\
\hline & & 175 & 350 & $241 \mathrm{~cm}$ above tank bottom \\
\hline & & 600 & 1000 & $193 \mathrm{~cm}$ above tank bottom \\
\hline & & 500 & 1600 & $193 \mathrm{~cm}$ above tank bottom \\
\hline & & 1000 & 1700 & $145 \mathrm{~cm}$ above tank bottom \\
\hline & & 1000 & 2000 & $97 \mathrm{~cm}$ above tank bottom \\
\hline & & 400 & 800 & $48 \mathrm{~cm}$ above tank bottom \\
\hline \multirow[t]{5}{*}{ SY-103 } & 2 & 30 & 70 & $290 \mathrm{~cm}$ above tank bottom \\
\hline & & 100 & 200 & $240 \mathrm{~cm}$ above tank bottom \\
\hline & & 150 & 250 & $193 \mathrm{~cm}$ above tank bottom \\
\hline & & 300 & 450 & $145 \mathrm{~cm}$ above tank bottom \\
\hline & & 150 & 250 & $97 \mathrm{~cm}$ above tank bottom \\
\hline U-103 & 1 & 40 & 75 & 166 inches above tank bottom \\
\hline
\end{tabular}


Table A.2 (cont'd)

\begin{tabular}{|c|c|c|c|c|}
\hline \multirow[t]{19}{*}{ Tank } & Reference & $\begin{array}{c}\text { Lower Bound Shear } \\
\text { Strength (Pa) }\end{array}$ & $\begin{array}{c}\text { Upper Bound } \\
\text { Shear Strength } \\
\text { (Pa) }\end{array}$ & Comment \\
\hline & & 200 & 300 & 158 inches above tank bottom \\
\hline & & 25 & 25 & 172 inches above tank bottom \\
\hline & & 50 & 150 & 162 inches above tank bottom \\
\hline & & 100 & 250 & 142 inches above tank bottom \\
\hline & & 50 & 250 & 13 inches above tank bottom \\
\hline & & 800 & 1200 & 8 inches above tank bottom \\
\hline & & 600 & 800 & 24 inches above tank bottom \\
\hline & & 600 & 1000 & 62 inches above tank bottom \\
\hline & & 800 & 1600 & 72 inches above tank bottom \\
\hline & & 400 & 600 & 86 inches above tank bottom \\
\hline & & 1000 & 1600 & 100 inches above tank bottom \\
\hline & & 1000 & 2500 & 110 inches above tank bottom \\
\hline & & 35 & 35 & 170 inches above tank bottom \\
\hline & & 60 & 60 & 133 inches above tank bottom \\
\hline & & 100 & 200 & 120 inches above tank bottom \\
\hline & & 149 & 300 & 110 inches above tank bottom \\
\hline & & 800 & 1200 & 77 inches above tank bottom \\
\hline & & 25 & 25 & 48 inches above tank bottom \\
\hline \multirow[t]{26}{*}{$\mathrm{U}-107$} & 1 & 25 & 50 & 140 inches above tank bottom \\
\hline & & 25 & 75 & 135 inches above tank bottom \\
\hline & & 250 & 500 & 76 inches above tank bottom \\
\hline & & 200 & 400 & 62 inches above tank bottom \\
\hline & & 300 & 600 & 59 inches above tank bottom \\
\hline & & 200 & 300 & 55 inches above tank bottom \\
\hline & & 60 & 150 & 50 inches above tank bottom \\
\hline & & 100 & 200 & 39 inches above tank bottom \\
\hline & & 200 & 400 & 39 inches above tank bottom \\
\hline & & 40 & 60 & 13 inches above tank bottom \\
\hline & & 20 & 30 & 135 inches above tank bottom \\
\hline & & 50 & 50 & 130 inches above tank bottom \\
\hline & & 20 & 60 & 118 inches above tank bottom \\
\hline & & 20 & 75 & 113 inches above tank bottom \\
\hline & & 50 & 150 & 108 inches above tank bottom \\
\hline & & 25 & 60 & 131 inches above tank bottom \\
\hline & & 25 & 55 & 101 inches above tank bottom \\
\hline & & 150 & 300 & 92 inches above tank bottom \\
\hline & & 450 & 650 & 82 inches above tank bottom \\
\hline & & 300 & 450 & 73 inches above tank bottom \\
\hline & & 25 & 75 & 58 inches above tank bottom \\
\hline & & 60 & 200 & 113 inches above tank bottom \\
\hline & & 100 & 300 & 94 inches above tank bottom \\
\hline & & 75 & 200 & 79 inches above tank bottom \\
\hline & & 300 & 450 & 70 inches above tank bottom \\
\hline & & 300 & 500 & 55 inches above tank bottom \\
\hline
\end{tabular}


Table A.2 (cont'd)

\begin{tabular}{|c|c|c|c|c|}
\hline Tank & Reference & $\begin{array}{c}\text { Lower Bound Shear } \\
\text { Strength (Pa) }\end{array}$ & $\begin{array}{c}\text { Upper Bound } \\
\text { Shear Strength } \\
(\mathrm{Pa})\end{array}$ & Comment \\
\hline & & 25 & 25 & 127 inches above tank bottom \\
\hline & & 25 & 25 & 127 inches above tank bottom \\
\hline \multirow[t]{13}{*}{ AN-103 } & 3 & $166,13 \mathrm{~L}$ & 779 & 114 inches above tank bottom \\
\hline & & $166,15 \mathrm{~L}$ & 1255 & 76 inches above tank bottom \\
\hline & & $166,16 \mathrm{~L}$ & 1428 & 57 inches above tank bottom \\
\hline & & $166,16 \mathrm{U}$ & 1763 & 76 inches above tank bottom \\
\hline & & $166,16 \mathrm{U}$ & 991 & 76 inches above tank bottom \\
\hline & & $166,17 \mathrm{~L}$ & 991 & 38 inches above tank bottom \\
\hline & & $166,17 \mathrm{U}$ & 991 & 57 inches above tank bottom \\
\hline & & $166,18 \mathrm{~L}$ & 803 & 19 inches above tank bottom \\
\hline & & $167,11 \mathrm{~L}$ & 357 & 133 inches above tank bottom \\
\hline & & $167,14 \mathrm{~L}$ & 558 & 76 inches above tank bottom \\
\hline & & $167,15 \mathrm{~L}$ & 728 & 57 inches above tank bottom \\
\hline & & $167,15 \mathrm{U}$ & 1200 & 76 inches above tank bottom \\
\hline & & $167,17 \mathrm{~L}$ & 2618 & 19 inches above tank bottom \\
\hline \multirow[t]{5}{*}{ AN-104 } & 3 & 164,16 & 127 & 114 inches above tank bottom \\
\hline & & 164,17 & 286 & 95 inches above tank bottom \\
\hline & & $164,19 \mathrm{~L}$ & 606 & 38 inches above tank bottom \\
\hline & & $164,20 \mathrm{~L}$ & 795 & 19 inches above tank bottom \\
\hline & & $163,16 \mathrm{~L}$ & 226 & 95 inches above tank bottom \\
\hline \multirow[t]{3}{*}{ AW-101 } & 3 & $132,20 \mathrm{~L}$ & 351 & 38 inches above tank bottom \\
\hline & & $132,20 \mathrm{U}$ & 372 & 57 inches above tank bottom \\
\hline & & $132,20 \mathrm{U}$ & 165 & 57 inches above tank bottom \\
\hline \multirow[t]{21}{*}{ AY-102 } & 4 & 270,11 & 1460 & \\
\hline & & 270,12 & 1030 & \\
\hline & & 270,12 & 1300 & \\
\hline & & 270,12 & 1760 & \\
\hline & & 271,9 & 1440 & \\
\hline & & 271,11 & 1830 & \\
\hline & & 272,9 & 1550 & \\
\hline & & 272,11 & 1550 & \\
\hline & & 272,11 & 1340 & \\
\hline & & 272,12 & 620 & \\
\hline & & 273,10 & 860 & \\
\hline & & 273,12 & 790 & \\
\hline & & 273,12 & 960 & \\
\hline & & 273,12 & 1340 & \\
\hline & & 289,12 & 1370 & \\
\hline & & 289,12 & 1550 & \\
\hline & & 289,13 & 760 & \\
\hline & & 290,10 & 690 & \\
\hline & & 290,11 & 1020 & \\
\hline & & $290,12 \mathrm{~A}$ & 1790 & \\
\hline & & $290,12 \mathrm{RA}$ & 850 & \\
\hline
\end{tabular}

A. 11 
Table A.2 (cont'd)

\begin{tabular}{|c|c|c|c|c|}
\hline Tank & Reference & $\begin{array}{l}\text { Lower Bound Shear } \\
\text { Strength }(\mathrm{Pa})\end{array}$ & $\begin{array}{l}\text { Upper Bound } \\
\text { Shear Strength } \\
\text { (Pa) }\end{array}$ & Comment \\
\hline & & 300,11 & 1410 & \\
\hline & & 300,11 & 670 & \\
\hline & & 300,11 & 480 & \\
\hline & & 300,11 & 390 & \\
\hline \multirow[t]{14}{*}{ B-203 } & 3 & $115,1 \mathrm{~L}$ & 62 & 258 inches above tank bottom \\
\hline & & $115,4 \mathrm{U}$ & 50 & 210 inches above tank bottom \\
\hline & & $115,4 \mathrm{U}$ & 923 & 210 inches above tank bottom \\
\hline & & $115,5 \mathrm{~L}$ & 1445 & 182 inches above tank bottom \\
\hline & & $115,5 \mathrm{U}$ & 865 & 191 inches above tank bottom \\
\hline & & $115,6 \mathrm{~L}$ & 1615 & 163 inches above tank bottom \\
\hline & & $115,6 \mathrm{U}$ & 765 & 172 inches above tank bottom \\
\hline & & $115,7 \mathrm{~L}$ & 1179 & 144 inches above tank bottom \\
\hline & & $115,7 \mathrm{U}$ & 789 & 153 inches above tank bottom \\
\hline & & $115,8 \mathrm{~L}$ & 891 & 125 inches above tank bottom \\
\hline & & $115,8 \mathrm{U}$ & 1354 & 134 inches above tank bottom \\
\hline & & $115,9 \mathrm{~L}$ & 1095 & 106 inches above tank bottom \\
\hline & & $115,10 \mathrm{~L}$ & 1316 & 87 inches above tank bottom \\
\hline & & $115,10 \mathrm{U}$ & 1968 & 96 inches above tank bottom \\
\hline \multirow[t]{26}{*}{ B-204 } & 3 & $112,2 \mathrm{U}$ & 26 & 248 inches above tank bottom \\
\hline & & $112,3 \mathrm{U}$ & 104 & 229 inches above tank bottom \\
\hline & & $112,3 \mathrm{~L}$ & 450 & 220 inches above tank bottom \\
\hline & & $112,5 \mathrm{U}$ & 730 & 191 inches above tank bottom \\
\hline & & $112,6 \mathrm{~L}$ & 889 & 163 inches above tank bottom \\
\hline & & $112,6 \mathrm{U}$ & 298 & 172 inches above tank bottom \\
\hline & & $112,6 \mathrm{~L}$ & 1586 & 163 inches above tank bottom \\
\hline & & $112,7 \mathrm{~L}$ & 988 & 144 inches above tank bottom \\
\hline & & $112,8 \mathrm{~L}$ & 1213 & 125 inches above tank bottom \\
\hline & & $112,8 \mathrm{U}$ & 1152 & 135 inches above tank bottom \\
\hline & & $112,9 \mathrm{~L}$ & 1000 & 106 inches above tank bottom \\
\hline & & $112,9 \mathrm{U}$ & 1534 & 115 inches above tank bottom \\
\hline & & $112,10 \mathrm{~L}$ & 935 & 87 inches above tank bottom \\
\hline & & $112,10 \mathrm{U}$ & 860 & 96 inches above tank bottom \\
\hline & & $112,11 \mathrm{U}$ & 554 & 77 inches above tank bottom \\
\hline & & $112,12 \mathrm{~L}$ & 1153 & 49 inches above tank bottom \\
\hline & & $112,13 \mathrm{~L}$ & 1009 & 30 inches above tank bottom \\
\hline & & $112,13 \mathrm{U}$ & 921 & 39 inches above tank bottom \\
\hline & & $112,14 \mathrm{~L}$ & 500 & 11 inches above tank bottom \\
\hline & & $112,14 \mathrm{U}$ & 1066 & 20 inches above tank bottom \\
\hline & & $114,2 \mathrm{U}$ & 20 & 248 inches above tank bottom \\
\hline & & $114,2 \mathrm{~L}$ & 46 & 239 inches above tank bottom \\
\hline & & $114,2 \mathrm{~L}$ & 216 & 239 inches above tank bottom \\
\hline & & $114,3 \mathrm{~L}$ & 102 & 220 inches above tank bottom \\
\hline & & $114,4 \mathrm{~L}$ & 497 & 201 inches above tank bottom \\
\hline & & $114,5 \mathrm{~L}$ & 253 & 182 inches above tank bottom \\
\hline
\end{tabular}

A. 12 
Table A.2 (cont'd)

\begin{tabular}{|c|c|c|c|c|}
\hline \multirow[t]{16}{*}{ Tank } & Reference & $\begin{array}{c}\text { Lower Bound Shear } \\
\text { Strength (Pa) }\end{array}$ & $\begin{array}{l}\text { Upper Bound } \\
\text { Shear Strength } \\
\text { (Pa) }\end{array}$ & Comment \\
\hline & & $114,6 \mathrm{~L}$ & 347 & 163 inches above tank bottom \\
\hline & & $114,8 \mathrm{~L}$ & 753 & 125 inches above tank bottom \\
\hline & & $114,8 \mathrm{U}$ & 821 & 134 inches above tank bottom \\
\hline & & $114,9 \mathrm{~L}$ & 1201 & 106 inches above tank bottom \\
\hline & & $114,9 \mathrm{U}$ & 700 & 115 inches above tank bottom \\
\hline & & $114,10 \mathrm{~L}$ & 875 & 87 inches above tank bottom \\
\hline & & $114,10 \mathrm{U}$ & 629 & 96 inches above tank bottom \\
\hline & & $114,11 \mathrm{~L}$ & 1207 & 68 inches above tank bottom \\
\hline & & $114,11 \mathrm{~L}$ & 1217 & 68 inches above tank bottom \\
\hline & & $114,12 \mathrm{~L}$ & 826 & 49 inches above tank bottom \\
\hline & & $114,12 \mathrm{~L}$ & 1178 & 49 inches above tank bottom \\
\hline & & $114,13 \mathrm{~L}$ & 1410 & 30 inches above tank bottom \\
\hline & & $114,13 \mathrm{U}$ & 594 & 39 inches above tank bottom \\
\hline & & $114,14 \mathrm{~L}$ & 1091 & 11 inches above tank bottom \\
\hline & & $114,14 \mathrm{U}$ & 996 & 20 inches above tank bottom \\
\hline \multirow[t]{2}{*}{ SY-103 } & 3 & 62,12 & 206 & 57 inches above tank bottom \\
\hline & & 62,13 & 312 & 38 inches above tank bottom \\
\hline \multirow[t]{6}{*}{$\mathrm{T}-110$} & 3 & $180,2 \mathrm{~L}$ & 194 & 131 inches above tank bottom \\
\hline & & $180,4 \mathrm{~L}$ & 1000 & 93 inches above tank bottom \\
\hline & & $180,7 \mathrm{~L}$ & 971 & 36 inches above tank bottom \\
\hline & & $180,7 \mathrm{~L}$ & 1586 & 36 inches above tank bottom \\
\hline & & $180,8 \mathrm{~L}$ & 1990 & 17 inches above tank bottom \\
\hline & & $180,8 \mathrm{U}$ & 1296 & 27 inches above tank bottom \\
\hline \multirow[t]{4}{*}{$\mathrm{T}-201$} & 3 & $192,6 \mathrm{~L}$ & 1469 & 52 inches above tank bottom \\
\hline & & $192,6 \mathrm{U}$ & 864 & 61 inches above tank bottom \\
\hline & & $192,7 \mathrm{~L}$ & 2065 & 33 inches above tank bottom \\
\hline & & $192,7 \mathrm{U}$ & 2738 & 42 inches above tank bottom \\
\hline \multirow[t]{8}{*}{$\mathrm{T}-202$} & 3 & $191,1 \mathrm{~L}$ & 84 & 90 inches above tank bottom \\
\hline & & $191,1 \mathrm{U}$ & 68 & 99 inches above tank bottom \\
\hline & & $191,3 \mathrm{~L}$ & 572 & 52 inches above tank bottom \\
\hline & & $191,4 \mathrm{~L}$ & 996 & 33 inches above tank bottom \\
\hline & & $191,4 \mathrm{U}$ & 901 & 42 inches above tank bottom \\
\hline & & $191,5 \mathrm{~L}$ & 794 & 14 inches above tank bottom \\
\hline & & $191,5 \mathrm{~L}$ & 1112 & 14 inches above tank bottom \\
\hline & & $191,5 \mathrm{U}$ & 1027 & 23 inches above tank bottom \\
\hline \multirow[t]{9}{*}{$\mathrm{T}-203$} & 3 & $190,1 \mathrm{~L}$ & 79 & 175 inches above tank bottom \\
\hline & & $190,1 \mathrm{U}$ & 70 & 185 inches above tank bottom \\
\hline & & $190,1 \mathrm{U}$ & 62 & 185 inches above tank bottom \\
\hline & & $190,2 \mathrm{~L}$ & 387 & 156 inches above tank bottom \\
\hline & & $190,4 \mathrm{~L}$ & 903 & 118 inches above tank bottom \\
\hline & & $190,5 \mathrm{~L}$ & 1315 & 99 inches above tank bottom \\
\hline & & $190,5 \mathrm{U}$ & 926 & 109 inches above tank bottom \\
\hline & & $190,6 \mathrm{~L}$ & 1196 & 80 inches above tank bottom \\
\hline & & $190,7 \mathrm{~L}$ & 835 & 61 inches above tank bottom \\
\hline
\end{tabular}


Table A.2 (cont'd)

\begin{tabular}{|c|c|c|c|c|}
\hline \multirow[t]{5}{*}{ Tank } & Reference & $\begin{array}{l}\text { Lower Bound Shear } \\
\text { Strength }(\mathrm{Pa})\end{array}$ & $\begin{array}{l}\text { Upper Bound } \\
\text { Shear Strength } \\
\text { (Pa) }\end{array}$ & Comment \\
\hline & & $190,8 \mathrm{~L}$ & 1130 & 42 inches above tank bottom \\
\hline & & $190,9 \mathrm{~L}$ & 1605 & 23 inches above tank bottom \\
\hline & & $190,9 \mathrm{U}$ & 1337 & 33 inches above tank bottom \\
\hline & & $190,1 \mathrm{~L}$ & 863 & 175 inches above tank bottom \\
\hline \multirow[t]{13}{*}{$\mathrm{T}-204$} & 3 & $188,1 \mathrm{~L}$ & 95 & 187 inches above tank bottom \\
\hline & & $188,1 \mathrm{U}$ & 47 & 196 inches above tank bottom \\
\hline & & $188,2 \mathrm{U}$ & 63 & 177 inches above tank bottom \\
\hline & & $188,3 \mathrm{U}$ & 58 & 158 inches above tank bottom \\
\hline & & $188,4 \mathrm{~L}$ & 581 & 130 inches above tank bottom \\
\hline & & $188,5 \mathrm{~L}$ & 752 & 111 inches above tank bottom \\
\hline & & $188,6 \mathrm{~L}$ & 1476 & 92 inches above tank bottom \\
\hline & & $188,6 \mathrm{U}$ & 1086 & 101 inches above tank bottom \\
\hline & & $188,7 \mathrm{U}$ & 1017 & 82 inches above tank bottom \\
\hline & & $188,8 \mathrm{~L}$ & 1637 & 54 inches above tank bottom \\
\hline & & $188,8 \mathrm{U}$ & 1165 & 63 inches above tank bottom \\
\hline & & $188,9 \mathrm{~L}$ & 1990 & 35 inches above tank bottom \\
\hline & & $188,9 \mathrm{U}$ & 747 & 44 inches above tank bottom \\
\hline \multicolumn{5}{|c|}{$\begin{array}{l}\text { References: } \\
\text { 1. Hedengren DC, TA Hu, MA Kufahl, DJ McCain, CW Stewart, JL Huckaby, LA Mahoney, and KG Rappe.. } \\
\text { 2001. Data and Observations of Single-Shell Flammable Gas Watch List Tank Behavior. RPP-7249, } \\
\text { CH2MHILL Hanford Group, Inc., Richland, Washington. } \\
\text { 2. Gauglitz PA, and JT Aikin. 1997. Waste Behavior During Horizontal Extrusion: Effect of Waste Strength for } \\
\text { Bentonite and Kaolin/Ludox Simulants and Strength Estimates for Wastes from Hanford Tanks 241-SY-103, AW- } \\
\text { 101, AN-103, and S-102. PNNL-11706. Pacific Northwest National Laboratory, Richland, Washington. } \\
\text { 3. Rassat SD, LA Mahoney, BE Wells, DP Mendoza, and DD Caldwell. 2003. Assessment of Physical } \\
\text { Properties of Transuranic Waste in Hanford Single-Shell Tanks. PNNL-14221. Pacific Northwest National } \\
\text { Laboratory, Richland, WA. } \\
\text { 4. Onishi Y, and BE Wells. 2004. Feasibility Study on Using Two Mixer Pumps for Tank 241-AY-102 Waste } \\
\text { Mixing. PNNL-14763. Pacific Northwest National Laboratory, Richland, WA. }\end{array}$} \\
\hline
\end{tabular}




\section{Appendix B}

Sludge Weight Analysis 



\section{Appendix B: Sludge Weight Analysis}

This appendix contains a letter report that was originally provided to $\mathrm{CH} 2 \mathrm{M}$ Hill Hanford Group, Inc. in 2004 The original report, identified as TWS04.009, was not cleared for public release, and its distribution was limited. It is being included here to document the analysis. The information in this appendix has been reviewed following the quality requirements described in Section 1.1 and shown below.

\section{Quality Requirements}

Pacific Northwest National Laboratory's (PNNL's) Quality Assurance Program is based on requirements defined in U.S. Department of Energy (DOE) Order 414.1C, Quality Assurance, and 10 CFR 830, Energy/Nuclear Safety Management, Subpart A-Quality Assurance Requirements (a.k.a. the Quality Rule). PNNL has chosen to implement the requirements of DOE Order 414.1C and 10 CFR 830, Subpart A by integrating them into the laboratory's management systems and daily operating processes. The procedures necessary to implement the requirements are documented through PNNL's Standards-Based Management System.

PNNL implements the River Protection Project—Waste Treatment Plant Support Program (RPP-WTP) quality requirements by performing work in accordance with the RPP-WTP Quality Assurance Plan (RPP-WTP-QA-001, QAP). Work will be performed to the quality requirements of NQA-1-1989, Part I, Basic and Supplementary Requirements, NQA-2a-1990, Part 2.7, and DOE/RW-0333P, Rev 13, Quality Assurance Requirements and Descriptions (QARD). These quality requirements are implemented through the RPP-WTP Quality Assurance Manual (RPP-WTP-QA-003, QAM).

This report is based on data from testing performed under prior programs as referenced. PNNL assumes that the data from these references have been fully reviewed and documented in accordance with the analysts' QA programs. PNNL only analyzed data from the referenced documentation, with the single exception of some shear strength estimates reported in Figure 3.4 that were made previously but not previously published. At PNNL, the performed calculations as well as the documentation and reporting of results and conclusions were performed in accordance with the RPP-WTP QAM. Internal verification and validation activities were addressed by conducting an independent technical review of the final data report in accordance with PNNL procedure QA-RPP-WTP-604. This review verifies that the reported results are traceable and that inferences and conclusions are soundly based. This review procedure is part of PNNL's RPP-WTP QAM. 
Page intentionally blank.

B. 2 


\section{Estimating the Shear Strength of Hanford Waste Based on Sampler Static Equilibrium}

BE Wells

Pacific Northwest National Laboratory

Z Ritzke

CH2MHILL Hanford Group, Inc.

Pacific Northwest National Laboratory

Richland, Washington 
Page intentionally blank. 


\subsection{Introduction}

Hanford waste tanks may contain both solid and liquid waste. In solids-containing waste tanks, the solids are typically settled to the tank bottom and form a sediment layer under the supernatant liquid. A floating crust layer may also be present. The waste sediment is a solid, liquid, and gas matrix that varies in composition from tank to tank. Methods to determine the volume or thickness of the sediment layer include waste temperature profiles, ball rheometer data, neutron and gamma logs, and core sampling (Hedengren et al. 2000). Sludge weights or densitometers may also be employed. For these techniques, a device is lowered into the waste through the liquid layer until vertical motion is halted. The location at which the device ceases to descend is identified as the interface between the sediment and liquid layers.

Waste management and retrieval issues such as flammable gas retention and release and waste mixing and transport are dependent on physical parameters of the sediment including thickness and yield stress in shear. Yield stress in shear, or shear strength as it is commonly referred to in the literature, may be defined as the point at which the sediment material ceases to deform like a solid under applied stress but instead flows like a truly viscous material with a finite viscosity. The ability of a sludge weight type device to descend under its own weight into and through a sediment is therefore dependent on the sediment's shear strength.

It is of interest to determine the relation between the identified sediment/liquid interface and the sediment's shear strength for numerous reasons including:

- Tank solids inventory. Does the identified sediment level account for all of the tank solids? That is, is there a "weak" region of solids-containing sediment that the sludge weight (or similar) does not identify? Solids content may directly affect waste retrieval and storage methodologies.

- Gas retention inventory. Gas is retained in sediment with sufficient shear strength (Gauglitz et al. 1996, etc.). Does the identified sediment level account for all of the sediment capable of retaining gas? Flammable gas is a significant safety issue.

This document provides an estimate for the sediment shear strength at the static equilibrium of a sludge weight or densitometer in that sediment, based on the available literature. In Section 2, an overview of the approach is discussed. Data and results from the reviewed literature are presented in Section 3, and applications of these data are discussed. Recommendations are provided in Section 4. Cited references are listed in Section 5. 


\subsection{Approach}

Limitations of available instrumentation, the varied sediment conditions and compositions, ${ }^{(a)}$ and the influence of the sediment history for a given tank or waste sample render the determination of in situ sediment shear strength a challenging task. Investigations attempting to correlate sediment shear strength with other measures of the material's rheology are therefore also subject to great uncertainty.

No direct analytical solutions have been developed to determine shear strength based on tensile strength given the uncertainty of the various (e.g. von Mises, Tresca, Taylor...) criterion for Hanford wastes. However, visual (Gauglitz and Aikin 1997) and extrusion length (Rassat et al. 2003) correlations between horizontal core extrusions (representing tensile strength) and shear strength of Hanford sediment and simulants have shown acceptable results. The visual results of Gauglitz and Aikin (1997) generally agreed within a factor of two with in situ shear strength data, and it was concluded in Rassat et al. (2003) that, in the absence of definitive in situ measurements, or in support of them, the extrusion length methodology is expected to produce representative results for the waste shear strength.

For sludge weight type devices, correlation of a sediment's compressive strength with its shear strength is required. In the simplest approach, the compressive strength of the sediment may be estimated by the pressure required to support the device at static equilibrium. How does this compressive strength correlate with the shear strength? As with tensile strength, analytical solutions are uncertain in application. The current project scope does not allow for experimental work on waste samples/simulants. Therefore, the literature is reviewed for data that presents or will allow for compressive/shear strength correlations. Hanford experience focused the review on the movement of spheres in non-Newtonian fluids (from ball rheometer and gas retention investigations; see Hedengren et al. (2000) and Stewart et al. (1996) for ball rheometer description, Gauglitz et al. (1996) for gas retention considerations). Results from the SY-101 crust strength evaluation were also considered (Rassat et al. 2000). Extensive literature searches were also performed; compressive and shear strength comparisons from various slurries/sediments were identified.

(a) The rheological properties of a sediment depend on parameters including solids loading, particle size and distribution, material microstructure, chemistry of the system, surface-chemistry properties of the particles, temperature, and gas content. 


\subsection{Estimating Shear Strength}

The approaches presented in Section 2 are utilized to estimate the shear strength at which a sediment would prevent downward motion of a sludge weight or densitometer. In Section 3.1, investigations of the movement of spheres in non-Newtonian fluids, which provide methodologies for estimating shear strength directly based on a sampling devices physical configuration, are considered. Application of these results to a sludge weight and densitometer are discussed. The compressive force required to impinge an object into a simulant with a known shear strength was investigated for evaluation of the historic floating crust layer in SY-101. Results from this analysis are summarized in Section 3.2. Compressive and shear strength comparisons from various slurries/sediments as identified from the literature are presented in Section 3.3.

\subsection{Static Equilibrium of Spheres}

The equilibrium and motion of spheres in non-Newtonian (e.g. Bingham plastic, Herschel-Buckley, etc.) fluids has been studied. A dimensionless parameter $\mathrm{Y}$, the critical gravity yield number, is defined by equating the buoyant weight of a sphere to the vertical component of the yield stress (in shear) acting over the surface of the sphere or

$$
Y=\frac{\tau}{\operatorname{gd} \Delta \rho}
$$

neglecting constants. The shear strength is denoted by $\tau$, gravitational acceleration by $\mathrm{g}$, sphere diameter by $\mathrm{d}$, and $\Delta \rho$ is the difference in the sphere and bulk fluid densities (Attapatu et al. 1995, Chhabra 1992). Andres' (1961) analytical solution has $Y=0.22$. However, he noted that values from 0.06 to 0.59 had been determined, and that better results could be achieved through experimental analyses for the fluid in question.

The dimensionless yield stress (shear strength) $\tau *$ is also often considered and evaluated (Beris et al. 1985, Blackery and Mitsoulis 1997, Beaulne and Mitsoulis 1997) and is related to the critical gravity yield number by

$$
\mathrm{Y}=\frac{\tau *}{3}
$$

A summary of the critical gravity yield numbers for the incipient motion of a sphere under gravity is presented in Chhabra (1992). The results fall into two groups: 1) $\mathrm{Y} \sim 0.04-0.08$ results from numerical solutions of the equations of motion, from those experiments using observation of motion/no motion of spheres in free fall, and from the measurement of residual forces after the cessation of fluid motion, and 2) $Y \sim 0.2$ from analytical solutions (Andres 1961) and measurements of a tethered sphere in an unsheared medium. The numerical results of Beris et al. (1985) fall in the former group at $Y=0.048$. Similarly, Blackery and Mitsoulis (1997) and Beaulne and Mitsoulis (1997) numerically achieve critical gravity yield numbers of 0.054 and 0.065 respectively. 
Two arguments may be made to consider the numerical (Y 0.2) or motion/no motion ( $\mathrm{Y} \sim 0.04-0.08$ ) results for the current sludge weight/densitometer problem. First, arguing against the analytical and tethered sphere results, Ansley and Smith (1967) note that, once motion ceases, the stress distributions are not known. Further, the pressure may not be hydrostatic so that the buoyant force on the sphere may not be relevant. Consideration of a sphere in a medium suggests that normal as well as shear stresses contribute to supporting the sphere, which makes the apparently larger critical gravity yield number result not unexpected for a balance computed solely on the vertical component of the shear strength as was done by Andres (1961). Second, the sludge weight or densitometer descending on/into the sediment more closely resembles the motion/no motion experiments. Therefore, for a spherical sludge weight or densitometer, the critical gravity yield number is $Y \sim 0.04-0.08$. The most probable value may be given by Attapatu et al. (1995), who report that the available experimental data indicate $Y \sim 0.061$. In regards to the uncertainty of the results, Attapatu et al. (1995) and Chhabra (1992) suggest that methods used to determine the materials shear strength and experimental setup may contribute.

Insight into the applicability of $\mathrm{Y} \sim 0.061$ for cessation of downward motion for a sludge weight or densitometer may be gained by examining the ball rheometer results (Stewart et al. 1996, Hedengren et al. 2000) as compared to shear strength estimates from the extrusion length methodology (Rassat et al. 2003a). The extrusion length methodology uses waste simulant data to correlate the horizontal extrusion length of waste core samples to a shear strength. The ball rheometer was lowered through the sediment in specific double-shell tanks (DSTs) until motion was stopped. Meyer et al. (1997), using Y=0.061, determined that the ball was supported when the shear strength of the sediment was at least $900 \mathrm{~Pa}$. Table 3.1 gives the ball rheometer elevation at the cessation of motion and extrusion length shear strength estimates at similar elevations.

Shear strength measurements may vary horizontally and vertically throughout sediment layers (Stewart et al. 1996, Hedengren et al. 2000, Rassat et al. 2003a, etc.). Further, the extrusion length methodology can only be expected to produce representative results, and the extrusion length estimate elevations may differ from the ball rheometer evaluations (Rassat et al. 2003a). Note also that the methodology evaluation criterion for the extrusion length results is the ball rheometer data. ${ }^{(a)}$ Given the uncertainty of the methodologies, reasonable agreement (up to a factor of 3 ) is shown. While certainly not providing conclusive support for a specific critical gravity yield number for spheres in Hanford sediment, this data does not refute $\mathrm{Y} \sim 0.061$. Further, these data support the numerical or motion/no motion critical gravity yield number as opposed to the analytical and tethered sphere results, as a higher Y would imply a higher shear strength from the ball rheometer data.

(a) Comparison of extrusion length results to ex-tank shear vane measurements has also shown reasonable comparisons in sludge tanks (Barker et al. 2003, Onishi and Wells 2004). 
Table 3.1. Hanford DST Sludge Weight Sediment Depth and Associated Shear Strength

\begin{tabular}{||c|c|c|c||}
\hline $\begin{array}{c}\text { Tank } \\
\text { Name }\end{array}$ & $\begin{array}{c}\text { Ball Rheometer } \\
\text { Stopped (in) [riser] }\end{array}$ & $\begin{array}{c}\text { Ball Rheometer Shear } \\
\text { Strength (Pa) }\end{array}$ & $\begin{array}{c}\text { Median Extrusion Length Shear Strength } \\
\text { (Pa) [cores, segments] }\end{array}$ \\
\hline AN-103 & $89[16 \mathrm{~B}], 62[1 \mathrm{~B}]$ & 900 & $1,100[\mathrm{C} 166, \mathrm{~S} 15,16,17 ; \mathrm{C} 167, \mathrm{~S} 14,15]$ \\
\hline AN-104 & $26[16 \mathrm{~B}], 29[1 \mathrm{~B}]$ & 900 & $700[\mathrm{C} 164, \mathrm{~S} 19,20]$ \\
\hline AW-101 & $37[1 \mathrm{C}]$ & 900 & $400[\mathrm{C} 132, \mathrm{~S} 20]$ \\
\hline SY-103 & $40[17 \mathrm{C}], 41[22 \mathrm{~A}]$ & 900 & $300[\mathrm{C} 62, \mathrm{~S} 13]$ \\
\hline
\end{tabular}

\subsubsection{Static Equilibrium Applied to Sludge Weight}

The tank sludge level assembly, Hanford drawing H-2-71950, consists of a sludge weight suspended on a cable. The sludge weight is comprised of a rod assembly and vertically oriented 1.5 inch long by 2.375 inch diameter stainless steel pipe with a wall thickness of 0.436 inch. As such, the direct application of the spherical results is not applicable. As discussed previously, it is expected that a static sphere will be supported by significant normal as well as shear stresses. For a vertically aligned thin-walled pipe, it is reasonable that the shear stresses will dominate. However, the ratio of the bottom horizontal surface area of the sludge weight compared to the cylinder's interior and exterior surface area is approximately 0.15 , indicating that, as with a sphere, normal stresses may be significant. Therefore, though an analytical solution for the sludge weight is expected to be elevated, it will provide an upper bound. For the cessation of vertical motion, the buoyant weight of the pipe,

$$
\mathrm{W}_{\mathrm{B}}=\pi \mathrm{L}\left(\mathrm{r}_{\mathrm{o}}^{2}-\mathrm{r}_{\mathrm{i}}^{2}\right) \mathrm{g} \Delta \rho
$$

is equal to the shear stress acting on the pipe surface

$$
\mathrm{S}=2 \pi \mathrm{L}\left(\mathrm{r}_{\mathrm{o}}+\mathrm{r}_{\mathrm{i}}\right) \tau
$$

where $L$ is the pipe length and $r_{o}$ and $r_{i}$ are the outer and inner pipe radii. The required shear strength for static equilibrium is therefore

$$
\tau=\frac{\left(r_{o}^{2}-r_{i}^{2}\right) g \Delta \rho}{2\left(r_{o}+r_{i}\right)}
$$

With the mass of the rod assembly, the apparent density of the pipe section of the sludge weight is approximately $8,430 \mathrm{~kg} / \mathrm{m}^{3}$. The median DST sediment density from Barker and Hedengren (2003) is $1,560 \mathrm{~kg} / \mathrm{m}^{3}$. An upper bound for the shear strength to support the sludge weight is therefore approximately $370 \mathrm{~Pa}$. As discussed, however, it is expected that this result is affected by normal stresses.

If normal stresses for this hollow cylinder contributed the same fraction of the total support as that for spheres, the shear strength prediction from Eq. (3.5) could be elevated by a factor of 3.3, i.e., the ratio of spherical critical gravity numbers neglecting/including normal stresses (approximately $0.2 / 0.061$ ). 
Straight application of this ratio to the sludge weight, although questionable, indicates a required shear strength of approximately $110 \mathrm{~Pa}$.

More compelling evidence of the apparent contribution of normal stresses and indication for a meaningful correlation can be taken from in-tank data. Sludge weight sediment level data is compared to bestestimate shear strength data at the same elevation for select DSTs in Table 3.2. For AY-102 and AZ-101, the horizontal core extrusions were evaluated for shear strength estimates. Applying the extrusion length method to the upper-sediment cores gave shear strength estimates clearly exceeding the analytical estimate (370 Pa) from Eq. (3.5). These results therefore only serve to reinforce that "strong" sediment will resist vertical motion of the sludge weight. The relatively small differences in the sediment levels between the sludge weight and core profiles (Table 3.2, columns 2 and 3) are not considered to be meaningful.

In AW-101, shear strength estimates from the ball rheometer are available at intervals throughout the sediment depth (Stewart et al. 1996, Hedengren et al. 2000). The shear strength is shown to increase with depth into the sediment, Figure 3.1. The alternative sediment depth measurements also show a deeper sediment layer than the 67 inch value from the sludge weight. ${ }^{\text {(a) }}$ Therefore, the sludge weight apparently moved through "weaker" sediment until it reached sediment capable of supporting its buoyant weight. These results indicate, with acknowledgement of the illustrated variability of the sediment shear strength depending on sampling location and the time difference of the measurements (1987 for sludge weight, 1995 for the ball rheometer ${ }^{(b)}$ that the sludge weight is supported by sediment of approximately $160 \mathrm{~Pa}$ (average of $128 \mathrm{~Pa}$ in Riser 13A and $195 \mathrm{~Pa}$ in Riser 1C). This result is in remarkable agreement with the analytical result "corrected" for normal stress as discussed above (110 Pa) and within a factor of 2.3 of the $370 \mathrm{~Pa}$ value computed directly from Eq. (3.5) assuming only shear stresses support the sludge weight.

\subsubsection{Static Equilibrium Applied to Densitometer}

A potential densitometer used at Hanford is the Enraf buoyancy gauge (Hanford drawing H-2-817634). The displacer assembly used for the buoyancy gauge is a vertically oriented cylinder $(1.6875 \mathrm{inch}$ diameter, 4.5 inch length including the conical ends, VI\# 31560). The bulk density of this assembly is approximately $1,780 \mathrm{~kg} / \mathrm{m}^{3}\left(0.24 \mathrm{~kg}, 1.35 \mathrm{E}-4 \mathrm{~m}^{3}\right.$, Work Package 2E-98-01244W).

(a) AW-101 was filled to its current volume in 1986 (Hedengren et al. 2000). The sludge weight measurement is from September 3, 1987.

(b) The buoyant displacement gas release events observed in AW-101 (Hedengren et al. 2000) are expected to keep the sediment in a semi-disturbed state, i.e., strength may only build up for a limited time until the sediment is again disturbed. The waste state in 1987 is therefore not necessarily precluded from being similar to that in 1995. 
Recalculating Equations (3.3) to (3.5) in terms of a cylindrical displacer (the small conical sections of the displacer are ignored), the shear strength for no motion is

$$
\tau=\frac{1}{4} \operatorname{dg} \Delta \rho
$$

With $\mathrm{d}=1.6875$ inches and $\Delta \rho=1,780-1,560=220 \mathrm{~kg} / \mathrm{m}^{3}$, the shear strength required to support the densitometer is approximately $25 \mathrm{~Pa}$. The ratio of the projected bottom horizontal surface area of the displacer to the cylindrical vertical surface area is approximately 0.09 , indicating that normal stresses may have an influence; $25 \mathrm{~Pa}$ may be an upper bound for the analyzed displacer as determined by this technique.

Table 3.2. Hanford DST Sludge Weight Sediment Depth and Associated Shear Strength

\begin{tabular}{|c|c|c|c|}
\hline Tank Name & $\begin{array}{l}\text { Sludge Weight } \\
\text { Sediment Depth } \\
\text { (in) }\end{array}$ & $\begin{array}{c}\text { Alternative Methodology } \\
\text { Sediment Depth } \\
\text { (in) }\end{array}$ & $\begin{array}{c}\text { Shear Strength } \\
\text { (Pa) }\end{array}$ \\
\hline AW-101 & 67 & $\begin{array}{l}\text { 126: Multi Instrumentation } \\
\text { Tree validation probe } \\
\text { (Hedengren et al. 2000) } \\
\text { 102, 109: ball rheometer, } \\
\text { Risers } 1 \mathrm{C} \text { and } 13 \mathrm{~A} \\
\text { (Hedengren et al. } 2000 \text { ) }\end{array}$ & $\begin{array}{l}\text { 195, 128: deployment of ball } \\
\text { rheometer in Risers } 1 \mathrm{C} \text { and } 13 \mathrm{~A} \\
\text { (interpolation to } 67 \text { inches from } \\
\text { Stewart et al. 1996, Hedengren } \\
\text { et al. 2000) }\end{array}$ \\
\hline AY-102 & 61 & 66: Core 289 & $\begin{array}{l}\text { 1,436, 1,550: extrusion length } \\
\text { methodology, Core } 271 \text { Segment } \\
9 \text { and Core } 272 \text { Segment } 9 \\
\text { (Onishi and Wells, 2004) }\end{array}$ \\
\hline AZ-101 & 16 & 19: Core 283 & $\begin{array}{l}\text { 613: extrusion length } \\
\text { methodology, Core } 283 \text { Segment } \\
17 \mathrm{~A}^{1}\end{array}$ \\
\hline
\end{tabular}




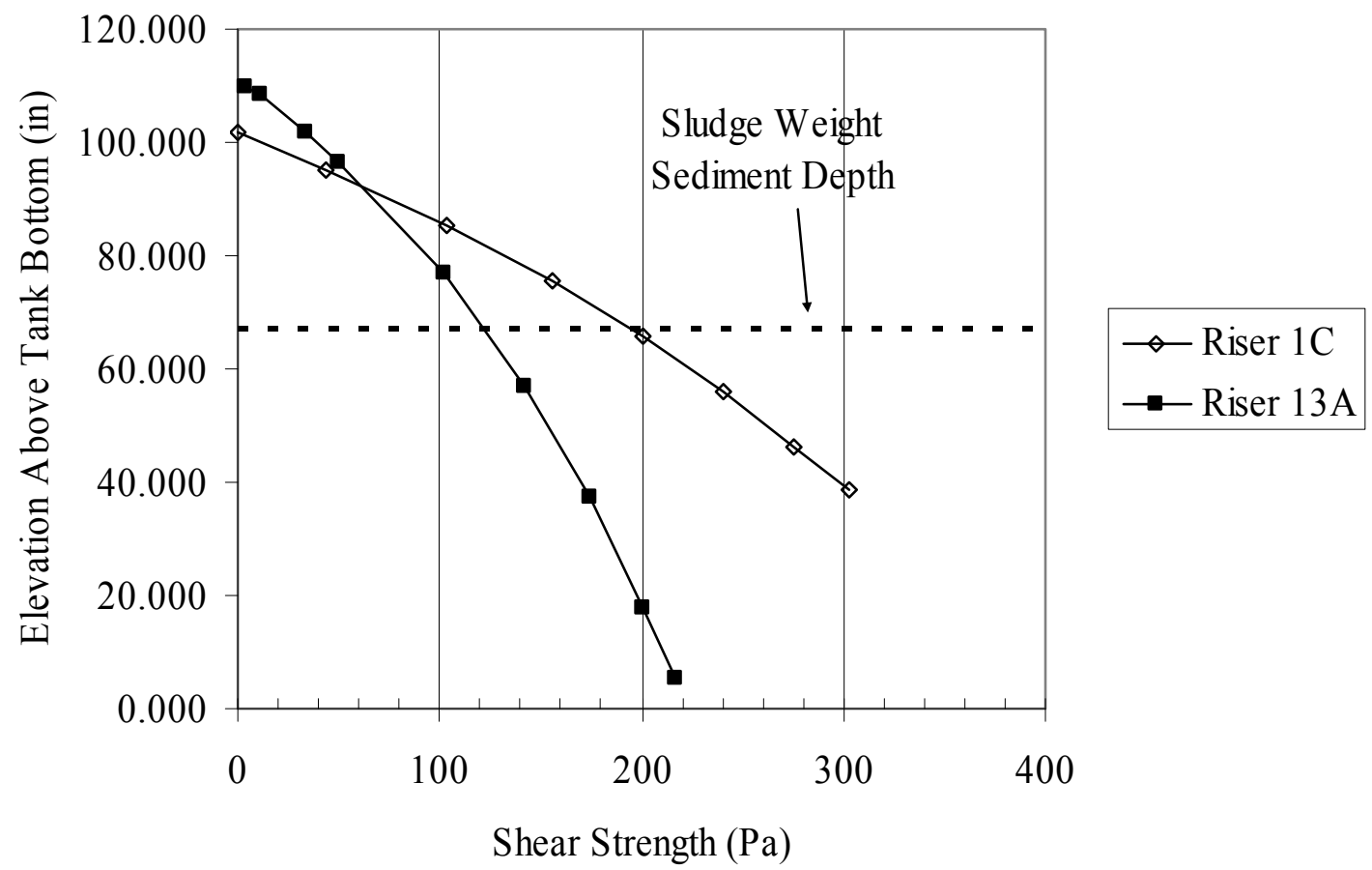

Figure 3.1. AW-101 Ball Rheometer Sediment Shear Strength (Hedengren et al. 2000)

\subsection{SY-101 Crust Shear Strength}

The historic floating crust layer in SY-101 was evaluated in detail in Rassat et al. (2000). Estimates for the shear strength of the crust were made based on operational data. The force required to penetrate the Mechanical Mitigation Arm (MMA) and water lance into regions of the crust was compared to the force required to impinge different test arms into simulants (Cab-o-sil/mineral oil and bentonite clay/water) of known shear strength. The shear strength was written as

$$
\tau=\frac{\mathrm{F}}{\eta \mathrm{A}}
$$

where $\mathrm{F}$ is the weight required to impinge the object into the simulant and $\mathrm{A}$ is the object's area (or projected area). Although large variance was observed, it was suggested that $\eta=7$ was representative of the operations. Analytical analyses indicated $\eta>5$ for plastic media (applicable to Hanford waste). With $\eta=7$, the sludge weight (approximately $0.55 \mathrm{~kg}, 1.7 \mathrm{E}-3 \mathrm{~m}^{2}$ ), has a required shear strength of $450 \mathrm{~Pa}$. A shear strength of $230 \mathrm{~Pa}$ is determined for the densitometer described in Section $3.1 .2(0.24 \mathrm{~kg}, 1.44 \mathrm{E}-$ $3 \mathrm{~m}^{2}$ ). Given the overall uncertainty of the waste rheology, it is encouraging that these results are not significantly (i.e. $\leq \mathrm{O}(1)$ ) different from the static equilibrium results of Section 3.1. Conversely, the disparity in the results is not unexpected given that $\eta$ had significant variability depending on the simulant and test arm geometry $(\eta \sim 1-12$; the $\eta$ values approaching 12 were achieved with the bentonite clay simulant) and the results of Eq. (3.7) were not compared in application to any Hanford waste data; the 
validity of the $\eta$ results has not been conclusively established. The bentonite clay data discussed in Section 3.3 is in agreement with the higher $\eta$ values.

\subsection{Compressive and Shear Strength Data}

Compressive and shear strength data is available from the literature for various slurries/sediments. This data may be loosely grouped into two categories: 1) sediment with specific compressive and shear strength tests conducted, and 2) sediment (typically soils) with unconfined compression tests and shear strength (vane) measurements.

Comparisons of compressive and shear strength (yield stress) have been made for latex, silica, alumina suspensions, and bentonite clay. The materials are typically stronger in compression than they are in shear. For the latex, Buscall et al. (1987) found that the compressive strength was approximately 55 times the shear strength. Channell and Zukoski (1997) achieved an equivalent result in alumina suspensions. Meetan (1994) reported a ratio of approximately 100 for the silica of Buscall et al. (1988), and found 11.1 for his bentonite analysis. It is suggested that the variability of the results (approximately 10 to 100) is caused by the properties (microstructure, particle interactions, particle size, etc.) of the simulants.

Given that bentonite clay is often utilized as a simulant for Hanford waste (Gauglitz and Aikin 1997, Gauglitz et al. 1996, etc.), it may not be unreasonable to apply the 11.1 result to Hanford sediment. The bentonite clay results of Rassat et al. (2000) appear to support these results. The sludge weight therefore requires a shear strength of $280 \mathrm{~Pa}$ to be supported. A shear strength of $150 \mathrm{~Pa}$ is determined for the densitometer. The sludge weight results compare reasonably with the "experimental" tank results from AW-101 (128 and $195 \mathrm{~Pa}$, Table 3.2) and the "corrected" analytical result presented in Section 3.1.1 (greater than $110 \mathrm{~Pa}$, less than $370 \mathrm{~Pa}$ ). The densitometer results are seven times larger than the analytical static equilibrium results $(25 \mathrm{~Pa})$, Section 3.1.2. Note that the ratio of 11.1 provides, from the data referenced (including Rassat et al. 2000), an upper bound for the shear strength.

The yield stress of soils has been investigated intensively. There are numerous methodologies employed to measure soil shear strength. It is universally accepted that vane instrumentation provides the "best" shear strength results. Other methodologies may be employed, one of which is the unconfined compression (UC) test. The UC test results are typically correlated to a soil's shear strength by $\tau=\sigma_{\mathrm{UC}} / 2$ where $\sigma_{U C}$ is the unconfined compressive strength (Tanaka 1994, 2002, Tsuchida 2000, Fredlund and Vanapalli 2002). Although this relation has been supported by practice as well as by experimentation and numerical results, it is not universally accepted. In addition to this uncertainty, the objection to applying this result directly to the sludge weight or densitometer lies in the uncertainty of the relation of $\sigma_{U C}$ to the estimated compressive stress due to the device. The apparent over prediction of the required shear strength (from $\tau=\sigma_{U C} / 2$ ) as compared to the above discussed results suggests that $\sigma_{U C}$ is less than the device's compressive stress. 


\subsection{Recommendations}

Definitively determining a Hanford sediment shear strength that will support a sampling device (e.g. sludge weight or densitometer) is not possible based on the available data. However, as presented in Section 3, the existing data is in agreement with the supporting evaluations, and therefore probable results are defined.

The recommended approach for determining the sediment shear strength required for static equilibrium of a sampling device is, as discussed in Section 3, a function of the device's physical characteristics. In-tank Hanford data indicates that a sediment shear strength of approximately $160 \mathrm{~Pa}$ (from two extrapolated data points; $128 \mathrm{~Pa}$ and $195 \mathrm{~Pa}$ ) will statically support the sludge weight, and this result is reasonably corroborated by the static equilibrium analysis (Section 3.1, $110 \mathrm{~Pa}$ "corrected") and the bentonite clay correlation (Section 3.3, $280 \mathrm{~Pa}$ ). The apparent success of the models in reproducing the in-tank measurements gives some degree of confidence to applying them to other devices. However, as noted, the model results for the densitometer may vary by a factor of seven (25 Pa to $150 \mathrm{~Pa})$. Therefore, although the analytical results for devices that do not have in-tank data may be bounding, they must only be considered as guidelines. Deployment of the sludge weight and densitometer in low shear strength tanks (shear strength data as a function of depth is required) and ex-tank experimental results in well characterized simulants would be invaluable at providing definitive answers for the specific devices. As

may be inferred from Section 3, certain device geometries may be more appropriate for investigations of this type. 


\subsection{References}

Andres UT. 1961. Equilibrium and Motion of Spheres in a Viscoplastic Liquid. Soviet Physics Doklady (USA), 5, pp 723-726.

Ansley RW, and TN Smith. 1967. Motion of Spherical Particles in a Bingham Plastic. AIChE Journal, 13, 6, pp 1193-1196.

Attapatu DD, RP Chhabra, and PHT Uhlherr. 1995. Creeping Sphere Motion in Herschel-Bulkley Fluids: Flow Field and Drag. Journal of Non-Newtonian Fluid Mechanics, 59, pp 249-265.

Barker SA, and DC Hedengren. 2003. Methodologies and Calculations for the Assignment of Waste Groups for the Large Underground Waste Storage Tanks at the Hanford Site. RPP-10006, Rev. 2. CH2M HILL Hanford Group, Inc., Richland, WA.

Beaulne M, and E Mitsoulis. 1997. Creeping Motion of a Sphere in Tubes Filled with Herschel-Bulkley Fluids. Journal of Non-Newtonian Fluid Mechanics, 72, pp 55-71.

Beris AN, JA Tsamopoulos, RC Armstrong, and RA Brown. 1985. Creeping Motion of a Sphere Through a Bingham Plastic. Journal of Fluid Mechanics, 158, pp 219-244.

Blackery J, and E Mitsoulis. 1997. Creeping Motion of a Sphere in Tubes Filled with a Bingham Plastic Material. Journal of Non-Newtonian Fluid Mechanics, 70, pp 59-77.

Buscall R, PDA Mills, JW Goodwin, and DW Larson. 1988. Scaling Behaviour of the Rheology of Aggregate Networks formed from Colloidal Particles. Journal of the Chemical Society, Faraday Transactions 1, 84 (12), pp 4249-4260.

Buscall R, IJ McGowan, PDA Mills, RF Stewart, D Sutton, LR White, and GE Yates. 1987. The Rheology of Strongly-Flocculated Suspensions. Journal of Non-Newtonian Fluid Mechanics, 24, pp 183202.

Channell GM, and CF Zukoski. 1997. Shear and Compressive Rheology of Aggregated Alumina Suspensions. AIChE Journal, 43 (7), pp 1700-1708.

Chhabra RP. 1992. Bubbles, Drops, and Particles in Non-Newtonian Fluids. CRC Press, Inc. Boca Raton, FL.

Fredlund DG, and SK Vanapalli. 2002. Shear Strength of Unsaturated Soils. Chapter 2.7, Handbook of Agronomy, Soil Society of America.

Gauglitz PA, and JT Aikin. 1997. Waste Behavior During Horizontal Extrusion: Effect of Waste Strength for Bentonite and Kaolin/Ludox Simulants and Strength Estimates for Wastes from Hanford Waste Tanks 241-SY-103, AW-101, AN-103, and S-102. PNNL-11706. Pacific Northwest National Laboratory, Richland, WA. 
Gauglitz PA, SD Rassat, PR Bredt, JH Konynenbelt, SM Tingey, and DP Mendoza. 1996. Mechanisms of Gas Bubble Retention and Release: Results for Hanford Waste Tanks 241-S-102 and 241-SY-103 and Single-Shell Tank Simulants. PNNL-11298. Pacific Northwest National Laboratory, Richland, WA.

Hedengren DC, KM Hodgson, WB Barton, CW Stewart, JM Cuta, and BE Wells. 2000. Data Observations on Double-Shell Flammable Gas Watch List Tank Behavior. RPP-6655. Rev. 0. CH2M HILL Hanford Group, Inc., Richland, Washington.

Meetan GH. 1994. Shear and Compressive Yield in a Filtration of a Bentonite Suspension. Colloids and Surfaces A: Physicochemical and Engineering Aspects, 82, pp 77-83.

Meyer PA, ME Brewster, SA Bryan, G Chen, LR Pederson, CW Stewart, and G Terrones. 1997. Gas Retention and Release Behavior in Hanford Double-Shell Waste Tanks. PNNL-11536. Pacific Northwest National Laboratory, Richland, WA.

Onishi Y and BE Wells. 2004. Feasibility Study on Using Two Mixer Pumps for Tank 241-AY-102 Waste Mixing. PNNL-14763. Pacific Northwest National Laboratory, Richland, WA.

Rassat SD, LA Mahoney, BE Wells, DP Mendoza, and DD Caldwell. 2003. Assessment of Physical Properties of Transuranic Waste in Hanford Single-Shell Tanks. PNNL-14221. Pacific Northwest National Laboratory, Richland, WA.

Rassat SD, CW Stewart, BE Wells, WL Kuhn, ZI Antoniak, JM Cuta, KP Recknagle, G Terrones, VV Viswanathan, JH Sukamto, and DP Mendoza. 2000. Dynamics of Crust Dissolution and Gas Release in Tank 241-SY-101. PNNL-13112. Pacific Northwest National Laboratory, Richland, WA.

Stewart CW, JM Alzheimer, ME Brewster, G Chen, RE Mendoza, HC Reid, CL Shepard, and G Terrones. 1996. In Situ Rheology and Gas Volume in Hanford Double-Shell Waste Tanks. PNNL 11296. Pacific Northwest National Laboratory, Richland, WA.

Tanaka H. 2002. A Comparative Study on Geotechnical Characteristics of Marine Soil Deposits Worldwide. Proceedings of the Twelfth International Offshore and Polar Engineering Conference, Kitakyushu, Japan, May 26-31, 2002.

Tanaka H. 1994. Vane Shear Strength of a Japanese Marine Clay and Applicability of Bjerrum's Correction Factor. Soils and Foundations, 34 (3), pp 39-48.

Tsuchida T. 2000. Evaluation of Undrained Shear Strength of Soft Clay with Consideration of Sample Quality. Soils and Foundations, 40 (3), pp 29-42. 


\section{Appendix C}

Steady-State Gas Holdup and Comparison to the Maximum Allowed Release of Hydrogen 


\section{Appendix C: Steady-State Gas Holdup and Comparison to the Maximum Allowed Release of Hydrogen}

Table C.1 shows the input parameters and both the intermediate and final calculated results for predicting the volume of retained hydrogen gas during steady-state operations and the comparison of this hydrogen volume to the maximum allowed release during an off-normal event. Below is a summary of these calculations and the input data, beginning on the left hand side of Table C.1.

The hydrogen generation rate and the time to LFL (lower flammability limit) for each vessel were taken from Eager. ${ }^{\text {(a) }}$ Note that the hydrogen generation rate is for a full vessel, and the hydrogen volume is at the temperature and pressure (1 atm) in the vessel vapor space. The maximum liquid volume for hydrogen gas release (HGR) calculations and the total vessel vapor space when full were taken from Tsang ad Eager ${ }^{(b)}$. The vessel diameter was taken from Waste Treatment Plant (WTP) documentation on vessel geometry. ${ }^{(c)}$

The maximum allowed hydrogen release is determined by multiplying the hydrogen generation rate for the full vessel times the time to LFL and converting units to gallons. The hydrogen generation superficial velocity is calculated by dividing the hydrogen generation rate for the vessel by the vessel cross sectional area. Hydrogen is known to be only a portion of the gas that is generated within the waste, and for these calculations, we follow Stewart et al. (2007) and assume that hydrogen is $25 \mathrm{vol} \%$ of the total generated gas. With this assumption, the total gas-generation superficial velocity is 4 times the hydrogen generation superficial velocity.

The predicted total gas holdup fraction uses the $30 \mathrm{~Pa}$ AZ/AFA correlation from Figure 5.13 of Stewart et al. (2007), which is Equation 5.3 in this report. The holdup correlation uses the total gas-generation superficial velocity as the input parameter and predicts the total gas-holdup volume fraction. This volume fraction represents the total gas at the average pressure in the vessel. Note, also, that the gas-generation superficial velocity must be at the average gas pressure in the vessel, which can be approximated as the pressure at half the depth of the waste. The gas-volume fraction is converted to the total gas-holdup volume by multiplying the maximum liquid volume for HGRs by the ratio (gas volume fraction)/(1-gas volume fraction). This volume needs to be converted from the average pressure to the vapor space pressure of $1 \mathrm{~atm}$. Assuming a cylindrical vessel and neglecting equipment inside the vessel that occupies space, the average gas pressure is the pressure at half the liquid depth. One simple approach to estimating the average waste depth is to divide the maximum liquid volume for HGRs by the vessel cross sectional area and take half of this value as half the liquid depth. The pressure at that depth is the hydrostatic pressure plus the $1 \mathrm{~atm}$ pressure in the vessel dome space. Assuming a liquid density of $1200 \mathrm{~kg} / \mathrm{m}^{3}$ and using the depth for halfway in the vessel, the result in Table C.1 for the total gas holdup corrected to $1 \mathrm{~atm}$ in the headspace is obtained with the ideal gas law as shown below:

(a) K Eager. 2008. Calculation of Hydrogen Generation Rates and Times to Lower Flammability Limit for WTP. Calculation Sheet, ECCN No: 24590-WTP-M4E-V11T-00007, January 16, 2008, Richland. Washington.

(b) I Tsang, and K Eager. 2006. Calculation of Hydrogen Generation Rates and Times to Lower Flammability Limit for WTP. Calculation Sheet, ECCN No: 24590-WTP-M4C-V11T-00004, May 17, 2006, Richland. Washington.

(c) M3 PJM Mixing Systems Basic Data 02-21-07, 2007. CCN 151865, see Vessel PJM Data Table. 


$$
\operatorname{Vol}(\text { at } 1 \mathrm{~atm})=\operatorname{Vol}(\text { at average depth }) * \frac{\mathrm{P}(\text { at average waste depth })}{\mathrm{P}(\text { at } 1 \mathrm{~atm})}
$$

Finally, the result for the predicted hydrogen holdup corrected to $1 \mathrm{~atm}$ is $1 / 4$ of the total gas holdup, again assuming that hydrogen is only $25 \mathrm{vol} \%$ of the total gas that is retained.

The final column shows the result for the ratio between the steady-state holdup of hydrogen (corrected to $1 \mathrm{~atm}$ in the headspace) to the maximum allowed release (also at $1 \mathrm{~atm}$ in the headspace). The results for each vessel are sorted from highest to the lowest, and the highest ratio is $23 \%$ for UFP-VSL00001A/B.ratio. This ratio shows that the estimated steady-state holdup is a significant fraction of the maximum allowed release during an off-normal event.

While this estimate is high, this calculation used a holdup correlation for a material that had a 30-Pa yield stress throughout the vessel. In the situation where the solids settle, it is expected that gas will only be retain in the portion of the vessel where the solids concentration is sufficiently high to create a yield stress, so the actual holdup will be less than this conservative estimate. 
Table C.1. Parameters for Calculating Steady-State Gas Holdup and Maximum Allowed Hydrogen Release

\begin{tabular}{|c|c|c|c|c|c|c|c|c|c|c|c|c|c|c|c|c|}
\hline WTP Vessel & $\begin{array}{c}\text { Hydrogen } \\
\text { Generation Rate } \\
\text { (liter H2 @ } 1 \text { atm, } \\
\text { @temp, per hour }\end{array}$ & $\begin{array}{l}\text { Time to LFL } \\
\text { (hours) }\end{array}$ & $\begin{array}{l}\begin{array}{c}\text { Maximum } \\
\text { Liquid Volume } \\
\text { for HGRs } \\
\text { (gal) }\end{array} \\
\end{array}$ & $\begin{array}{c}\text { Total Vapor } \\
\text { Space Volume } \\
\text { (gal) } \\
\end{array}$ & $\begin{array}{c}\text { Vessel } \\
\text { Diameter } \\
\text { (ft) }\end{array}$ & $\begin{array}{c}\text { Vessel } \\
\text { Area } \\
\left(\mathrm{t}^{\wedge} 2\right) \\
\end{array}$ & $\begin{array}{c}\text { Maximum Allowed } \\
\text { Hydrogen Release } \\
\text { (at } 1 \text { atm \& } \\
\text { vessel temp) } \\
\text { (gal) }\end{array}$ & $\begin{array}{c}\text { H2 Gas } \\
\text { Generation } \\
\text { Superficial } \\
\text { Velocity } \\
\text { (mm/sec) } \\
\end{array}$ & $\begin{array}{c}\text { Total Gas } \\
\text { Generation } \\
\text { Superficial } \\
\text { Velocity } \\
(\mathrm{mm} / \mathrm{sec}) \\
\end{array}$ & $\begin{array}{c}1 / 2 \\
\text { Waste } \\
\text { Depth } \\
\text { (tt) } \\
\end{array}$ & $\begin{array}{c}\text { Total Gas } \\
\text { Generation } \\
\text { Superficialal } \\
\text { Velocity } \\
\text { Corrected to } \\
\text { Pressure at } 1 / 2 \\
\text { Waste Depth } \\
\text { (mm/sec) } \\
\end{array}$ & \begin{tabular}{|c|} 
Predicted Total \\
$\begin{array}{c}\text { Gas Holdup } \\
\text { Fraction } \\
\text { (percent) }\end{array}$ \\
\end{tabular} & $\begin{array}{c}\text { Predicted Total } \\
\text { Gas Holdup } \\
\text { (gal) }\end{array}$ & $\begin{array}{c}\text { Total Gas Holdup } \\
\text { Corrected to } 1 \\
\text { atm in the } \\
\text { headspace } \\
\text { (gal) }\end{array}$ & $\begin{array}{c}\text { Predicted } \\
\text { Steady State } \\
\text { Hydrogen } \\
\text { Holdup at } \\
1 \text { atm } \\
\text { (gal) } \\
\end{array}$ & $\begin{array}{c}\text { Steady State } \\
\text { Hydrogen Holdup } \\
\text { H } \\
\text { Max Allowed } \\
\text { Hydrogen Release } \\
\text { (percent) } \\
\end{array}$ \\
\hline & Ref 1 & Ref 1 & Ref 2 & Ref 2 & Ref 3 & & & & comment 1 & & Comment 2 & Ref 4 & Comment 2 & & Comment 1 & \\
\hline UFP-VSL-00001A/B & 130 & 10 & 61,854 & 13,739 & 20 & 314 & 343 & 0.00124 & 0.00495 & 13 & 0.00338 & 0.2815 & 175 & 256 & 64 & 18.6 \\
\hline HLP-VSL-00022 & 280 & 22 & 214,184 & 56,416 & 38 & 1134 & 1627 & 0.00074 & 0.00295 & 13 & 0.00204 & 0.2125 & 456 & 660 & 165 & 10.1 \\
\hline FEP-VSL-00017A/B & 22 & 89 & 67,750 & 17,746 & 22 & 380 & 517 & 0.00017 & 0.00069 & 12 & 0.00049 & 0.0954 & 65 & 92 & 23 & 4.4 \\
\hline FRP-02A/B/C/D & 16 & 508 & 406,800 & 67,200 & 47 & 1735 & 2147 & 0.00003 & 0.00011 & 16 & 0.00007 & 0.0325 & 132 & 206 & 51 & 2.4 \\
\hline RLD-VSL-00008 & 0.38 & 974 & 10,628 & 3,146 & 13 & 133 & 98 & 0.00001 & 0.00003 & 5 & 0.00003 & 0.0196 & 2.1 & 2.5 & 0.6 & 0.6 \\
\hline Comment 1 & Hydrogen is assume & $\mathrm{d}$ to be $1 / 4$ of & otal gas & & & & & & & & & & & & & \\
\hline Comment 2 & Gas pressure is at a & verage waste $c$ & & & & & & & & & & & & & & \\
\hline Reference 1 & Farar (2008) c coe to & be $8-1$ and 8 - & & & & & & & & & & & & & & \\
\hline Reference 2 & Tsang and Eager (2) & $06)$; see table & F-1.(b) & & & & & & & & & & & & & \\
\hline Reference 3 & CCN151865 (2007); & see Vessel Pu & M Data Table.(c) & & & & & & & & & & & & & \\
\hline Reference 4 & Stewart et al. (2007) & 30 Pa AZIAFF & correlation; see & Figure 5.13. & & & & & & & & & & & & \\
\hline
\end{tabular}

(a) Eager K. 2008. Calculation of Hydrogen Generation Rates and Times to Lower Flammability Limit for WTP. Calculation Sheet, ECCN No: 24590-WTP-M4E-V11T-00007, January 16, 2008, Bechtel National, Inc., Richland, Washington.

(b) Tsang I, and K Eager. 2006. Calculation of Hydrogen Generation Rates and Times to Lower Flammability Limit for WTP. Calculation Sheet, ECCN No: 24590-WTP-M4C-V11T-00004, May 17, 2006, Richland. Washington.

(c) M3 PJM Mixing Systems Basic Data 02-21-07, 2007. CCN 151865, see Vessel PJM Data Table. 


\section{Distribution}

No. of

Copies

\section{OFFSITE}

1 Bechtel National, Inc.

K. J. Knight

Bechtel National, Inc.

5275 Westview Dr.

Frederick, MD 21703
No. of

Copies

ONSITE

31 Pacific Northwest National Laboratory

J. A. Bamberger K7-15

C. A. Burns K3-61

R. C. Daniel P7-22

C. W. Enderlin K7-15

J. A. Fort K7-15

P. A. Gauglitz (10) K9-75

W. L. Kuhn K7-15

D. E. Kurath K3-52

L. A. Mahoney K7-15

P. A. Meyer K7-15

M. J. Minette P7-25

S. D. Rassat K6-28

D. R. Rector K7-15

P. A. Scott K7-15

G. L. Smith K6-24

J. M. Tingey P7-25

B. E. Wells (5) K7-15

Project Office K3-52

Information Release (pdf)

8 Bechtel National, Inc.

P. Kuehlen (5) H4-02

S. L. Thomson H4-02

WTP R\&T Docs (2) H4-02

Distr. 1 